COLLABORATIVE SPATIAL LEARNING FOR IMPROVING PUBLIC PARTICIPATION PRACTICE IN INDONESIA 



\title{
COLLABORATIVE SPATIAL LEARNING FOR IMPROVING PUBLIC PARTICIPATION PRACTICE IN INDONESIA
}

\author{
DISSERTATION \\ to obtain \\ the degree of doctor at the University of Twente, \\ on the authority of the rector magnificus, \\ prof.dr.ir. A. Veldkamp \\ on account of the decision of the Doctorate Board, \\ to be publicly defended \\ on Thursday 11 November 2021 at 14.45 hrs
}

by

Aulia Akbar

born on $4^{\text {th }}$ June 1981

in Binjai, Indonesia 
This thesis has been approved by

\author{
Supervisor \\ prof. dr. ir. M.F.A.M van Maarseveen \\ Co-supervisors \\ dr. J. Flacke \\ dr. J.A. Martinez
}

ITC dissertation number 405

ITC, P.O. Box 217, 7500 AE Enschede, The Netherlands

ISBN 978-90-365-5222-6

DOI $10.3990 / 1.9789036552226$

Cover designed by Viriega Fauzia Rachmanda, Aulia Akbar

Printed by CTRL-P Hengelo

Copyright (c) 2021 by Aulia Akbar, The Netherlands. All rights reserved. No parts of this thesis may be reproduced, stored in a retrieval system or transmitted in any form or by any means without permission of the author. Alle rechten voorbehouden. Niets uit deze uitgave mag worden vermenigvuldigd, in enige vorm of op enige wijze, zonder voorafgaande schriftelijke toestemming van de auteur.

\title{
UNIVERSITY OF TWENTE.

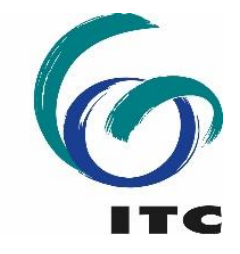


Graduation committee:

\section{Chairman/Secretary}

prof.dr. F.D. van der Meer

University of Twente

\section{Supervisor}

prof. dr. ir. M.F.A.M van Maarseveen

University of Twente

\section{Co-supervisors}

dr. J. Flacke

dr. J.A. Martinez

University of Twente

University of Twente

\section{Committee Members}

prof. dr. M.J. Kraak

University of Twente prof. dr. K. Pfeffer University of Twente prof. dr. R.V. Sliuzas prof. dr. R.L. Holzhacker prof. dr. ir. B. Setiawan University of Twente University of Groningen Universitas Gadjah Mada 
Dedicated to my beloved parents, my lovely wife, and my beautiful children 


\section{Acknowledgements}

In the name of Allah, The Most Gracious, The Most Merciful

Did We not expand for you, [O Muhammad], your breast?

And We removed from you your burden.

Which had weighed upon your back, and raised high for you your repute.

For indeed, with hardship [will be] ease [i.e., relief].

Indeed, with hardship [will be] ease.

So when you have finished [your duties], then stand up [for worship].

And to your Lord direct [your] longing.

(Al-Qur'an Chapter 94: Ash-Sharh [The Relief])

Alhamdulillah. My utmost thanks go to Allah the Almighty who provided this $\mathrm{PhD}$ opportunity and made it possible for me to go through it successfully.

I need to acknowledge and say thanks to many people who have contributed to this research. I want to gratitude to the Indonesian Government through the Indonesia Endowment Fund for Education (LPDP (Lembaga Pengelola Dana Pendidikan)) scholarship for funding my PhD study. This study would not have been possible without the full support from LPDP from the beginning to the end of my study.

I am very grateful to my promotor, Prof. Martin van Maarseveen, for dedicating his time to supervise my PhD study. His unparalleled encouragement, support, and advice were very useful to shape my ideas throughout the study period. I would also like to extend my gratitude to my daily supervisor, Dr. Johannes Flacke, who has a wonderful approach of dealing with students and particularly with me. I benefited enormously from his intellectual input. His feedback on many versions of texts, and his full support and encouragement had made this academic journey less daunting and a memorable one. Also, I would like to also thank my second daily supervisor, Dr. Javier Martinez, for his theoretical and practical advice, especially on how to design and apply diverse research methods. He encouraged me to think critically and trained me to always reflect on various scholarly work when working on my research. 
I am also indebted to the Embassy of the Republic of Indonesia, The Hague-The Netherlands, Mr. Mayerfas and Mr. I Gusti Agung Wesaka Puja (current and former Ambassador), Prof. Din Wahid, Prof. Bambang Hari Wibisono (current and former Atdikbud), the government of Sumatra Utara province, Mr. Edi Rahmayadi Nasution and Mr. Tengku Erry Nuradi (current and former Governor), and to the government of Deli Serdang district for supporting me in pursuing this doctoral degree. For Mr. Ashari Tambunan (the Regent of Deli Serdang), Mr. Irman and Mr. Abdul Haris Lubis (former Heads of Bappeda of Deli Serdang), Mr. Remus H. Pardede (current Head of Bappeda of Deli Serdang), bang Jeffrey Siregar, Sigit Pramulia, bang Ismail, Rudi Akmal Tambunan, kak Aflah, kak Julyatin, Andriza, Nesfa, Robet, Ardhianto, Arri Arvingko, Diah, Ika, Juwita, Yosi Sukmono, Bisman Ritonga, and all staffs in various institutions, thank you for always provided supports when I needed one.

Thanks to the all of the village officials and the citizens of Kramat Gajah, Denai Lama, Kolam, Sidoharjo I Pasar Miring, and Tandem Hulu II for allowing me to learn many things. Working with the villagers has taught me many lessons. My previous assumptions that most villagers are less educated or lack experiences changed after I had close interactions with them during the study period. I was astonished at how villagers could acquire various types of knowledge and life experiences. The way they used their local knowledge was beyond my expectations. I always admired their willingness to improve the quality of life of their communities. They treated me very well with great hospitality and were very helpful every time I came for a visit. I learned much from their sincerity and knowledgeable responses during the interviews and discussions.

Within the ITC campus, I want to thank to all academic staff for fruitful discussions during many presentations, coffee breaks, or department outings: Prof. Jaap Zevenbergen, Prof. Karin Pfeffer, Prof. Richard Sliuzas, Prof. Yola Georgiadou, Mafalda M. Madureira, Sherif Amer, Luc Boerboom, Cheryl de Boer, Frans van den Bosch, Mark Brussel, Ana Bustamante, Andre da Silva Mano, Anna Grigolon, Divyani Kohli, Dimo Todorovski, Mila Koeva, Monika Kuffer, Diana Reckien, Nina Schwarz, Liza Groenendijk, Funda Atun Girgin, Jon Wang, and Fran Meissner. Many thanks go to my office mates Rehana Shrestha, Alice Nikuze, Mahmoud Abdelkader, Lilin Zhang, Claudia Stoecker, Sophia Crommelink, and Brian Masinde. We shared and discussed a lot about many things, from our research, concerns about the world, including 
our families. I would like to also thank my other colleagues and friends in ITC for the support and encouragement, especially Rosa M. Aguilar, who collaborated with me during my second fieldwork. Her intelligence in programming and developing software and mapping applications helped me a lot, especially her OGITO tool that we used in the village participatory mapping workshops. I always said to her that the OGITO was not only useful for the villagers to produce their village maps but has also saved almost half of my PhD journey. For Abubakari Zaid, who always asked about my progress and provided his time to read and comment on my paper manuscripts. I also thank all my colleagues in ITC building, Islam Fadel, Sergio Alvarado Vazquez, Fenna Hoefsloot, Andres Morales, Simba Chereni, Deepshika Purwar, Abdullah Banger, Akshay Anand, Christ Sven, Lydia Prieto Leon, Yang Chen, Ying Yue, Yanwen Wang, Debbie Oyeku, Nestor, Evangelia Balla, Rachel Keeton, Vidit Kundu, Angela, Giada Limongi, Vicky, Eli, Fardad Maghsoudi, Jonathan Franco, Charis Chalkiadakis, Sameer, and many other ITC colleagues and friends. Furthermore, to the professional and administrative staff of ITC who made my PhD study smooth and delightful; in particular to Petra Weber, Loes Colenbrander, Annelies Klos, Esther Hondebrink, Lyande Eelderink, Tia Muharamiah den Hartog, Marga Koelen, Emile Dopheide, Jeroen Verplanke, Katinka A. Jager-Ringoir, Grietha de Jonge, Jorien M. Terlouw, Paul Oostrom, Gerrit Polman, Aiko Mulder, Theresa van den Boogaard, Marie-Chantal, Wendy Kremer-Stiksma, Roelof Schoppers, Roland Willink, Benno Masselink, and Job Duim.

I also thanks to my colleagues in UGM, USU, UNIMED, and ITM, Pak Trias Aditya, Pak Heri Sutanta, Bambang Kun Cahyono, Bu Latifah, Bu Anita Zaitunah, Pak Samsuri, Ade Candra, Anthoni Veery Mardianta, Bu Nina, M. Farouq Ghazali Matondang who gave full support, place, and time for discussion during my study period. Special thanks for the IndieMap crew, Ziki Wahyu Rinaldi, Faisal Andrean, Umar Hamdan Hasibuan, Andrian Lozi, and DTM Damai Syahputra who helped a lot during my second fieldtrip. Your full support during the mapping workshops, map post-processing, and observations were really useful to finish this study.

The Indonesian community in Enschede and the Netherlands has also been very supportive. Lots of thanks to Jarot Mulyo Semedi, Astisiasari, Aji Putra Perdana, Muhammad Aufaristama, Devara Prawira, Adityo 
Nugroho, Kartika Palupi Savitri, Iqbal Yulizar, Inon Aslam, Yan Restu Freski, Viriega (for designing the cover of this thesis), Sari, Rahmat Aris Pratomo, Pugo Sambodo, Endratno Budi, Fauzan Muzakki, Raynouval, Ridwan Saptoto, Dwi Resty Andriani, Dhadhang Wahyu Kurniawan, Pesi, Nova, Giri, Imam, Abdel, Wibi, Candra Herdianto, Nisa, Syifa, Dennis, mbak Rani Meise, mbak Pipit, mbak Rani, kang Deden, kang Lukman, pak Gun, Indra Tosri, Joko Sampurno, Ristiono, and all of the Indonesians that I cannot mention one by one. Special thanks to bu Dewi Nurhamad who always welcomes us to her lovely house in Hengelo. Also, to all organisations (PPIE, PPI Belanda, UT Muslims, ITC Muslims, IMEA, IVEO Enschede, SGB Utrecht, FORKOM$\mathrm{NL}$, Tahsin Enschede, Gowespora), I thank everyone for the companionship and love you have given me over the study period.

A final word of gratitude goes to my family and friends who provided support in many capacities throughout this period, especially my lovely wife Aisyatur Ridha who managed the affairs of the family alone in my absence. To all my children, Ahmad Fursanul Akbar, Amrina Rasyada Akbar, and Haniyya Mardhiyya Akbar who always prayed for me and made me smile every single day. To my parents, Papa Agusnar bin Abdul Rani (of blessed memory) and Mama Mulia Rita Susilawati, I thank you for the love, encouragement, and prayers you have given me. To my father in law, Bapak Muliadi, and my mother in law, Ibu Nasiem Anas Salamah, for all the support and assistance especially for taking care my children during my study abroad. To all my siblings, mbak Yanti, bang Tika, mbak Devi, mas Antok, mas Amay, mbak Sri, mbak Icut, mas Agus, Roy, Wita, Putra, Yani, Khanza, Dilla, Rahmat, Ela, Edi, Taqim, Dilla and all my niece, nephews, and grandchildren, thanks for the love, encouragement and support. 


\section{Table of contents}

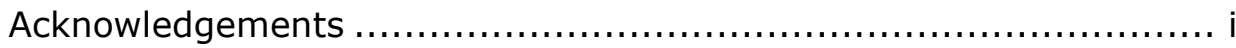

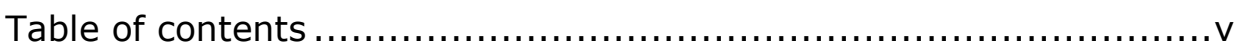

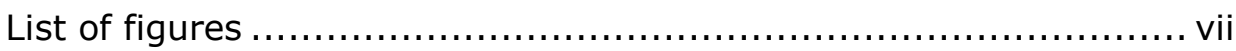

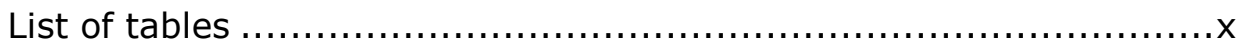

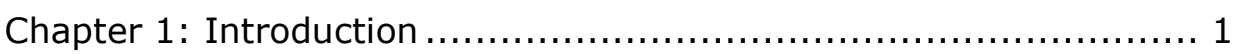

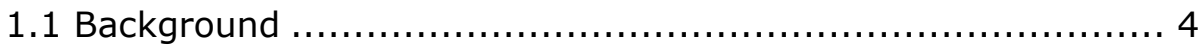

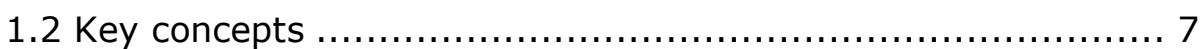

1.3 Research problem.................................................. 21

1.4 Research objectives and questions............................. 22

1.5 Research methodology ........................................... 25

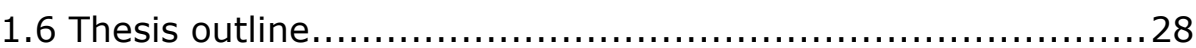

Chapter 2: Participatory planning practice in rural Indonesia: A sustainable development goals-based evaluation .......................31

2.1 Public participation process evaluation framework ...............33

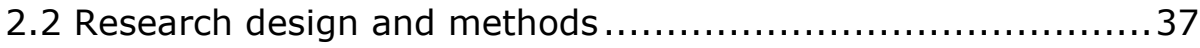

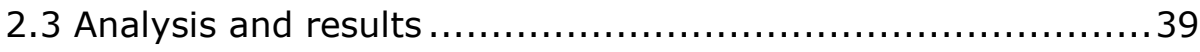

2.4 Discussion and conclusions ...................................... 48

Chapter 3: Spatial knowledge: A potential to enhance public participation? ......................................................... 53

3.1 The relevance of spatial knowledge for public participation ....55

3.2 Material and methods ............................................61

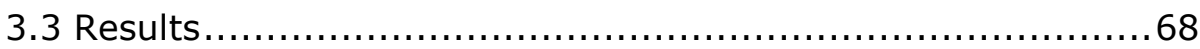

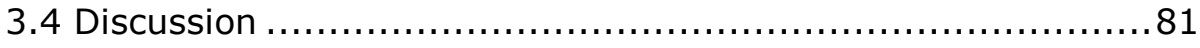

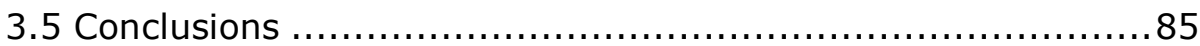

Chapter 4: Knowing my village from the sky: A collaborative spatial learning framework to integrate spatial knowledge of stakeholders in achieving Sustainable Development Goals.............................. 87

4.1 Eliciting spatial knowledge to achieve global goals ...............91 
4.2 Implementation of the collaborative spatial learning framework

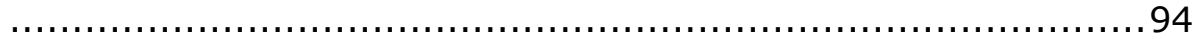

4.3 Insights from the participatory mapping workshops .......... 102

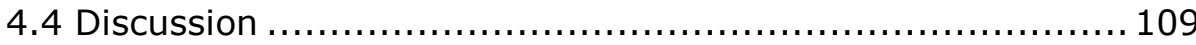

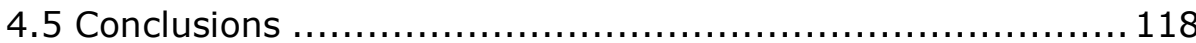

Chapter 5: The role of participatory village maps in strengthening public participation practice.

5.1 Participatory village maps for strengthening public participation

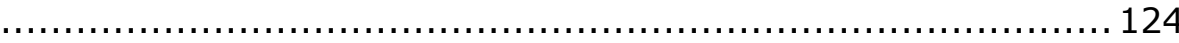

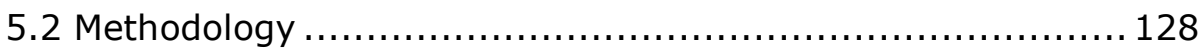

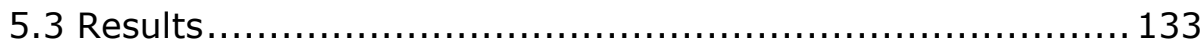

5.4 Discussion and Conclusions.................................... 149

Chapter 6: Synthesis................................................ 155

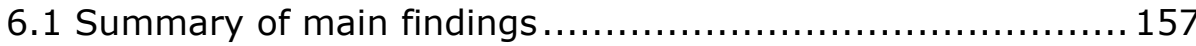

6.2 Overall goals and general conclusions ........................ 164

6.3 Reflections and Main Contributions ............................ 166

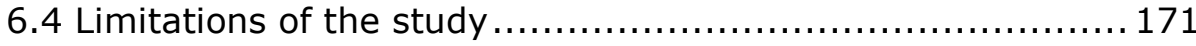

6.5 Recommendations for future research ...................... 173

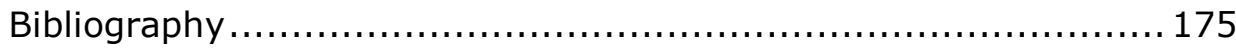

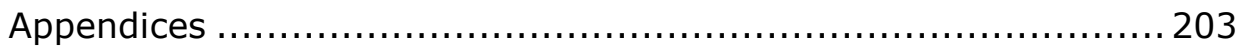

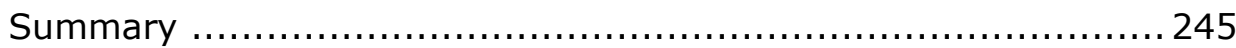

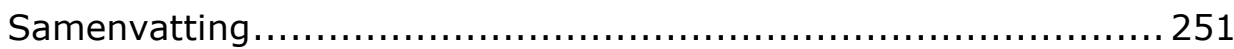

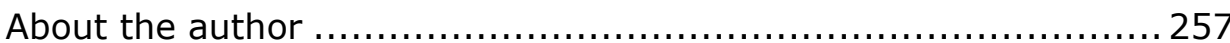




\section{List of figures}

Figure 1-1. Key concepts

8

Figure 1-2. The stages for preparing the annual village development

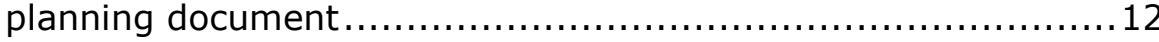

Figure 1-3. Regulatory framework to localise the SDGs and village maps availability in Indonesia ....................................20

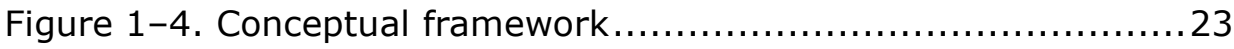

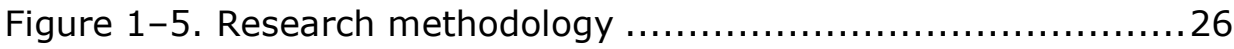

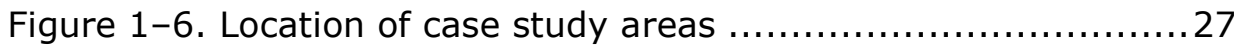

Figure 2-1. SDGs based assessment framework for public participation

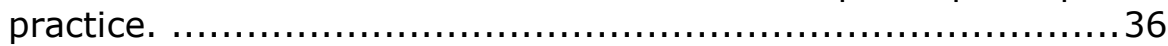

Figure 2-2. Responses about knowledge sharing during the process.

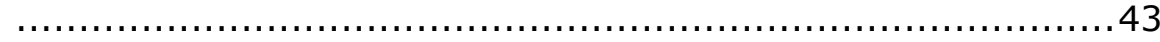

Figure $2-3$. Responses about defining problems ......................44

Figure 2-4. Responses about learning experiences....................45

Figure 2-5. Response about the domination of certain stakeholders. 46

Figure 2-6. Typical Musrenbang meeting at the village level using the classroom setting ................................................... 47

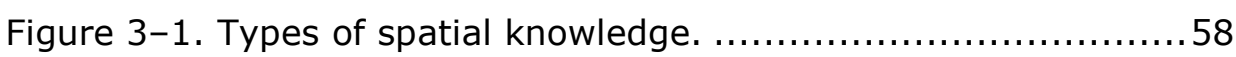

Figure $3-2$. Levels of spatial knowledge............................. 58

Figure 3-3. Connection of spatial forms and social relations (types of

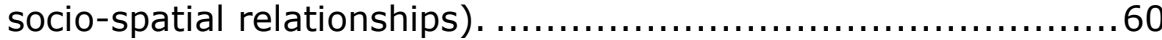

Figure 3-4. The cube framework to understand the utilisation of spatial

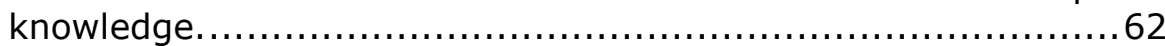

Figure 3-5. A respondent in Kramat Gajah village drawing a sketch map (left); focus group discussion in Sidoharjo I Pasar Miring village (right).

Figure 3-6. Number of respondents in each stakeholder group with particular types of spatial knowledge (percentages in brackets). 68

Figure 3-7. Percentage of respondents in each stakeholder group who own a certain level of spatial knowledge (counts in brackets). ..71 
Figure 3-8. Sketch map of Kolam village is hanged on the wall of the village office (left); map of neighbourhood XII in Kolam village, showing detailed information about the neighbourhood (social economy, facilities, housing, etc.) (right). ....................... 77

Figure 3-9. Percentage of respondents in each stakeholder group who agree, partially agree, and do not agree with the potential use of maps in the Musrenbang practice 78

Figure 3-10. Percentage of respondents in each stakeholder group who agree, partially agree, and do not agree to create maps through participatory mapping exercise 80

Figure 4-1. The collaborative spatial learning framework. .93

Figure 4-2. The OGITO (Open Geospatial Interactive Tool) application displayed on a maptable screen

Figure 4-3. Digital participatory mapping workshop in the Denai Lama village (a), and non-digital mapping workshop in the Kolam village (b). 98

Figure 4-4. The sequence of activities in the participatory mapping workshops.

Figure 4-5. Older-aged participants in Denai Lama were observing and giving advice/additional information to the younger participants (a); The older-aged participants actively engaged in the participatory mapping of the Kolam village while giving additional information that the younger participants might not know (b). 107

Figure 5-1. A conceptual framework to assess how village maps produced during participatory mapping activities can strengthen

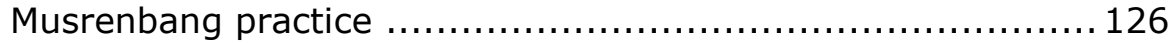

Figure 5-2. The participatory village map-making process, from a sketch map, created during digital or non-digital participatory mapping workshops, to a (georeferenced) village map........... 131

Figure 5-3. The helpfulness of village maps to the respondents for knowing more about their villages .............................. 134

Figure 5-4. The village map was used at the Musrenbang: (a) Denai Lama, (b) Kramat Gajah, and (c) Kolam ....................... 135

Figure 5-5. The availability of data to support the Musrenbang process

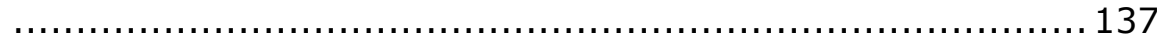

Figure 5-6. The importance of having data to support the Musrenbang 139

Figure 5-7. The effective use of available data during the Musrenbang. 
Figure 5-8. The use of village maps to support the deliberative process

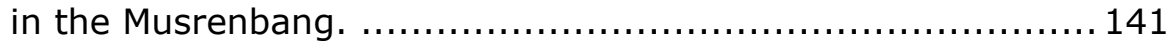

Figure 5-9. Domination of the Musrenbang deliberations by certain participants. ..................................................... 142

Figure 5-10. Participants' satisfaction with the Musrenbang process. 148 


\section{List of tables}

Table 1-1. Targets and indicators of SDGs Goal 11 and $16 \ldots \ldots \ldots 10$

Table 1-2. The division into intervention and control groups in the case

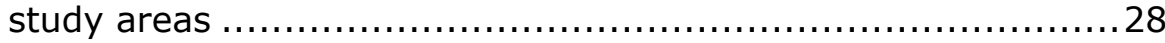

Table 2-1. Targets and indicators of SDGs 11.3 and $16.7 \ldots \ldots \ldots \ldots . .35$

Table 3-1. Criteria and means of verification of the types and levels of the participants/respondents' spatial knowledge ..................63

Table 3-2. Stakeholders interest and influence in utilising spatial knowledge and spatial data in Musrenbang......................... 75

Table 4-1. Assessment criteria and means of verification............. 101

Table 4-2. Participants' responses to the communication stage of the workshops..................................................... 103

Table 4-3. Participants' responses to the collaboration stage of the workshops....................................................... 104

Table 4-4. Participants' responses on knowledge co-production

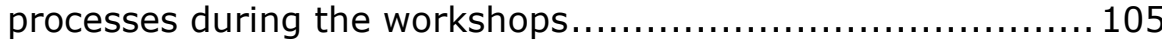

Table 4-5. Participants' responses on social learning processes during

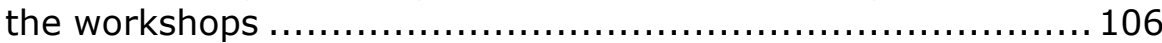

Table 5-1. Information about participatory mapping workshop participants, Musrenbang participants, and interviewees ........132 
Chapter 1: Introduction 
I would like to start this chapter by reflecting on my own experiences as a junior planner in the Regional Development Planning Agency (BAPPEDA) of the Deli Serdang district, Indonesia, which motivated me to carry out this research and inspired me in shaping the research questions. After pursuing my bachelor's degree in Geodetic Engineering at Gadjah Mada University in 2004, I worked as a land surveyor at a local consultant agency for a couple of months. I then applied for a civil servant position in the Deli Serdang district and was accepted as a junior planner at BAPPEDA. In 2005, during the first week of my job, I was shocked to discover that all the maps in the spatial planning documents were mere sketches without any geographical scale. At the time, these unscaled sketch maps were attached to legal documents that formed the basis for development and planning, including the issuing of land use permits in the district. As a result, we often found it difficult to identify exact locations or measure the length and width of specific areas because the sketches were inaccurate and unreliable.

With some colleagues who had similar ideas about using geospatial data, I started to convince my supervisors and co-workers about the importance of having maps with scales to support our primary duty as planners. It was not an easy task, but after ten years, we finally transformed all the spatial planning maps from sketches into scale maps, using geospatial data software such as AutoCAD and ArcGIS. At the time, the upper government mandated us to work with reliable geospatial data, so more civil servants in our district became familiar and aware of maps' benefits for many development and planning purposes.

In Indonesia, one of the primary duties of the regional planning agencies, as stated by law 25 of 2004 in the National System of Development Planning and its regulations, is to organise the Musrenbang, a public participatory planning forum held annually from the village level to the national one. The Musrenbang takes place as a public meeting involving various stakeholders who discuss and decide on potential projects to be implemented in the following year. As a district planning agency, it is our responsibility to organise the Musrenbang at the district level and supervise the meeting at the subdistrict level. In 2005, I was very excited to attend my first sub-district Musrenbang in Kutalimbaru, but when I saw a formal, monotonous meeting, I felt disappointed. During the session, the participants looked bored. Half of the time was spent listening to honourable guests 
giving their opening remarks. There was hardly any discussion during the meeting, as some people dominated it. The meeting place and its facilities were inconvenient, and a lack of data to support the process also created problems. The Musrenbang became merely a ceremonial meeting with little added value for its participants. It was implemented only to fulfil regulatory requirements, not to help participants communicate and collaborate to make better development decisions.

I found that the Musrenbang had similar problems at the district, province and national levels. I soon realised that the higher the level of the Musrenbang, the more formal the meeting was. In my opinion, to strengthen public participation, improvements should begin at the earliest planning stage. This prompted me to question the Musrenbang at the village level, the lowest level mandated by the regulations. Government officials ignored the critical role of the village Musrenbang as the first step in a sequence of development planning schemes. At the district level, there was no obligation for civil servants to supervise or attend the Musrenbang at the village level; I did not attend it. Therefore, I was curious to understand the implementation of the village Musrenbang. Where and when did it take place? Did it have similar problems as the upper-level Musrenbang? Who were the village stakeholders attending it? Was it accessible to all the village's citizens?

I observed that no geospatial data, such as maps, was used in the Musrenbang at sub-district and district level, even though the programs being discussed in the meetings were closely related to specific geographical places. I thus wondered whether the village Musrenbang experienced the same situation. What kind of geospatial data did the villagers have? Did they use geospatial data during the Musrenbang discussion? Furthermore, as villagers have local knowledge of the village's places and spatial surroundings, did they use this knowledge during the discussion? If so, how?

If it appears that the village Musrenbang has similar problems to the Musrenbang at upper levels, how can we improve its implementation? How can we strengthen public participation? Can geospatial data be a solution? What kind of geospatial data? Why does geospatial data not exist in the village? How can we create geospatial data? Can we involve village stakeholders in geospatial data creation? How can we capture local knowledge to produce geospatial data? Would the produced geospatial data benefit village stakeholders as primary beneficiaries or 
as outsiders? I was grappling with all these questions when I decided to continue my studies.

Fortunately, I got an opportunity to seek the answers to these questions. In 2014, when I participated in a two-month course at ITCUniversity of Twente, I was impressed with the different participatory mapping methods introduced by the lecturers. I used this opportunity to briefly discuss with some lecturers potential research topics that could address my questions about the village Musrenbang.

After the short course, I tried to develop a research proposal about the village Musrenbang and the potential of geospatial data to strengthen its implementation. I also applied for a Lembaga Pengelola Dana Pendidikan (LPDP) scholarship, which I used to conduct my research at ITC. This story forms the background of this study, which started from my concern as a junior planner who tried to improve the implementation of the Musrenbang. I then began my academic journey and shifted my role and paradigms from a practitioner or professional to a researcher. A researcher who would critically investigate and seek answers to fill research gaps. A researcher who learnt how to conduct ethical research on a real-life, local community problem: the public participation practice of the Musrenbang.

\subsection{Background}

Public participation practice is an important aspect of the Sustainable Development Goals (SDGs). The demand to have sustainable public participation is mentioned in the SDGs target 11.3, which argues the need to "enhance inclusive and sustainable urbanisation and the capacity for participatory, integrated and sustainable human settlement planning and management in all countries"; sustainable public participation is also referred to in target 16.7, which stresses the need to "ensure a responsive, inclusive, participatory and representative decision-making at all levels" (The United Nations, 2016). These ambitious targets require contextualisation for each country by deliberately localising the global goals into local, tangible and operational targets and indicators (Pfeffer \& Georgiadou, 2019; UN-Habitat and UNDP, 2016). Local and regional governments should define SDGs targets and indicators according to their data collection capacities, including their human resources and technological facilities. 
Localisation would lead to better operationalisation of SDGs through public participation practices at the local level, including the rural or even the neighbourhood level (Pfeffer \& Georgiadou, 2019). It is important to note that SDGs implementation should be accompanied by adequate and reliable data at all governance level. The data should be usable for reaching SDGs targets and indicators, as well as for tracking their progress (Koch \& Krellenberg, 2018; UN-Habitat and UNDP, 2016). Therefore, localisation should also consider the collection of local data/information to ensure this data/information is relevant for attaining SDGs targets at the local scale, especially targets 11.3 and 16.7, which are related to public participation practices.

In Indonesia, the Musrenbang public participation practice may provide an opportunity to localise and achieve SDGs targets 11.3 and 16.7 at different governance levels. The Musrenbang is firmly regulated by the law as a mandatory procedure to involve citizens and relevant stakeholders in the development planning process (Blair, 2013). From the village to the national level, the government has implemented the Musrenbang regularly to discuss development issues such as infrastructure, public facilities, health, education, economy, human settlements and other sectors that are relevant to local communities. As a public meeting that involves multiple stakeholders, the Musrenbang can provide a medium to facilitate social learning among its participants (Aswad et al., 2012). The meeting can be understood as an iterative process during a group activity where participants can learn from each other and share their views, experiences, and ideas(Flacke \& de Boer, 2017). Furthermore, the Musrenbang has the potential to support knowledge co-production among its participants as the stakeholders attending it typically have competing values, goals and information that must be recognised and negotiated (Butler, Bohensky, Suadnya, et al., 2016).

Although held regularly, the Musrenbang is still far from ideal. Some studies revealed similar problems to the ones I experienced on the ground (see Introduction). Musrenbang meetings are often conducted poorly; they represent a 'ceremonial' activity rather than a democratic, participatory planning process for various stakeholders (Aswad et al., 2012; Grillos, 2017; Purba, 2010; Sopanah, 2012). Decisions are mostly made by local government elites who have more knowledge and understanding about the planning procedures (Purba, 2010; Sopanah, 2012). Communication and collaboration among participants-two 
crucial factors to strengthen deliberation and public participation (Fung, 2006)-are not optimal during the process (Aswad et al., 2012; Feruglio \& Rifai, 2017). Furthermore, participatory processes such as the Musrenbang often fail to stimulate stakeholders to express their knowledge explicitly during deliberation (Fung, 2015). The different types of knowledge that stakeholders possess, such as tacit, community, sectoral, expert and spatial knowledge (Elwood \& Leitner, 2003; van Ewijk \& Baud, 2009; Pfeffer et al., 2013), are often not integrated or used effectively during the Musrenbang (Butler, Bohensky, Darbas, et al., 2016; Feruglio \& Rifai, 2017).

Scholars also found that there is a lack of data/information available to support the deliberative processes of Musrenbang meetings (Aswad et al., 2012; Sumarto, 2008). Feruglio and Rifai (2017) have listed two common types of data/information that are often absent in the Musrenbang practice: 1 ) data/information for identifying the needs and priorities such as maps, public services and infrastructure, socioeconomic indicators, and 2) data/information regarding planning procedures, such as the laws/regulations to follow, including the timeline and details of each planning stage. Despite differences in the inhibiting factors mentioned, what these studies have in common is that they show how the Musrenbang urgently needs to be strengthened so that it can provide meaningful processes for its participants. Using geo-information technology or geospatial data like maps during the Musrenbang's practices could be a feasible option to enhance its implementation. Maps can help stakeholders to spatialise their problems and needs so that they can formulate better decisions to be implemented in their neighbourhoods (Feruglio \& Rifai, 2017). Additionally, maps can be produced locally in a collaborative and participatory manner, which is aligned with the idea of localising the SDGs through the availability of local data/information. Creating maps through participatory mapping could allow the local stakeholders to represent themselves spatially on their maps, while also enabling them to be recognised and included in natural resource planning and management (Corbett \& Keller, 2005). The use of maps produced through participatory mapping to strengthen the Musrenbang should be closely considered.

This study explicitly seeks to incorporate this consideration across various stages of the research. The aim is to understand the factors that enable or hinder the success of the Musrenbang public 
participation practice and test our assumption that participatory maps can have a role in strengthening the Musrenbang. We limit the scope of this research to the Musrenbang at the village level to investigate how the SDGs' implementation, particularly of targets 11.3 and 16.7, is localised at the rural level through the use of participatory village maps. The village Musrenbang offers the opportunity to investigate this question and is thus an ideal case for this type of inquiry.

\subsection{Key concepts}

This section presents the key concepts built upon in this research to provide a general understanding of the theoretical foundation used to examine the case studies (Figure 1-1). To localise the SDGs targets 11.3 and 16.7 by achieving better public participation practices, it is necessary to discuss five key concepts. It is crucial to understand why it is important to involve citizens in public participation practices and have an understanding of the context of the Musrenbang. Since public participation usually involves various stakeholders, it is also essential to distinguish the different types of knowledge used during participation practices. Geospatial data can then be employed to enhance public participation by involving local stakeholders in the mapping activities. Map creation at the local village level could lead to better localisation of SDGs, particularly targets 11.3 and 16.7 , which relate to public participation practices. Furthermore, the maps created could be used to strengthen participation. 


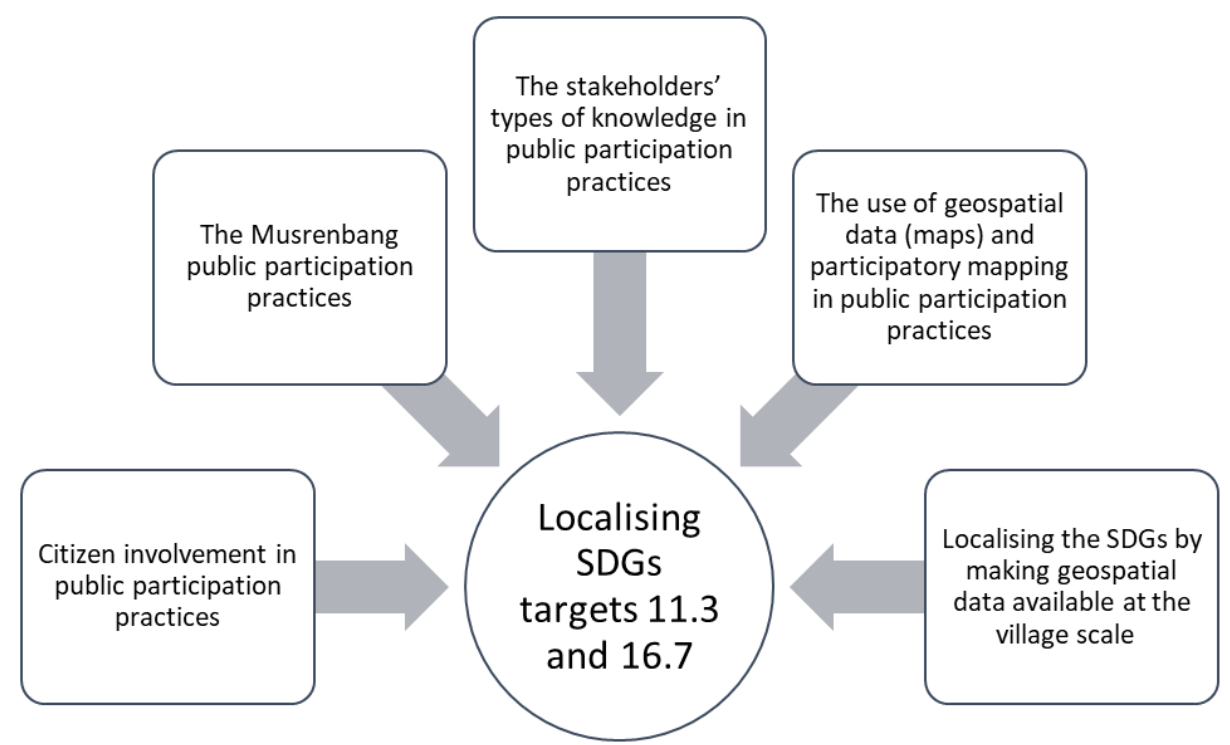

Figure 1-1. Key concepts

\subsubsection{Citizen involvement in public participation practices}

Public participation can be defined as the public's involvement in the planning and administrative process to influence the policies and actions undertaken (Callahan, 2007). In the past decades, governments have begun to involve citizens, private sector companies and social organisations in formulating policies and governance processes to adopt better and more democratic decisions (Edelenbos \& Klijn, 2006). Anokye (2013) stated that public participation practice is triggered by a fundamental development shift from centralisation to decentralisation, which provides space for local knowledge and bottomup initiatives. Consequently, more and more approaches have been developed and trialled so that public participation may meet the real needs of society.

One of the most referenced works in public participation discourse is Arnstein's ladder of participation, which classified several levels of citizens' participation. To determine the degree of public participation, Arnstein (1969) divided it into several rungs or ladders, ranging from non-participation (therapy and manipulation) and tokenism (placation, consultation and informing) to citizens' power (citizen control, delegated power and partnership). The concept is simple: the higher 
the ladder, the more participation in the processes (Coenen et al., 1998). Based on Arnstein's theory, other scholars developed various approaches and innovations to strengthen the implementation of public participation. The instruments used for participation have also been expanded thanks to the development of citizen participation theories and methods (Hordijk et al., 2015).

In the following decades, under the rubric of Participatory Learning and Action (PLA), Chambers (1981) introduced an approach that emphasised the learning processes in public participation activities and recognised local people's knowledge and active involvement. This approach (see also Chambers, 1994a, 1994b) then inspired Healey (1998b) to propose a more collaborative planning practice. Healey argued that the collaborative planning initiative has three main dimensions: knowledge resources, relational resources and mobilisation capacity. These dimensions are crucial for building an institutional capacity so that stakeholders may observe, listen and ask questions about their real needs and aspirations. Therefore, collaborative methods could facilitate communication and collaboration among stakeholders and reduce conflicts when producing and implementing development strategies. These methods are also helpful for building shared knowledge and understanding among stakeholders, as well as for working together locally and dealing with shared problems (Healey, 1998).

Innes and Booher (2004) also suggested that collaborative participation should support the deliberative processes of multiple stakeholders in formal or informal ways to reach a consensus. All actors must communicate and collaborate to develop mutual understandings when formulating appropriate solutions. By doing so, collaborative participation will encourage citizens to participate actively in the governance process, exercise their citizenship and synergise the relationship between the state and civil society (Hordijk, 2005).

Public participation is also an important aim of the SDGs, as stated in targets 11.3 and 16.7. Specifically, public participation is mentioned in indicators 11.3.2 and 16.7.2, which are classified in tier 3 (see Table 1-1). The Inter-Agency Expert Group on SDGs Indicator (IAEG-SDGs) has classified the SDGs indicators into three tiers based on the standards or methodologies of each listed indicator, as follows. Tier 1: the concept, methodology and standards of the indicators are clear and 
at least 50 percent of countries in the world regularly produce the necessary data; Tier 2: the methodology and standards are available but countries do not regularly produce the data; Tier 3: an established methodology or standards are not yet available (Kraak et al., 2018; UN Statistics Division, 2018). This classification provides opportunities for countries or scholars to contribute to the conceptualisation of SDGs by localising the indicators and making them more operational and tangible, especially those that are still classified in tier 3 (Koch \& Krellenberg, 2018; Kraak et al., 2018). Expert and scientific contributions are urgently needed to localise the targets and indicators to make them applicable and relevant at the local or regional level (Hák et al., 2016; Pfeffer \& Georgiadou, 2019).

Table 1-1. Targets and indicators of SDGs Goal 11 and 16

\begin{tabular}{|c|c|}
\hline Targets & Indicators \\
\hline \multicolumn{2}{|l|}{ Goal 11: Sustainable Cities and } \\
\hline \multicolumn{2}{|l|}{ Communities } \\
\hline $\begin{array}{l}11.3 \text { By } 2030, \text { enhance inclusive and } \\
\text { sustainable urbanisation and capacity for } \\
\text { participatory, integrated and sustainable } \\
\text { human settlement planning and management } \\
\text { in all countries }\end{array}$ & $\begin{array}{l}\text { 11.3.2 Proportion of cities with a direct } \\
\text { participation structure of civil society in urban } \\
\text { planning and management that operate regularly } \\
\text { and democratically }\end{array}$ \\
\hline \multicolumn{2}{|l|}{ Goal 16: Peace, Justice, and Strong } \\
\hline \multicolumn{2}{|l|}{ Institutions } \\
\hline $\begin{array}{l}\text { 16.7 Ensure responsive, inclusive, } \\
\text { participatory and representative decision- } \\
\text { making at all levels }\end{array}$ & $\begin{array}{l}\text { 16.7.2 Proportion of population who believe } \\
\text { decision-making is inclusive and responsive, by } \\
\text { sex, age, disability and population group }\end{array}$ \\
\hline
\end{tabular}

\subsubsection{The Musrenbang: participatory planning practice in Indonesia}

The period of democratic reform in 1998 was critical in supporting public participation practices in Indonesia. This period was characterised by the decentralisation of power and political structures and by the publication of new regulations to strengthen local governments' role in decision-making and financial autonomy (Antlöv, 2003; Widianingsih \& Morrell, 2007). After several changes, the planning and budgeting system is firmly regulated in law 25 of 2004 of the National Development Planning Systems. The decentralisation of planning and budgeting policy in Indonesia is implemented not only at 
the provincial and district/city level but also at the village level, after the Village Law (law 6) was enacted in 2014. The Village Law decentralised the tasks of planning, executing and monitoring rural development to the village government (Sutiyo, 2013). It provides a combination of better financial management systems, new institutional arrangements and citizens' empowerment that enables the village government to be more responsive and capable of running the governance process, and to collaborate with citizens (Antlöv et al., 2016).

In general, the law regulates how to formulate the development planning and budgeting document at different government levels in Indonesia. One of the steps in acquiring the development plans is holding a public meeting to discuss such plans, which is called Musrenbang. The word Musrenbang stands for three Indonesian words: "musyawarah (a community consensus-building meeting), perencanaan (planning, but also understood as budgeting) and pembangunan (development)" (Feruglio \& Rifai, 2017, p. 5). The meeting is implemented at each level of government structure: village (desa)/kelurahan, sub-district (kecamatan), district (kabupaten)/city (kota), province (provinsi) and nation (nasional). The Musrenbang is considered the legal mechanism for citizens to actively participate in local development planning and budgeting processes (Mahi, 2010).

At the village level, the Musrenbang is conducted as an annual meeting for various stakeholders to set the village priorities and plan for the following year. Participation is implemented through a public meeting with large audiences, including all the village's stakeholders. The village head usually leads the discussion. The meeting results take the form of an agreement to a list of program priorities that will be implemented in the village during the following year, as written down in the village budget revenue and expenditure document (APBDesa) and the programs proposed to the sub-district or district level of the Musrenbang (Sopanah, 2012). The Minister of Internal Affairs Decree $114 / 2014$ (Permendagri 114/2014) provides a comprehensive summary of the annual development planning stages at the village level (Figure 1-2). Although this decree regulates the annual development planning process in detail, in practice, many villages still conduct the Musrenbang in the middle of January, as regulated by the Minister of Internal Affairs Decree 54/2010 (Permendagri 54/2010). 


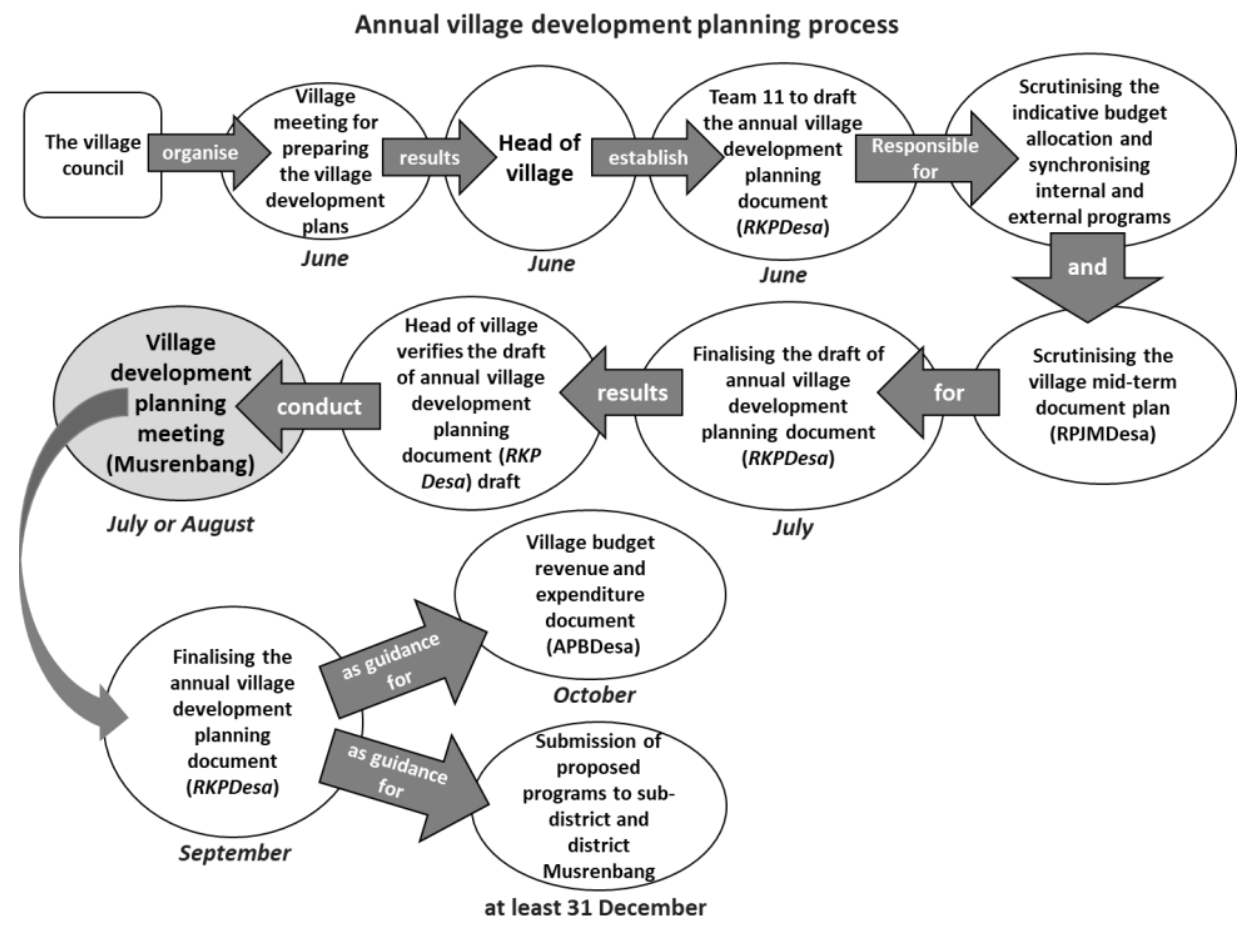

Figure $1-2$. The stages for preparing the annual village development planning document

Adapted from: The Minister of Internal Affairs Decree 114/2014 on Guidance for Village Development (Permendagri 114/2014)

There is a significant difference in terms of development and budgeting procedure between the periods before and after the Village Law was issued. Before the law was published, the funding for villages was considerably dependent on decisions taken at higher levels of local government; this resulted in limited funding for the development of villages. However, after the passing of the Village Law, various sources of funding were made available (Antlöv et al., 2016; Kushandajani, 2016). Villages now receive the village budget (Dana Desa), which is directly allocated by the national government to recognise the importance of villages. The villages also get other funding from the village budget allocation (Alokasi Dana Desa) of the district/city government and can also access village original revenue (Pendapatan Asli Desa). Sopanah (2011) found that citizen participation is very high if there are block grants given to the villages for rural development projects and if the villages have the freedom to manage and decide which projects to implement. This is reasonable since villagers might 
consider that the projects decided upon and implemented will meet their actual needs. Moreover, the village budget policy allows them to contribute to discussions and decisions regarding budget allocation through the Musrenbang.

Scholars have found some significant drawbacks in the Musrenbang's implementation, which have been discussed in the background section of this study. These drawbacks highlight the need for the Musrenbang to be strengthened so that the participatory process may become more effective and provide better results for communities. Stakeholders' knowledge might be a valuable source to address the shortcomings in question. Diverse knowledge could stimulate a negotiation in the participatory process that could lead to different types of knowledge becoming substantial sources of decision-making (M. A. Hajer \& Wagenaar, 2003). Knowledge bridges the communication and collaboration of various stakeholders as the individual interacts with the organisation through knowledge and knowledge production occurs at the individual, group and organisational level (Nonaka \& Takeuchi, 1995). Therefore, it is necessary to have a comprehensive understanding of the different kinds of knowledge that stakeholders possess to ensure this diversity benefits public participation practices.

\subsubsection{Stakeholders' knowledge in public participation practice}

Scholars have identified different types of knowledge. Polanyi (1967), for example, described two types: tacit and explicit knowledge. Tacit knowledge is constituted by informal knowledge based on intuition and gained from individual experiences and practices, while explicit knowledge is formal information based on data, scientific formulas, principles and theories (Shrestha et al., 2014). Nonaka \& Konno (1998) proposed two further dimensions of tacit knowledge. The first one is the 'technical dimension' related to individuals' informal skills (knowhow). The second one is the 'cognitive dimension' related to the beliefs, values and mental models embedded in each of us, which construct our perception of the world.

In another study, van Ewijk and Baud (2009) classified knowledge into four main types: tacit, community, sectoral and expert. They identified tacit knowledge as uncodified information that is mastered through individual practice and experience. Community knowledge is related to the information that residents possess about their social and political 
situation and their spatial surroundings. Sectoral knowledge comes from professionals and practitioners and is built through technical, economic and political practices. Expert knowledge is codified information owned by professional education organisations that are widely accepted in the scientific system. Some scholars imply that the production and exchange of different knowledge types link knowledge through the dissemination and learning processes (King \& McGrath, 2004; Verkoren, 2008). Each type of knowledge can be exchanged through communication and collaboration among parties involved in partnerships and provide mutual learning to stakeholders (van Ewijk \& Baud, 2009). Mutual learning tends to occur if the stakeholders involved can identify the outcomes of the knowledge production process.

Baud et al. (2011) pointed out the importance of space and place in governance networks and processes, as both wield great influence in structuring society. Different actors involved in these processes may face complex life problems, such as housing, public services, employment and consumption, which are related to geographical space and place. Various spatial knowledge types will be produced, used and exchanged by the stakeholders involved in governance processes dealing with these problems (Pfeffer et al., 2013). In this study, spatial knowledge is defined as the knowledge through which individuals, social groups and institutions perceive particular places with their characteristics and meanings (Elwood, 2006a). Spatial knowledge can also be defined as a set of information that is related to geo-coded or geo-referenced data, or as spatial relational facts and interdependencies perceived by individuals or groups that can be presented in maps (Pfeffer et al., 2013). Spatial knowledge can be a valuable source to promote social learning and knowledge coproduction among diverse stakeholders (Natarajan, 2017).

Considering the importance of spatial knowledge in governance processes, stakeholders' knowledge needs to be spatialised. Doing so "tak[es] place at two levels; that of the contributions that 'mapping' can make to a better understanding of particular situations, and more specifically the methodologies of producing spatial information and knowledge, which can contribute to our understanding of 'uneven' urban development" (Baud et al., 2011, p. 9). In Peru, Miranda Sara et al. (2016) have found that the integration of stakeholders' spatial knowledge through spatial representations has resulted in social 
learning for different actors involved in the process. Miranda Sara et al. applied collective and iterative mapping processes using the technical, organisational and geographical knowledge of various stakeholders in Lima. Linking the spatial knowledge of multiple stakeholders, such as governments, experts and practitioner networks, and using spatial tools like maps, helped the stakeholders in Lima better understand the risks of water management and work collaboratively to overcome the problems.

The use of different types of spatial knowledge requires suitable methods that can accommodate diverse stakeholders. Public participation practices and participatory mapping methods can be used as a means to connect society to the environment, as well as deliberate on the different forms of knowledge, practices and experiences of stakeholders (Baud et al., 2011; Whatmore, 2009). Natarajan (2017) noted that participatory planning practices can facilitate different stakeholders to experience social learning processes. However, merely gaining social learning in practice is not enough to achieve meaningful participation. Natarajan argued that actors involved in community practices might obtain a better result from the participatory process if they also have a good understanding of space. However, this aspect is still underexplored. The socio-spatial learning approach is relevant since the public participation practice would also adopt knowledge as "a factor of community empowerment, when lay knowledge reworks planning knowledge in an arena of conceptual learning about space in public participation" (Natarajan, 2017, p. 6). In short, socio-spatial learning is an approach where spatial knowledge is reworked or reframed upon community engagement. Thus, using visualisation or spatial tools like maps and geoinformation technologies promises to achieve a more meaningful public engagement in participatory planning practices.

\subsubsection{The use of geospatial data and participatory mapping in public participation practices}

It is important to note that to participate effectively in a participatory process, citizens need adequate information about their geographical areas. This knowledge should be understandable and usable to support deliberative processes. Providing geospatial data, such as maps, can help make the participatory process more effective. Maps can store, 
portray and represent various types of information for different stakeholders and can support the decision-making process in public participation practices (Carton, 2007; Kraak, 2004; Perkins, 2013). In addition, a map can also depict various interlinked objects and have spatial characters that make the objects well-presented and understandable by multiple stakeholders. The use of maps in public decision-making practices is becoming more popular as the rapid development of geoinformation technologies in the past few decades has made the production of maps less expensive and more accessible (Bednarz et al., 2006; Kraak, 2003; Parker, 2006; Rambaldi, 2005). Carton and Thissen (2009) added that a map is also helpful in promoting public participation by making map production and utilisation as inclusive as possible. This inclusivity can be attained by involving stakeholders in the mapping activities, such as data collection, problem diagnosis, designing of alternatives and impact assessment. An inclusive approach is also helpful to gain citizens' opinion and views on issues and locations, providing valuable sources for the governance process (Martinez et al., 2016).

Regarding map production, scholars have noted the need to emphasise local issues and local knowledge (Sieber, 2000). Local spatial knowledge is essential as an added value to enrich planners and experts' datasets and analyses, as well as cross-check the data (McCall, 2008). Therefore, engaging local stakeholders in a participatory mapping activity, understood as joint data/information production or as a map-making process undertaken by a group of people (typically non-experts) who are linked to one another based on their common interest (Corbett, 2009), is a method that acknowledges stakeholders' local spatial knowledge. Participatory mapping can be used to communicate lay people's input to planners, policymakers and scientists, thus producing better decisions. This method is widely used in development contexts since it does not confine the maps produced simply to geographic information but includes also local people's social, cultural and historical knowledge (Chambers, 2006). The participatory mapping technique has been used for various purposes, such as forest management (Beverly et al., 2008), ecosystem services (RamirezGomez et al., 2015), flood management (Cinderby \& Forrester, 2016), land-use changes (Lubis \& Langston, 2015), countryside conservation (Wood, 2005) and even social and cultural land recognition (Dewi, 2016). 
Corbett (2009) described six purposes of participatory mapping: help the community to articulate and communicate their spatial knowledge to other stakeholders, retrieve and preserve local knowledge, support land-use planning and resource management, empower communities to advocate their causes, improve communities' capacity in problem formulation or solving, and address conflicts among stakeholders. These purposes can only be achieved if the mapping processes are conducted inclusively, thus enabling various stakeholders to communicate and work collaboratively to create the maps. Accordingly, choosing the correct methods and tools is essential.

The methods and tools of participatory mapping are varied, from using only traditional tools such as ground mapping or sketch mapping to sophisticated computer-based mapping (Corbett, 2009; McCall \& Dunn, 2012). The widespread use of Geographical Information Systems (GIS) and other geoinformation and technology tools has increased the effectiveness of participatory mapping. However, relying heavily on technology has also consequences. For example, web-based participatory mapping might not be accessible to citizens with limited knowledge and access to online platforms. Although such tools can provide rich information in a high-quality format, they can remain exclusive. As these tools are highly dependent on access to geoinformation technology and computer literacy, they might prevent inclusive decision-making processes (Martinez et al., 2011). Chambers (2006) has discussed the differences between ground maps, paper maps and GIS maps in participatory mapping practices. He found that each tool has its strengths and weaknesses, as certain tools may work well for some stakeholders but not for others. Therefore, in addition to choosing the right tools, good participatory mapping also requires suitable methods. Chambers also suggested that the behaviours and attitudes of facilitators who control the mapping process are essential. They have to be able to use and manage the deliberative process as well as the mapping tools to increase the locals' participation and not endanger their empowerment (Chambers, 2006). 


\subsubsection{Localising the SDGs by making geospatial data available at the village level}

For three decades now, global leaders have attempted to achieve sustainable development when formulating, deciding and applying their development policies. The concept has received multidisciplinary attention as it encompasses three main pillars of development: economy, society and environment (Shao et al., 2011). Sustainable development has evolved globally and manifested in the launch of the Millennium Development Goals (MDGs) 2015 and then of the Sustainable Development Goals (SDGs) 2030. Since their launch in 2015, the SDGs have provided a roadmap for countries to achieve sustainable development through 17 universal goals, 169 targets and 232 indicators (Kraak et al., 2018; The United Nations, 2016).

Operationalising global goals into local contexts is a daunting task for policymakers; still, doing so is needed to prevent more significant gaps between global indicators and local needs and understandings (Tan et al., 2019). Most nations do not have the means, knowledge and infrastructure to reach SDGs goals, especially at the local level (Coonrod, 2015). Thus, it is important to ensure that operationalisation is not trapped by 'bean counting' since the indicators may focus on the indicator, not on attaining sustainability (Pogge \& Sengupta, 2015). Countries need to localise the SDGs into their local and regional development contexts. The UNDP and UN-Habitat clearly stated the importance of localising the SDGs in pursuing the 2030 agenda:

"Localisation relates both to how the SDGs can provide a framework for local development policy and to how local and regional governments can support the achievement of the SDGs through action from the bottom up and to how the SDGs can provide a framework for local development policy" (UN-Habitat and UNDP, 2016, p. 6).

Localising the SDGs also requires governments to have sufficient and reliable data because lack of data availability at local scales may limit their ability to use the global indicators (Klopp \& Petretta, 2017; Koch \& Krellenberg, 2018; Patel et al., 2017). However, for many governments, especially for national statistical offices, limited budgets and resources to collect and produce reliable datasets are a considerable challenge (MacFeely, 2018). The urgent need for data provides opportunities for non-governmental actors to produce, disseminate and access information for development purposes (Fisher 
\& Fukuda-Parr, 2019). Localising data production through bottom-up approaches could solve the data availability problem while enabling stakeholders' knowledge articulation at local scales (Tan et al., 2019). However, it is crucial to ensure that the stakeholders involved can access or use the data produced to prevent the risk that data production becomes mere data extraction. Stakeholders should benefit from their participation in data production activities. For instance, their skills or knowledge should increase so that they may better participate in public participation practices. To ensure the availability of geospatial data for SDGs implementation, in 2018 the United Nations published the Integrated Geospatial Information Framework (IGIF), which supports, monitors and assesses the SDGs' progress (UN-GGIM, 2018). The IGIF framework aims to support the implementation of the SDGs with sufficient and reliable geospatial data at different governance levels, from the global to the local (Avtar et al., 2020).

In Indonesia, the government has published several regulations to localise the SDGs. It has issued the Presidential Decree 59/2017 as the legal framework for SDGs implementation (Morita et al., 2020), as can be seen in Figure 1-3. The decree mandates all government institutions to adopt and apply the SDGs in their action plans. The Ministry of Village Development in Disadvantaged Regions and Transmigration followed up the Presidential Decree by launching the village SDGs program through the Minister Decree 13/2020, which aims to achieve the SDGs' implementation at the village level. In Indonesia, the achievement of the SDGs in villages through 18 goals is claimed to account for up to 74 percent of national SDGs targets (Ministry of Village Development in Disadvantaged Regions \& Transmigration, 2020). 


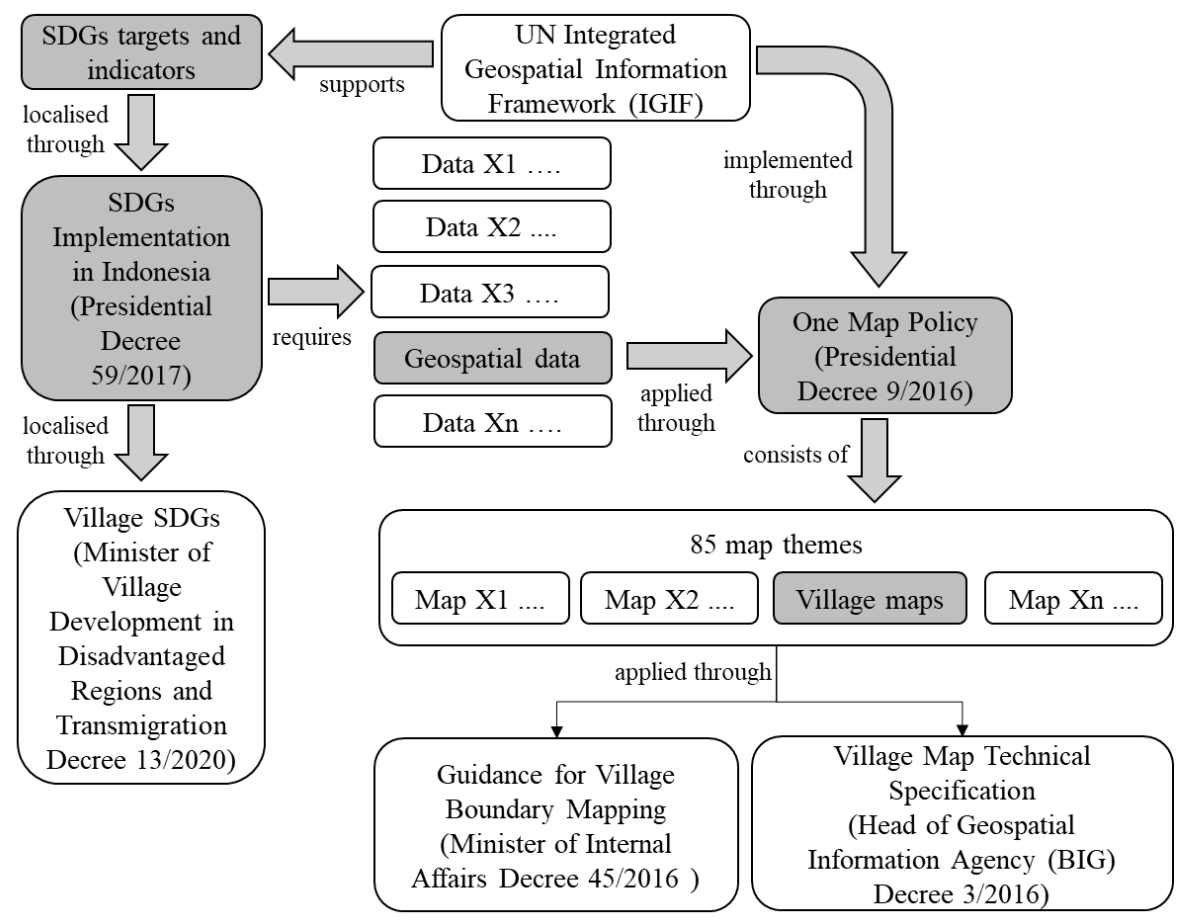

Figure 1-3. Regulatory framework to localise the SDGs and village maps availability in Indonesia

Concerning geospatial data availability in Indonesia, the government has introduced the One Map Policy (OMP) through Presidential Decree 9/2016 to ensure the country has sufficient data to support the SDGs' implementation (Figure 1-3). This decree is considered to be a national strategy to create an integrated spatial data infrastructure by targeting the production of 85 thematic maps, including the village map, as a prominent goal to achieve by 2019 (Patmasari, 2019). The government has also introduced other regulations as technical guidance for village mapping. For example, it has issued the Minister of Internal Affairs decree 45/2016 and the Head of Geospatial Information Agency regulation 3/2016. Village maps are needed not only to achieve the SDGs at the village scale but also to support the planning and development of village areas (Patmasari, 2019). Although it is an essential target, the government has difficulties in reaching the village map availability required by the OMP. Of 83.436 villages in Indonesia, only 31.147 had been delineated in 2019 (Abidin, 2019). Until this thesis is written in 2021, the goal has not been achieved. This explains why it is hard to find relevant data to support the Musrenbang, such 
as village maps. Because the central government has difficulties in providing the village maps (Patmasari, 2019), localising map production might be a feasible solution to solve this problem.

\subsection{Research problem}

Since the announcement of the SDGs in 2015, several attempts have been made to localise the SDG concept at national and local levels (Burford et al., 2013; Fisher \& Fukuda-Parr, 2019; Klopp \& Petretta, 2017; Koch \& Krellenberg, 2018; Liu et al., 2019). However, these studies examine the localisation of SDGs in urban areas where the problems are considered to be more complex and have a greater impact on national, regional and global development. Limited attention has been paid to sustainable rural development, despite the vital role of rural areas in supporting regional and national development (Murdoch, 1993). Public participation practice at the rural level, which has a crucial role in achieving sustainable development, has also received little attention (Bednarska-Olejniczak et al., 2020).

Regarding the Musrenbang, various studies have explored and reported different aspects of its implementation, but they have only explained either the failure or the success of the practice (Aswad et al., 2012; Feruglio \& Rifai, 2017; Grillos, 2017; Purba, 2010; Sopanah, 2012). There are no studies that investigate the question of how to strengthen the current practices. Similarly, no study has yet explored the impact of a geospatial data intervention on the Musrenbang. There is also a knowledge gap concerning the role of a local public participation practice like the Musrenbang in achieving the SDGs targets 11.3 and 16.7. Cabannes (2019), for example, said that participatory planning and budgeting could be considered a relevant SDGs indicator, particularly for targets 11.3 and 16.7.

Therefore, rather than working on the SDGs at a global scale, I wish to work on them at a local-rural one by localising targets 11.3 and 16.7 and by evaluating and strengthening the Musrenbang with village stakeholders. My research sets out to understand the factors that affect the Musrenbang's implementation and then considers incremental ways to enhance the existing implementation. Unlike previous research, this study uses a participatory research method to explore and identify the reasons that underlie the impediments to the 
Musrenbang's implementation, while observing the impact of the maps intervention on the Musrenbang process. This approach requires a comprehensive understanding of the problems underlying the Musrenbang from the point of view of its participants and then exploring options with them to formulate feasible solutions.

\subsection{Research objectives and questions}

This study uses a participatory research method by involving local people in the villages in a sequential reflection and action process so that their local knowledge and perspectives are not only acknowledged but also shape the research and planning (Cornwall \& Jewkes, 1995). Inspired by the use of spatial knowledge in the literature (Natarajan, 2017; Pfeffer et al., 2013, 2015; Shrestha et al., 2018b), this study attempts to localise the SDGs targets 11.3 and 16.7 by developing a collaborative spatial learning framework that makes use of the spatial knowledge of village stakeholders to produce joint geospatial data in the village maps format. The framework would allow stakeholders to effectively use their spatial knowledge, enabling communication, collaboration, knowledge co-production and social learning. As producers and owners of the maps, the village stakeholders could then use them during the Musrenbang. It is expected that the participatory village maps will improve the Musrenbang's practices. So, this study aims to investigate to what extent these participatory mapping activities and the maps produced can help to strengthen the Musrenbang's public participation practices. The conceptual framework of the research is presented in Figure 1-4. 


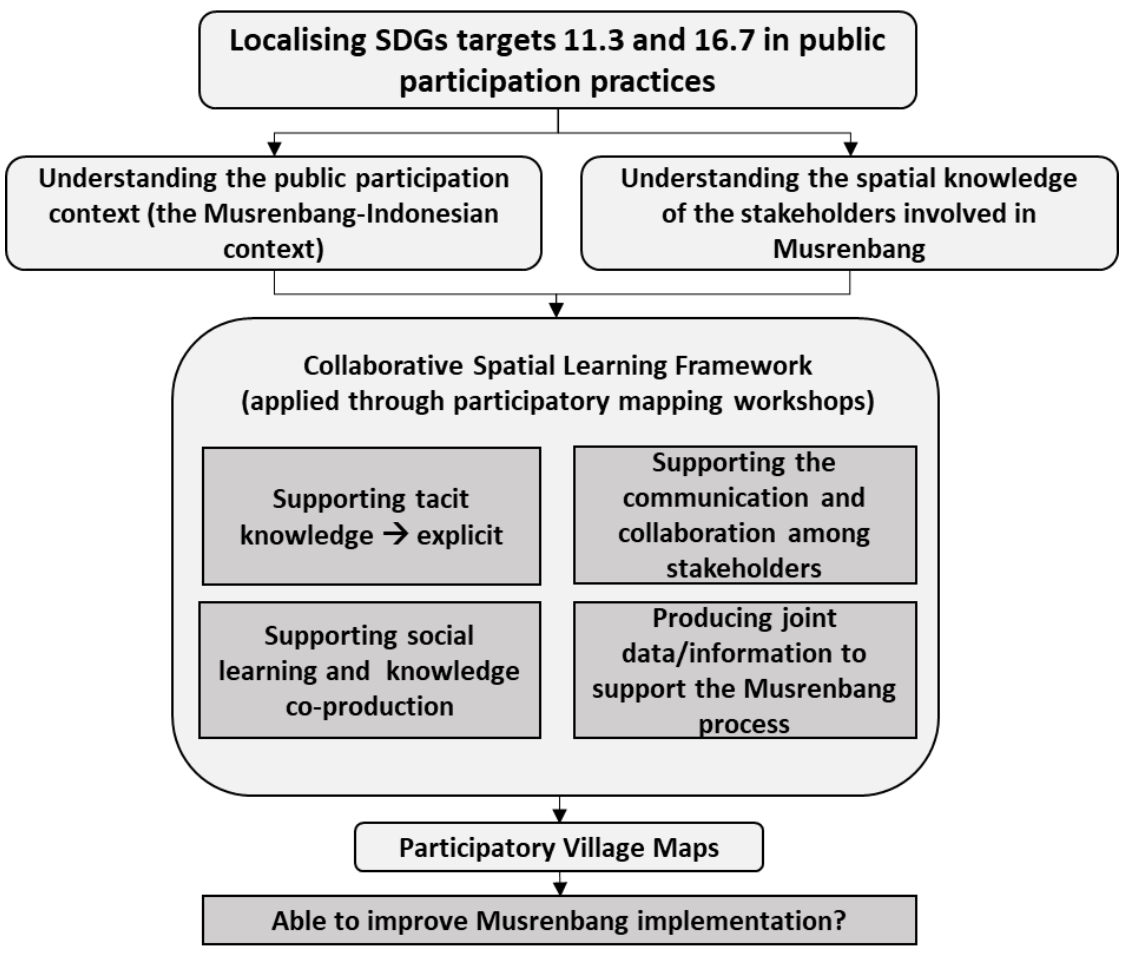

Figure 1-4. Conceptual framework

To achieve its main aim, this study is divided into four research objectives.

\section{Objective 1:}

To evaluate the implementation of the Musrenbang at the village level in Indonesia by using an SDG-based evaluation framework

- Who are the stakeholders involved in the Musrenbang participatory planning and budgeting practice? What are their interests and influences?

- What are the main factors that hinder the success of the Musrenbang's implementation?

\section{Objective 2:}

To examine the extent of spatial knowledge, the scale of its use in formal public participation practice and its potential to enhance practice

- What spatial knowledge and geospatial data do villagers have (and do not have)? 
- How are spatial knowledge and geospatial data used in the Musrenbang practice (and how are they not used)?

- To what extent do spatial knowledge and geospatial data help to support public participation?

\section{Objective 3:}

To develop a collaborative spatial learning framework that enables the integration of stakeholders' spatial knowledge, facilitates their communication and collaboration, and leads stakeholders in knowledge co-production and social learning processes

- To what extent does the framework help in pursuing and localising SDGs at the rural scale?

- To what extent does the collaborative spatial learning framework enable village stakeholders to better understand sustainable development issues at the local-rural level?

- To what extent does the collaborative spatial learning framework help integrate village stakeholders' spatial knowledge?

- What challenges occur when participants from rural communities engage in mapping tasks using non-digital and digital mapping tools?

\section{Objective 4:}

To assess the extent to which village maps produced at participatory mapping workshops help strengthen public participation practice at the village level

- To what extent do the participatory village maps support the Musrenbang by facilitating communication among participants?

- To what extent do the participatory village maps help the Musrenbang by enabling collaboration among participants? 


\subsection{Research methodology}

The research problems and objectives above provide a pathway to the approach, methodology and methods used in this research. Different methods and techniques were adopted depending on specific objectives and questions since no single approach can fulfil all the research objectives. The case study research design and multiple methods were used to access various data sources, which makes any findings or conclusions more credible and robust (Yin, 2003). With plentiful evidence collected during the research, the findings will be validated using data triangulation. Triangulation allows different information sources to converge, which will increase the research accuracy and credibility (Hussein, 2009). The overview of the methodology used in this research can be seen in Figure 1-5 below. 


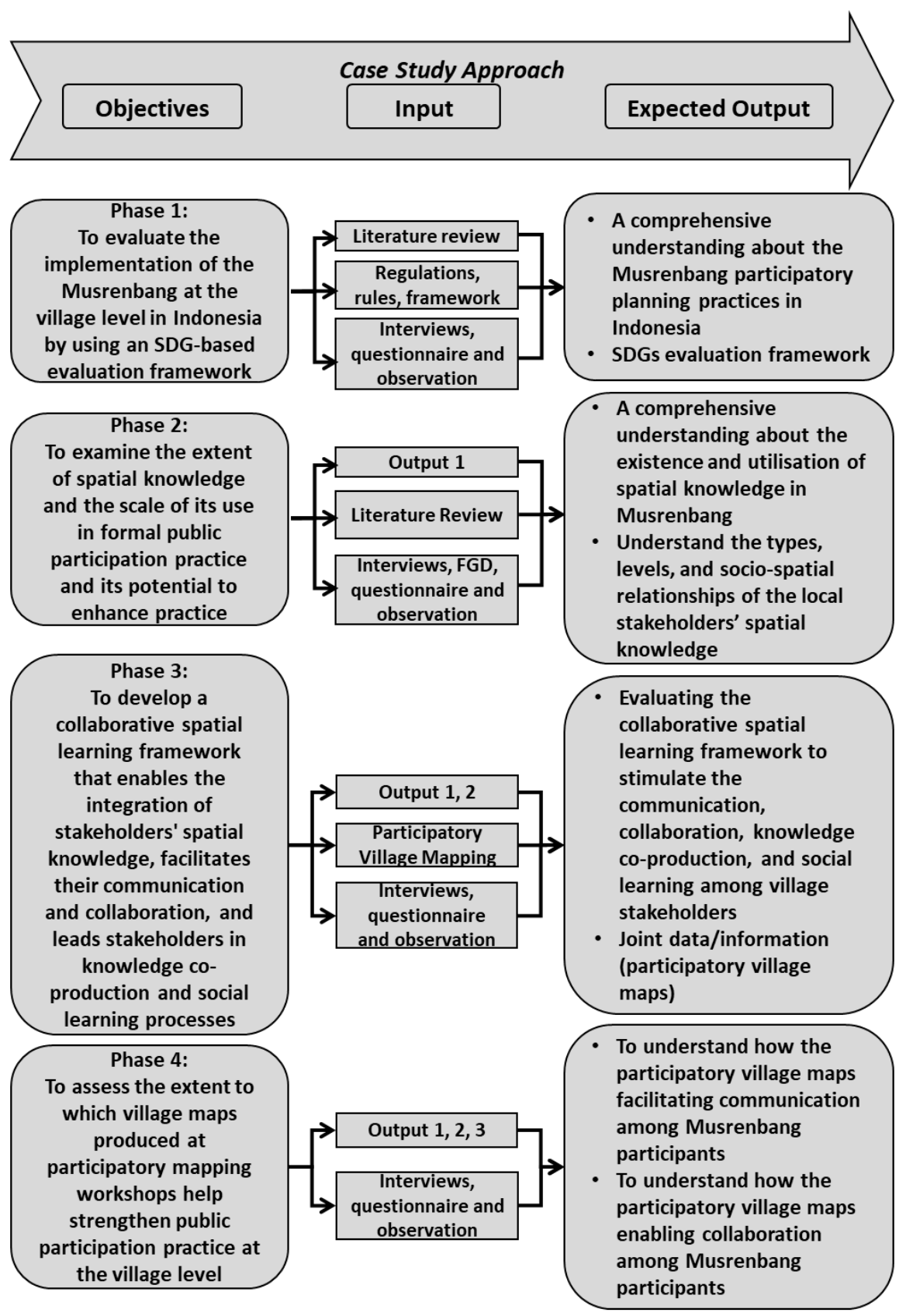

Figure 1-5. Research methodology

Five villages in the Deli Serdang district, Indonesia, were chosen for data collection (Figure 1-6). The selection was based on four criteria: (1) the village is located in different sub-districts; (2) the ethnicity of 
the population is primarily Javanese; (3) the main livelihood of the population is farming/agriculture; (4) the villagers are willing to participate in the study. The selected villages were: Denai Lama, Kramat Gajah, Kolam, Sidoharjo I Pasar Miring, and Tandem Hulu II.

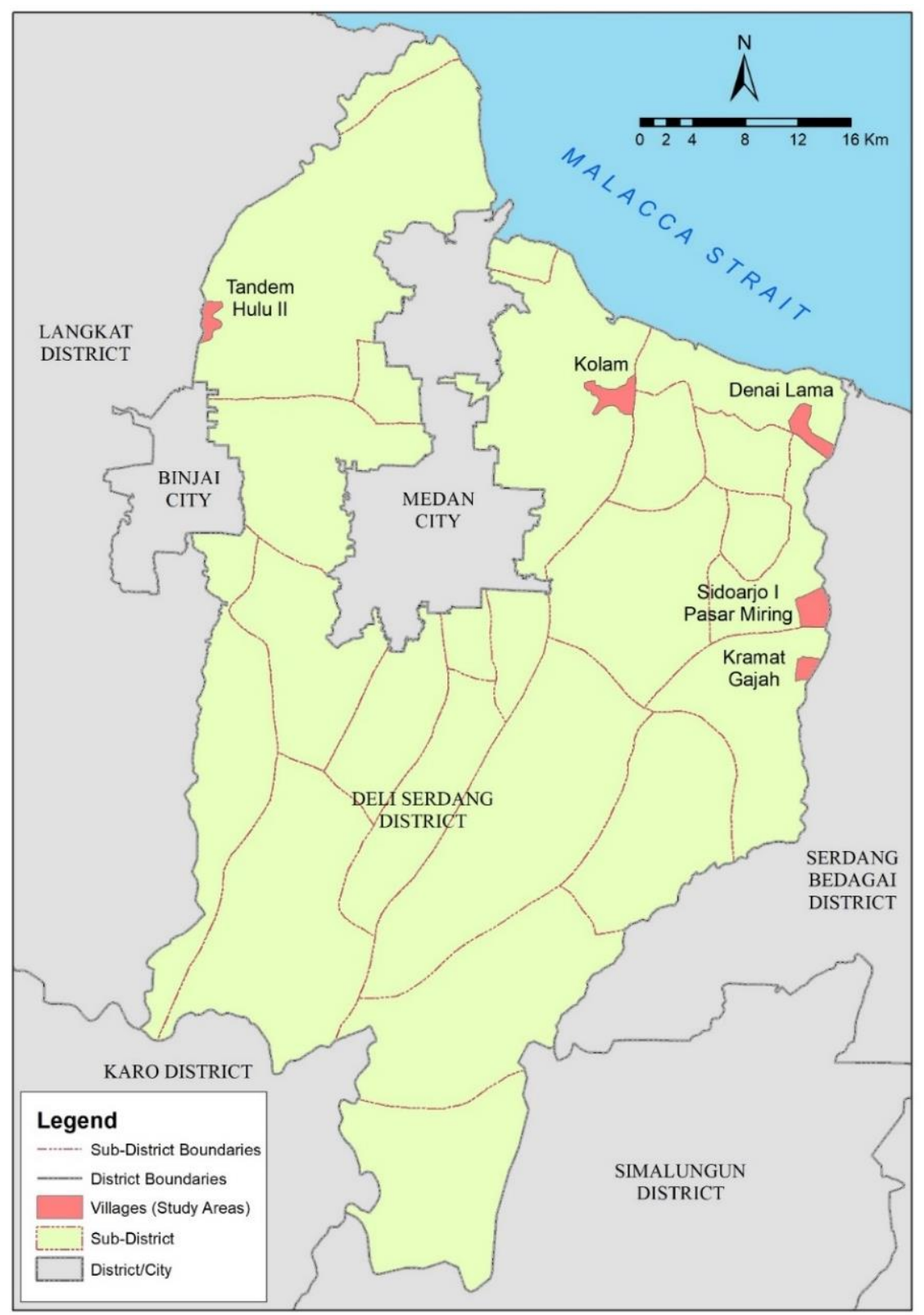

Figure 1-6. Location of case study areas

Source: PODES 2003 (Statistics Indonesia (BPS)) 
The selected villages were divided into intervention and control groups (Table 1-2). Comparing contrasting cases or situations with different treatments helps to explain and understand the social phenomena in other contexts (Bryman, 2012).

Table 1-2. The division into intervention and control groups in the case study areas

\begin{tabular}{cccc}
\hline Villages & $\begin{array}{c}\text { Denai Lama and } \\
\text { Kramat Gajah }\end{array}$ & Kolam & $\begin{array}{c}\text { Sidoharjo I Pasar } \\
\text { Miring and Tandem } \\
\text { Hulu II }\end{array}$ \\
\hline \multirow{2}{*}{ Treatment } & $\begin{array}{c}\text { Digital participatory } \\
\text { village mapping } \\
\text { (Intervention group) }\end{array}$ & $\begin{array}{c}\text { Non-digital participatory } \\
\text { village mapping } \\
\text { (Intervention group) }\end{array}$ & $\begin{array}{c}\text { No mapping activities } \\
\text { (Control group) }\end{array}$ \\
\hline
\end{tabular}

Four maps were produced from the participatory village mapping: village boundary map, facilities map, land-use map and proposed development map. Direct observation were carried out to verify the impact of the participatory mapping activities and village maps during the village Musrenbang's practices.

\subsection{Thesis outline}

The outline of this thesis is as follows:

Chapter 1 describes the background and context of the study. It provides a brief description of the research background, the key concepts, the context of the Musrenbang implementation, the research problems, the research objectives and questions, and the thesis's outline.

Chapter 2 addresses the first research objective. The chapter provides an overview of current Musrenbang practices and evaluates the participatory processes of the Musrenbang. Public participation is not explicitly included in the SDGs; however, their goals, targets and indicators implicitly aim to provide better public participation practices for different stakeholders. Therefore, the chapter presents a methodological approach to evaluating the Musrenbang's public participation practice using a SDGs framework. The framework was used to assess the Musrenbang at the village level in the Deli Serdang district. 
Chapter 3 addresses the second research objective. The chapter presents a methodological approach to examine the spatial knowledge used during Musrenbang practices. The approach consists of three main characteristics of spatial knowledge use: the types, levels and socio-dynamics of spatial knowledge.

Chapter 4 addresses the third research objective. The chapter presents a methodological approach to enable village stakeholders to use their spatial knowledge. It discusses the development and testing of a collaborative spatial learning framework through participatory mapping workshops in three villages. This framework aims to support communication and collaboration among stakeholders while integrating their spatial knowledge through social learning experiences.

Chapter 5 addresses the fourth research objective. The chapter revisits the villages of the case study and evaluates the impacts of the use of participatory village maps on the strengthening of public participation practices in the Musrenbang.

Chapter 6 provides a synthesis of the research, including a summary of its main contributions and its relevance to contemporary scholarship. The chapter also reflects on the study's limitations and discusses directions for future research. 
Chapter 2: Participatory planning practice in rural Indonesia: A sustainable development goals-based evaluation ${ }^{*}$

* This chapter is based on the published paper: Akbar, A., Flacke, J., Martinez, J., van Maarseveen, M. F. A. M. (2020). Participatory planning practice in rural Indonesia: A sustainable development goals-based evaluation. Community Development, 51(3), 243260. https://doi.org/10.1080/15575330.2020.1765822 
Public participation has become the central issue of urban planning in recent decades as a response to the inefficiency of dominant top-down models and expert-driven approaches in planning practices (Tandon, 2008). The term refers to various activities that denote peoples' involvement in the planning and administrative process to influence policies and actions (Cornwall, 2008). It has been practiced in many countries as a prerequisite for successful decentralisation, democracy, and good governance (Fung, 2015; Tandon, 2008).

Manifold studies have discussed the goals and benefits of public participation (Arnstein, 1969; Innes \& Booher, 1999), the utilisation of different approaches or methods (Chambers, 1981, 1994b; Healey, 1998a), and the factors that influence the success of public participation (Beierle \& Konisky, 2000; Irvin \& Stansbury, 2004). However, little attention has been given to the field of participation evaluation. Laurian and Shaw (2008) noticed these gaps and argued that planning practitioners and academics need firm definitions, criteria, and methods to evaluate public participation practices. Moreover, the limited literature on public participation evaluation makes it difficult to determine the evaluation methods that fit the specific context of public participation practice.

The idea of public participation has received enormous attention through Sustainable Development Goals (SDGs), which were published by the United Nations (UN) in 2015 (Ludwig, 2017). Furthermore, two indicators put notions on public participation. Indicator 11.3.2 targets the proportion of cities with a direct participation structure within civil society, while indicator 16.7.2 targets a proper proportion of the population to be actively involved in decision-making processes (The United Nations, 2017). Both indicators are still in tier III, which indicates that the settled concept, methodology, and standards of the indicators are not yet available (UN Statistics Division, 2018). Achieving these SDGs by 2030 requires immediate operationalisation. Thus, conceptualising indicators into a more reliable and operational evaluation framework is crucial. It would provide guidelines for many nations to achieve sound public participation in their countries. Furthermore, it would help them to evaluate their public participation practices in achieving SDGs. 
Therefore, in this chapter, we aim to develop a framework of public participation evaluation based on indicators 11.3.2 and 16.7.2 of the SDGs. The framework is built upon our understanding of SDGs' discourses and the existing evaluation criteria developed by various scholars. Then, we used the framework to evaluate an annual public participatory planning practice in Indonesia, called Musrenbang, as the case study. The case study provides evidence of how well the SDGs evaluation framework could measure the success or failure of participatory processes in Musrenbang.

\subsection{Public participation process evaluation framework}

\subsubsection{Relevance and limitations of public participation}

Despite the rapid innovation of participatory methods to engage citizens in the governance process, the dominant form of public participation is commonly exercised through public meetings or public hearings (Fung, 2015; UN-Desa, 2018)(Fung, 2015; UN-Desa, 2018). This method is useful to disseminate information to large audiences while providing a forum for people to raise their opinions or concerns (Videira et al., 2006).

Nonetheless, public meetings can also have limitations. A public meeting can cause conflict among participants or reach a deadlock when discussing contentious issues (Videira et al., 2006), while an inadequate deliberative process hinders a collaborative dialogue among stakeholders, making their participation less intensive (Mostert, 2003; Rowe \& Frewer, 2005). Furthermore, stakeholders who have more time, better resources, or positions than the broader population often have the opportunity to dominate the participatory process rather than the disadvantaged groups who have a lack of power or the necessary verbal skills to express their opinions (Fung, 2015). Many governments have adopted policies to increase the participation of marginalised groups, such as women, children, people with disabilities, and those working in the informal sectors (Feruglio \& Rifai, 2017). However, power relations within these communities usually become the main impediment for them to participate (Mosedale, 2005). The citizens' voices are considered merely as non-mandatory advice for the government's development proposals, while their participation is like a 
rubber stamp to fulfil the requirement of a participatory process (Antlöv, 2003; Fung, 2015; Sutiyo, 2013).

This same situation has also taken place during the Musrenbang process, as it is implemented through public meetings. Studies have revealed that the Musrenbang is poorly implemented and is similar to a ceremonial meeting (Sopanah, 2012). Thus, the role of the Musrenbang tends to be limited to only administrative purposes to produce plan documents at the expense of the quality of the process and outcomes of the discussions (Aswad et al., 2012). Furthermore, in 2008 , Indonesia passed the law $10 / 2008$, which regulates a 30 percent quota for women to participate in political activities; however, women are still not fully involved in decision-making processes due to strong patriarchal values within society (Rhoads, 2012). Therefore, unequal power relations exist, as the decisions are mainly made by certain actors who have more power and influence among those in society (Grillos, 2017).

\subsubsection{Evaluation criteria and framework}

Due to the limitations of public participation practices, evaluating the participatory process is necessary to improve its practice (Chess, 2000). As such, the evaluation needs a robust framework that meets the specific goals, purposes, and local context of the participatory practice (Asthana et al., 2002; Fung, 2015; Laurian \& Shaw, 2008).

SDGs, as a global agenda, have had significant influences in steering global policies and actions in public participation practices (Tebbutt et al., 2016). Therefore, developing an SDGs' evaluation framework is relevant to provide a solid basis in participatory theory and practice.

From 232 indicators in the SDGs framework, there are two indicators (11.3.2 and 16.7.2) that offer the notion of how public participation should be applied. As can be seen in Table 2-1, public participation should be implemented regularly and democratically, as well as in an inclusive and responsive manner (UN-Desa, 2018). 
Table 2-1. Targets and indicators of SDGs 11.3 and 16.7

\begin{tabular}{lll}
\hline \multicolumn{1}{c}{ Targets } & \multicolumn{1}{c}{ Indicators } & Tier \\
\hline $\begin{array}{c}\text { 11. Sustainable Cities and } \\
\text { Communities }\end{array}$ & & \\
$\begin{array}{l}\text { 11.3 By 2030, enhance inclusive and } \\
\text { sustainable urbanisation and capacity for } \\
\text { participatory, integrated and sustainable } \\
\text { human settlement planning and }\end{array}$ & $\begin{array}{l}11.3 .2 \text { Proportion of cities with a } \\
\text { direct participation structure of } \\
\text { civil society in urban planning and } \\
\text { management that operate }\end{array}$ & Tier III \\
$\begin{array}{c}\text { 16. Peace, Justice, and Strong } \\
\text { Institutions }\end{array}$ & $\underline{\text { regularly and democratically }}$ & \\
$\begin{array}{l}\text { 16.7 Ensure responsive, inclusive, } \\
\text { participatory and representative decision- } \\
\text { making at all levels }\end{array}$ & $\begin{array}{l}\text { 16.7.2 Proportion of population } \\
\text { who believe decision-making is } \\
\text { inclusive and responsive, by sex, }\end{array}$ & Tier III \\
& $\begin{array}{l}\text { age, disability, and population } \\
\text { group }\end{array}$ & \\
\hline
\end{tabular}

Hák, Janoušková, and Moldan (2016) argued that the experts working on the SDG indicator selection should use relevant science or evidencebased knowledge within a robust conceptual framework to prevent irrelevant or ambiguous criteria. Elder, Bengtsson, and Akenji (2016) suggested that one should think about goals as a means when conceptualising SDGs. Thus, we argue that making use of the criteria in the existing evaluation framework could provide a more operational evaluation framework of SDG indicators 11.3.2 and 16.7.2 that reflects upon the importance of SDGs in public participation discourses.

Generally, scholars divide the public participation evaluation framework into two main criteria: those criteria that relate to the process of participation (Abelson et al., 2003; Beierle, 2002; Innes \& Booher, 1999) and those that relate to the outcome of the process (Rowe et al., 2004; Webler et al., 2001). For developing the framework, we chose fifteen criteria based on the goals, purposes, and local context of the Musrenbang practice (see Appendix A).

Thus, we developed the SDGs based evaluation framework by classifying the notions from indicators 11.3.2 (regularly, democratically) and 16.7.2 (inclusive, responsive) into three central themes: regular, democratic/inclusive, and responsive. We added social learning as the fourth theme since the learning process is also an essential factor to achieve SDGs (UN-Desa, 2018), as public 
participation practice commonly encourages learning experiences and knowledge exchange among participants (Shrestha et al., 2017, 2018a). Thereafter, we sorted various criteria from the existing evaluation framework into each theme.

The linkage of criteria from the existing framework and the four main themes conceptualise the SDG indicators (11.3.2 and 16.7.2) and facilitate the operationalisation and assessment of public participation practices. The conceptual framework is summarised in Figure 2-1.

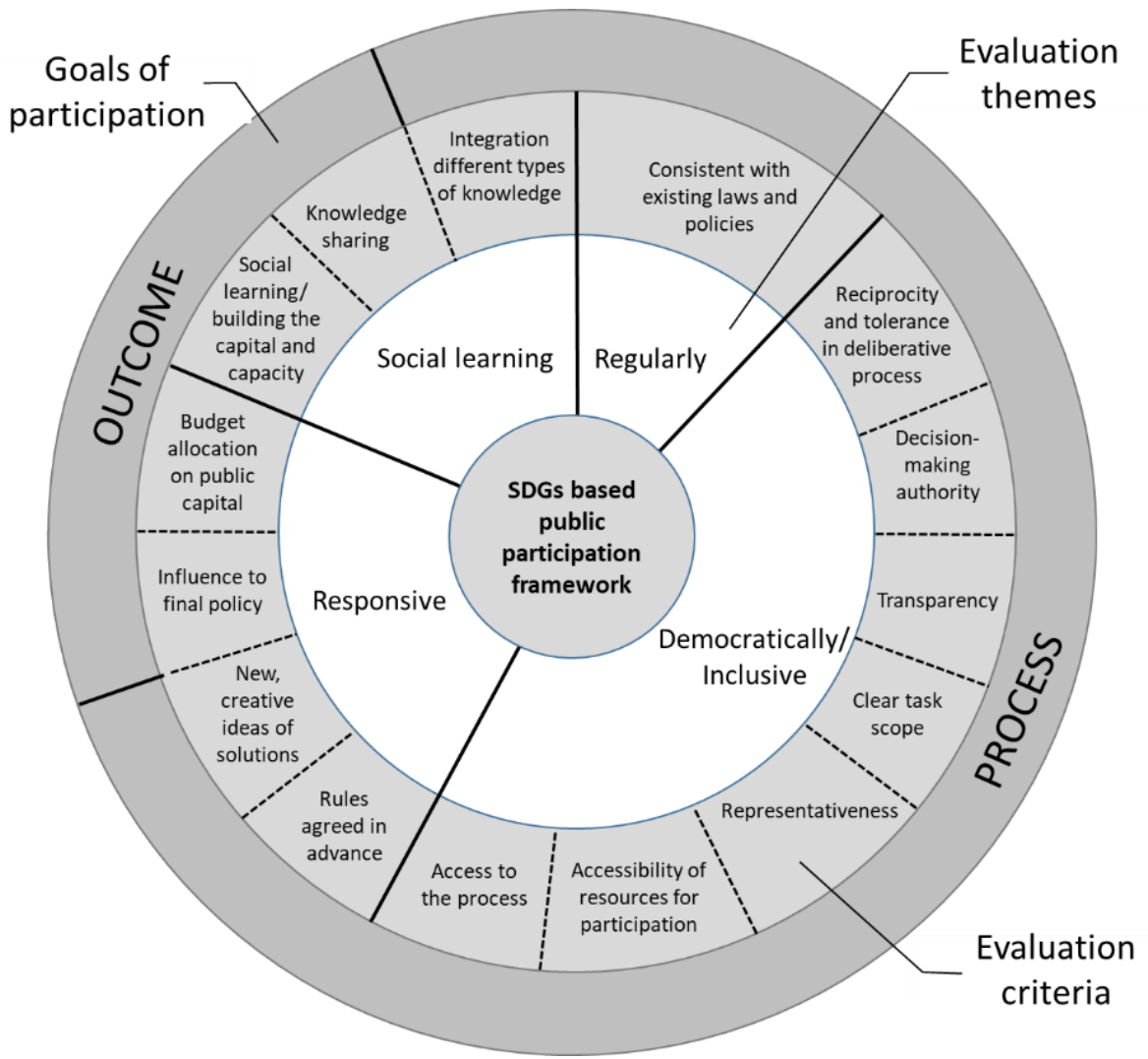

Figure 2-1. SDGs based assessment framework for public participation practice 


\subsection{Research design and methods}

\subsubsection{The case study: The Musrenbang practice}

Musrenbang is a participatory planning practice that provides a forum for citizens to participate in the development planning processes. According to Sutiyo (2013), after the Reformation Movement in 1998, followed by the decentralisation policy in 1999, there was a need to establish a development forum that involved the public in the planning and decision-making process. This idea was then applied by enacting the law 25/2004, which introduced Musrenbang as a form of public participatory planning and budgeting practice at different levels of government in Indonesia. As stated in the law, the Musrenbang process is executed annually in a public meeting format at each level of government structure, from the village (desa/kelurahan) level to the national (nasional) level. This study focuses on the annual Musrenbang at the village level as the first phase of the hierarchical planning stages in Indonesia, which provides more opportunities for citizens to participate in the processes.

At the village level, the annual Musrenbang is implemented through a public meeting that involves various stakeholders, from government officials, citizens, to other stakeholders, ranging from grass-roots organisations, non-governmental organisations (NGOs), community leaders, religious leaders, and private sectors. Two results are expected from the meeting: the village's policies and plans for composing the village's annual development planning document (called RKPDesa) and the village's revenue and spending budget (APBDesa). The agreed upon development proposals are to be brought and discussed at a higher level at Musrenbang (Sopanah, 2012).

\subsubsection{Study area}

The study area is the Deli Serdang district in North Sumatra, Indonesia. The district covers an area of $2497,72 \mathrm{~km} 2$, with a population of around 2.155.625 persons, and consists of twenty-two sub-districts and 394 villages (BPS, 2018). In 2013, the Ministry of National Planning awarded the Deli Serdang district the Anugerah Pangripta Nusantara award. This award is given to the best district in Indonesia that produces an outstanding and comprehensive local government work plan document (RKPD). Winning this award indicates that Deli Serdang 
has implemented an excellent participatory planning process from the village level to the district level. In this chapter, we are aiming to understand how and why the implementation of Musrenbang in a district won such a prestigious national award.

To understand the participatory process of Musrenbang, we selected five villages according to the following criteria: (1) the village is located in different sub-districts; (2) the ethnicity of the population is primarily Javanese; (3) the primary livelihood of the population is farming and agriculture; (4) the village officials are willing to participate in this study. The villages where the Javanese ethnic population is dominant were chosen because the Javanese have a consensus-seeking tradition that profoundly influences decision-making and deliberative processes in Indonesia (Boyle, 1998). Therefore, we assume that the Musrenbang is implemented more successfully in the villages where the Javanese are the majority. Based on the criteria, we chose the Denai Lama, Kolam, Kramat Gajah, Sidoarjo I Pasar Miring, and Tandem Hulu II villages as the locations of the case study.

\subsubsection{Methods}

Data collection included direct observation, questionnaires, and semistructured in-depth interviews. The data were collected from January to May 2018. Using the participant as observer role in the observation (Gold, 1958), the lead author made direct observations by attending the public meetings. The observations were written in field notes and recorded for further analysis.

For the questionnaire, we developed sixteen questions derived from the evaluation framework with five different responses (Strongly Agree, Agree, Neutral, Disagree, and Strongly Disagree). The questionnaire was created for anonymous responses, while the participants attending the Musrenbang (see profile in Appendix B) filled out the self-questionnaire forms (Appendix $C$ ). The responses from the questionnaires were then analysed using descriptive frequency analysis.

We used semi-structured in-depth interviews to capture the perceptions of stakeholders about the implementation of the Musrenbang (see Appendix $D$ and $E$ ). The respondents included village officials, village council (BPD), village community resilience board (LKMD), women representatives (PKK), youth representatives (Karang 
Taruna), community leaders or religious leaders, village supervisors, the sub-district officials, district officials, and district parliament members.

The lead author acted as the interviewer for the entire interview process. The interviews were conducted in Bahasa, Indonesia and recorded, while the responses were reviewed and cross-checked with stakeholders in other interview sessions to produce reliable and robust data (see Appendix $\mathrm{F}$ for detailed information about the interviewees). The interviewees' names have been kept anonymous. For the analysis, we used qualitative content analysis to scrutinise 56 interviews. A coding strategy was employed as a means to use specific labels to categorise the interviewees' responses. While we used an evaluation framework to decide coding themes, we also conducted open coding to ensure that the critical emerging aspects of the qualitative data were not missing. The responses from the interviews were sorted according to the framework outlined in sections using ATLAS.ti software.

For stakeholder analysis, we used the extended interest-influence matrix to analyse the levels of interest and influence. This method is useful and provides comprehensive reasons for the interest and influence owned by each stakeholder (Raum, 2018).

\subsection{Analysis and results}

\subsubsection{Stakeholder analysis}

Various stakeholders were involved in the Musrenbang process in Deli Serdang. We identified nineteen groups of stakeholders who directly or indirectly affected the participatory process in Musrenbang (see Appendix $G$ for detail information). We classified them into four different groups:

(1) The upper government, which includes the Regional Development Planning Agency (Bappeda), Village Citizen Empowerment Department (DPMD), District Council (DPRD), head of sub-district (Camat), and the sub-district office staff. They have significant influence but low interest toward the village Musrenbang. The village supervisor (PD) can also be put into this category. Even though they are not a government employee,they work closely with the upper and village 
governments. In several villages, they play a significant role in connecting the upper government and the village government and have a significant influence on decision-making processes;

(2) Village elites, which include the village head, village secretary, Village Council (BPD), Village Empowerment Board (LKMD), and the head of the neighbourhood. These positions are usually elected by the community and have strong influence and interest in the Musrenbang processes. Among them, the village head has the most considerable power in directing the meeting to attain his/her interests. Most of the decisions made also are derived from his/her final policies. However, the influence owned by BPD, LKMD, and the head of the neighbourhood also requires significant bargaining power in determining the Musrenbang result. Thus, the group of village elites usually become the organisers, which enables them to prepare and set how the Musrenbang works;

(3) Village elite' supporters, which include the village office staff, the women group (PKK), and the youth group (Karang Taruna). This group has a medium interest and influence on the process. They tend to have similar point of views with the village elites when discussing plans/programs. This group also has a close relationship with the village elites. The chairwoman of the PKK is the village head wife, while the committee usually consists of the wives of the village secretary, village staff, and head of neighbourhoods. The youth group seems reluctant to care about Musrenbang discussion topics.

(4) Community-based organisations/ordinary citizens. This group has high interest but low influence; however, the people in this group are most affected by the policies decided at the Musrenbang meeting. Their attendance at the meeting is highly dependent more or less on the village elites, particularly the village head and village staff, who have full authority to decide who should or should not be invited to the meeting. 


\subsubsection{Evaluation result}

Based on the evaluation framework, we have identified three main results that portray some gaps in the Musrenbang practice, including problems in abiding the laws, integrating/sharing knowledge, and managing power relations. The results also showed that the problems are interrelated.

\subsubsection{Musrenbang is implemented regularly, but not timely}

The Musrenbang was implemented in all five villages regularly, as it is obligatory, according to the laws. Interviewee F2, a district official, said that the Musrenbang became more popular after law 6/2014 was enacted. Before the law was published, many villages did not conduct the Musrenbang, albeit it is compulsory. The villagers consider Musrenbang to be a time-consuming procedure with less or no impact on the villages. However, law 6/2014 requires the upper government to decentralise the budgeting policy by allocating a village budget for each village annually and in turn, the village must conduct the Musrenbang to access and use the budget. Consequently, nowadays, the Musrenbang is conducted more regularly in villages (F2, personal communication, 26 March 2018).

Most interviewees expressed their confusion regarding the laws/regulations that should be followed. The village planning procedures in Indonesia are mainly regulated by two different laws (laws 25/2004 and laws 6/2014), which are published by two different ministries. The Bappeda, as the responsible institution at the district level, published a guidebook about how the Musrenbang should be conducted. It was written based on law 25/2004 and its derivative regulations ( $F 1$, personal communication, 18 April 2018).

The guidebook mandated that the villages ensure that the programs listed in the RKPDesa/APBDesa (annual) documents correspond with the RPJMDesa (middle-term) document. One of our respondents stated, "New programs can be accepted. If there is a new program proposed, we can approve it. However, we have to revise our RPJMDesa" (E7, personal communication, 6 April 2018). This revision process takes time, as it requires the village to hold another Musrenbang with the RPJMDesa revision as the main agenda. For that reason, many village governments often bypass the procedures by only revising the programs without any RPJMDesa Musrenbang. Thus, they 
"fulfill" all of the administrative documents by creating fabricated meeting notes as if the revision had been through the RPJMDesa Musrenbang process.

Moreover, the differences among laws/regulations also affect the schedule. If we refer to Permendagri 114/2016, the village Musrenbang should be implemented from July to August. However, based on Permendagri 54/2010, which is referred to in Bappeda's guidebook, it is implemented in January. This situation leads to delays in development implementation since APBDesa as the final product of the planning process is typically finalised in April or May. This means that the villagers only have six or seven months left to execute their development plans.

Similarly, delays are not only caused by planning processes, but also by the village government's decision to submit their APBDesa late to the upper government for verification. They do this because villages who submit APBDesa early often become the object of prosecutors' audits or gain NGOs/media attention (E4, personal communication, 6 April 2018). Thus, they tried to avoid such risks, although it causes delays in executing their plans.

\subsubsection{Musrenbang is not effective in supporting knowledge integration and learning}

From the participants' profile (Appendix B), it is clear that the participants have diverse knowledge and backgrounds. Unfortunately, the Musrenbang does not support knowledge integration or exchange among participants. The questionnaire revealed that around $90 \%$ of the respondents from five villages indicated that they were unable to acquire knowledge and share their knowledge with other participants in the Musrenbang (Figure 2-2). The percentage consists of 116 out of 133 male respondents and 59 out of 61 female respondents (see profile in Appendix B). 


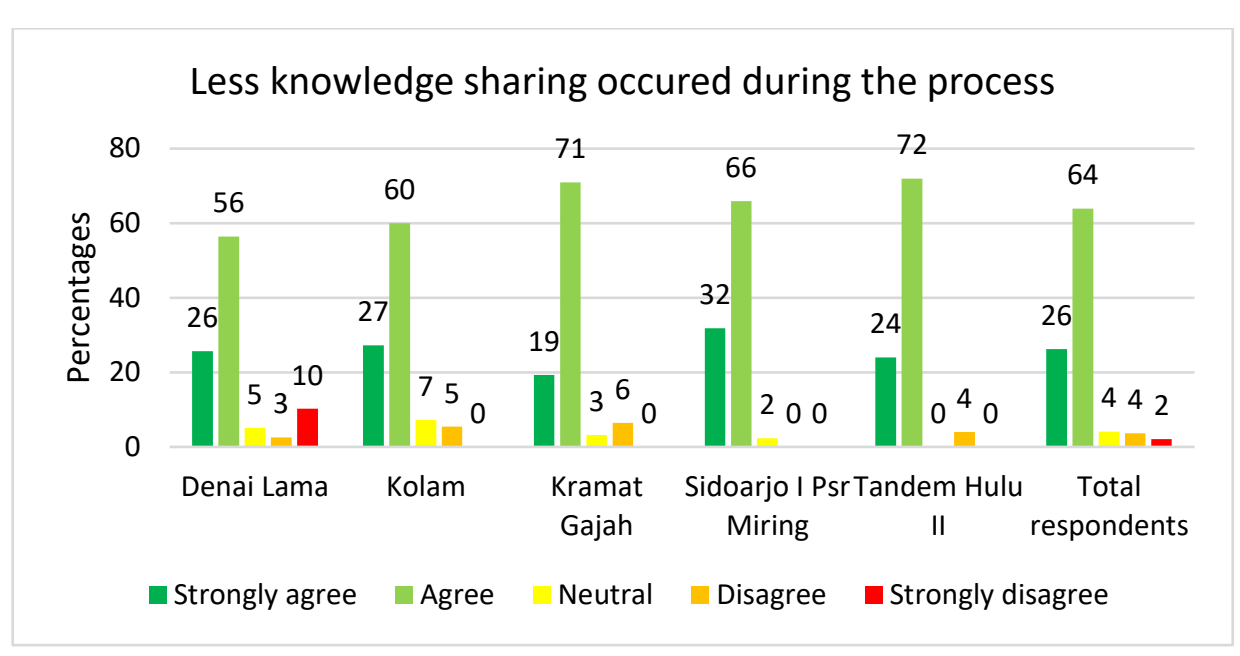

Figure 2-2. Responses about knowledge sharing during the process

From the interviews, we found that the interviewees recognised two types of knowledge owned by the stakeholders, namely explicit knowledge from formal education and tacit knowledge from daily practices or experiences. However, knowledge integration or knowledge sharing did not take place effectively in the Musrenbang. A community leader from Denai Lama stated, "It did not happen. If the format and setting of the meeting are monotonous, I think knowledge sharing is not going to happen" (A8, personal communication, 8 March 2018). The head of the LKMD also gave the same response: "There was no knowledge sharing at the Musrenbang. The knowledge sharing occurred in our daily interactions or activities, not in the Musrenbang. For example, we talked about how to get better crops in other places or other occasions. It is not possible to do it during the Musrenbang" (C3, personal communication, 7 March 2018). A village head said that different data standards and formats owned by each neighbourhood also make it challenging to integrate the data into a uniform data format that can be read and discussed together as a group (A2, personal communication, 1 March 2018).

The previous result is aligned with the fact that more than half of the total respondents claimed that they have difficulties in defining their real needs and problems in a more comprehensive and integrated way (Figure 2-3). These answers were given by 66 out of 133 male respondents and 32 out of 61 female respondents (see profile in Appendix B). From the interviews, most interviewees responded that a lack of available data is one of the reasons why they are only able to 
see problems within their neighbourhoods' perspective, not in a broader context, such as problems that are affecting other neighbourhoods or villages. A village head stated, "It would be helpful for participants in the discussion session if data were available for the participants so that they can see and give responses to issues beyond their neighbourhoods" (A2, personal communication, 1 March 2018).

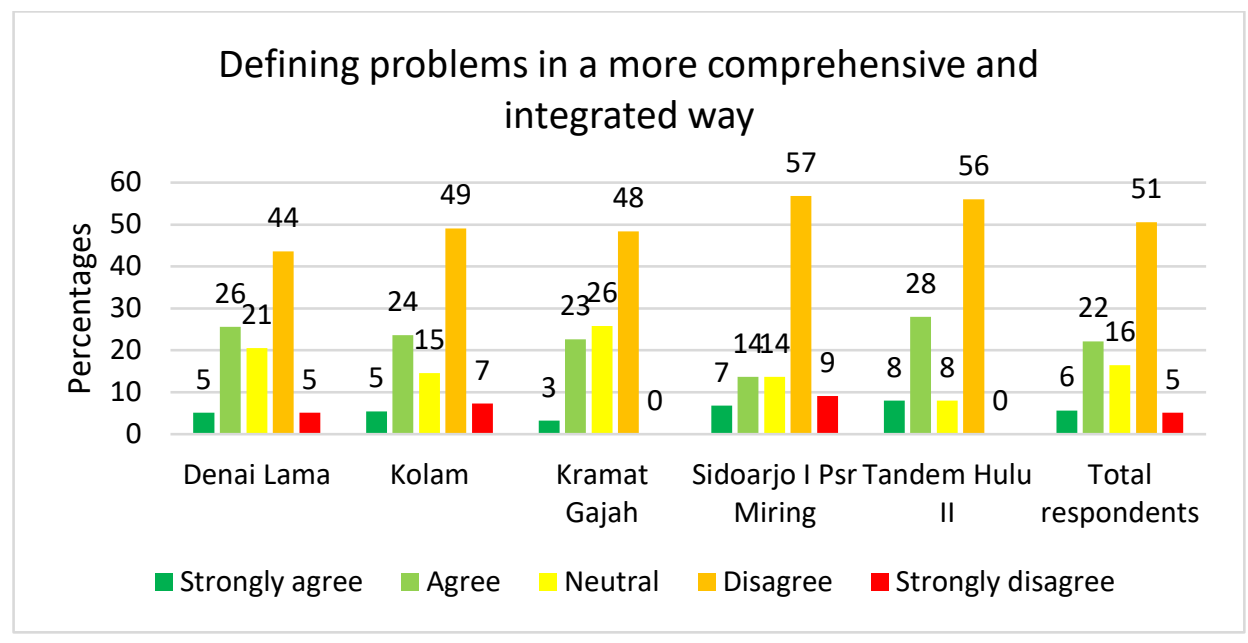

Figure 2-3. Responses about defining problems

Practically, the head of the neighbourhood plays a significant role in data collection by listing problems and possible solutions. They collect data directly by site-visits but without any supporting data, such as maps, pictures, or statistical data, when determining problems and solutions.

However, there are some weaknesses in this site-visit primary data. Firstly, there is no standard for a data format, as well as the data being difficult to read and understand. Secondly, it is problematic to integrate the data among neighbourhoods since each neighbourhood has different methods for collecting and presenting the data. Thirdly, the data is only collected and used for a short-term period. Thus, there are no standard guidelines on how to use and manage data for long-term usage.

As a consequence of less knowledge sharing and a lack of data availability, the learning process in Musrenbang is also less effective. Figure 2-4 shows that the majority of the questionnaire respondents said that they learned nothing from other participants, including 121 
out of 136 male participants and all (61 out of 61 ) of the female participants (see profile in Appendix B).

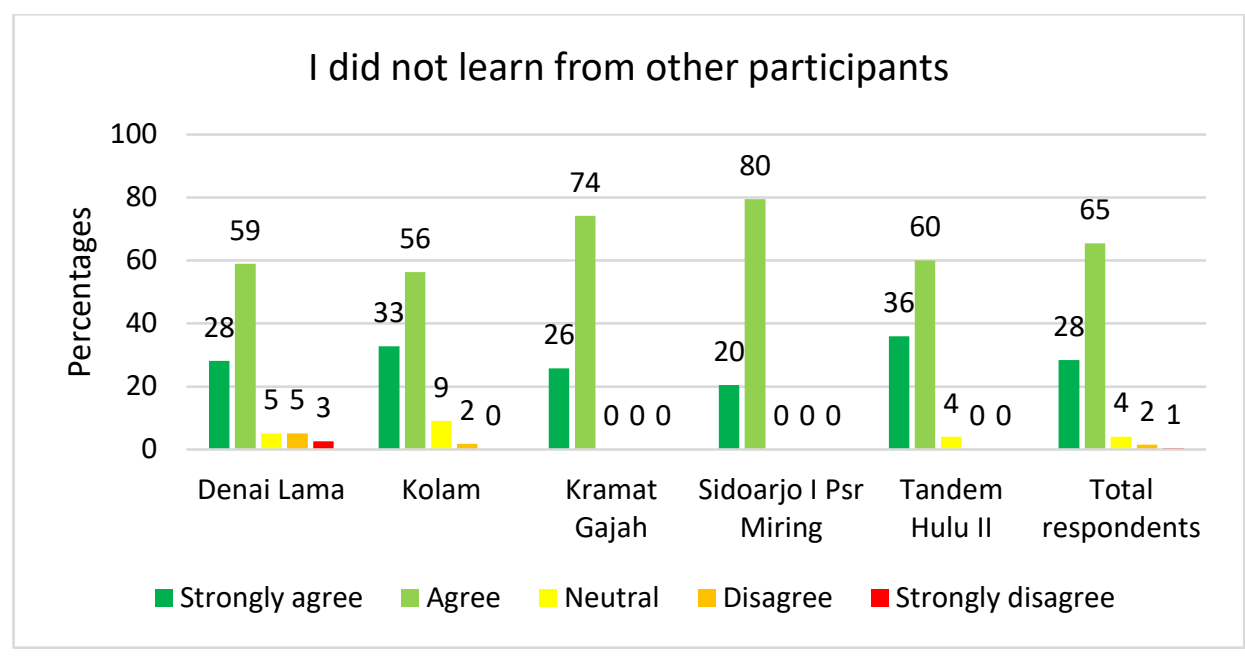

Figure 2-4. Responses about learning experiences

It is also evident that it is not difficult to reach a consensus among Musrenbang participants. However, the process often unintentionally brought the participants to follow the mechanisms and accept every decision without arguing about it. As such, the village elites who have more power and influence can choose and make the final decisions; therefore, social learning did not occur during the deliberative processes of the Musrenbang.

\subsubsection{Power relations exist in the Musrenbang practice}

Regarding the deliberative process, around $61 \%$ of the total respondents expressed disagreement, which indicates that the deliberative process was excellent and was not dominated by individual stakeholders (Figure $2-5$ ). Contrarily, around $34 \%$ of the respondents (mostly respondents with age 21-40 years old) showed agreement that certain elites occupied deliberative processes. Almost half of the respondents were aged 41-50 years old (see profile in Appendix B), and three-quarters of them disagreed that certain people dictated the discussions. 


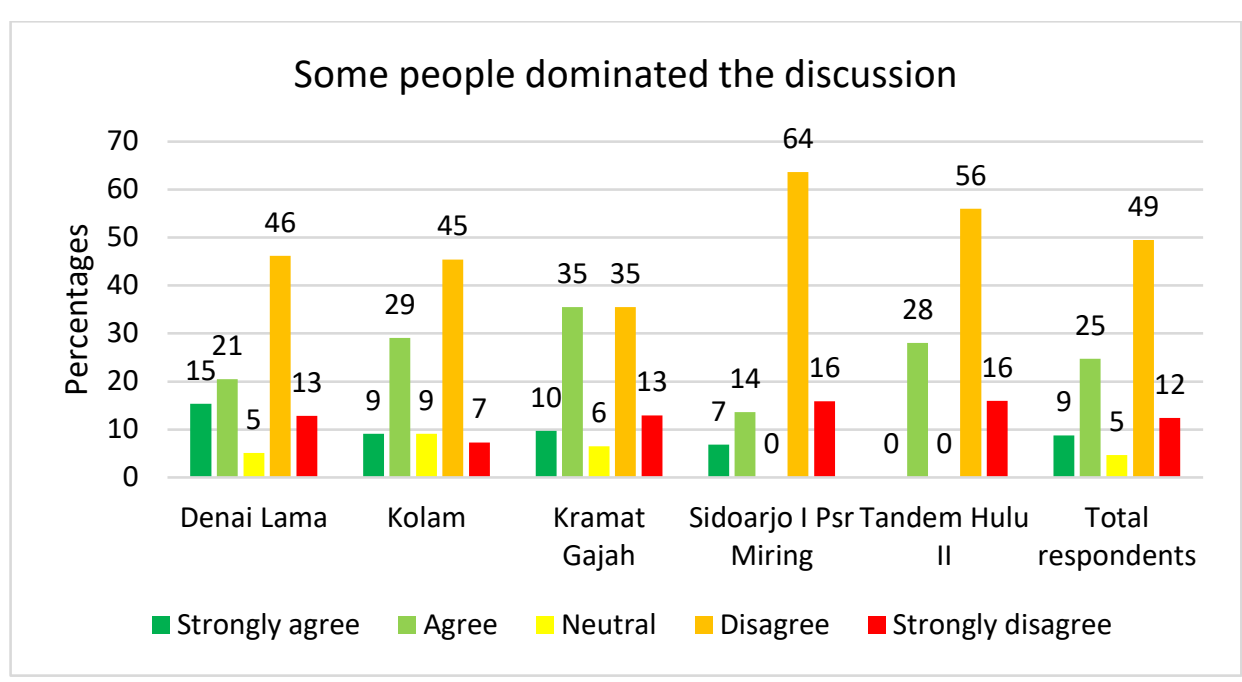

Figure 2-5. Response about the domination of certain stakeholders

We found this to be contrary, as the deliberative process was dominated by the village elites. This group has more power and influence to control the topic of discussion, while citizen representatives had fewer opportunities to engage in the discussion. Furthermore, the classroom setting of the venue was a bit intimidating for participants. All village elites and honoured guests sat in front of the participants with a comfortable chair and tables, accompanied with beverages and snacks (Figure 2-6), while participants sat only in a chair without a table and with modest snacks. A community leader stated, "The setting unintentionally directs the participants to behave well during the Musrenbang meeting" (A8, personal communication, 8 March 2018). This resulted in ordinary citizens, especially women, feeling less confident to articulate their needs and concerns. As seen in the participants' profile in Appendix B, women's participation is relatively high in two villages (Kramat Gajah and Sidoarjo I Pasar Miring) and considerably lower in the other three villages (less than $30 \%$ ). However, a high proportion of women participants does not guarantee that the women are fully empowered during participatory processes, as they still feel shy or afraid to have a say at the meeting. When we asked a woman representative why no women expressed their ideas or opinions during the discussion, she said, "I was afraid. There were many people at the meeting. If we make mistakes when speaking, people might taunt us. I would feel shy and awkward" (A5, personal communication, 8 March 2018). 

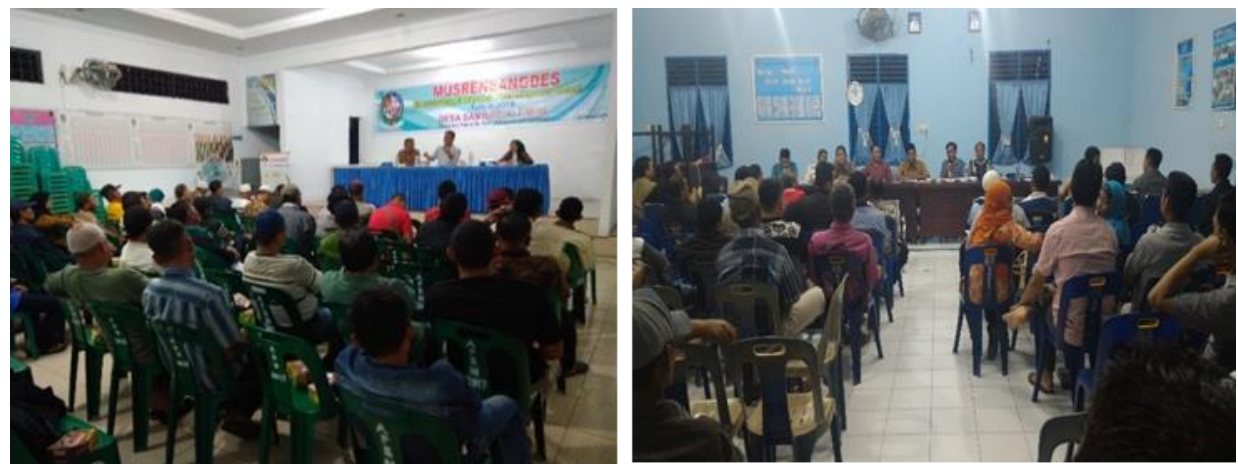

Figure 2-6. Typical Musrenbang meeting at the village level using the classroom setting

Source: author photo

The decision-making process is also problematic. Due to village elites' significant influence in the decision-making process, there is no guarantee that the programs proposed by participants will be adopted or prioritised, which was expressed by a community leader from the Kramat Gajah village (C7, personal communication, 7 March 2018). As regulated in the laws, each village must form a so-called "Team 11", who is responsible for drafting the RKPDesa document. This team consists of eleven members, with a village head as the team supervisor, the village secretary as the team leader, the head of LKMD as the secretary, and team members from the village staff, community leaders, and citizen representatives. However, this structure clearly shows that Team 11 represents the village elites' interests and influence, as this team has full authority to accept or reject the proposed programs based on their judgments. Consequently, the final decision in the Musrenbang still resides with the village elites. Nevertheless, since the list of programs produced by Team 11 were then discussed and decided by the whole of the participants at the Musrenbang, this explains why the majority of participants feel satisfied with the decision-making process at the Musrenbang, as they feel involved when deciding the list.

Regarding representativeness, if we compare the number of participants with the total population of the village, the representativeness is questionable. In Denai Lama, the percentage of Musrenbang participants to the total population is around $1,77 \%$, Kolam 0,33\%, Kramat Gajah 1,6\%, Sidoarjo I Pasar Miring 1,34\% and Tandem Hulu II $0,32 \%$. However, there is no clear guidance about 
minimum attendees to ensure that the meeting is still considered legitimate, even though it was attended by a small proportion of the total village population. From this proportion, it was also found that the number of participants were less than expected and dominated mostly by the village elites and their supporters. A women representative said that the village head has the authority to select the participants of the meeting purposively. As such, he/she tends to invite people who have the same vision as him/her rather than people who oppose him/her (E3, personal communication, 2 May 2018). This situation explains why most respondents agreed with the statement that the participants had represented the whole society. The majority of respondents were preselected by the elites, so there is a significant possibility that they have the same views of the elites.

Our findings also show that some relevant stakeholders were intentionally left out, particularly, marginalised groups, such as the disabled and impoverished people in the community. This was exposed by a village supervisor (K2, personal communication, 5 April 2018). Another village supervisor (J2) also said that the village government did not invite disabled citizens because it might not be easy for disabled people to travel to the meeting venue. Furthermore, many facilities and transportation in most villages are not disability friendly, while poor citizens were also not invited due to unclear criteria and their lack of influence within society. Consequently, no one spoke on their behalf and in turn, the real needs of both groups were unintentionally neglected (J2, personal communication, 4 April 2018).

\subsection{Discussion and conclusions}

As a global framework, SDGs tend to have standardised targets and indicators. A solid understanding about a particular context of public participation practice is crucial to translate the global targets or indicators into actual actions and interventions that offer real impacts to society (Howard \& Wheeler, 2015). Thus, our evaluation framework provides a practical way of assessing SDG 11.3.2 and 16.7.2 achievement in a particular public participation practice.

The core findings of this study show that the participatory process of the village Musrenbang faces substantial challenges in practice to match with the SDG goals. All four evaluation themes of the SDGs 
based assessment framework (regularly, democratically/inclusive, responsive, and social learning) require further actions to achieve a sound public participation practice. Moreover, the implementation of the Musrenbang has severe problems in abiding by existing laws and regulations, supporting knowledge integration and learning processes, and minimising power gaps among stakeholders. Even though Deli Serdang won the local government work plan in 2013, the implementation of the Musrenbang at the village level to some extent was not well executed. We observed that this happened because the criteria used for the award were different from the criteria of our SDGs framework.

The village Musrenbang has been implemented regularly, as the law obliges it. Law 6/2014 has provided a combination of better financial management systems, new institutional arrangements, and citizen empowerment at the village level (Antlöv et al., 2016). However, the law might be useful in theory but not easy in implementation. Different laws that regulate the Musrenbang have caused confusion, resulting in delays in planning and carrying out development programs. These delays are not only caused by the contradictions among laws, but also by the willingness of the villages to apply planning procedures and submitting the results promptly. Therefore, the village governments need to be assured that their timely submission is appreciated and has no consequences toward the infringement of the law.

The participants also acknowledged that each participant has their own kind of knowledge, tacitly or explicitly; however, they felt that the Musrenbang was not a suitable place to exchange or integrate that knowledge. Moreover, the formal setting of the public meeting hindered lively discussions among participants, limiting knowledge integration and exchange. The situation was further aggravated due to limited time, strict schedules or agendas, as well as long speeches by honoured guests, which unintentionally shaped the Musrenbang as a formal meeting to legalise the proposed development proposals.

This study also revealed that most of the participants agreed that data and information, such as planning area, population, facilities and infrastructure, budget availability and so forth, are essential to supporting participatory planning processes. They found it challenging to identify their common problems due to limited data availability, as the data collected by the head of the neighbourhoods is often too local, 
with different standards and formats. Thus, the villagers found difficulties when compiling and using the data in an integrated way to support the planning process in the Musrenbang.

Lack of knowledge sharing and integration, as well as a lack of data, caused the learning process in the Musrenbang to be less effective. The majority of the respondents felt that they learned nothing new from the deliberative process. If we consider the Musrenbang as a regular participatory process prescribed by the laws, it is promising to serve as a social learning medium, leveling up the stakeholder's interaction into a learning process (Aswad et al., 2012). A village supervisor stated, "Regarding social learning, I think that when people learn how to articulate their opinions, how to make other people hear his opinions, that is a social learning process. It is created naturally through their participation at the Musrenbang" (K2, personal communication, 5 April 2018). Understanding the levels of knowledge and utilising the stakeholders' knowledge will be necessary to improve the knowledge integration and learning process in the Musrenbang.

The implementation of the Musrenbang is also prone to power struggles. After the publication of law 6/2014, the village's authority is becoming more substantial as the new laws decentralised the tasks to plan, execute, and monitor rural development for the village government (Sutiyo, 2013). The opportunities provided by the laws were used by the elites to control the entire participatory planning process in the Musrenbang. Among the four different stakeholder groups that we have identified, the domination of the village elites' group is apparent to some extent. This group not only has the power to decide who should be invited to the meeting but also has considerable authority in decision-making processes. This situation is quite similar to the findings of the Musrenbang implementation in Solo, where elites have significant power to control final decisions (Grillos, 2017).

This finding contradicts the SDG indicators 11.3 .2 and 16.7.2, which explicitly emphasise the proportion of people who are actively involved in participatory processes (UN Statistics Division, 2018). The involvement should also consider sex, age, disability, and population groups representing minorities. In other words, both indicators demand not only more people but also a diversity of people to participate in the process. In reality, only certain people were invited 
to the Musrenbang, and they were pre-selected by the village elites. Women representatives still cannot fully participate in the process, even though their participation is imposed by the laws, while marginalised groups, such as people with disabilities, have limited access and information to attend the meeting. New ways of thinking and applying the public participation practice, which can facilitate policy-making with local areas directly affected by the decisions made is necessary (Flacke \& de Boer, 2017). The involvement of most affected groups, particularly the marginalised groups, in the participatory process is essential to give them more opportunities to sound their real needs and problems.

We also found that ordinary citizens did not find it convenient to articulate their views in front of the public. Thus, the head of neighbourhood or community leaders usually represented them at the meeting. Similarly, it is not easy to facilitate a public meeting like the Musrenbang because the public meeting is considered low on the scale of public influence and empowerment (Fung, 2015). Furthermore, the classroom setting at the venue inevitably splits the participants into several groups, all with different powers and influences. The setting benefits the village elites and allows them to control the discussion topics and suggesting solutions while undermining new ideas or solutions coming from the participants. Most of the decisions are finalised by the village elites' group through Team 11, who have full authority in deciding prioritised programs. All of these problems undermine the achievement of SDG indicators (11.3.2 and 16.7.2) since the participants have a lack of representativeness while the decision-making processes are still dominated by certain groups of stakeholders.

In conclusion, this study clearly shows that the SDG indicators (11.3.2 and 16.7.2) can be a starting point to provide a relevant framework to evaluate a current participatory planning practice. The developed framework is useful to find gaps in the Musrenbang practice at the village level and puts forth notions about aspects that need to be improved to enhance current practices. The critical question of whether the developed framework is applicable elsewhere always rests in where public participation takes place, as well as what the local context is. However, evaluating public participation is not a one-size-fits-all policy, but must deal with the particularities of local circumstances (Antlöv, 2003). Therefore, it is crucial to note that both SDG indicators require 
proper conceptualisation and contextualisation before conducting an evaluation. Conceptualisation is essential for both indicators to be more tangible, understandable, and applicable, while contextualisation is crucial to fit the context of the public participation practice being evaluated.

This study also revealed that proper knowledge and procedures are not available to achieve meaningful participation. Therefore, understanding the knowledge owned by stakeholders, providing a platform to integrate their knowledge, and supporting the learning methodology to enhance the stakeholders' knowledge to be used in the planning process may become feasible solutions to improve current Musrenbang practices. As power relations, knowledge integration, and learning processes were some salient problems identified throughout this study, we suggest investigating these issues for further research so that the influence of these factors to improve the Musrenbang public participation practice can be further explored. 


\section{Chapter 3: Spatial knowledge: A potential to enhance public participation?*}

\footnotetext{
* This chapter is based on the published paper: Akbar, A., Flacke, J., Martinez, J., van Maarseveen, M. F. A. M. (2020). Spatial knowledge: A potential to enhance public participation? Sustainability, 12(12), 5025. https://doi.org/10.3390/su12125025
} 
Public participation is commonly applied in many countries to enable citizens to participate in decision-making processes. Despite its considerable utilisation, there has been an extensive amount of literature that has discussed its shortcomings in implementation, including frequently failing to adequately facilitate deliberative processes among participants (Mostert, 2003; Rowe \& Frewer, 2005) and its proneness to elite capture (Fung, 2015; Grillos, 2017). Thus, citizens' participation is becoming like a rubber stamp to fulfill the requirement of a participatory process (Antlöv, 2003; Fung, 2015). Moreover, meetings often become ceremonial activities (Sopanah, 2012).

To overcome the shortcomings of public participation practice, some scholars suggest the utilisation and improvement of spatial knowledge owned by the stakeholders involved in the process (Baud et al., 2014; Natarajan, 2017) as well as the use of geospatial data (Pfeffer et al., 2015; Sieber et al., 2016). In public participation deliberative processes, spatial knowledge, which is the knowledge of how individuals, social groups, and institutions perceive particular places and their characteristics and meanings (Elwood, 2006a), is commonly used by people when illustrating specific locations to relate the discussion topic into the context (Ghose, 2003). Information about geographical space and place is frequently used, as individuals are firmly attached to the places where they live and participate in their activities (Healey, 1997). Spatial knowledge is of significant importance because it carries not only information on geographic locations (space), but also on the meanings and experiences that people and communities have on those areas. Despite this growing interest, the characteristics of spatial knowledge owned by the actors in the public participation practice and how they use their spatial knowledge are not well understood, or are often neglected by scholars.

This study aims to examine to what extent spatial knowledge exists and is used in a formal public participation practice, as well as its potential to enhance the public participation practice. We use a participatory planning practice called Musrenbang in five villages located in Indonesia as the case study. Musrenbang is a participatory planning practice held annually to gain public inputs in the formulation of the village's annual development planning and budgeting documents and proposals. The Musrenbang implementation commonly uses a public meeting format that is attended by various actors; government 
officials and citizens, community or religious leaders, local NGOs, and individuals from the private sector. During implementation, the literature shows some problems with the Musrenbang practice, such as limited knowledge sharing or integration among stakeholders (Antlöv, 2003; Sopanah, 2012), lack of data available to support the planning process (Feruglio \& Rifai, 2017), and power relations among participants (Akbar, Flacke, Martinez, \& van Maarseveen, 2020a; Grillos, 2017).

This chapter is organised as follows: section 3.1 gives an overview of the relevance of spatial knowledge in public participation practice. Section 3.2 describes the methodology, case study, and framework used for analysis in this chapter. Section 3.3 describes the results of the study, while section 3.4 and 3.5 discuss the lessons learned and conclusions of the study. Three main questions are expected to be answered throughout this study: What are the spatial knowledge and geospatial data that the villagers have (or do not have)? How are they used in the Musrenbang practice (or how are they not used)? To what extent do spatial knowledge and geospatial data help to support public participation?

\subsection{The relevance of spatial knowledge for public participation}

During the discussion on public participation practice, spatial knowledge is commonly used when referring to the location of a particular object. This section elaborates on the relevance between public participation practice and spatial knowledge to better understand the critical role of spatial knowledge in public participation practices.

\subsubsection{Challenges in public participation}

The implementation of public participation remains a challenge for practitioners and scientists. Kahila-Tani, Kytta, and Geertman (2019) point out three main problems in public participation practice, including how to arrange effective public participation, how to engage more people in the process, and how to produce and exchange the knowledge effectively. First, arranging effective public participation is problematic, as there is 'no one size fits all' method to overcome the 
complexity of urban problems (Innes \& Booher, 2010). In the Musrenbang practice, the organisers often formally set the public meeting, with a tight schedule and limited topics of discussion (Akbar, Flacke, Martinez, \& van Maarseveen, 2020a; Sopanah, 2012). Consequently, participation is not active. Furthermore, strict arrangements with limited space for direct involvement could cause a few people to engage in the process (Rowe \& Frewer, 2005). Adjusting the participatory method to suit the local context is needed, as it could influence the participants' motivation to engage in participatory processes (Leino, 2012).

Second, any participatory methods aim to encourage more people to participate. However, involvement is not always successful, as there are always some people who are classified as the 'silent majority' among participants (Yanow, 2003). This silent majority mainly comes from the disadvantaged groups, who need to be empowered during participatory sessions (Albrechts, 2002). This situation also occurs in the Musrenbang practices, where certain groups, particularly the elites and their supporters, tend to control the process (Akbar, Flacke, Martinez, \& van Maarseveen, 2020a). Thus, it is vital to implement an inclusive process that ensures that different actors, issues, and sectors can work collaboratively to solve their common problems (Healey, 1998b; Quick \& Feldman, 2011).

Third, scholars are often confronted with the question of how to produce and exchange knowledge effectively in public participation practices. As most human activities are situated in specific spatial contexts, spatial knowledge owned by stakeholders could be useful to enhance public participation practice (Eilola et al., 2015; Pfeffer et al., 2013). At the same time, the geospatial data can help to gain optimum benefits of spatial knowledge utilisation (Kahila-Tani et al., 2016; Pfeffer et al., 2015; Shrestha et al., 2018a).

\subsubsection{Spatial knowledge}

Spatial knowledge is practical knowledge about how people perceive the spatial concepts of interrelated facts, such as the identities of places and landmarks, network connections, directions, or distances between places (Hernández, 1994; Pfeffer et al., 2013). People use this knowledge for many purposes, such as to get to destinations, to 
understand navigational directions, to understand and use maps, and to plan the shortest and efficient route of trips.

In a deliberative process of public participation, spatial knowledge is commonly used by stakeholders when referring to a particular geographical place that needs improvement. In Musrenbang, knowledge about places is essential, as it can determine whether a project proposal can be accommodated in the development plan and budget priorities (Feruglio \& Rifai, 2017). Consequently, knowing distinct types and levels of spatial knowledge, as well as the sociospatial relationships among different stakeholders when using spatial knowledge, are important to understand how spatial knowledge was used and how it can be amplified to improve current public participation practice.

\subsubsection{Types of spatial knowledge}

Theoretically, there are different types of spatial knowledge. Pfeffer et al. (2013) divided spatial knowledge into four main categories: Tacit knowledge, community knowledge, sectoral knowledge, and expert knowledge (see Figure 3-1). Tacit knowledge is knowledge owned by people, whether laypeople or experts, which is often unexpressed or unwritten. Community knowledge is knowledge owned by people in a specific area concerning the context of the social, political, or spatial surroundings of the area. Sectoral knowledge is knowledge in particular sectors, such as farming or engineering, obtained from the experience or practice of professionals or practitioners. Expert knowledge is the codified knowledge owned or developed by academics or professionals (Pfeffer et al., 2013). 


\begin{tabular}{|c|c|}
\hline Tacit knowledge & $\begin{array}{l}\text { - Unexpressed knowledge, gained from experiences } \\
\text { - Uncodified knowledge }\end{array}$ \\
\hline $\begin{array}{l}\text { Context-embedded } \\
\text { community } \\
\text { knowledge }\end{array}$ & $\begin{array}{l}\text { - Knowledge gained from community or social } \\
\text { networks } \\
\text { - Knowing about the spatial surroundings, the political } \\
\text { and social context of particular areas }\end{array}$ \\
\hline $\begin{array}{l}\text { Context-embedded } \\
\text { sectoral knowledge }\end{array}$ & $\begin{array}{l}\text { - Knowledge gained from professionals or } \\
\text { practitioners in specific sectors } \\
\text { - Developed professionally through learning, } \\
\text { experiences, practices }\end{array}$ \\
\hline Expert knowledge & $\begin{array}{l}\text { - Academically/professionally written and } \\
\text { disseminated } \\
\text { - Codified knowledge }\end{array}$ \\
\hline
\end{tabular}

Figure 3-1. Types of spatial knowledge

Adapted from: Pfeffer et al. (2013)

\subsubsection{Levels of spatial knowledge}

Research in psychology has examined different levels of spatial knowledge. Many scholars are influenced by Siegel and White's framework to describe different levels of spatial knowledge (Siegel \& White, 1975). They classify spatial knowledge into three different levels: Landmarks, routes, and configurations (Stern \& Leiser, 1988), as can be seen in Figure 3-2.

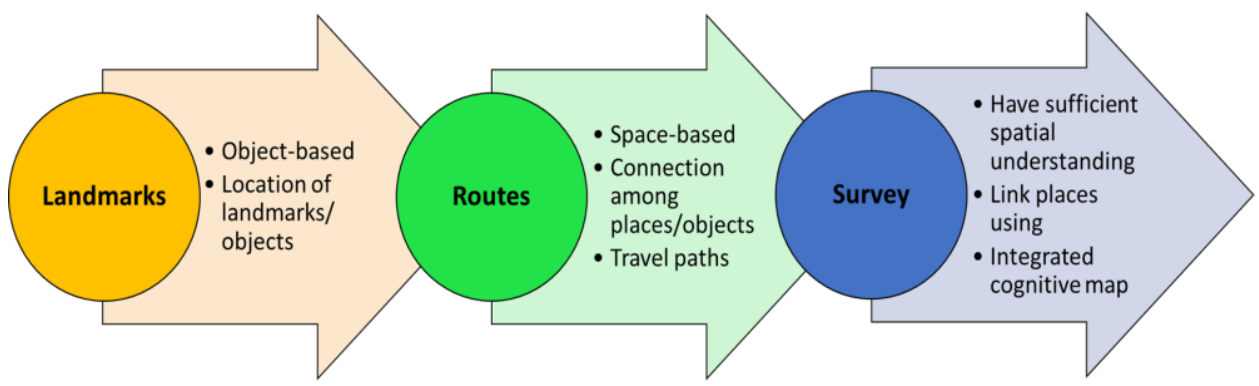

Figure 3-2. Levels of spatial knowledge

Adapted from: Siegel and White (1975), Stern and Leiser (1988)

The first level, landmarks, identifies the specific geographical location of an object. It is a visual representation for human adults and can be known without connecting a particular object to other objects (Siegel $\&$ White, 1975). People at this level are unable to draw the relative 
position of objects located in different places or to travel between places (Stern \& Leiser, 1988).

Through learning or experiences, one can move to the upper level of spatial knowledge, the route level. At this level, one can link one location to other locations and travel between places (Schweizer et al., 1998). Individuals at this level still experience a lack of overall spatial understanding, even though occasionally they can still recognise or recall memories of the travel paths (Stern \& Leiser, 1988).

The next level focuses on the configurations of the landmarks and route levels (Siegel \& White, 1975) or what other scholars call the survey level (Montello, 1998; Richardson et al., 1999; Stern \& Leiser, 1988). At this level, individuals have mastered sufficient spatial understanding and are able to link and navigate between landmarks or places without being limited by travel paths (Montello, 1998; Stern \& Leiser, 1988). The three levels are also relevant, with two main approaches focusing on how people use their spatial knowledge. The landmarks level is related to the object-based approach, while the route and survey levels are closely related to the space-based approach (Yeap \& Jefferies, 2000).

It is also important to note that the three levels of spatial knowledge show the development stages of how individuals acquire spatial knowledge rather than showing the hierarchy. Ishikawa and Montello (2006) stated that spatial knowledge gained through adaptive ways helps us to adapt to the environment. This knowledge guides people to adjust their behavior to the environment, not only as perceived, but also as conceived and remembered (Ishikawa \& Montello, 2006). The transition from one level to another level can be achieved through learning or experiences. In this study, we refer to Siegel and White's levels of spatial knowledge, as their theoretical framework is still relevant and dominant in spatial knowledge discourses (Kirschner et al., 2018; Montello, 1998).

\subsubsection{Socio-spatial relationships}

When discussing spatial knowledge, this concept cannot be separated from the interaction of people who own and use spatial knowledge and their relations with space. To understand these relations, it is crucial to conceptualise the connections between space as a geometrical form and society as a social relation form (Osti, 2015). Humans build social 
relations in their everyday life, while space serves as a medium for people to do activities and develop their social relations. Schatzki (1991) proposed the concept of social space to illustrate the strong relationship between space and people:

"Social space is a distribution of such items (objects, places, settings, action-governing factors, and causal transactions) among places and paths, which automatically happens along with interrelated lives and which underlies both the objective dimensions of social spatiality and the construction of the built environment" (Schatzki, 1991, p. 667).

To better understand the connection between space and society, Osti (2015) elaborated on the concept of socio-spatial relations through three dimensions: The spatial form, social relation, and the sociospatial relationship (Figure 3-3).

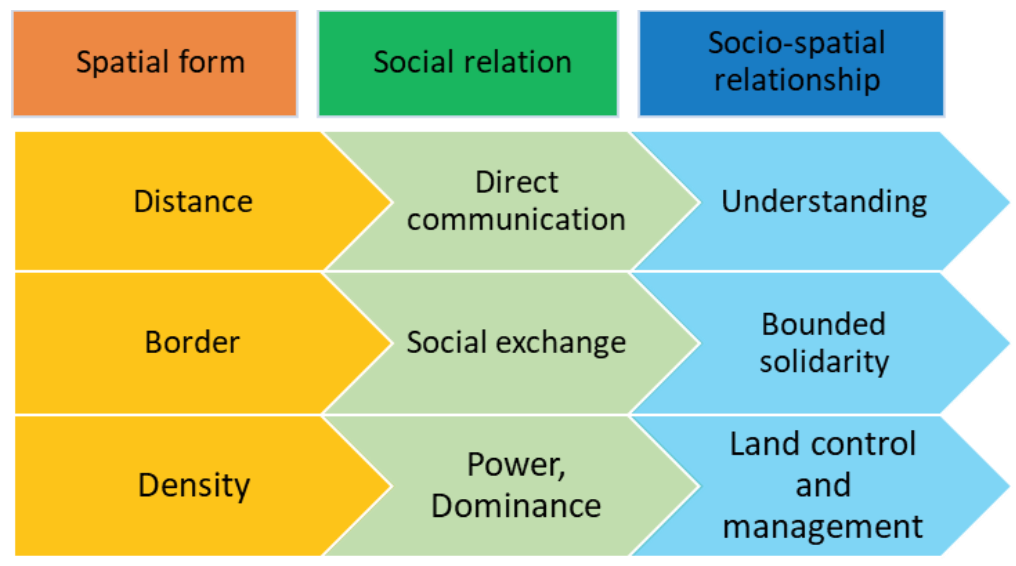

Figure 3-3. Connection of spatial forms and social relations (types of socio-spatial relationships)

Adapted from: Osti (2015)

To conceptualise the socio-spatial process, one cannot rely only on a single dimension. Socio-spatial relations must be viewed from different aspects, as they are mutually essential and interrelated with one and another (Jessop et al., 2008). Spatial elements, such as spatial proximity, accessibility, and connectivity, play a crucial role in supporting the performance or development of a region (Murphy, 2007). Therefore, the structural framework proposed by Osti suggests a clear distinction between three different but intertwined aspects that explain how space can affect people's relations. Understanding among individuals who live distantly can be built through direct interactions (Osti, 2015). The existence of borders can stimulate the exchange of 
knowledge and material flows, and strengthen the solidarity of the communities who live in the same region (Daskalaki, 2018). Dominance is commonly exercised through land use management to manifest the municipal officials' strong position in power relations. As leaders, they must be able to examine the social form of their governed area, identify social relations between the communities, and finally put the policies and directions of the spatial forms that would bring positive impacts to regions (Murphy, 2007).

\subsection{Material and methods}

\subsubsection{The case study}

Musrenbang is an annual participatory planning and budgeting process implemented in different levels of governance, from the village level to the national level. At the village level, Musrenbang is implemented through a public meeting that involves various stakeholders with various backgrounds, interests, influence, and knowledge. In our previous study, we classified the stakeholders into four main groups, namely the upper government, village elites, village elites' supporters, and ordinary citizens (Akbar, Flacke, Martinez, \& van Maarseveen, 2020a). The planning process aims to produce the village's annual development planning document, the financial plans, and development proposals for upper governments (Grillos, 2017; Sopanah, 2012).

This study aims to investigate the utilisation of spatial knowledge in the Musrenbang practices, including its potential to improve the current practice. To better understand the spatial knowledge of the village stakeholders and how the knowledge is used during the Musrenbang practice, we chose five villages in the Deli Serdang district in Indonesia. We purposely chose the villages based on their similarities in four different criteria: (1) The village is located in different sub-districts; (2) the ethnicity of the population is primarily Javanese; (3) the primary livelihood of the population is farming and agriculture; (4) the village officials are willing to participate in this study. Based on these criteria, the Denai Lama, Kolam, Kramat Gajah, Sidoharjo I Pasar Miring, and Tandem Hulu II were chosen as the case study locations. 


\subsubsection{A framework to examine spatial knowledge}

In pursuit of a generalised form of the spatial knowledge concept, which is more evidence-based, we employed a three-dimensional cube framework. The cube framework depicts spatial knowledge as a mutually dependent interplay between types, levels, and the sociospatial relationship of spatial knowledge (Figure 3-4). The threedimensional framework is useful to classify and identify the dynamics, actors, and activities involved in the utilisation of spatial knowledge.

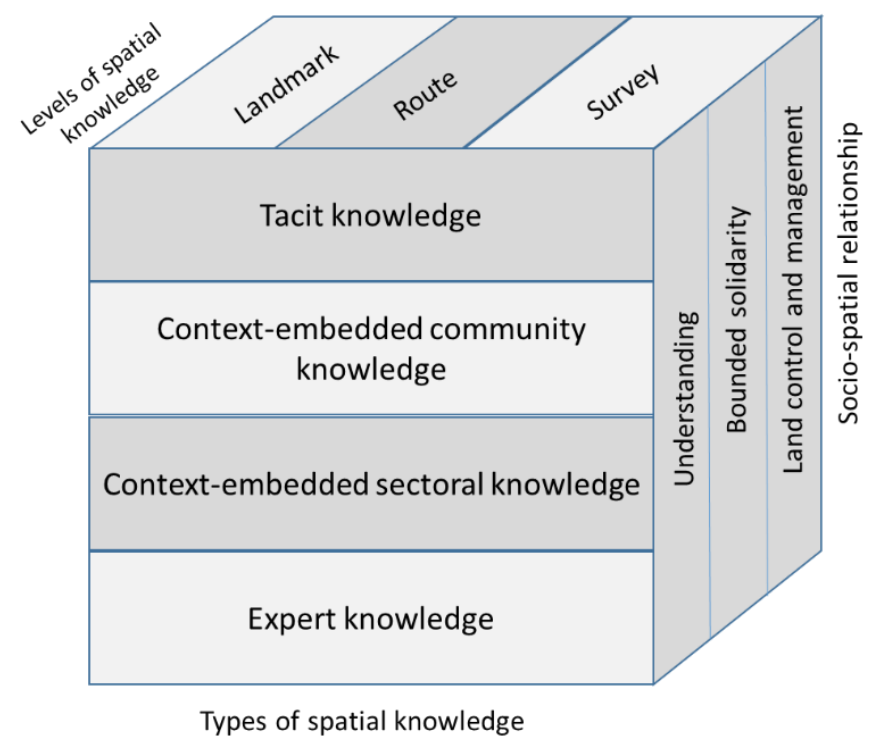

Figure 3-4. The cube framework to understand the utilisation of spatial knowledge.

Adapted from: Pfeffer et al. (2013), Stern and Leiser (1988), Osti (2015).

Examining the types and levels of spatial knowledge and socio-spatial relationships is necessary to understand the hierarchy and relations between different individuals and groups of stakeholders. This examination is also useful to understand the mechanisms and processes that influence the utilisation of spatial knowledge. As the framework aims to encompass the salient aspects of spatial knowledge in the village context, this study also attempted to identify the geospatial data that are used, available, or accessible to the villagers to enrich the discussion. 


\subsubsection{Data collection and analysis}

For the data collection, we used field observations, interviews, and focus group discussions (FGDs). The data were collected from January to May 2018, and we always asked participants/respondents' informed consent before collecting the data. Based on the cube framework in Figure 3-4, we developed a set of criteria to examine the types and levels of the stakeholders' spatial knowledge, as can be seen in Table 3-1. From the assessment criteria, a set of questions for the interviews and FGDs were also developed.

Table 3-1. Criteria and means of verification of the types and levels of the participants/respondents' spatial knowledge

\begin{tabular}{|c|c|c|c|}
\hline $\begin{array}{c}\text { Topic of } \\
\text { assessment } \\
\text { Types of } \\
\text { spatial } \\
\text { knowledge }\end{array}$ & $\begin{array}{c}\text { Means of } \\
\text { verification }\end{array}$ & $\begin{array}{c}\text { Assessment criteria } \\
\text { (characteristics) }\end{array}$ & References \\
\hline $\begin{array}{l}\text { 1. Tacit } \\
\text { knowledge }\end{array}$ & $\begin{array}{l}\text { Observations, } \\
\text { interviews, and } \\
\text { group discussions }\end{array}$ & $\begin{array}{l}\text { The participants/respondents can } \\
\text { identify a specific object in a particular } \\
\text { location that is being discussed in the } \\
\text { Musrenbang discussion or during } \\
\text { interviews. } \\
\text { The participants/respondents admitted } \\
\text { that they acquired the knowledge } \\
\text { through self-experience, not from formal } \\
\text { education. } \\
\text { Even though the } \\
\text { participants/respondents have the } \\
\text { knowledge about places, they never } \\
\text { express it to other people. }\end{array}$ & $\begin{array}{l}\text { (Baud et al., } \\
2011,2014, \\
2015 ; \text { Holden, } \\
2008 ; \text { Hordijk } \\
\text { et al., 2015; } \\
\text { Martinez et } \\
\text { al., 2016; } \\
\text { Pfeffer et al., } \\
2013 \text { ) }\end{array}$ \\
\hline $\begin{array}{l}\text { 2. Context- } \\
\text { embedded } \\
\text { community } \\
\text { knowledge }\end{array}$ & $\begin{array}{l}\text { Observations, } \\
\text { interviews, and } \\
\text { group discussions }\end{array}$ & $\begin{array}{l}\text { The participants/respondents can } \\
\text { identify a specific object in a particular } \\
\text { location that is being discussed in the } \\
\text { Musrenbang discussion or during } \\
\text { interviews. } \\
\text { The knowledge is commonly owned and } \\
\text { acquired by the local people who live in } \\
\text { particular areas. } \\
\text { The knowledge typically portrays the } \\
\text { spatial surroundings, the political and } \\
\text { socio-economic situation of a specific } \\
\text { administrative area, i.e., who and where } \\
\text { the houses of the poor citizens, slum } \\
\text { areas of a neighbourhood, how many } \\
\text { children live in a particular house, the } \\
\text { residence of the elders or landlords, etc. } \\
\text { The participants/respondents admitted } \\
\text { that they acquired the knowledge } \\
\text { through their daily social interactions } \\
\text { with their neighbours or villagers. }\end{array}$ & $\begin{array}{l}\text { (Baud et al., } \\
\text { 2011, 2014, } \\
\text { 2015; Hordijk } \\
\text { et al., 2015; } \\
\text { Martinez et } \\
\text { al., 2016; } \\
\text { Pfeffer et al., } \\
\text { 2013) }\end{array}$ \\
\hline
\end{tabular}




\begin{tabular}{|c|c|c|c|}
\hline & & $\begin{array}{l}\text { The knowledge about places is } \\
\text { exchanged through social interactions } \\
\text { between individuals. }\end{array}$ & \\
\hline $\begin{array}{l}\text { 3. Context- } \\
\text { embedded } \\
\text { sectoral } \\
\text { knowledge }\end{array}$ & $\begin{array}{l}\text { Observations, } \\
\text { interviews, and } \\
\text { group discussions }\end{array}$ & $\begin{array}{l}\text { The participants/respondents can } \\
\text { identify a specific object in a particular } \\
\text { location that is being discussed in the } \\
\text { Musrenbang discussion or during } \\
\text { interviews. } \\
\text { The knowledge is commonly owned and } \\
\text { acquired by the people who work in a } \\
\text { specific sector, i.e., farming, civil } \\
\text { engineering, governments, etc. } \\
\text { The participants/respondents admitted } \\
\text { that they acquired the knowledge } \\
\text { through their learning, experiences, and } \\
\text { practices. } \\
\text { The knowledge about places is } \\
\text { exchanged and spread through the } \\
\text { interactions between professionals or } \\
\text { practitioners in particular sectors. }\end{array}$ & $\begin{array}{l}\text { (Baud et al., } \\
\text { 2011, 2014, } \\
\text { 2015; Hordijk } \\
\text { et al., 2015; } \\
\text { Martinez et } \\
\text { al., 2016; } \\
\text { Pfeffer et al., } \\
\text { 2013) }\end{array}$ \\
\hline $\begin{array}{l}\text { 4.Expert } \\
\text { knowledge }\end{array}$ & $\begin{array}{l}\text { Observations, } \\
\text { interviews, and } \\
\text { group discussions }\end{array}$ & $\begin{array}{l}\text { The participants/respondents can } \\
\text { identify a specific object in a particular } \\
\text { location that is being discussed in the } \\
\text { Musrenbang discussion or during } \\
\text { interviews by using written/drawn } \\
\text { materials such as maps, graphs, journal } \\
\text { articles, regulations, etc. } \\
\text { The knowledge is scientifically generated } \\
\text { through specific methodological } \\
\text { protocols. } \\
\text { Knowledge is commonly owned and } \\
\text { acquired by participating in formal } \\
\text { education or structured training. } \\
\text { The knowledge is codified systematically } \\
\text { and disseminated through the } \\
\text { interactions between professionals or } \\
\text { practitioners in specific expertise. }\end{array}$ & $\begin{array}{l}\text { (Baud et al., } \\
\text { 2011, 2014, } \\
\text { 2015; Hordijk } \\
\text { et al., 2015; } \\
\text { Martinez et } \\
\text { al., 2016; } \\
\text { Pfeffer et al., } \\
\text { 2013) }\end{array}$ \\
\hline \multicolumn{4}{|l|}{$\begin{array}{l}\text { Levels of } \\
\text { spatial } \\
\text { knowledge }\end{array}$} \\
\hline $\begin{array}{l}\text { 1.Landmarks } \\
\text { level }\end{array}$ & $\begin{array}{l}\text { Interviews and } \\
\text { group discussions }\end{array}$ & $\begin{array}{l}\text { The participants/respondents can } \\
\text { identify specific landmarks in a particular } \\
\text { location that is being discussed in the } \\
\text { Musrenbang discussion or during } \\
\text { interviews. } \\
\text { The participants/respondents can draw a } \\
\text { sketch map of their } \\
\text { neighbourhood/village. } \\
\text { The participants/respondents can } \\
\text { mention several points of interest } \\
\text { (landmarks) in their } \\
\text { neighbourhood/village. } \\
\text { The participants/respondents can } \\
\text { recognise a specific point of interest } \\
\text { (landmarks) in their }\end{array}$ & $\begin{array}{l}\text { (Ishikawa \& } \\
\text { Montello, } \\
\text { 2006; Lokka \& } \\
\text { Çöltekin, } \\
\text { 2020; Stern \& } \\
\text { Leiser, 1988; } \\
\text { Teghil et al., } \\
\text { 2019) }\end{array}$ \\
\hline
\end{tabular}




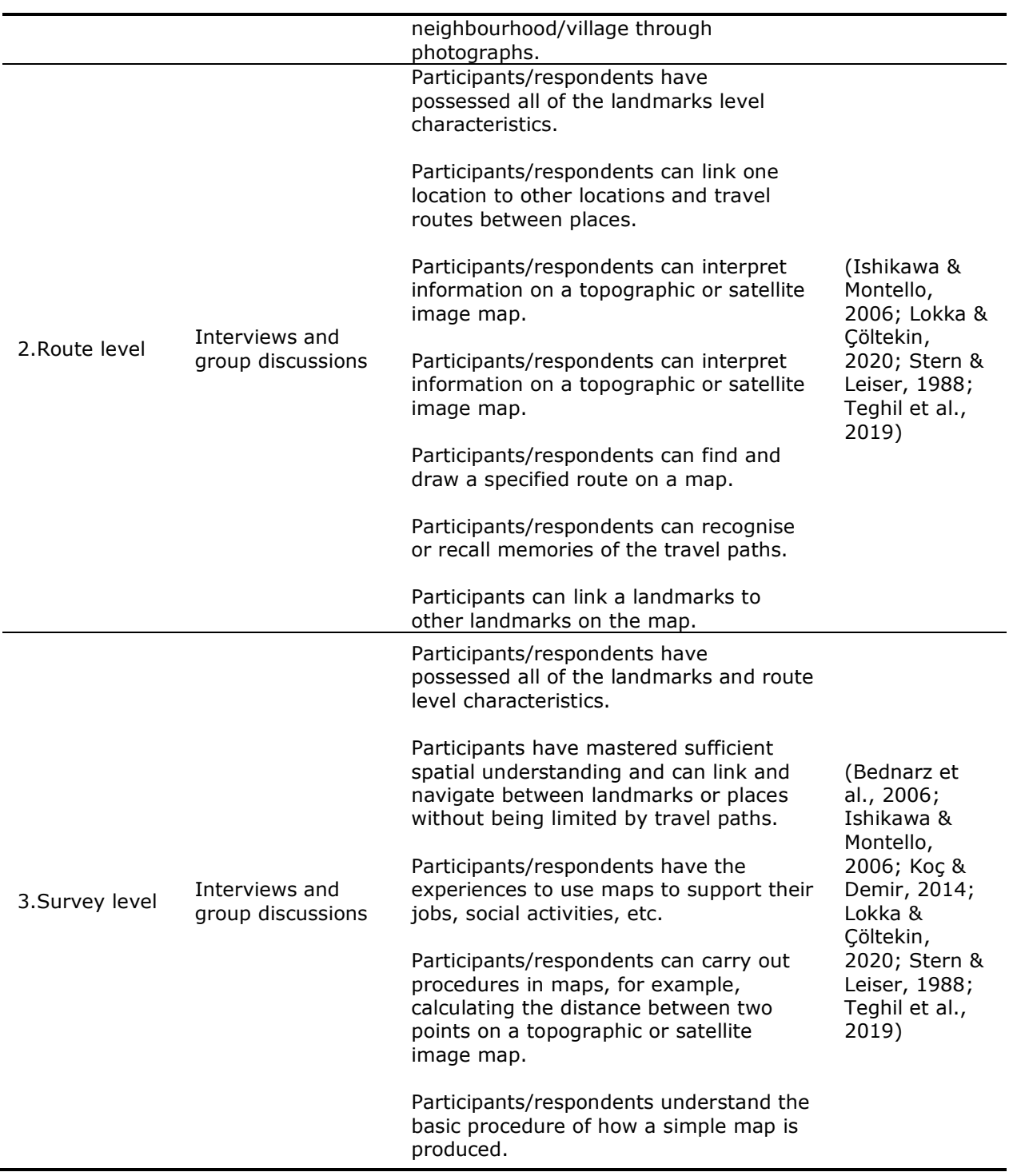

We conducted a stakeholder analysis for examining the socio-spatial relationship among the stakeholders of the Musrenbang practices. To obtain a more detailed understanding of the key stakeholders, firstly, we grouped the identified stakeholders according to their roles in the village Musrenbang practices, including their interest and influence based on the lead author's judgment. Using the semi-structured interviews and FGDs, we asked the respondent to identify the degree of interest and influence of each group of stakeholders and their reasons with regard to the utilisation of spatial knowledge and 
geospatial data in the Musrenbang practices. We used the extended interest-influence matrix method to analyse the levels of interest and influence of the stakeholder groups (Raum, 2018). The method is useful to differentiate a number of key stakeholders and provides comprehensive reasons for the interest and influence owned by each stakeholder (Reed et al., 2009).

The lead author acted as the direct observer in the observations by attending Musrenbang public meetings. The observations were written in field notes and recorded for further analysis. When observing the Musrenbang implementation, we also asked the participants to fill a self-administered questionnaire to collect their responses and opinions towards the Musrenbang implementation and the types of data used during the Musrenbang process (Appendix $\mathrm{C}$ ). From the selfadministered questionnaire, we gained the profile of the Musrenbang participants, as can be seen in Appendix B. The design of the questionnaire is based on previous research (Akbar, Flacke, Martinez, \& van Maarseveen, 2020a).

We conducted fifty-six semi-structured in-depth interviews and four FGDs to understand how the village stakeholders perceived spatial knowledge and how they used spatial knowledge in the Musrenbang (list of questions can be seen in Appendix $\mathrm{H}$ and I). Open-ended questions were used because this type of question allows respondents to answer in their own terms and provide new or unprecedented information that the researcher may not have contemplated (Bryman, 2012). The participants and respondents for FGDs and interviews were mostly villagers who have never had any experiences with interviews. Using the open-ended questions was helpful for the authors to interview the respondents with a certain set of questions derived from the case study design while keeping the respondents as comfortable as possible, as the interviews will be more like a usual daily conversation (Yin, 2003).

The participants/respondents were pre-selected by considering the representativeness of each group of stakeholders. The FGD's participants consisted of village officials, a village council (BPD), the village empowerment board (LKMD), women representatives (PKK), youth representatives (Karang Taruna), community leaders, or religious leaders, and village supervisors. For the interviews, we also 
included the sub-district officials, district officials (Bappeda and DPMD), and a member of the district parliament (Appendix F).

The lead author took the interviewer or facilitator roles for all interviews and FGDs (see Figure 3-5). All the interviews and FGDs were recorded and transcribed for further analysis. The respondents' names were kept anonymous. During the interviews and FGD sessions, we used a tablet and slide projector to show the respondents their village area on the default topographic map, satellite image maps, in Google Maps and Google Street View. We asked them to explore the maps, identify some important landmarks in the area, the location between two or more landmarks, and to manually draw a sketch map of their villages using a blank paper and a pen (Figure 3-5). Using the assessment criteria in Table 3-1, we classified the types and levels of spatial knowledge owned by the respondents as individuals and as a stakeholder group. We also asked them about the geospatial data they have or use, and the utilisation of geospatial data in planning practices.

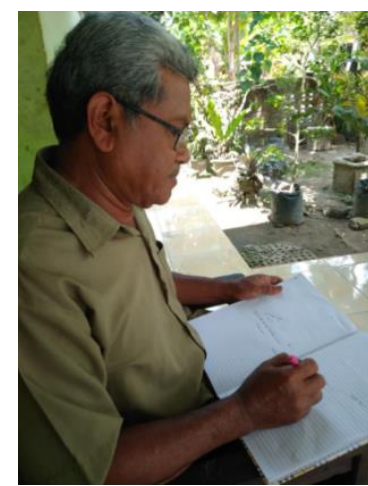

(a)

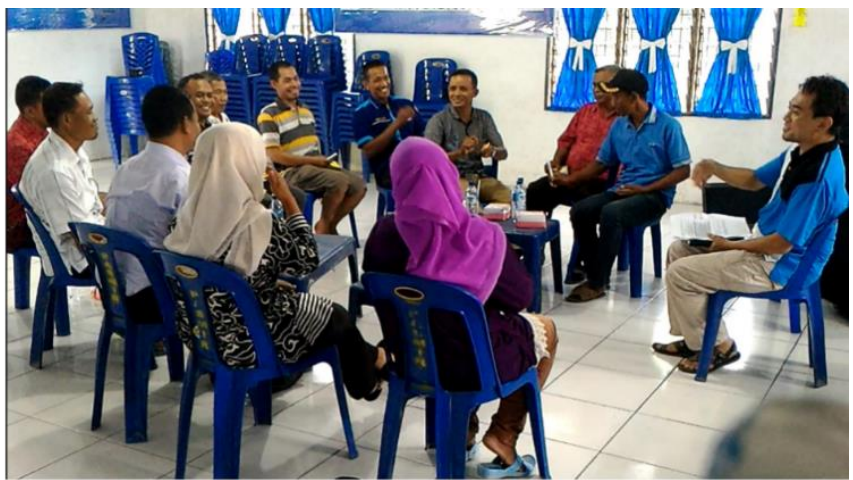

(b)

Figure 3-5. A respondent in Kramat Gajah village drawing a sketch map (a); focus group discussion in Sidoharjo I Pasar Miring village (b)

Source: author photo

We employed qualitative content analysis to scrutinise the observation notes, interviews, and FGDs. A coding strategy was employed to use specific labels to categorise the respondents' answers. We used axial coding themes based on the framework and open coding to ensure that the critical emerging aspects of the qualitative data were not missing (Bryman, 2012). The analysis was conducted iteratively using the ATLAS.ti software. 


\subsection{Results}

Based on the observation, interviews, and FGDs, we achieved the following insights into how spatial knowledge exists and was used at the Musrenbang meeting.

\subsubsection{Types, levels of spatial knowledge, and socio-spatial relationships of the village stakeholders}

The results show that the types, levels, and socio-spatial relationships among the stakeholders play a significant role in the utilisation of spatial knowledge in the Musrenbang practice.

\subsubsection{Types of spatial knowledge}

This study finds that all four types of spatial knowledge existed among the respondents (tacit, context-embedded community, contextembedded sectoral, and expert knowledge), and each individual had one or more types of spatial knowledge. The knowledge was acquired through their daily activities in or out of the village area, for instance, in their working place, formally or informally. The summary of the types of knowledge of all respondents (classified into stakeholder groups in Musrenbang) can be seen in Figure 3-6 below.

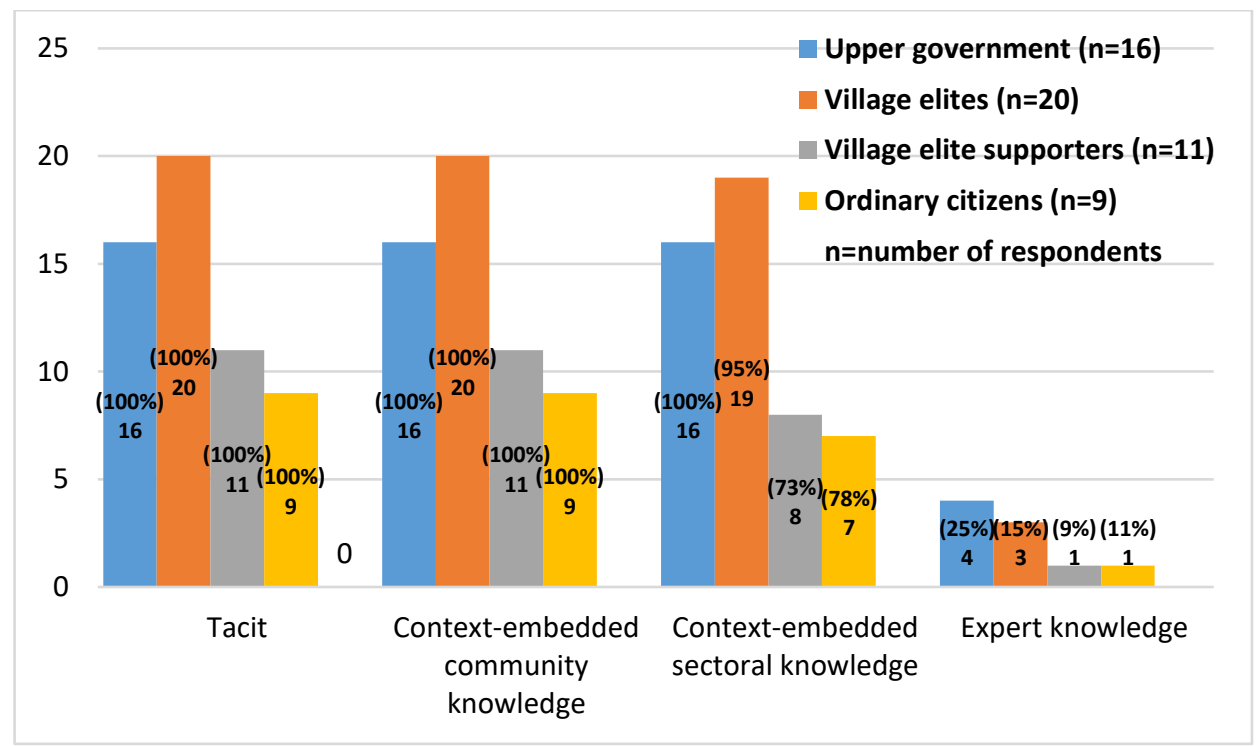

Figure 3-6. Number of respondents in each stakeholder group with particular types of spatial knowledge (percentages in brackets) 
Figure 3-6 shows that all respondents have tacit knowledge. Based on the interviews and FGDs, it was evident that respondents often used their tacit knowledge during the Musrenbang and daily activities. They acquired and learned the knowledge through self-experience. Respondent B7 said in the interview, "I know exactly each part of the road heading to the Tembung area, which is in damaged condition. I know all the holes here and there" (B7, 26 February 2018, personal communication). Moreover, D1 responded:

"Yes, they [the participants] have it [spatial knowledge]. It is because they often go there or pass by the area. I suppose that they know how many turns [to reach a specific place in the village], how many holes, where are the location of the mosque and the houses nearby the mosque they also know" (D1, personal communication, 6 March 2018).

Examining the existence of tacit knowledge is a non-trivial task. Most respondents used their tacit knowledge intuitively when referring to a specific object in a particular location that was being discussed during the Musrenbang discussion. The tacit knowledge is a knowledge that is not easy to identify, as it is challenging to record, transfer, or communicate to other people (Holden, 2008). The knowledge often remains implicit and unspoken, even though the owners may use the knowledge unwittingly in their daily activities.

The same phenomenon also occurred with context-embedded community knowledge; all respondents used community knowledge in their daily activities (see Figure 3-6). This knowledge is gained through social networks and interactions. From these interactions, new knowledge was transferred and exchanged, which eventually became common facts or knowledge among society. In this study, the existence of community knowledge can be found in the way our respondents described a specific place by linking the place with the information of ownership or the people who lived in nearby locations. For instance: "From end to end of this neighbourhood, I am familiar with all the houses, the owners, how many children in each house, I know" (C5, personal communication, 7 March 2018). D4 gave the same response: "We know who the owners of all the houses in this village are and the inhabitants" (D4, personal communication, 6 March 2018). 
The context-embedded knowledge is a knowledge that is commonly used during a participatory process. This knowledge is a valuable source that can reveal the realities within the communities. As this type of knowledge is usually acquired through social relations, it is quite useful to support the existing formal databases that governments have (Baud et al., 2011), to identify the exact locations of poor households, for example (Martinez et al., 2016).

The context-embedded sectoral knowledge is commonly built through daily work or professional activities. Practitioners or professionals often create this type of knowledge from their experiences from practice (Martinez et al., 2016). When they get involved in participatory processes, they would use their professional skills to validate the information they gain during the process. For example, during Musrenbang, interviews, and FGDs, respondents with a government background tended to use terminologies related to governmental issues. In contrast, respondents from the farmers' group tended to talk about irrigation or crop schedule. Providing a suitable method which can link variants of sectoral knowledge used by participants during the discussion becomes crucial. Giving the participants the opportunities to draw sketches (Lokka \& Çöltekin, 2020) or rich pictures (Shrestha et al., 2017) may be useful to facilitate their communications while preventing the knowledge gaps among them.

Expert knowledge is the least type of spatial knowledge that can be found among communities. This type of knowledge is usually created through specific scientific protocols and codified by experts (Martinez et al., 2016). In Figure 3-6, most of the respondents at Musrenbang who had expert knowledge were respondents with a government background (upper government and village elites). As exemplified in the interviews, respondent D88 talked about the importance of maps in development planning and the laws that regulate the process (personal communication, 18 April 2018), while respondent D89 spoke about the laws that regulate the village planning stages and types of documents to be made (personal communication, 26 March 2018). Only a few participants demonstrated this type of knowledge during Musrenbang, as this knowledge was typically generated scientifically and acquired through formal education such as schools or training (Pfeffer et al., 2013). 


\subsubsection{Levels of spatial knowledge}

At the village level, our findings show that the levels of spatial knowledge were also varied. From the fifty-six respondents interviewed, there were five respondents at the landmarks level only, thirty-eight respondents attained the route level, and thirteen respondents exhibited characteristics consistent with the survey level (Figure 3-7).

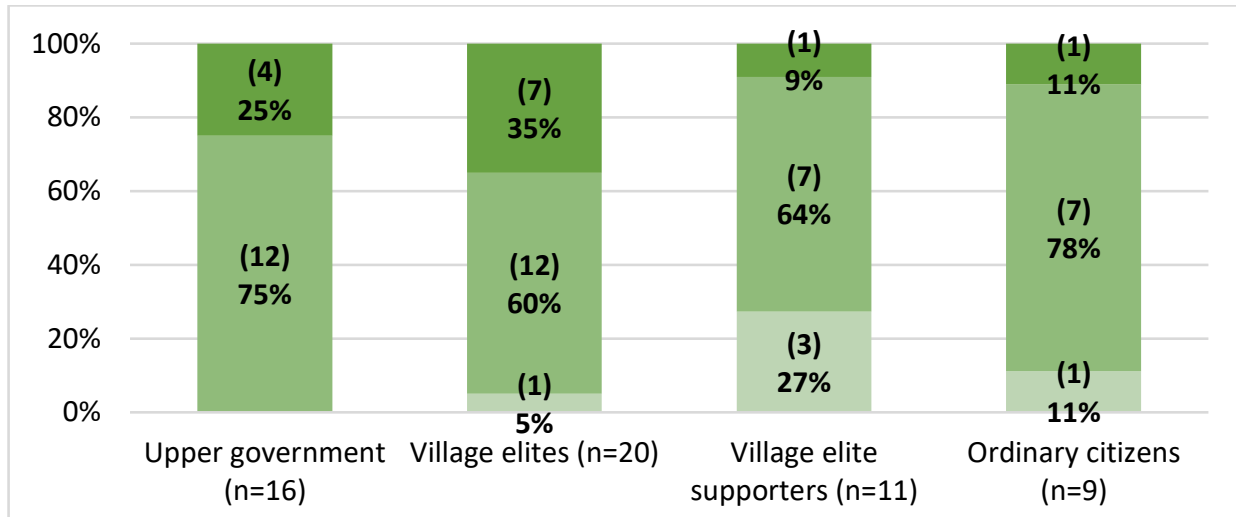

$\square$ Landmarks level (\%) Route level (\%) - Survey level (\%) n=number of respondents

Figure 3-7. Percentage of respondents in each stakeholder group who own a certain level of spatial knowledge (counts in brackets)

All of the respondents possessed spatial knowledge at the landmarks level. Fifty-one respondents passed the landmarks level, while five respondents were still at this level. Most of the villagers have lived in the village for decades, so they know most of the primary landmarks, such as the village head office, health facility, mosque, schools, and the houses of the village government officers. During the interviews and FGDs, the respondents often used those landmarks for orientation when they identified information on the maps. The landmarks usually are attractive elements that are easy to identify, and often situated in locations where people would pay more attention (Lokka \& Çöltekin, 2020).

The majority of the respondents were on the route level. They could identify several landmarks within the village and could instantly provide information about the shortest route to connect those landmarks. 
"We know about every place in this village, as we have traveled or passed by most of the areas. For example, if we want to go to Neighbourhood 1, after passing by the village head office, we will find a T-junction. If we turn right, we are heading to Neighbourhood 3. If we turn left, we are heading to Neighbourhood 1, and it will end up at the village border, which is the Denai Sarang Burung village, our neighbour village" (A1, personal communication, 1 March 2018).

"This is Mawar Street, this is Balai Desa Street. This is the road heading to Neighbourhood 4. If we go North, we will get Neighbourhood 3, then this is the [village] border. This is the rice mill" (A6, personal communication, 1 March 2018).

The statements above clearly show that most participants who demonstrated characteristics of route level acquired the knowledge when they regularly navigate along a specific travel path. They memorise the information on the travel paths during the journeys through an egocentric perspective. The egocentric perspective is useful for acquiring the route spatial knowledge as it represents the location of objects in space relative to the viewpoint of our eyes (Lokka \& Çöltekin, 2020).

While the route level is commonly obtained and used through an egocentric perspective, the survey level is often practiced through the allocentric view (Ishikawa \& Montello, 2006). Individuals at the survey level typically can interpret or use two-dimensional maps (Hernández, 1994), which are in line with our findings that show respondents at the survey level are mostly government officials. Their duties as government employees require them to be able to use and interpret maps to support their jobs. When we asked them to read the digital maps displayed on the tablet during the interviews, they can point out several landmarks and explain the distance and travel paths that connect different landmarks. As an example, A1 said, "Yes, I can read the [Google] map. This is the village head office. This is the rice mill. I was part of the team that made the first [sketch] map of this village (A1, personal communication, 1 March 2018).

Our findings also revealed that participants reacted faster to identify the landmarks or routes when we used the Google Street View than the Google Maps in the interviews and FGDs. The Google Street View supports the egocentric perspective, while the Google Map supports the allocentric view, which is not easy to interpret. We also found that age differences are crucial to executing the given tasks. Younger 
respondents have a better ability than older participants to understand the maps provided in the Google Map platform. Younger respondents have more opportunities to be exposed to the rapid development of new technologies nowadays, enabling them to better interact with the virtual geo-technology means (Lokka \& Çöltekin, 2020).

\subsubsection{Socio-spatial relationships of the village stakeholders}

Most respondents are quite familiar with their village areas. However, the village officials, head of neighbourhoods, and women respondents demonstrated more knowledge about the village than other respondents. The village officials and heads of neighbourhoods knew about their areas because their duties force them to understand their governing areas. When working on their duties, the head of the neighbourhoods often goes to the neighbourhoods to identify and list the programs needed by citizens, working with the land administration and registration, to survey and measure the length, width, or depth of a specific location in the village (B1, personal communication, 5 March 2018)

The women have more extensive knowledge of the area, as they spend most of their time in the villages where they can exercise and extend their social network with other village stakeholders (Akbar, Flacke, Martinez, \& van Maarseveen, 2020a). Respondent C5, for instance, said that they know the exact location of each house in their neighbourhoods, who the owners are, and who the individuals living in the house are (C5, personal communication, 7 March 2018). Direct face-to-face communication has a significant role in enabling individuals or groups to have a better understanding of their living space and its surroundings.

From the responses, it seems that the respondents often refer to the village border when identifying landmarks or routes. Borders or boundaries are essential for location orientation in the village. For instance, when we asked a woman representative from the Denai Lama village to explain the route from the village head office to her house, she used the village border for orientating her route.

"So, from Denai Sarang Burung [village neighbour], this is the village border. We are going straight. Only the main roads, right? We will pass a mosque, then we simply follow the roads, we find a junction, we turn right to the village head office, passing the office, then we 
turn right, go straight follow the road heading here, so here we are" (A5, personal communication, 8 March 2018).

Borders are also essential to claim the existence of activities managed by stakeholder groups. Farmer groups, for example, also have sketch maps to illustrate the rice fields in the village (D8, personal communication, 7 March 2018). This finding is aligned with Osti's framework, as the border can create bounded solidarity among the people who live in a particular area (Osti, 2015). Some respondents also stated administrative boundaries as an underlying problem that can provoke conflicts between neighbourhoods, villages, or subdistricts. In Denai Lama, disputes have arisen in the past, and until now, the border problem with their neighbours still exists ( $A 1, A 2$, personal communication, 1 March 2018). Delineating boundaries is essential to decide the scope of development planning as well as reducing conflicts over administrative areas (Baud et al., 2015).

Regarding power relations, our findings show that various stakeholders were involved in village Musrenbang practices. We classified them into four main stakeholder groups, as can be seen in Table 3-2 below. 
Table 3-2. Stakeholders interest and influence in utilising spatial knowledge and spatial data in Musrenbang

\begin{tabular}{|c|c|c|c|c|c|c|}
\hline $\begin{array}{l}\text { Stakeholder } \\
\text { groups }\end{array}$ & Impact & $\begin{array}{l}\text { Inte- } \\
\text { rest }\end{array}$ & $\begin{array}{l}\text { Influ- } \\
\text { ence }\end{array}$ & $\begin{array}{l}\text { What is } \\
\text { important to the } \\
\text { stakeholder? }\end{array}$ & $\begin{array}{l}\text { How could the } \\
\text { stakeholder } \\
\text { contribute to } \\
\text { the practice? }\end{array}$ & $\begin{array}{l}\text { How could the } \\
\text { stakeholder } \\
\text { block the } \\
\text { practice? }\end{array}$ \\
\hline $\begin{array}{c}\text { Upper } \\
\text { government }\end{array}$ & Low & Low & High & $\begin{array}{l}\text { Codified spatial } \\
\text { knowledge is } \\
\text { useful to support } \\
\text { planning } \\
\text { practices as well } \\
\text { as to formulate } \\
\text { development } \\
\text { planning } \\
\text { documents }\end{array}$ & $\begin{array}{c}\text { Providing } \\
\text { spatial data at } \\
\text { the district, } \\
\text { sub-district, } \\
\text { and village } \\
\text { level }\end{array}$ & $\begin{array}{l}\text { Lack of } \\
\text { knowledge on } \\
\text { how to } \\
\text { produce } \\
\text { reliable and } \\
\text { accurate } \\
\text { spatial data }\end{array}$ \\
\hline $\begin{array}{l}\text { Village } \\
\text { elites }\end{array}$ & High & High & High & $\begin{array}{l}\text { Spatial } \\
\text { knowledge is } \\
\text { useful to identify } \\
\text { areas that need } \\
\text { improvements }\end{array}$ & $\begin{array}{c}\text { Utilising } \\
\text { spatial } \\
\text { knowledge and } \\
\text { spatial data } \\
\text { to: } \\
\text { 1) Better } \\
\text { conceptualise } \\
\text { development } \\
\text { plans; 2) } \\
\text { stimulate the } \\
\text { discussions } \\
\text { among } \\
\text { Musrenbang } \\
\text { participants }\end{array}$ & $\begin{array}{l}\text { 1) Lack of } \\
\text { knowledge } \\
\text { about how to } \\
\text { produce and } \\
\text { use reliable } \\
\text { and accurate } \\
\text { spatial data; } \\
\text { 2) show } \\
\text { hesitation to } \\
\text { use spatial } \\
\text { data in the } \\
\text { Musrenbang }\end{array}$ \\
\hline $\begin{array}{l}\text { Village elite } \\
\text { supporters }\end{array}$ & Medium & $\begin{array}{l}\text { Medi } \\
\text { um }\end{array}$ & $\begin{array}{l}\text { Medi } \\
\text { um }\end{array}$ & $\begin{array}{l}\text { Spatial } \\
\text { knowledge is } \\
\text { useful to identify } \\
\text { areas that need } \\
\text { improvements }\end{array}$ & $\begin{array}{c}\text { Utilising } \\
\text { spatial } \\
\text { knowledge and } \\
\text { spatial data to } \\
\text { better } \\
\text { conceptualise } \\
\text { development } \\
\text { plans }\end{array}$ & $\begin{array}{c}\text { Lack of } \\
\text { knowledge } \\
\text { about how to } \\
\text { produce and } \\
\text { use spatial } \\
\text { data }\end{array}$ \\
\hline $\begin{array}{l}\text { Ordinary } \\
\text { citizens }\end{array}$ & High & High & Low & $\begin{array}{c}\text { Spatial } \\
\text { knowledge is } \\
\text { useful to } \\
\text { understand the } \\
\text { distribution of } \\
\text { village } \\
\text { development } \\
\text { projects }\end{array}$ & $\begin{array}{l}\text { Use their } \\
\text { spatial } \\
\text { knowledge } \\
\text { supported by } \\
\text { sufficient } \\
\text { spatial data to } \\
\text { enrich the } \\
\text { discussion of } \\
\text { village } \\
\text { development } \\
\text { plans. }\end{array}$ & $\begin{array}{l}\text { Lack of } \\
\text { knowledge on } \\
\text { how to use } \\
\text { spatial data } \\
\text { effectively }\end{array}$ \\
\hline
\end{tabular}

Table 3-2 clearly shows the stakeholders' positive and negative influence on the utilisation of spatial knowledge and spatial data at the Musrenbang. Each group of stakeholders has different interests and influences towards the process, which potentially creates gaps and conflicts among them.

In the village Musrenbang, the village elites play a vital role in controlling the discussion. The regulation gives them the right to enlist 
programs that need to be prioritised. As they have better knowledge about the regulations and the village's geographical locations of the proposed projects, most of the programs listed by the elites are often agreed upon by the participants. However, only slight adjustments can be made to the list since the result of the discussion at the Musrenbang is only considered as recommendations that are not binding.

\subsubsection{Use of spatial knowledge and geospatial data in the Musrenbang}

Our findings revealed that spatial knowledge was used during the Musrenbang discussion. Below are two examples of participants' responses to the question of how spatial knowledge was used at the Musrenbang:

"When a participant said that they need to build an asphalt road in a specific area, we can visualise that area in our mind instinctively as we have traveled to that area a couple of times and we know the road condition is severe. So, the project is urgent. Yes, I think spatial knowledge is used" (B5, personal communication, 4 March 2018).

"They use (spatial) knowledge (in Musrenbang). Even though they do not know the exact length of the irrigation tunnel, they already know where the location of the flooding is. They know that it happens due to no tunnel being available to discharge the water. So, they used their [spatial] knowledge" (A2, personal communication, 1 March 2018).

From the responses above, it is evident that during the Musrenbang discussion, when someone at the meeting mentions a particular place within the village, the participants often unwittingly use their spatial knowledge to identify the place. However, the utilisation of spatial knowledge was not optimal due to a lack of geospatial data in the villages. They have village sketch maps, hand-drawn without proper scales or coordinates, but the maps were never used at the Musrenbang. All of the village maps are hanging on the wall of the village office, so basically, they are used for office decoration only (see Figure 3-8). We only found one respondent who created his own handdrawn neighbourhood map. The map depicts the situation of the neighbourhood with all the houses, infrastructure, roads, and alleys (Figure 3-8). The map is regularly updated and only for internal use 
for visualising the situation of the neighbourhood (B3, personal communication, 5 March 2018).

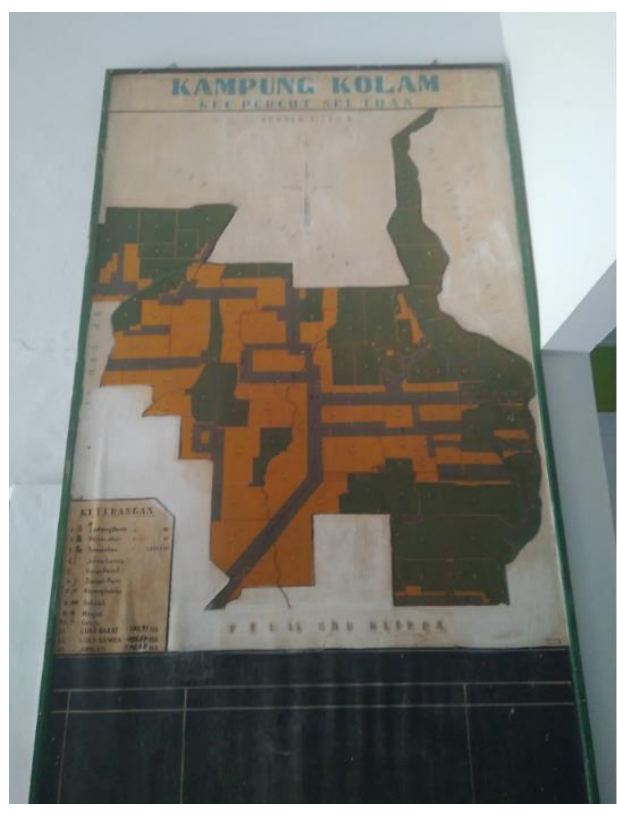

(a)

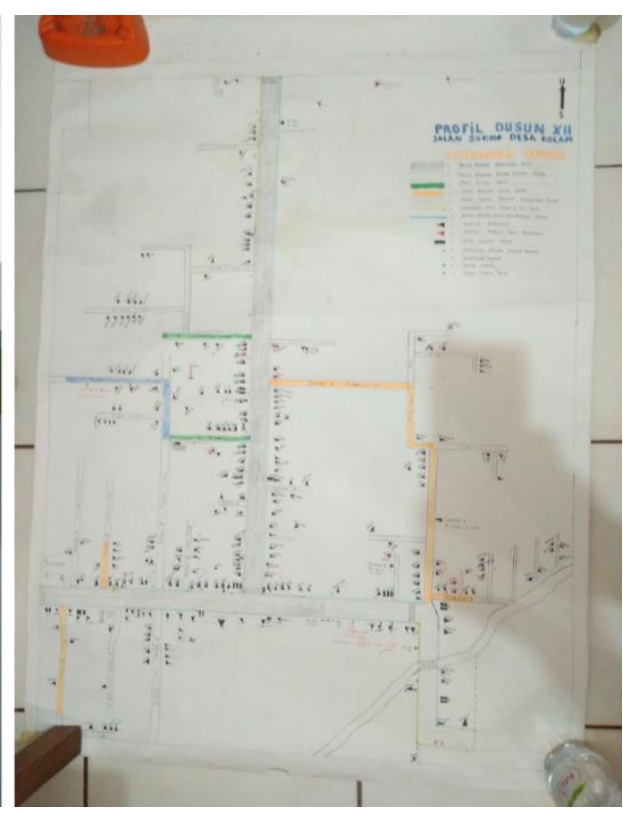

(b)

Figure 3-8. Sketch map of Kolam village is hanged on the wall of the village office (a); map of neighbourhood XII in Kolam village, showing detailed information about the neighbourhood (social economy, facilities, housing, etc.) (b)

Further, we asked the respondents about the potential use of maps during the Musrenbang discussion. Most respondents gave positive feedback towards our question, as can be seen in Figure 3-9. 


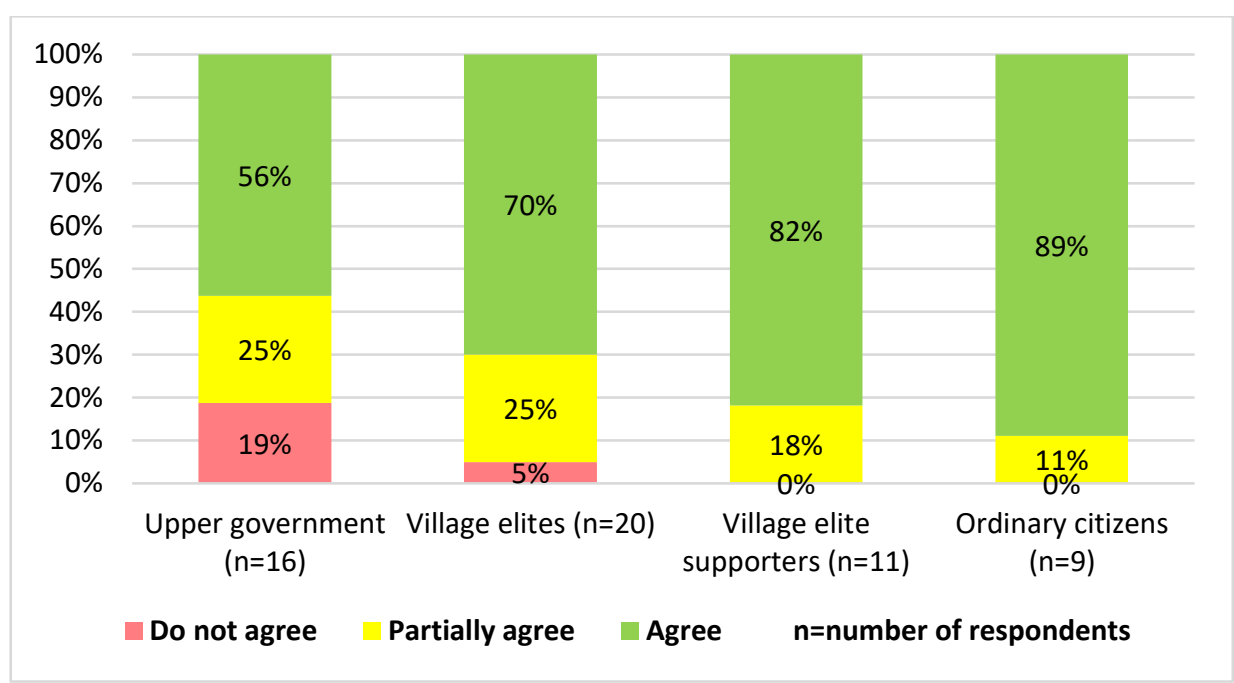

Figure 3-9. Percentage of respondents in each stakeholder group who agree, partially agree, and do not agree with the potential use of maps in the Musrenbang practice

Some respondents described their reasons why they think using maps would be useful to enhance Musrenbang implementation. Spatial data like maps would be helpful to visualise the geographical locations of the Musrenbang projects, which are being discussed (A8, personal communication, 8 March 2018). The visualisation could stimulate the discussion, as now participants can see the spatial distribution of the project's locations (B5, personal communication, 4 April 2018). A6 implied that by using maps, the discussion would be more productive. Showing the village maps during the Musrenbang may result in additional opinions to ensure the allocation of projects is to be more equitably distributed and solve the most urgent problems that the village may have (A6, personal communication, 1 March 2019). Martinez et al. (2016) suggested that maps would be useful to stimulate in-depth discussions while enriching the debates among stakeholders. 


\subsubsection{To what extent do spatial knowledge and geospatial data support the participatory processes?}

Even though the stakeholders were often unconsciously using their spatial knowledge during the discussions, the respondents admitted that spatial knowledge is useful to help them in identifying particular places during the Musrenbang discussion.

"For example, when someone said Masjid Street, our mind starts to think about where it is. Oh, it is at the village border. The border is around some kilometers away from here. So, it [the location] just comes up. When somebody talks about that place, we can simply imagine it. We do not see it physically, but we can see it through our minds" (A9, personal communication, 8 March 2018).

C3 expressed that even without any supporting pictures or visiting the area, they could imagine a particular place in the village because they are very familiar with the area (personal communication, 7 March 2018). The same response was given by D1, who said that participants could visualise a location even though they were not in that specific place, as it is automatically visualised in their minds (personal communication, 6 March 2018). However, their knowledge was not acquired through formal learning; they gained this kind of knowledge from their daily interaction with the other people in the village and unintentionally memorised the information gained through these interactions (B1, personal communication, 5 March 2018).

These responses show clear examples of how tacit knowledge is transformed into community knowledge. A person tacitly knows a place and the people who live nearby based on his/her experiences. When they interact with other people, they express their tacit knowledge, which then becomes explicit. As a result, the people with whom he/she interacts gains new knowledge from the conversation. Thus, social networks play an essential role in utilising and acquiring the community's spatial knowledge as well as transforming tacit knowledge into becoming explicit.

When we asked the participants about their support towards the idea to produce village maps through a participatory mapping exercise, ordinary citizens showed high acceptance. In contrast, the upper government, village elites, and their supporters showed hesitation towards the idea to involve the citizens in the participatory mapping activities (Figure 3-10). 


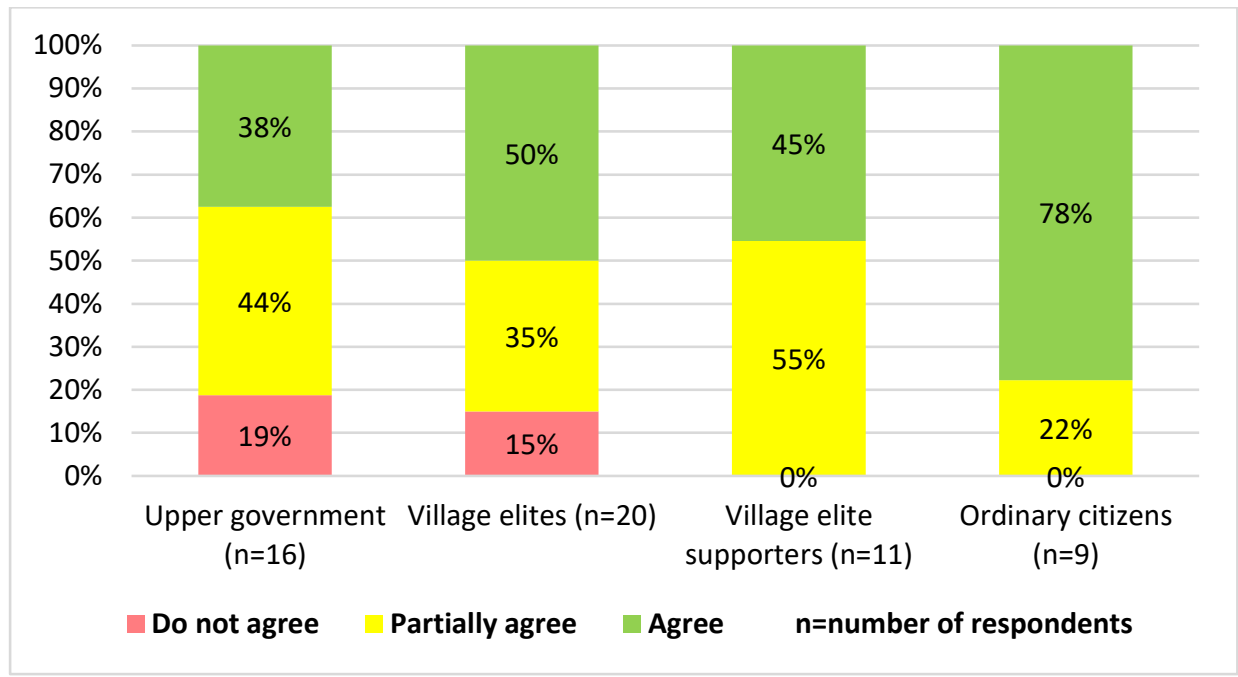

Figure 3-10. Percentage of respondents in each stakeholder group who agree, partially agree, and do not agree to create maps through participatory mapping exercise

During the interviews, when we asked for reasons for the hesitation, E1 responded that ordinary citizens have no time to engage in social activities, like a participatory mapping exercise (E1, personal communication, 3 May 2018). The same response was given by B5, who said, "[We] do not need to involve the citizens. Just involve the village officers, BPD, LKMD, and the head of neighbourhoods to create the maps" (B5, personal communication, 4 April 2018). Another respondent stated, "Only [involve] the governments. Creating maps needs a specialised expertise. If we involve the ordinary citizens, it will be very difficult to create the maps" (E4, personal communication, 6 April 2018). Involving citizens is quite tricky. E3 implied that if citizens see the development gaps among neighbourhoods on the maps, this could trigger concerns and protests from the Musrenbang participants (E3, personal communication, 2 May 2018). Thus, this could be one of the reasons why the village elites and their supporters prefer to limit the participation of ordinary citizens in participatory mapping activities. Developing a participatory mapping method that can facilitate the integration of various spatial knowledge while minimising power inequalities is not straightforward but necessary. The engagement in the participatory mapping activities should not only aim to enhance the participants' spatial understanding about their villages but also accommodating different interests and influences of the stakeholders in the village (Martinez et al., 2016). 
It appears that the survey level moves beyond what is placed at a certain location (landmarks level). Community members that operate at the survey level, by understanding the landscape in a holistic manner, are also able to know why and how changes in a specific location may have an impact in some parts of the village. Involving the people who are at the survey level would enrich a participatory mapping exercise and make the mapping process more efficient (Eilola et al., 2019). The selection of participants for the participatory mapping exercise should not only consider the representativeness of the stakeholders in the region, but also needs to consider the level of spatial knowledge that an individual may have.

\subsection{Discussion}

In this research, we identified how various groups of stakeholders have and make use of different types, levels of spatial knowledge, and sociospatial relations. These three different dimensions are mutually connected and show the capability of each group of stakeholders in perceiving and utilising their spatial knowledge. Three main challenges need further actions to optimise the spatial knowledge used by the village stakeholders.

\subsubsection{Spatial knowledge is used in Musrenbang, but not properly}

The participants of Musrenbang have distinct types and levels of spatial knowledge, but they are not aware of its potential in helping them in planning processes. The interviews and FGDs in this study were useful to raise awareness of the valuable knowledge that could be used to help them better participate in the Musrenbang practice.

As an annual public meeting prescribed by the laws 25/2004, the participatory process in Musrenbang is still far from ideal. An ideal public participation practice should allow participants to share their ideas and opinions (Quick \& Feldman, 2011; Yanow, 2003), as well as supporting mutual communication and collaboration among them (Healey, 1997; Innes \& Booher, 2004). In the implementation, as Indonesian villages have characteristics associated with stronger social networks (Antlöv, 2003), the village elites typically have full control to direct the conversation and make final decisions. The 'silent majority' 
among the participants, mostly ordinary citizens from marginalised groups, remains uninvolved (Albrechts, 2002; Grillos, 2017; Yanow, 2003).

However, this situation did not prevent village stakeholders from using their spatial knowledge. As the topics of discussion in Musrenbang cannot be separated from discussing specific geographical places, by nature, discussion about places would contribute to stimulating the participants to use their spatial knowledge, tacitly or explicitly. The active usage of spatial knowledge provides the potential for the knowledge co-production process. Previous studies have shown good examples, such as the knowledge co-production to solve the pollution issue in Durban (Pfeffer et al., 2013), to collect toponym information in Indonesia (Perdana \& Ostermann, 2018, 2019), or to tackle environmental burdens in Dortmund urban areas (Shrestha et al., 2017),

How to effectively use spatial knowledge is also a challenge. Our results reveal that most of the participants in Musrenbang limited their focus mainly on their own neighbourhoods, giving the impression that the spatial boundaries have a significant influence on the formation of bounded solidarity within a community. Consequently, they did not put any attention to projects implemented in a broader context, such as in other neighbourhoods or at the village scope. Redesigning the participatory method that engages as many as participants as possible (Flacke et al., 2020; Innes \& Booher, 2010) and meets the local context (Feng et al., 2020; Leino, 2012) could be a solution to achieving a better participatory process. For example, the proposed method should acknowledge the importance of borders for villagers, as borders have complex social constructions with various implications for society, not only simple lines/signs in space or on maps (Haselsberger, 2014).

Further, the design of the participatory method should also enable the village stakeholders to think systematically to leverage their voices in the decision-making process (Eilola et al., 2019). Thus, rather than only knowing about where the location of a healthcare facility is, for instance, the participants should also be able to use their spatial knowledge to understand the impact of maps for other development purposes. For example, they can use their spatial knowledge to identify the best location for the new healthcare facility, or to assess how the 
relocation of a traditional market to a new site can affect the transportation routes of their villages.

\subsubsection{Codifying knowledge to integrate the local spatial knowledge and support the Musrenbang practice}

Data availability is crucial to support public participation practices. However, data availability is commonly limited (Shrestha et al., 2018a) or inaccessible for users (Corbett \& Keller, 2004). In Musrenbang, each project discussed often has information about the name of the project, quantity, and location of the project. Nevertheless, in all five villages, there was no spatial data/information, such as maps, available to support the discussion about the project.

Lack of codified knowledge, like maps, caused the participants to not pay attention to the topics discussed, as they lost interest in the issues, particularly as they put more concern on their own neighbourhoods' issues. Eventually, the public meeting as a means of participation is subverted in practice, as the elites could smoothly steer the decisionmaking process more favorably for themselves (Feruglio \& Rifai, 2017; Grillos, 2017).

Most of the respondents gave positive responses to the utilisation of geospatial data in the Musrenbang. However, they were confronted with the fact that there is no or limited geospatial data available in the villages. The question is now how to codify and make spatial data available. Nowadays, the production and use of spatial data have shifted from only an expert-driven process to a process where organisations or citizens worldwide can get involved (Eilola et al., 2015; Szyszka \& Polko, 2020). For instance, the universal use of spatial data applications, such as Google Maps and Open Street Map, allows people to become an active contributor to spatial data (Haklay, 2010; Perdana \& Ostermann, 2018; Santos et al., 2011). Despite broader access to various types of online geospatial data and information, we found that the village stakeholders did not make use of the available data to enhance the decision-making process. Age could be a primary impediment to the use or manipulation of those types of online geospatial data (Lokka \& Çöltekin, 2020). Most of the village elites are older people, while the youth citizens seldom have essential positions at the elites' level as well as rarely engage in public participation practices. Lack of access to the internet is another problem. Many 
citizens in rural areas, especially the elderly, tend to show hesitation to install internet connections at home or even use the internet on their mobile phones. The internet connections in rural areas are often less stable, while infrastructure needed to provide a stable internet connection might be costly for most internet service providers. Consequently, these circumstances hinder the optimal use of freeavailable geospatial data to enhance the spatial knowledge of the stakeholders and to improve the current Musrenbang practices.

Involving the stakeholders of Musrenbang in a co-production process to produce their own spatial data into codified knowledge has the potential to solve data availability problems. The co-production of spatial knowledge to produce joint data/information could help enrich public participation practices. Participants with different backgrounds could contribute by solving common problems faced by communities (Aguilar et al., 2020; Curşeu \& Schruijer, 2020; Shrestha et al., 2017), increasing trust (Innes \& Booher, 2004), nurturing a sense of belonging (Healey, 1998b), ensuring more sustainable land management decisions (Eilola et al., 2015), and promoting the optimal use of spatial knowledge (Pfeffer et al., 2013). Ultimately, the valuable tacit, community, sectoral, and expert spatial knowledge owned by diverse stakeholders could be transformed into codified knowledge.

\subsubsection{Willingness to use spatial knowledge among stakeholders of Musrenbang}

Further typical questions when initiating participatory processes, such as knowledge co-production, are how significant the (upper) government commitments to support the process of knowledge exchange among stakeholders are. As prescribed by the law 6/2014, each village must have three types of maps: The satellite image, infrastructure/facilities, and land use/land cover maps. Although stated by laws, the upper government typically put their attention to other tangible developmental priorities, particularly for infrastructure (Warburton, 2016), and did not take any actions to support the production of village maps.

At the village level, the village elites gave positive responses to the use of spatial data in the Musrenbang process. As discussed in the previous section, spatial data can be produced through knowledge co-production activities, such as participatory mapping (Eilola et al., 2019). However, 
our findings reveal that half of the respondents from the village elites' group showed hesitation to involve many as participants in the participatory mapping exercise. They preferred only to include the village elites and their supporters. It seems that the elites are a bit concerned about losing their control over ordinary citizens. Maps could threaten the elites' authority and raise citizens' concerns towards the policies made by elites, for instance, criticising the fairness of project distributions in all neighbourhoods. There are many cases where participatory mapping exercises lead to counter-mapping activities that could challenge powerful elites (Corbett \& Keller, 2004; McCall \& Dunn, 2012). Moreover, there may be a concern for the elites that coproduction processes could sacrifice the provisions of the services (Bovaird \& Loeffler, 2012); in this case, the quality of the village map produced may be lower than the expected standard.

On the other hand, ordinary citizens have the confidence to utilise spatial data and information during the Musrenbang practice, as well as to participate in the map-making process. However, their main concern is how to produce maps without the capability of creating maps with proper coordinates and projections. The availability of map experts is essential for the sustainability of a participatory mapping project (Corbett et al., 2006; Wästberg et al., 2020).

\subsection{Conclusions}

Our research introduces a feasible and straightforward framework to better understand the stakeholders' spatial knowledge and how they use knowledge in a public participation practice. The developed framework is universal, as it portrays spatial knowledge as a mutually dependent interplay between types, levels, and the socio-spatial relationship of spatial knowledge. The framework enables the authors to examine the dynamics, actors, and activities involved in the utilisation of spatial knowledge in public participation practices. The framework has the potential to be used elsewhere, of course, by adjusting or modifying certain aspects to meet the real context of other localities. For example, when applying the framework in urban areas, using an online assessment form is possible since the urban population tends to be more adaptable and open to online and virtual communication. 
We recognise that this study has limitations. When assessing the types and levels of respondents' spatial knowledge in the interviews, the tools that we used were only a tablet to display the maps, and pens and blank sheets of paper for respondents to draw a sketch map. As the acquisition of spatial knowledge is highly related to the human cognitive aspects (Schweizer et al., 1998; Yeap \& Jefferies, 2000), using a device that allows respondents to experience the navigational experiences, such as mobile mapping tools, might be more powerful to examine the respondents' spatial knowledge (Aguilar et al., 2020; Flacke et al., 2020; Lokka \& Çöltekin, 2020).

This chapter confirms that most respondents agree that spatial knowledge has the potential to enhance public participation, particularly the current Musrenbang practice. The participants, with better use of their spatial knowledge, can better engage in a fruitful discussion during the Musrenbang, which leads to better decisionmaking processes. For example, they can locate specific issues on the maps, examining the impacts of particular projects in the village area, or creating a more equitable funding allocation for all neighbourhoods. Further, better use of spatial knowledge could stimulate more in-depth discussions and collaboration between participants in other village development projects, especially when supported with sufficient and accurate geospatial data.

Knowing the types, levels, and socio-spatial relationships among stakeholders provides a profound understanding of identifying better methods to utilise and integrate stakeholders' spatial knowledge. Developing a suitable method, i.e., the participatory mapping, could enable stakeholders to express their spatial knowledge while stimulating collaboration between ordinary citizens and the elites. The collaboration should put attention on the local context and consider the characteristics of different stakeholders in using their spatial knowledge. In the long run, the collaboration could also solve the problem of a lack of geospatial data in the villages. This study calls for further research to explore the most effective way to manage the potential of spatial knowledge of stakeholders in codifying their knowledge and utilising the knowledge in real practice, like public participation processes. 


\section{Chapter 4: Knowing my village from the sky: A collaborative spatial learning framework to integrate spatial knowledge of stakeholders in achieving Sustainable Development Goals ${ }^{\star}$}

\footnotetext{
* This chapter is based on the published paper: Akbar, A., Flacke, J., Martinez, J., Aguilar, R., van Maarseveen, M. F. A. M. (2020). Knowing my village from the sky: A collaborative spatial learning framework to integrate spatial knowledge of stakeholders in achieving sustainable development goals. ISPRS International Journal of Geo-Information, 9(9), 515. https://doi.org/10.3390/ijgi9090515.
} 
Sustainable Development Goals (SDGs) target 11.3 and 16.7 aim to "enhance inclusive and sustainable urbanisation and capacity for participatory, integrated and sustainable human settlement planning and management in all countries", while "ensuring responsive, inclusive, participatory and representative decision-making at all levels" (The United Nations, 2016). The achievement and monitoring of SDGs require vast geospatial data and the integration of knowledge from different development actors. The United Nations initiative on Global Geospatial Information Management (UN-GGIM) emphasises this notion by strengthening the institutional arrangements of countries on geospatial information management through integrated geospatial data, particularly georeferenced maps (UN-GGIM, 2018). However, as the SDGs are not legally binding, states should take the responsibility to establish a national framework to achieve the SDGs (Janoušková et al., 2018). They should be able to adapt and localise the targets and indicators of SDGs into their country policies, from the national level to the rural or community levels, including to ensure the availability of geospatial data to support the implementation of SDGs at different levels of governmental structures (Kent et al., 2020; Scott \& Rajabifard, 2017).

For many countries, localising SDGs could be troublesome as it requires operationalised indicator frameworks, which should be applicable in a specific context (Janoušková et al., 2018). The same challenge can also be found in making geospatial data available at the local level, especially in a rural context. Mapmaking is still considered an expensive project. Complex geographical terrain, lack of knowledge and technologies and weak coordination among institutions are issues that restrict governments from producing maps (Ambarwulan et al., 2018; Patmasari, 2019). Consequently, many countries in the global south are still experiencing a lack of spatial data that visualise the landscape, socio-economic and resource characteristics that are needed for supporting rural development processes, including public participation practices (Akbar, Flacke, Martinez, \& van Maarseveen, 2020a; Eilola et al., 2019).

In public participation practices, scholars are still confronted with how to better integrate various spatial knowledge owned by diverse stakeholders (Akbar, Flacke, Martinez, \& van Maarseveen, 2020b; Bradley, 2018; Natarajan, 2017). Scholars suggest the utilisation of visualised geospatial data, such as maps, to integrate the diverse 
spatial knowledge of stakeholders, as they are useful in facilitating communication and collaboration among diverse participants with different backgrounds, interests, influence and knowledge (McCall, 2003; McCall \& Dunn, 2012; Pfeffer et al., 2015). Over the past decades, the rapid advancement of geo-technologies, referring to geoinformation technologies or the tools that we use to obtain or process the geospatial data, e.g., a maptable, GIS software (Pfeffer et al., 2015), has made the production of maps more accessible and reliable. However, operational approaches to optimise stakeholders' spatial knowledge in mapmaking processes are often lacking (Akbar, Flacke, Martinez, \& van Maarseveen, 2020b; Kahila-Tani et al., 2019; Manrique-Sancho et al., 2018).

Chambers (1994a) proposed a Participatory Rural Appraisal (PRA) approach that involves rural stakeholders in the data collection and mapmaking processes. The involvement of stakeholders by means of participatory mapping could help to integrate their spatial knowledge while also enabling them to use their spatial knowledge properly in decision-making processes (Burdon et al., 2019; Corbett et al., 2016; McCall et al., 2015). Participatory mapping methods have been widely used in various development contexts, as they do not confine the maps produced to geographic information, but also include the social, cultural and historical knowledge of the local people (Chambers, 2006). The approach is powerful to solve data scarcity problems and to map rural issues or resources, for mapping rural poverty-prone areas (Ahamed et al., 2009), for mapping flood-prone areas (Kienberger, 2014) or mapping the hunting yields of indigenous people (Smith, 2003), as examples.

Satellite images are often used to involve participants in participatory mapping approaches. Several case studies reported that satellite images helped in visualising a specific area from a sky view in the photomap format and enabled the participants to explore their territories. Kienberger (2014) used satellite images in Mozambique to guide participants to orientate themselves on the maps and to draw and highlight potential flood hazards in their living area. Satellite images were also helpful in engaging the participants in mapping the land cover in Panama (Vergara-Asenjo et al., 2015). In Ethiopia, a participatory mapping workshop used satellite images to map the mental models of shepherds, choosing their grazing areas (Wario et al., 2015). In spatial planning, satellite images were used to map a 
neighbourhood in Yogyakarta to gain better geospatial data, which supports neighbourhood planning practices (Aditya, 2010). These examples show that satellite images were beneficial in helping stakeholders better understand the mapped areas while allowing stakeholders to use their spatial knowledge properly during mapmaking processes.

Producing maps collaboratively could trigger knowledge co-production and social learning among involved workshop participants (Miranda Sara et al., 2016; Shrestha et al., 2017). A participatory approach that provides spatial data and information support would accommodate a dynamic deliberative process, allowing stakeholders to communicate and collaborate effectively while eliciting and integrating their tacit and explicit knowledge (Perdana \& Ostermann, 2019; Shrestha et al., 2018b; Sutanta et al., 2013). As participatory mapping is considered a renowned approach to obtaining and managing different knowledge sources to produce maps (Martinez et al., 2016), developing an applicable participatory mapping method that can better integrate various types of knowledge owned by stakeholders, as well as meeting the local context, is urgently needed.

Despite the fact participatory mapping has been widely discussed in various studies, there remains a gap as to how to develop a collaborative framework to operationalise the production of geospatial data implied by SDGs' agenda into a local implementation. This chapter addressed this gap by moving beyond the global theoretical framework of SDGs into a localised operationalisation at the rural scale. We developed a novel collaborative spatial learning framework, which was contextualised from the SDGs agenda into a local-rural context. We applied the framework through participatory mapping workshops in three villages in the Deli Serdang district, Indonesia. The workshops would not only produce georeferenced village maps but also fulfil the SDGs' specific emphasis in the participatory process to create geospatial data in a participatory manner. Therefore, we conducted mapping workshops that enable the integration of stakeholders' spatial knowledge, facilitate their communication and collaboration and lead stakeholders in knowledge co-production and social learning processes. We used different participatory mapping approachesdigital and non-digital-to compare the strengths and limitations of both approaches in engaging participants in a mapmaking process. Based on the above arguments, this chapter aimed to investigate to 
what extent our collaborative spatial learning framework helps in pursuing SDGs and localising SDGs at the rural scale. To reach this goal, we established three main questions:

- To what extent does the collaborative spatial learning framework enable village stakeholders to better understand sustainable development issues at the local-rural level?

- To what extent does the collaborative spatial learning framework help to integrate the spatial knowledge of the village stakeholders?

- What challenges do occur when participants from rural communities are engaging in mapping tasks using non-digital mapping tools and digital ones?

This chapter is organised as follows: Section 4.1 gives an overview of the relevance of spatial knowledge integration in achieving SDGs. Section 4.2 describes a case study and the implementation of the participatory mapping workshops. Section 4.3 describes the results, whereas Sections 4.4 and 4.5 discuss the lessons learned and the conclusions of the study.

\subsection{Eliciting spatial knowledge to achieve global goals}

Most sustainable development challenges are highly related to places and geographical locations and involve various stakeholders in nature (Scott \& Rajabifard, 2017). Therefore, UN-GGIM has established nine main strategies to achieve an integrated geospatial information framework to support countries in reaching global goals (UN-GGIM, 2018). One of the key strategies is community and engagement, which emphasises the importance of public participation in reaching global goals.

In public participation practices, the stakeholders involved commonly have different types and levels of spatial knowledge (Akbar, Flacke, Martinez, \& van Maarseveen, 2020b; Ishikawa \& Montello, 2006; Pfeffer et al., 2013). They are also diverse in terms of their background, influence and interests when engaging in participatory processes and using their spatial knowledge (Mostert, 2003; Osti, 2015). This diversity provides opportunities for them to learn together while utilising and exchanging their spatial knowledge (Natarajan, 2017). Participating in a collaborative mapping activity might help them to 
better integrate their spatial knowledge and co-produce knowledge while also promoting social learning (Akbar, Flacke, Martinez, \& van Maarseveen, 2020b; Flacke et al., 2020; McCall \& Dunn, 2012).

Thus, to achieve knowledge co-production and social learning experiences, good communication and collaboration among stakeholders are crucially needed. Therefore, the participatory mapping activity should enable communication and collaboration processes among the stakeholders involved. The communication component is successfully achieved when (a) diverse knowledge is used during mapping processes (Bradley, 2018; Flacke et al., 2020); (b) communication is fair and open to all participants (Mostert et al., 2007) and (c) participants can elicit and share their tacit and explicit knowledge (Aditya, 2010; McCall \& Dunn, 2012).

Collaboration is another critical factor that enables knowledge coproduction and social learning among multi-stakeholders (Elwood, 2006b; Pahl-Wostl et al., 2007). Dialogue among participants is collaborative when participants: (a) appreciate others' perspectives by acknowledging that each participant has their own knowledge that may be distinct from one another (Webler et al., 1995); (b) gain new knowledge when stakeholders share, and exchange knowledge during interactions (Bradley, 2018); (c) decide to get involved in a joint data/information activity, such as participatory mapping (Aditya, 2010; Flacke et al., 2020).

Good communication and collaboration during participatory mapping would provide a context where stakeholders are able to co-produce spatial knowledge. Nonaka and Takeuchi (1995) suggested knowledge production as a circling process that involves two types of knowledge: explicit and tacit knowledge. The shift from tacit knowledge into explicit knowledge occurs through four key phases. First, socialisation of knowledge (tacit with tacit), where individuals are aware that each individual has tacit knowledge that is often unspoken or implicit (Nonaka \& Takeuchi, 1995). Second, externalisation (tacit with explicit) occurs when individuals in the group start to share their tacit knowledge with other participants (Aditya, 2010; Elwood, 2006b). Third, the combination (explicit with explicit) appears when interpersonal trust is built within the group during the mapmaking process (Shrestha et al., 2018a). Fourth, internalisation (explicit with 
tacit) is achieved when participants are ready to take collective actions during and after codifying their knowledge (Kahila-Tani et al., 2019).

Another output of the participatory mapping activity is the social learning experience. This occurs whenever multi-stakeholders with different interests, influences and perspectives acknowledge their differences, sit together in a dialogue and then deal with their disputes and conflicts to achieve a common purpose (Mostert et al., 2007). Thus, at this stage, participants are expected to gain learning experiences individually and within a group. Through the learning environment, participants begin to think systematically and holistically (Dana \& Nelson, 2012; Johnson et al., 2012; Shrestha et al., 2018a), create collaborative relationships (Schusler et al., 2003; Webler et al., 1995) and develop a common understanding within the group (Eilola et al., 2019; Schusler et al., 2003).

To better conceptualise a collaborative spatial learning framework to support SDGs' operationalisation, we proposed a framework that would integrate the spatial knowledge of the stakeholders, as can be seen in Figure 4-1 below.

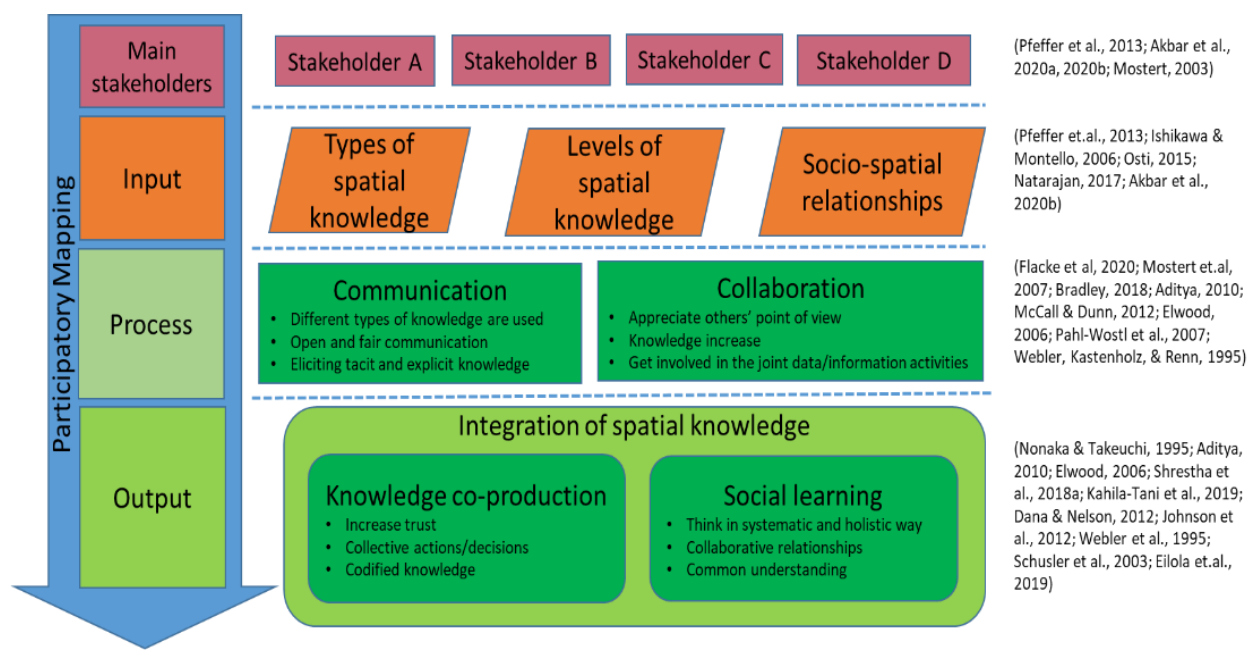

Figure 4-1. The collaborative spatial learning framework

The framework is divided into four main stages. Diverse stakeholders with different types and levels of spatial knowledge and socio-spatial relationships will work collaboratively in a participatory mapping workshop. The process stage would allow diverse stakeholders with distinct spatial knowledge to elicit their spatial knowledge, communicate and collaborate to produce joint maps in a participatory 
manner. In the next stage, it is expected that stakeholders could integrate their spatial knowledge through knowledge co-production and social learning experiences. Therefore, the involvement of relevant stakeholders as the primary users and beneficiaries of the maps during the mapmaking process is fundamental. These created maps should fit the local context (Schlossberg \& Shuford, 2005), and mapping activity should be doable, particularly for participants with little or no experience with mapping technologies (Eilola et al., 2019). For these purposes, satellite images will be used in the mapping workshops because it could help different stakeholders to better understand the mapped areas while allowing them to use their spatial knowledge effectively during mapmaking processes (Kienberger, 2014).

\subsection{Implementation of the collaborative spatial learning framework}

\subsubsection{Context}

This research was developed in the context of public participation practices in rural Indonesia, which is known as the Musrenbang. The Musrenbang is a participatory planning and budgeting practice held annually to formulate and produce the planning and budgeting documents (Akbar, Flacke, Martinez, \& van Maarseveen, 2020a). Problems of the Musrenbang include limited knowledge sharing or integration among stakeholders (Akbar, Flacke, Martinez, \& van Maarseveen, 2020a; Antlöv, 2003), power relations among participants (Grillos, 2017) and lack of data availability, particularly visualised geospatial data to support Musrenbang participatory planning practices (Feruglio \& Rifai, 2017).

In Indonesia, the laws 6-year 2014 stated that each village must have at least three maps, namely, a satellite image map, facilities/infrastructure map and land-use map. The government needs these maps for determining legal boundaries, supporting village development, deciding on village allocation funds (Patmasari, 2019) and supporting Musrenbang practices (Feruglio \& Rifai, 2017). Until 2019 , there were only 31,147 villages out of 83,436 villages in Indonesia that have been delineated in the village boundary map format (Abidin, 2019). Consequently, in the Musrenbang 
implementation, it is hard to find such data used to support the stakeholders' discussions. Limited funding for mapping the whole village, diverse geographical terrain, a lack of expertise and technologies for producing maps and a lack of coordination among institutions are the main limitations that inhibit governments from producing village maps (Ambarwulan et al., 2018).

The framework of this study was implemented by applying participatory mapping workshops in three villages in the Deli Serdang district, Indonesia, namely, the Kramat Gajah, Kolam and the Denai Lama villages. All three villages did not have village maps, only a village sketch map hanging on the wall of each village office that was produced between the 1970s-1990s. Since the upper governments were unable to provide the villages with maps that had an accurate scale and coordinates, the current sketch village maps were useless to support decision-making processes in the villages.

\subsubsection{Workshop design and implementation}

This chapter followed a participatory design approach by involving the Musrenbang village stakeholders in the design phase and the implementation of the mapping workshops (Moore \& Elliott, 2016; Vaughn \& Jacquez, 2020). In previous steps, activities, such as focus group discussion, questionnaire and semi-structured interviews with the village stakeholders, were conducted to elicit their opinions and ideas about the Musrenbang and the potential of spatial knowledge and geospatial data to improve the current village Musrenbang practices (Aguilar et al., 2021; Akbar, Flacke, Martinez, \& van Maarseveen, 2020a, 2020b). This involvement allowed the researcher to construct the collaborative spatial learning framework and to create the design of the participatory mapping workshops. Based on the results and findings of the previous work, we decided to capture the local knowledge of the stakeholders by applying image interpretation techniques through photo-mapping, supported with a sketch mapping method. The participants of the workshop drew their knowledge on existing satellite images using two different methods. They could draw the maps digitally by using a computer touchscreen and non-digitally by using analogue, traditional tools, such as transparent layers, markers and stickers. 
There are various techniques in participatory mapping from low-cost and straightforward methods to high-cost and sophisticated techniques (Pánek, 2015a; Vergara-Asenjo et al., 2015). As this study was built on previous studies on improving public participation practices by utilising the spatial knowledge of the stakeholders (Akbar, Flacke, Martinez, \& van Maarseveen, 2020a, 2020b), we conducted a participatory research design to gain insights from the village stakeholders when deciding the most suitable methods (Moore \& Elliott, 2016; Vaughn \& Jacquez, 2020). We did an experiment with the village stakeholders during interviews and focus group discussions by showing them several participatory mapping methods and tools, such as sketch mapping, drones, maptable and photo-mapping, to find out what worked best for them. Based on that experiment, most of our respondents preferred photo-mapping as the most convenient method for them to identify and draw their villages on maps. This finding was the main reason for using photo-mapping, understood as scale mapping activities using an aerial photograph or satellite images of the study area (Pánek, 2015a), as the primary method. Additionally, sketch mapping was used as the supplementary method to prepare the participants before the photo-mapping activities.

We applied the framework through three different participatory mapping workshops between October-November 2019. In each workshop, we used a Worldview high-resolution satellite image of each village. The satellite image data were taken between January-May 2019. Map symbols, lines, colours and other technical specifications required for the production of the village maps followed the guidelines of the Head of Geospatial Information Agency (BIG) regulation 3-year 2016 (Patmasari, 2019).

We applied two different types of mapping methods in the participatory mapping workshops to identify the strengths and limitations of each technique during the participatory mapping activities. The Kolam village used a non-digital participatory mapping method; this nondigital approach consisted of using transparent plastic layers above printed satellite images, and the participants drew their village maps on the plastic sheets using markers and stickers. In the Kramat Gajah village and Denai Lama villages, we used a digital participatory mapping method using an application called OGITO (Open Geospatial Interactive Tool), which is an open-source software application designed to support collaborative spatial planning processes with a 
maptable (Aguilar et al., 2020, 2021). The application displayed the satellite image on a touchscreen monitor, and the participants drew the maps by touching the screen with their fingers on top of it (Figures 4-2 and 4-3). The features of the application were written in the local language (Bahasa Indonesia) to ease the participants to understand and use the OGITO. The name OGITO was derived from the words 'Oh Gitu', meaning 'Oh, I got it' or 'Okay, I understand' in Bahasa Indonesia. It was inspired by the reactions of some participants when using the tool during the mapmaking process. When they managed to use the tool or they showed an understanding of something or the tasks given, they would say these words.

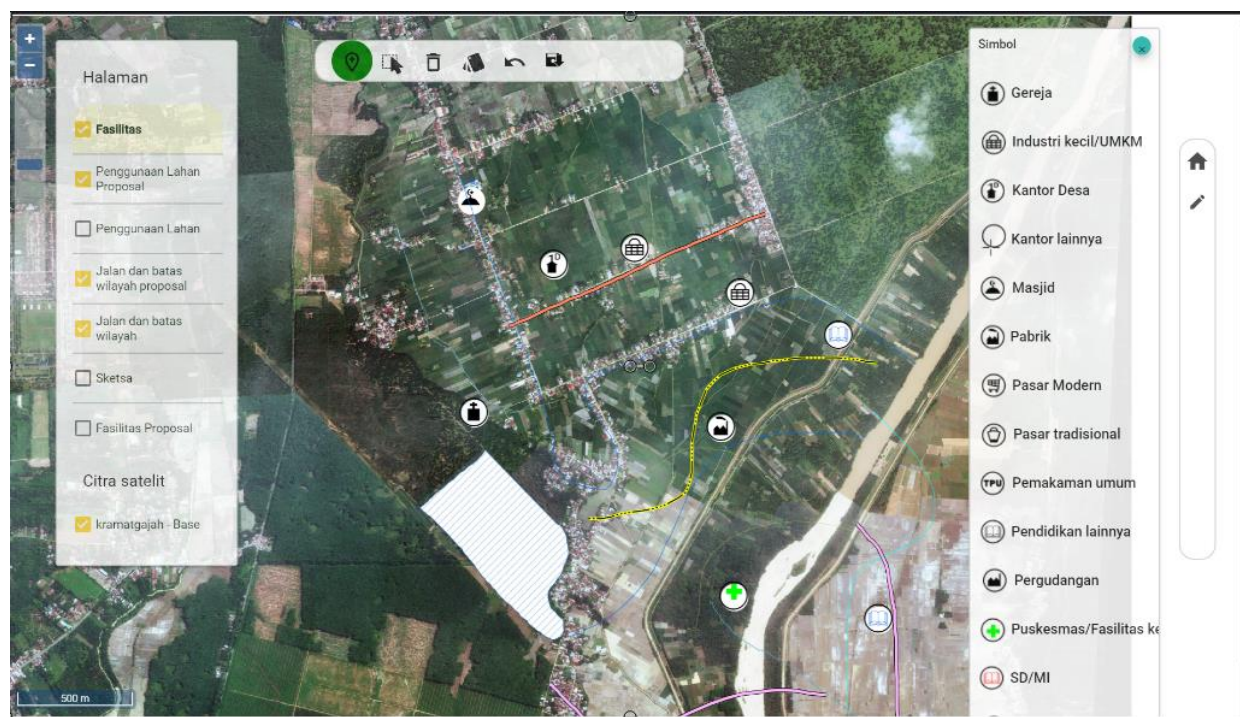

Figure 4-2. The OGITO (Open Geospatial Interactive Tool) application displayed on a maptable screen

A maptable used for digital mapping. It had a display size of 27-inches. As a result, fewer participants could participate at the same time around the table in the digital mapping workshop than the non-digital mapping method (Figure 4-3). The number of participants was limited to a maximum of eight participants for the digital mapping and 40 participants for the non-digital mapping to ensure the effectiveness of the workshops. The participants represented the stakeholder groups who participated in the village Musrenbang, which consisted of the village head, village secretary, village council (BPD), village empowerment board (LKMD), community leaders, youth group (Karang Taruna) and women group (PKK). Furthermore, we only 
considered the representativeness of the village stakeholders' groups regardless of age, educational level and mapping experiences of the participants. We limited the participants of the workshops to the representatives of the stakeholder groups who attended the Musrenbang implementation because we wanted to keep the participants in the mapping workshops as similar as possible with the participants in the real Musrenbang situation. We did not interfere with the existing power structures within the village, i.e., the villagers took the decisions of who should be invited to the workshops based on a list that we provided. Based on this list, the village officials had an internal discussion with other stakeholders in the village to decide on the participants who would become the representatives of each stakeholder group and then invited them to the workshops.

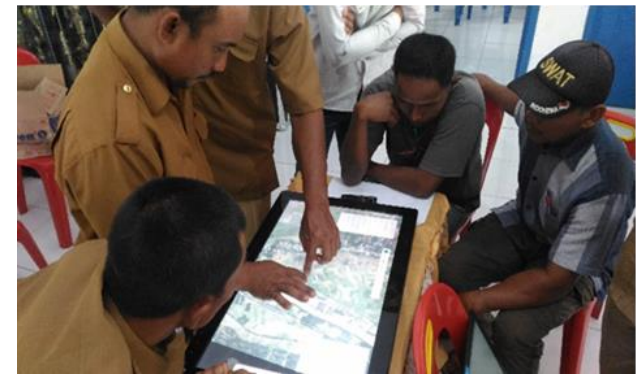

(a)

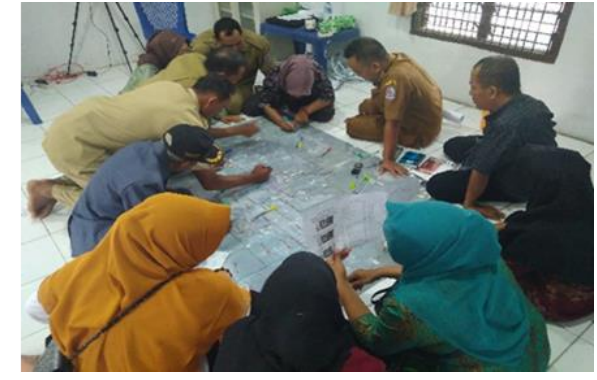

(b)

Figure 4-3. Digital participatory mapping workshop in the Denai Lama village (a), and non-digital mapping workshop in the Kolam village (b).

At the day of implementation, we had more participants for the digital workshops because the village officials invited more people to their workshops. However, it appeared that not all participants were able to attend the workshops, especially women participants in Kramat Gajah and Denai Lama. The workshops in Kramat Gajah and Denai Lama were followed by 10 and 16 participants, respectively; all participants were males. The workshop in Kolam village was attended by 30 participants, 15 males and 15 females. The profile of the participants in all villages can be seen in Appendix J.

Each mapping workshop was implemented in the village hall, and participants spent close to one full day for the implementation-five hours in Kramat Gajah and eight hours at the Kolam and Denai Lama villages. At least three facilitators were needed in the digital workshops for (a) moderating the discussion and guiding the mapping process; (b) providing technical assistance; (c) recording the workshop using 
videos, audios and observation notes. The non-digital workshops needed five facilitators, as three facilitators guided the participants (one per group) to draw maps, while the other two served as technical support and recorded the mapping sessions.

The workshop was implemented in the local language (Bahasa Indonesia) to ease communication among participants. During the workshops, the Javanese language was also used by the participants since the dominant population of the villages are Javanese. The facilitator who moderated the workshops is Indonesian, and he understood the local languages (Bahasa Indonesia and Javanese languages) as well as the cultural background of the participants. A script of workshop activities was also prepared to moderate the sequences of the workshop implementation (Figure 4-4) to have consistency in the sequence of activities in each group. The script was tested in three preliminary workshops and refined to meet the real context of the place where the workshops were undertaken.

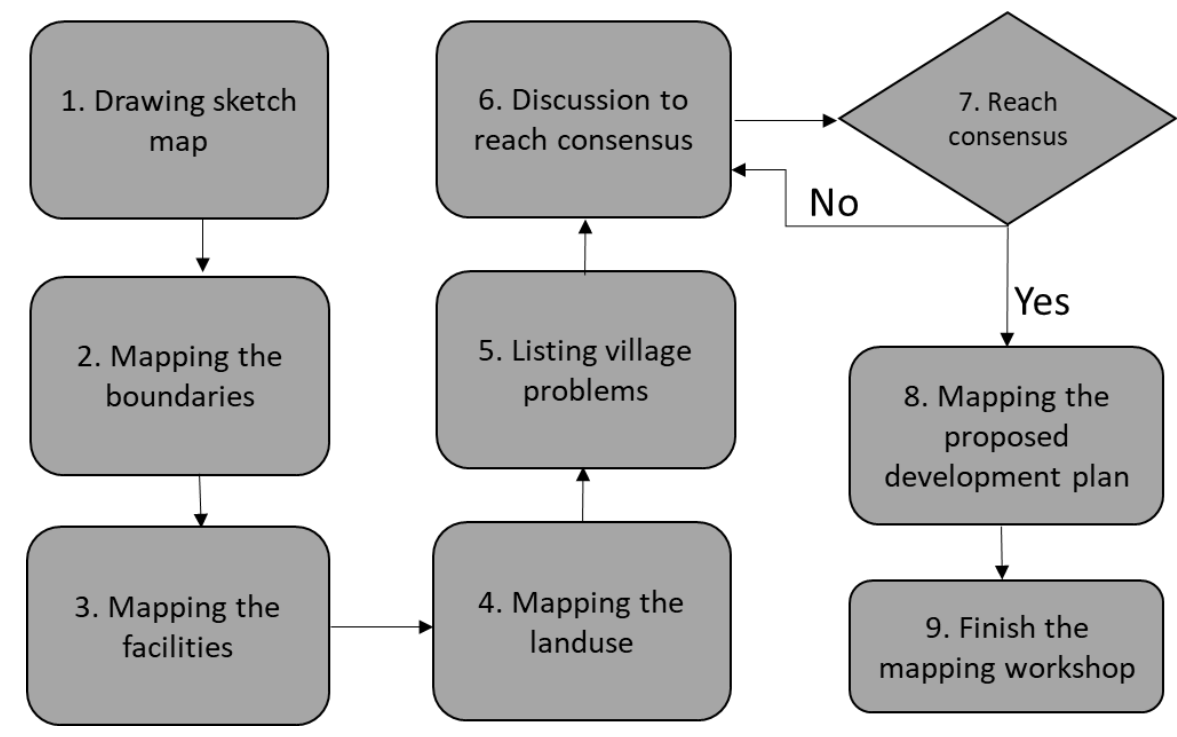

Figure 4-4. The sequence of activities in the participatory mapping workshops

In both mapping approaches, the session began with an introduction of the workshop and the study area. The participants were asked to manually draw their villages in a sketch map using a pen and a blank sheet of paper (No. 1). Thereafter, they were asked to compare and discuss their drawings in a group. This activity was intended to raise the participants' awareness of their local knowledge about their villages 
so they would be more prepared when doing the real drawing using the mapping tools. The moderator gave a short explanation about the steps and mapping tools and then guided the participants in each mapping session (No. 2-4). Again, we asked the participants to identify and write down three main village problems individually (No. 5), followed by a group discussion to formulate possible development plans to solve the problems (No. 6). Thereafter, there was a group discussion to reach a consensus on five to ten proposed development plans (No. 6-7). Then, they were asked to draw the proposed development plans into the map (No. 8). At the end of the session, a short group discussion was conducted to reflect on their learning experiences and to complete a questionnaire (Appendix K).

\subsubsection{Workshop analysis}

We used a list of assessment criteria and means of verification to evaluate the implementation of mapping workshops in integrating the participants' spatial knowledge by enabling communication, collaboration, knowledge co-production and social learning among the participants (Table 4-1). Data for analysis were collected from four sources, namely, the village maps produced during the mapping session, observations (through voice recording, video recording and observation notes), a short-group discussion immediately after the workshop, a post-session questionnaire and semi-structured interviews with selected participants after the workshops. 
Table 4-1. Assessment criteria and means of verification

\begin{tabular}{|c|c|c|}
\hline & Assessment criteria & Means of verification \\
\hline \multicolumn{3}{|c|}{ Process } \\
\hline \multicolumn{3}{|c|}{ Communication } \\
\hline 1 & Different types of knowledge used & Questionnaire, observations \\
\hline 2 & Open and fair communication & Questionnaire, observations \\
\hline 3 & Eliciting tacit and explicit knowledge & $\begin{array}{l}\text { Questionnaire, group discussion, } \\
\text { observations }\end{array}$ \\
\hline \multicolumn{3}{|c|}{ Collaboration } \\
\hline 4 & Appreciate others' point of view & Interviews, observations \\
\hline 5 & Knowledge increase & Interviews, group discussion, observations \\
\hline 6 & Producing joint data/information & Questionnaire, interviews, observations \\
\hline \multicolumn{3}{|c|}{ Output } \\
\hline \multicolumn{3}{|c|}{ Knowledge co-production } \\
\hline 7 & Increase trust & Questionnaire, interviews \\
\hline 8 & Collective actions/decisions & Questionnaire, interviews \\
\hline 9 & Codified knowledge & Group discussion, village map produced \\
\hline \multicolumn{3}{|c|}{ Social learning } \\
\hline 10 & Think in a systematic and holistic way & Questionnaire, interviews \\
\hline 11 & Collaborative relationships & Questionnaire, interviews \\
\hline 12 & Common understanding & Questionnaire, interviews \\
\hline
\end{tabular}

The village maps captured the interactions between participants to integrate their spatial knowledge during the mapmaking process. The observations consisted of video, audio recording and observation notes so that the authors could recall and reflect on the workshop implementation when analysing the data. A self-reported questionnaire collected participants background, expectations and reflections on the workshop using a five points Likert scale (Bryman, 2012). All participants filled out the post-session questionnaire except for one participant from the Kolam village, who left the workshop early before the session ended. A short group discussion was held to gain participants' opinions about the workshops, and both were held directly after each mapping workshop. We also conducted in-depth semistructured interviews to obtain additional information about the mapping workshops (Appendix $L$ ). We interviewed 15 respondents in the Kolam village, nine respondents in Denai Lama, and eight respondents in Kramat Gajah. Furthermore, we analysed the data through content analysis (Bryman, 2012) using ATLAS.ti. To fulfil the 
European General Data Protection Regulation-GDPR (https://gdprinfo.eu/), we always asked participants for their informed consent for using the audios, videos, pictures and questionnaire for research and publications before the data collection (Aguilar et al., 2020).

\subsection{Insights from the participatory mapping workshops}

The presentation of the results has been divided into two parts. First, in the process stage, we discussed communication and collaboration among stakeholders. Second, we discussed knowledge co-production and social learning processes in the output stage.

\subsubsection{Process stage: Enabling communication and collaboration}

Our findings showed that both approaches-the digital and non-digital workshops-supported communication and collaboration among the participants. The sketch mapping technique conducted at the beginning of the workshops was useful to prepare the participants before engaging in the scale mapping activity. It allowed participants to freely draw sketches of their village and to compare their drawings with their peers, and thus triggered communication and collaboration among them. The participants enthusiastically tried to combine their sketch maps to form their village, which brought positive influence to the next stage when they started to draw on the satellite images. The sketch map built their awareness about their local knowledge and prepared them mentally when engaging with the photomap activities.

The satellite images used in both workshops functioned as a platform for the participants to explore and navigate themselves in their villages. They were helpful by stimulating communication among participants, particularly when exploring or clarifying specific places around the villages. The results of the questionnaire indicated that both workshops (digital and non-digital methods) were quite useful to provide fair and open communication among participants (Table 4-2). 
Table 4-2. Participants' responses to the communication stage of the workshops

\begin{tabular}{|c|c|c|c|c|c|c|}
\hline \multirow[t]{2}{*}{ Questionnaire } & \multirow[t]{2}{*}{ Villages } & \multicolumn{5}{|c|}{$\begin{array}{c}\text { Responses in the self-questionnaire (in } \\
\text { numbers and \%) }\end{array}$} \\
\hline & & SA & $\mathbf{A}$ & $\mathbf{N}$ & D & SD \\
\hline \multirow{3}{*}{$\begin{array}{l}\text { The participants discussed } \\
\text { the issues in an open way }\end{array}$} & Kramat Gajah & $5(50 \%)$ & $5(50 \%)$ & 0 & 0 & 0 \\
\hline & Denai Lama & $8(50 \%)$ & $8(50 \%)$ & 0 & 0 & 0 \\
\hline & Kolam & $13(45 \%)$ & $16(55 \%)$ & 0 & 0 & 0 \\
\hline I can articulate my & Kramat Gajah & $4(40 \%)$ & $6(60 \%)$ & 0 & 0 & 0 \\
\hline opinions during the & Denai Lama & $5(31 \%)$ & $10(63 \%)$ & $1(6 \%)$ & 0 & 0 \\
\hline mapping workshop & Kolam & $11(38 \%)$ & $18(62 \%)$ & 0 & 0 & 0 \\
\hline Each participant has the & Kramat Gajah & $4(40 \%)$ & $6(60 \%)$ & 0 & 0 & 0 \\
\hline same opportunities to & Denai Lama & $8(50 \%)$ & $8(50 \%)$ & 0 & 0 & 0 \\
\hline share their knowledge & Kolam & $12(41 \%)$ & $15(52 \%)$ & $2(7 \%)$ & 0 & 0 \\
\hline
\end{tabular}

Most participants also gave positive responses that the workshops were helpful in expressing their opinions (Table 4-2). However, there was one participant in Denai Lama who gave a neutral response. It seems that the number of participants in the digital mapping workshop affected the participants' chances to have a say in the workshop. Reflecting on the digital workshops, having more than eight people working around a 27-inch map table might not be convenient for some participants.

We also found that the majority of participants gave positive responses concerning they had the same opportunities to share their knowledge in the workshop (Table 4-2). In the interview, A9 said," There was no problem in communication. The mapping workshop was running well. The [tool helped] communication getting better" (A9, personal communication, 18 February 2020).

Regarding collaboration among participants, both methods also got positive feedback. Most respondents in all of the villages also gave positive responses towards the statement that other participants listened to what they had to say (Table 4-3), indicating that they actively engaged in the mapping workshops, and their opinions received proper attention from other participants. However, in the Kolam village, there were three participants who responded neutrally to the question that other participants listened to them during the workshop. In this village, each working group was separated only by 3-4 $\mathrm{m}$ from the other groups, and the village hall was noisy due to the short distance. This might explain why three participants in Kolam village responded neutrally to the question. Besides, in the postdiscussion session, a participant expressed that sometimes they could not hear what other participants' were saying due to the noise. 
Knowing my village from the sky

Table 4-3. Participants' responses to the collaboration stage of the workshops

\begin{tabular}{|c|c|c|c|c|c|c|}
\hline \multirow[t]{2}{*}{ Questionnaire } & \multirow[t]{2}{*}{ Villages } & \multicolumn{5}{|c|}{$\begin{array}{c}\text { Responses in the self-questionnaire (in } \\
\text { numbers and \%) }\end{array}$} \\
\hline & & SA & $\mathbf{A}$ & $\mathbf{N}$ & D & SD \\
\hline \multirow{3}{*}{$\begin{array}{l}\text { Other participants at } \\
\text { the workshop listened } \\
\text { to what I said }\end{array}$} & Kramat Gajah & $2(20 \%)$ & $8(80 \%)$ & 0 & 0 & 0 \\
\hline & Denai Lama & $2(13 \%)$ & $13(81 \%)$ & $1(6 \%)$ & 0 & 0 \\
\hline & Kolam & $11(38 \%)$ & $15(52 \%)$ & $3(10 \%)$ & 0 & 0 \\
\hline \multirow{3}{*}{$\begin{array}{l}\text { My knowledge about } \\
\text { my village increased }\end{array}$} & Kramat Gajah & $6(60 \%)$ & $4(40 \%)$ & 0 & 0 & 0 \\
\hline & Denai Lama & $8(50 \%)$ & $8(50 \%)$ & 0 & 0 & 0 \\
\hline & Kolam & $16(55 \%)$ & $13(45 \%)$ & 0 & 0 & 0 \\
\hline
\end{tabular}

Table 4-3 also indicates that all workshops were a success in increasing the participants' knowledge about their villages. Even though seeing their village from the sky might be new for most participants, the satellite images proved to be effective in helping the participants to orientate and explore their villages. For example, in the interviews, respondents C4 stated, "Especially the boundaries. The satellite images clearly showed our villages, showed the village boundaries, [we can identify] the rice field [owners] and the borders. It was clear, very clear" (C4, personal communication, 7 February 2020); while respondent $\mathrm{B} 1$ conveyed.

"The satellite images used in the workshop displayed the real situation of our village, and we worked together to identify and draw the data [boundaries, facilities, land use]. The workshop was helpful to sharpen our area knowledge and to fully understand our administrative area" (B1, personal communication, 28 January 2020).

The satellite images were also beneficial in increasing the participants' knowledge about their villages and current geo-technologies, as implied by respondent A7, "I feel that my knowledge increased, especially with the [current map] technologies. It is getting easier [to use]" (A7, personal communication, 18 February 2020). The participants also expressed that the satellite images enabled them to think critically towards the information provided in the images. For instance, respondent B3 stated that the satellite images helped them to identify the changes of land use around their villages, "We get to know the village boundaries and also the land-use changes in our village. For example, I found a certain location, which was previously a rice field that had changed into settlements" (B3, personal communication, 12 February 2020). 
The responses from participants confirmed the benefits of using satellite images in participatory mapping workshops. The true-colour composite of the satellite image that displayed natural colours enabled participants to better identify and explore their villages from the sky view. These benefits would be advantageous for them to better coproduce their spatial knowledge while experiencing social learning.

\subsubsection{Output stage: Experiencing knowledge co-production and social learning while creating village maps}

Insights from the questionnaire and the short group discussion confirmed that both mapping methods were useful in motivating knowledge co-production among participants. They were able to actively contribute to each session of the workshops, codifying their spatial knowledge into the village maps. Participants reported that their trust in other participants increased after they collaborated in the mapping workshops (Table 4-4). This could be a good indicator that they would be able to collaborate on other projects, including in the Musrenbang public participation practices.

Table 4-4. Participants' responses on knowledge co-production processes during the workshops

\begin{tabular}{|c|c|c|c|c|c|c|}
\hline \multirow[t]{2}{*}{ Questionnaire } & \multirow[t]{2}{*}{ Villages } & \multicolumn{5}{|c|}{$\begin{array}{c}\text { Responses in the self-questionnaire (in } \\
\text { numbers and \%) }\end{array}$} \\
\hline & & SA & $\mathbf{A}$ & $\mathbf{N}$ & D & SD \\
\hline \multirow{3}{*}{$\begin{array}{l}\text { After this workshop, my } \\
\text { trust in other participants } \\
\text { increased }\end{array}$} & Kramat Gajah & $5(50 \%)$ & $5(50 \%)$ & 0 & 0 & 0 \\
\hline & Denai Lama & $3(19 \%)$ & $12(75 \%)$ & $1(6 \%)$ & 0 & 0 \\
\hline & Kolam & $11(38 \%)$ & $18(62 \%)$ & 0 & 0 & 0 \\
\hline \multirow{3}{*}{$\begin{array}{l}\text { I believe that the maps we } \\
\text { produced would be useful } \\
\text { for village development }\end{array}$} & Kramat Gajah & $8(80 \%)$ & $2(20 \%)$ & 0 & 0 & 0 \\
\hline & Denai Lama & $10(63 \%)$ & $6(38 \%)$ & 0 & 0 & 0 \\
\hline & Kolam & $21(72 \%)$ & $8(28 \%)$ & 0 & 0 & 0 \\
\hline \multirow{3}{*}{$\begin{array}{c}\text { I would recommend using } \\
\text { maps during the } \\
\text { Musrenbang practice }\end{array}$} & Kramat Gajah & $7(70 \%)$ & $3(30 \%)$ & 0 & 0 & 0 \\
\hline & Denai Lama & $7(44 \%)$ & $9(56 \%)$ & 0 & 0 & 0 \\
\hline & Kolam & $18(62 \%)$ & $11(38 \%)$ & 0 & 0 & 0 \\
\hline
\end{tabular}

Most participants also stated their agreement by taking collective actions to use the maps produced during the next Musrenbang practice (Table 4-4). In the interview, respondent C8 said, "The implementation of Musrenbang will be much better. Previously, we could only guess where the exact location of the topic being discussed was. Now, we will be able to see the sites [as they will be] displayed on the village maps" (C8, personal communication, 11 February 2020). 
The satellite images used in the digital and non-digital mapping workshops were helpful for the participants to work collaboratively by integrating and co-producing their spatial knowledge. For most participants, seeing their village displayed on a satellite image was something new for them. Thus, the satellite images helped them to better understand their village, facilitated the discussion and collaboration, while also co-producing their village maps, as required by the laws.

Regarding the social learning process, most of the participants expressed that they were able to work collaboratively as a group when doing the mapping exercises, which was indicated by most participants who chose "Strongly Agree" and "Agree" responses on the questionnaire (Table 4-5). Respondent A8 said, "We collaborated. Let me tell you why, when one participant drew a line, another participant checked the line, [if there were mistake] they corrected line, the line should be moved to this area, for example" (A8, personal communication, 18 February 2020).

Table 4-5. Participants' responses on social learning processes during the workshops

\begin{tabular}{|c|c|c|c|c|c|c|}
\hline \multirow[t]{2}{*}{ Questionnaire } & \multirow[t]{2}{*}{ Villages } & \multicolumn{5}{|c|}{$\begin{array}{c}\text { Responses in the self-questionnaire (in numbers and } \\
\% \text { ) }\end{array}$} \\
\hline & & SA & A & $\mathbf{N}$ & D & SD \\
\hline \multirow{3}{*}{$\begin{array}{l}\text { We collaborated } \\
\text { as a team to } \\
\text { produce the } \\
\text { village maps }\end{array}$} & $\begin{array}{l}\text { Kramat } \\
\text { Gajah }\end{array}$ & $10(100 \%)$ & 0 & 0 & 0 & 0 \\
\hline & Denai Lama & $5(31 \%)$ & $11(69 \%)$ & 0 & 0 & 0 \\
\hline & Kolam & $12(41 \%)$ & $17(59 \%)$ & 0 & 0 & 0 \\
\hline \multirow{3}{*}{$\begin{array}{l}\text { We learned from } \\
\text { each other } \\
\text { during the } \\
\text { mapping } \\
\text { workshop }\end{array}$} & $\begin{array}{l}\text { Kramat } \\
\text { Gajah }\end{array}$ & $7(70 \%)$ & $3(30 \%)$ & 0 & 0 & 0 \\
\hline & Denai Lama & $8(50 \%)$ & $8(50 \%)$ & 0 & 0 & 0 \\
\hline & Kolam & $18(62 \%)$ & $11(38 \%)$ & 0 & 0 & 0 \\
\hline \multirow{2}{*}{$\begin{array}{c}\text { We identified the } \\
\text { villages' } \\
\text { underlying } \\
\text { problems }\end{array}$} & $\begin{array}{l}\text { Kramat } \\
\text { Gajah }\end{array}$ & $1(10 \%)$ & $8(80 \%)$ & 0 & 0 & $1(10 \%)$ \\
\hline & $\begin{array}{l}\text { Denai Lama } \\
\text { Kolam }\end{array}$ & $\begin{array}{l}5(31 \%) \\
10(34 \%)\end{array}$ & $\begin{array}{l}11(69 \%) \\
16(55 \%)\end{array}$ & $\begin{array}{c}0 \\
2(7 \%)\end{array}$ & $\begin{array}{c}0 \\
1(3 \%)\end{array}$ & $\begin{array}{l}0 \\
0\end{array}$ \\
\hline
\end{tabular}

Most participants also agreed that the workshops enabled them to learn from each other during the mapping processes (Table 4-5). In the digital and non-digital workshops, the session on drawing the boundaries, facilities and land-use maps resulted in the participants eliciting their existing knowledge or mental models. When developing the proposed development maps, the participants were brought into an intense discussion, where they were arguing and reasoning. The participants were then given the opportunity to change or compromise 
their existing knowledge or mental models when they reached a common understanding or consensus.

Positive responses were also given towards the question of learning from each other. From the observations, the learning processes can be seen through how the participants distributed the mapping tasks. The older-aged participants in the digital workshop seemed to be more passive than the older-aged participants in the non-digital workshop. In Kramat Gajah and Denai Lama, younger participants acted as the drawer on a maptable, while the older-aged participants observed their younger colleagues drawing. When we asked for the reasons as to why they did not draw, they responded that the youths were better at drawing, and the drawing tool can only be used by one person at a time when drawing (A9, personal communication, 18 February 2020). Nevertheless, the older-aged participants could still contribute by giving information about boundaries or places that the younger participants did not know, as portrayed in Figure 4-5. Moreover, they were still active by giving or verifying information during the mapping process. Through these interactions, participants exchanged spatial knowledge while increasing knowledge about their villages.

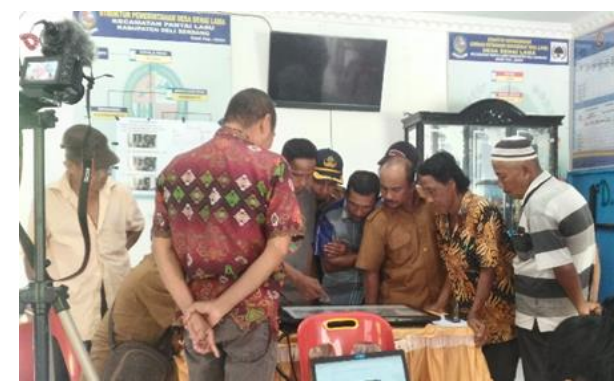

(a)

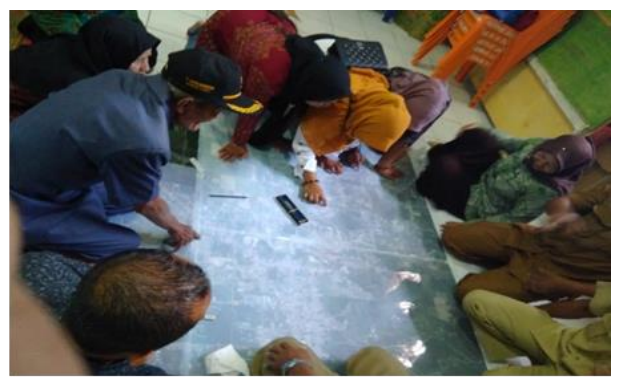

(b)

Figure 4-5. Older-aged participants in Denai Lama were observing and giving advice/additional information to the younger participants (a); The older-aged participants actively engaged in the participatory mapping of the Kolam village while giving additional information that the younger participants might not know (b).

In the non-digital mapping workshop, the collaboration of the olderaged participants was more active during the mapping process. For example, in Figure 4-5, the man wearing the black cap was more than 70 years old, but he was quite active in the mapping process. The task distribution went better than the digital mapping since every participant in the group could work manually and was drawing on the maps at the same time. Figure 4-5 also depicts how the women 
participants actively engaged in the mapping process of the Kolam village, while in the other two villages with digital mapping workshops, women's involvement could not be investigated due to no women participants attending the workshops.

The questionnaire also revealed that most participants agreed that the workshops were helpful in assisting them in identifying the villages' main problems (Table 4-5). However, there were four participants who did not show agreement-one participant in Kramat Gajah and three participants in the Kolam village. In the discussion and interviews, it was revealed that participants were in disagreement because they were confused about the administrative village boundaries. In Kramat Gajah, participants had an intense discussion about the vast plantation area along the river bank. Even though the area is located in the Kramat Gajah village, the village has no rights because the river and the banks are under the control of the central government, as stated in the laws. In the Kolam village, the participants discussed the legal boundaries of a neighbourhood. The area is out of their administration, but all the citizens who live in the area are administratively registered as citizens of the Kolam village. They cannot make decisions about the boundaries, as they have to consult with external parties who were not involved in the workshops, such as the upper government and the adjacent villages. Even when facing confusion, these findings showed that the administrative boundaries play a critical part in assisting the participants in identifying their villages' underlying problems. The discussions that arose from the village boundaries also indicated that the workshops helped participants think systematically beyond the tasks that we provided. The information displayed on the satellite image was powerful in triggering discussions among the stakeholders. Moreover, the mapping workshops were helpful to encourage participants to critically reflect on sustainable development agenda when thinking and acting at the local-village scale. 


\subsection{Discussion}

Proper geospatial data is urgently needed to achieve and monitor the SDGs implementation (Scott \& Rajabifard, 2017). The UN-GGIM promotes this urgent need by encouraging countries to improve their geospatial management strategies and to provide accurate and reliable geospatial data for supporting the development processes (UN-GGIM, 2018). Maps, as the visualised spatial data, play an essential role to address the complex and interlinked issues of SDGs implementation (Kent et al., 2020). However, the application of SDGs is often confronted with problems of contextualisation, concerning global goals, targets and indicators. The operationalisation at the national level is quite challenging, while at the local level, including rural areas, localising the SDGs concept into actions is more challenging (Giuliani et al., 2020; Saner et al., 2019; Scott \& Rajabifard, 2017).

Indonesia, as a country adopting the SDGs in its national policies, faces the same circumstances. The government has launched the One Map Policy aiming to fulfil the geospatial data availability at the national, regional, district/cities and rural levels while supporting the SDGs implementation in Indonesia (Abidin, 2019). Even though village maps are mandated by the laws, up to 2019, there was only about 37 per cent of the village boundaries, which have been delineated (Patmasari, 2019). This percentage should be a warning for the governments to take substantial actions to accelerate the village map production, as time is ticking, and SDGs will end in a few years.

The government, through the Geospatial Information Agency (BIG), has published regulation 3-year 2016 as the guidelines for the village map production. Moreover, the government has also encouraged citizens to contribute actively in the mapmaking processes by launching an application of PetaKita (https://petakita.big.go.id/) to enable citizens to participate in mapping their areas. The utilisation of the app was less successful in engaging citizens due to sophisticated map features, low intuitivity and user-friendliness as it needed to be connected to the internet when using it (Perdana \& Ostermann, 2019). In contrast, other participatory mapping initiatives, which facilitate people to have direct interactions in the mapmaking processes, have better results to engage people to contribute (Aditya, 2010; Corbett, 2009; Corbett \& Keller, 2005). As the SDGs place a specific emphasis on the participatory process, thus encouraging the production of 
geospatial data in a participatory manner, the contextualisation of global and national geospatial data targets into a local-rural scale is necessary. Developing a collaborative spatial learning framework, which has an impact on SDGs, notably on target 11.3 and 16.7 , is urgently needed. For this reason, the participatory mapping workshops used in this chapter emphasised on the process of communication, collaboration, knowledge co-production and social learning during the mapmaking processes.

Our findings showed that the mapping workshops gave significant positive outputs to pursue the SDGs operationalisation at the rural scale while achieving the SDGs and national targets to have proper village maps aiming for sustainable development processes. The workshops also helped village stakeholders to better understand sustainable development issues in the local context. Discussion about waste management, for instance, occurred during the mapmaking processes, although this was not listed in the mapping tasks. Some participants also became aware of the land-use changes in their villages. They criticised the changes by discussing the significant conversion of agricultural areas into settlement areas, which could endanger their main livelihood and thus increase poverty (SDG 1). They also had an intense discussion about the water allocation for their rice fields that might affect not only the farmers in their villages but also farmers in other villages, which used the same water resources (SDG 6). All these topics of discussions might seem simple and with moderate impacts for reaching the SDGs agenda. Still, in reality, it clearly shows how the grass-root citizens react to the SDGs issues, and how they gain awareness about the SDGs, and why it is crucial to apply village development in a sustainable way at the local context. By putting this information and knowledge on maps, the villagers, as the smallest social structure within the governmental hierarchies, have made their contribution to achieving the SDGs agenda (Kent et al., 2020).

Our findings also showed that in the local context, such as rural areas, the digital and non-digital participatory mapping approaches facilitated communication and collaboration among the participants. Moreover, the methods were also useful in integrating the spatial knowledge of the stakeholders while also supporting knowledge co-production and social learning processes. Our results were similar to other studies that showed how the non-digital and digital media of mapping were helpful 
in increasing the spatial understanding of the participants (Collins, 2018; Cunningham, 2005; Rambaldi et al., 2006).

Each mapping method has its own strengths and limitations. Nondigital mapping was powerful in engaging more people to participate, as people with less or no prior experience with digital geo-technologies were able to engage in the process (Eilola et al., 2019). The materials needed for the workshops were less expensive and easy to prepare. However, this method was complicated during the post-processing stage because the researcher needed to work harder to manually convert all the drawn objects from the transparent plastic layer into the digital map format. This method also required a large room for implementation and more facilitators to guide the processes.

In contrast, digital mapping was easy for the map post-processing stage. Fewer mistakes were made because the objects drawn by participants were more comfortable to interpret by the researcher. This method only required a small room and fewer facilitators for implementation. The drawbacks were that fewer people were able to engage due to the size limitations of the computer screen. The development of the mapping application needed particular expertise and was not easy to handle. The technology barrier could also be challenging, particularly for participants with a lack of knowledge or experience with geo-technologies. We should acknowledge that the potential strengths and limitations of using specific mapping approaches are highly context-dependent, beneficial in one situation, but maybe not as helpful in other contexts (Flacke et al., 2020; KahilaTani et al., 2019; Sutanta et al., 2013). Despite the successful implementation of the mapping workshops in this study, some issues need to be adequately managed to achieve excellent participatory mapping workshops.

When selecting a participatory mapping method to use, Corbett (2009) recommended certain factors to be considered, namely, how accurate the final product needs to be; how it will be utilised; the available resources for the mapmaking process. In this study, we chose to use the photo-mapping method by drawing the maps on high-resolution satellite images. The use of high-resolution satellite images for the mapping workshops helped the participants to better engage in the mapping processes while ensuring the maps were produced accurately. The satellite images use a true-colour composite that can display 
objects in the same, natural colours that human eyes would typically see them. Thus, the natural colours helped the participants interpret the information provided on the satellite images (Aditya, 2010; Kienberger, 2014). Using a georeferenced image, such as a satellite image in the participatory mapping workshops, offers more details of the landscape of the villages; therefore, it enhances the participants' spatial and functional understanding of their village areas, even for participants with no previous mapping experiences (Eilola et al., 2019; Giuliani et al., 2020; Pánek, 2015a). In this study, the satellite images increased the participants' understanding of their village, the village boundaries, existing land use and the village infrastructure/facilities.

It is also essential to use the most suitable map scale during the workshops since it might affect the participants' engagement in mapping processes. For digital mapping, the participants can apply the zooming in-out feature to get the most suitable scale when drawing; however, this is not possible in the non-digital mapping workshop. In the non-digital workshop, 1:2500 printed satellite images were used. Using the scale maps drawn on existing scaled satellite images helped the participants interpret the objects more accurately and oriented themselves while viewing the satellite images (Vergara-Asenjo et al., 2015). The scale map drawing was also helpful for post-processing to transform the manual hand-drawing maps into digital maps.

The requirements imposed by the regulations, to some extent, could inhibit the participants from expressing their tacit knowledge. The strict technical specifications required by regulation 3-year 2016, published by the Geospatial Information Agency (BIG), often created confusion for the participants. For instance, when they wanted to draw a specific object on the satellite images, they had to choose the standard lines, symbols and colours imposed by the regulation. The participants often used their local spatial knowledge by expressing uncertain boundaries, shapes or symbolic interpretations when describing the village landscapes (McCall \& Dunn, 2012). By only allowing them to use the standard guidelines, we may lose diverse, valuable, local knowledge and the original information owned by the local people (Rambaldi et al., 2006). Therefore, the mapping method should provide support for the participants to express local knowledge in their own way or even in their own local language. Wartmann and Purves (2017) underlined this issue. They argued that participatory mapping approaches should enable communities to use their local language during the mapmaking 
process. Further, the map produced should also adopt the local language of the communities to better represent the localness of the information captured on the maps. We were also confronted with this issue. Translating or capturing the tacit knowledge into spatial knowledge depicted on a map was also a tricky part in each workshop. Our digital and non-digital mapping workshops applied sketch mapping to enable participants to better elicit their tacit knowledge. The sketch mapping was useful for facilitating participants to draw a rich picture that might not be available in the mapping tool features (Shrestha et al., 2017). Sketch mapping method provides participants with free choices to draw and visualise their desired spatial objects (Cunningham, 2005; Manrique-Sancho et al., 2018). Rambaldi (2005) stated that the selection of features used in mapmaking processes is a crucial success of participatory mapping approaches since it would determine how the local knowledge is captured or drawn, and stimulating the sense of ownership and the benefits of maps among the communities. As a result, the maps produced by the communities would be more useful for the local use and understandable to the local communities. Thus, an amendment of current government regulations that allows local communities to draw their tacit knowledge into participatory maps should be a priority for governments, especially when they are aiming at reaching the SDGs targets in public participation practices.

The success of participatory mapping during the digital and non-digital workshops requires excellent facilitation. The facilitator should guide and create an inclusive workshop while inviting all participants to actively engage in each mapping session. The facilitator needs to provide an inclusive mapping process, where diverse participants with little or no mapping experiences are involved. To reach an inclusive process, the facilitator needs to use proper instructions with terminologies that are understandable for all participants (Eilola et al., 2019; Mostert et al., 2007). The number of participants also influences the implementation of the participatory mapping process. The more participants engaged in a workshop, the more complex the process could become. The number of participants highly depends on the context and the methods used for the mapping workshops. Moreover, the purpose of the mapping workshop, types of spatial data to be produced and the level of accuracy of the expected results have to be clear when selecting the participants (Brown \& Kyttä, 2014; Chambers, 
2006). It is important to note that in a participatory mapping process, the representativeness of key stakeholders as participants is indispensable (Aditya, 2010). However, involving all relevant stakeholders in the village area does not guarantee that the quality of the maps produced will increase. In this study, there were many participants, especially younger participants, who had a lack of knowledge about their villages before the workshop, indicating less local knowledge that could be captured during the mapping process. They acquired new knowledge about the village area from the olderaged participants who were more passive during the mapping process. Although the elders tended to be more passive during the mapping process, they were knowledgeable and became the primary source of knowledge about the village areas. Conversely, the elders learned how to use the mapping tool from the younger participants. This mutual learning experience among the younger and older participants clearly showed how knowledge co-production and social learning occurred during the mapping process.

The knowledge co-production process was also evident when participants worked collaboratively to codify their spatial knowledge into village maps. If we refer to Nonaka and Takeuchi's knowledge coproduction process (1995), the participants were actively using their tacit and explicit spatial knowledge. The participants discussed their tacit knowledge to other participants when they started to communicate during the initial stage of the workshop. They externalised their tacit spatial knowledge through a sketch mapping exercise. The combination was evident when they compared their sketch drawing results and started to draw on the satellite images. Furthermore, they internalised their spatial knowledge by coming to a consensus and learning new knowledge during the discussions. Their trust for the other participants increased when they took collective action and reached an agreement over the proposed development map. This finding proved that a stakeholder-driven approach, such as participatory mapping, is useful to better understand the region and stimulate the co-production of knowledge (Burdon et al., 2019).

The social learning process was also evident when the participants started to understand that they could work collaboratively to produce their own village maps. The experience enabled them to collaborate on other future projects. Single-loop and double-loop learning were also evident when the participants gradually acquired new knowledge while 
transforming their initial values or views (Muro \& Jeffrey, 2012; Shrestha et al., 2018a). For instance, single-loop learning occurred when participants felt a common understanding of needing to use maps when discussing village problems. The participants started to think systematically and holistically beyond the tasks given during the mapping workshops. In the Kolam village, participants discussed the solid-waste management problem during the mapping process, even though waste management was not listed in the task sequences prepared by the facilitators. Some participants also expressed their satisfaction in the interview, where the exact width of the area for each land use could now be measured accurately in their new village maps. Again, these findings clearly showed that participants had started to reflect on sustainability issues when discussing the development processes in their villages. The learning experiences are an example of how rural citizens could also contribute to the upper or central governments' efforts to achieve the SDGs.

Double-loop learning occurred when the participants started to realise that the maps could be used for other developmental purposes. Instead of having only three categories of maps required by regulations, they co-created other maps that they needed. The Kolam village made the neighbourhood maps and distributed the maps to each head of the neighbourhood. The head of the neighbourhoods was now responsible for updating the maps with data, such as the names of family members in each household, new or broken facilities or distribution of social safety nets in the neighbourhoods. The Denai Lama village created a farmers' group map to display the distribution of land allocation for each group. Thus, the visualised geospatial data and learning experiences enabled the stakeholders to better formulate their decisions and actions (Eilola et al., 2019).

In this study, the method was implemented in one full day, reducing the field day and cost of implementing a participatory mapping workshop. It is important to note that an all-day workshop requires careful preparation, skilful facilitation, suitable methodologies, sufficient allocated time and manageable tasks (Corbett, 2009; Corbett et al., 2016). However, the applicability of the participatory mapping method in different contexts should consider the livelihood of the participants, cultural settings, as well as the landscape environments where the participants live and do their activities. For example, in a village where most citizens do pastoral and grazing activities, a mobile 
mapping tool should be more reliable to get better map results (Wario et al., 2015), or planning the schedule properly to suit the available time of the participants to contribute on the mapmaking process (Corbett, 2009).

In this study, we also discovered that an unequal power relation among participants became a major impediment in the participatory processes. The fact that in two out of three villages, no females were involved in the mapping workshops contradicts the SDGs target 11.3 and 16.7, which emphasise the representativeness of people in participatory processes based on sex, age, disability and minority groups (UN Statistics Division, 2018). The strict patriarchal values within the social structure could be a reason why less or no women were involved (Rhoads, 2012). Most of the prominent positions in the villages are held by men. In the village structure, the women group was only represented by the PKK organisation, while the PKK is often chaired and organised by the wives of the village government officials. Moreover, the village officials often have more power to decide who should be invited into a meeting or workshop (Akbar, Flacke, Martinez, \& van Maarseveen, 2020a). These circumstances eventually limit options for women groups in the villages to participate actively in the public participation practices, including in the participatory mapping workshops.

Hence, some methods could be useful to overcome this shortcoming, for example, by choosing the most suitable time for the targeted participants to attend the workshop (Corbett, 2009). Other alternatives might be by providing visualised mapping tools, which can engage more participants (Chambers, 1994a), visiting the households (Smith, 2003) or using online mapping (McCall et al., 2015). However, even though all of these requirements are fulfilled, it would not guarantee that the participatory mapping activities are free from power gaps. Therefore, the facilitator plays an essential role in moderating the interaction of the participants. As facilitators are often confronted with power relations among participants, designing and facilitating a workshop that can accommodate different groups of stakeholders, particularly marginalised groups, is crucial (Burdon et al., 2019; Corbett, 2009; Corbett \& Keller, 2004). A combination of internal and external facilitators might help to reduce the biases caused by the community power structures towards the workshop implementation (Corbett, 2009). 
This study was more than just an extractive approach for gathering data because, during the mapping workshops, the participants also had an intense discussion to identify main problems that need to be addressed in their village. They also made suggestions and took decisions about possible solutions or potential projects that should be done to solve the problems, for example, by proposing to build new schools, to renovate a bridge or to build a dam. Then they put the project priorities into a village proposed development plan map, so that the map can be used during the Musrenbang discussion sessions or to submit proposals for funding allocations to upper governments. However, the final decisions, whether the project priorities would be implemented or not are beyond the scope of this chapter because they will be discussed and decided in the Musrenbang practices. If we refer to Arnstein's ladder of citizen participation (Arnstein, 1969), the participatory process occurred in this participatory mapping workshop could be classified at the partnership level. The workshops helped participants to generate localised knowledge. Furthermore, participants' opinions or suggestions were taken into account during the mapmaking process. These two examples indicated that the participatory process at the partnership level occurred during the workshops.

We acknowledge that the mapping workshops had some limitations. First, the composition of the participants was still far from ideal; for instance, there were no female participants at the Kramat Gajah and Denai Lama workshops. Ideally, the composition should not only consider the representativeness of the stakeholder groups but also include the gender, education level and other socio-economic characteristics, as prescribed by the principles of SDGs - leaving no one behind (The United Nations, 2016). For future research on participatory mapping approaches, it is crucial to include more women and, in general, more participants in the mapping activities. The representativeness of relevant stakeholders would ensure the participatory mapping activities to achieve a higher degree of participation, capture more knowledge to gain more reliable results and prevent participation into a small-group elitist activity (Kahila-Tani et al., 2019; Smith, 2003). Second, the cultural background of the participants, which tended to be polite and not very open to criticism, might influence the participants' feedback. Therefore, having different sources, such as observations and in-depth interviews, was helpful to 
crosscheck the responses given on the questionnaire. Third, technical issues, such as the computer screen size and quantity, should also need further consideration. Having larger computer screens, providing more displays or developing an online mapping platform might be useful in engaging more participants. The more participants engaged, the more knowledge can be captured during the participatory mapping processes.

It is also important to note that the rapid changes in the world situation might require immediate adaptation towards the participatory mapping practices. During the implementation of the workshops, gathering lots of people in a participatory mapping activity was not a problem. However, after the Covid-19 pandemic started, it appears that we need to change the participatory mapping methods, which have less direct contact or interactions due to physical distancing policies. Maceachren and Brewer (2004) in their paper mentioned that collaborative mapping could be implemented in four space-time situations: same time-same place; same time-different place; different time-same place; different time-different place. In this current pandemic situation, applying a participatory mapping workshop that facilitates group collaboration in different places but at the same or different time might be a better option to keep everyone safe during the mapmaking process.

\subsection{Conclusions}

In this study, we sought to develop a suitable approach to achieve the SDGs in terms of providing geospatial data to support decision-making processes at the local level. We developed a collaborative spatial learning framework to integrate the spatial knowledge of the stakeholders by building upon their communication and collaboration and facilitating knowledge co-production and social learning experiences. Through three participatory mapping workshops in the case study areas, this study clearly showed that the workshops helped to increase the participants' awareness to understand and apply sustainable development at the rural scale while helping them to produce accurate and georeferenced village maps. The photo-mapping method by using satellite images was useful to support the stakeholders' communication and collaboration and eventually, integrated the stakeholders' spatial knowledge through knowledge co- 
production and social learning processes. Working with satellite images was helpful to capture local spatial knowledge, increase the knowledge of the participants, support the collaboration of diverse stakeholders, and assist the co-production of reliable and accurate geospatial data. To be successful, having a clear and direct task sequence and skilful facilitators are necessary to actively engage the participants during a participatory mapping process. Yet, how the outcomes of such mapping experiences would affect the behaviour of the participants in a real public participation practice is still uncertain. In the long run, the impact of this initiative to achieve the SDGs also needs further investigation. Therefore, further studies may be worthwhile on how such mapping experiences and co-produced geospatial data could enhance public participation practices in villages, while also contributing to the achievement of SDG targets. 


\section{Chapter 5: The role of participatory village maps in strengthening public participation practice* $^{*}$}

* This chapter is based on the published paper: Akbar, A., Flacke, J., Martinez, J., van Maarseveen, M. F. A. M. (2021). The role of participatory village maps in strengthening public participation practice. ISPRS International Journal of Geo-Information, 10(8), 512. https://doi.org/10.3390/ijgi10080512 
Numerous studies have reported the benefits of participatory maps in helping stakeholders to solve diverse development problems. Participatory maps allow stakeholders to communicate and collaborate effectively, while eliciting and integrating their spatial knowledge during the deliberative process (Shrestha et al., 2018b), visualise spatial inequalities (Martinez, 2009), raise citizens' awareness of protecting their environment (Damastuti \& de Groot, 2019; RamirezGomez et al., 2015), and increase the decision-making capacity of local stakeholders (Eilola et al., 2019). Although advances in the technologies for collecting and producing maps have made the mapmaking process faster and more accessible, in the Global South, the situation might be challenging due to limited resources and capacity to obtain or produce maps (Aguilar et al., 2020; Akbar, Flacke, Martinez, Aguilar, \& van Maarseveen, 2020; Falco, 2016; Patel et al., 2017). For these countries, making maps available can be a complex endeavour that requires a great deal of effort, cost, and expertise.

Indonesia has a strong interest in making geospatial data, such as maps, available to support the decision-making process at different levels of government, from national, provincial, and district/city to the village. The government launched the One Map Policy (OMP) through Presidential Decree 9 of 2016 to reach a target of 85 thematic maps produced by 2019 (Patmasari, 2019). However, by 2019, the only mandated thematic map yet to be accomplished by the government was the village map. Only one-third of Indonesia's villages have been delineated but merely in village boundary map format (Abidin, 2019; Ambarwulan et al., 2018). The village map, which outlines the village boundary, facilities, and land use or land cover of the village area (Abidin, 2019), is needed to support spatial planning and claim the villages' boundaries (de Vos, 2018; Shahab, 2016). It is also essential for the village planning and development process (Akbar, Flacke, Martinez, Aguilar, \& van Maarseveen, 2020), notably for supporting the Musrenbang (in the Indonesian language, the word 'musrenbang' stands for 'musyawarah perencanaan pembangunan', which can be translated literally as 'community consensus building for budgeting, planning, and development'), the public participation practice held annually in villages (Feruglio \& Rifai, 2017). 
A bottom-up approach, such as participatory mapping, may be a feasible solution to deal with such a situation, particularly to address and support the collection and production of geospatial data at local scales (Solís et al., 2018). Localising map production at the grassroots scale by employing participatory mapping might be a practical option to accelerate the availability of maps (Solís et al., 2018). Involving village stakeholders in participatory mapping workshops would address the problem of unavailability of village maps and, at the same time, enable participants to communicate (Engen et al., 2018; Rambaldi et al., 2006) and collaborate on map making (Falco et al., 2019; Pánek, 2015b) and, in doing so, experience social learning (Brown \& Kyttä, 2014; Eilola et al., 2015) and integrate their local spatial knowledge into the village maps (Akbar, Flacke, Martinez, Aguilar, \& van Maarseveen, 2020; Cinderby \& Forrester, 2016; McCall, 2021). Participatory mapping activities allow village stakeholders to conceptualise their local knowledge, which may benefit the management of the village's local resources and spatial planning (Burdon et al., 2019; Wartmann \& Purves, 2017). Consequently, the maps produced may be of value to the Musrenbang public participation process at the village level.

This study tested this hypothesis by scrutinising how village maps produced by village stakeholders through participatory mapping workshops enhance Indonesia's Musrenbang public participation practice. Fox (2002) argued that a participatory mapping exercise may be regarded as successful if villagers not only participate in the mapmaking process but also claim and use the maps produced. Thus, following our previous Musrenbang evaluation in 2018 (Akbar, Flacke, Martinez, \& van Maarseveen, 2020a), and the participatory mapping workshops in 2019 (Akbar, Flacke, Martinez, Aguilar, \& van Maarseveen, 2020), we revisited the case study areas to evaluate the Musrenbang meeting in 2020 and observe the difference in implementation after they had village maps to hand. We aimed to answer the central question: To what extent do the participatory village maps produced from participatory mapping workshops help to strengthen public participation practice at the village level? We answered this question using the following two further questions: (1) To what extent do the participatory village maps support the Musrenbang by facilitating communication between participants? (2) 
To what extent do the participatory village maps help the Musrenbang by enabling collaboration between participants?

\subsection{Participatory village maps for strengthening public participation}

The production of village maps for all villages is a challenging task for the Indonesian government. Of the 83,436 villages in Indonesia, only 31,147 have been delineated by the central government (Patmasari, 2019). The rest do not have maps or have only sketch maps. Ambarwulan et al. (2018) found that most of the village sketch maps do not follow cartographic rules. The maps typically have no coordinates, are unclear about the sources of data, are unscaled, and are only drawn with modest drawing tools, such as pens or markers. Consequently, the village sketch map cannot be used for measuring the size of the village area or to calculate the distance of the village from other cartographic objects (such as main roads, rivers, or the subdistrict capital). The villagers never use sketch maps for any decisionmaking processes; consequently, the maps are usually displayed in the village head office only as decoration (Akbar, Flacke, Martinez, \& van Maarseveen, 2020b).

Some scholars have begun to work with villagers to produce village maps using cartographic rules, from conventional participatory mapping methods to sophisticated methods, such as the Geographic Information System (GIS), or a combination of both (Aditya, 2010; Corbett, 2003; Corbett \& Keller, 2004; Eilola et al., 2019; Pánek, 2015a). The village maps thus produced have been used for different purposes, such as counter-mapping (de Vos, 2018; Sirait et al., 1994), ecosystem service mapping (Brown \& Fagerholm, 2015; Burdon et al., 2019; Ramirez-Gomez et al., 2015, 2016), neighbourhood land-use planning (Aditya, 2010; Simão et al., 2009), and delineation of village administrative areas (Ambarwulan et al., 2018; Patmasari, 2019). Despite many studies in this field, there is a lack of empirical investigations addressing the role of such participatory village maps in supporting public participation practice. Examination of the Musrenbang may fill this gap as the topics of discussion in the process are closely linked to geographical locations, although maps are rarely 
used in Musrenbang implementation (Akbar, Flacke, Martinez, \& van Maarseveen, 2020b).

McCall and Minang (2005) classified participatory mapping activities according to four degrees of participation: manipulative or passive participation, consultation or functional participation, interactive involvement in decision making by all actors in most stages, and initiation of actions at the highest degree. Inspired by this classification, in a previous study, we conducted participatory mapping workshops in three case study areas where village stakeholders produced geospatial data by integrating their spatial knowledge and learning as a group in a participatory manner (Aguilar et al., 2021; Akbar, Flacke, Martinez, Aguilar, \& van Maarseveen, 2020). The mapping workshops aimed to produce participatory village maps, while stimulating village stakeholders' communication, collaboration, social learning and knowledge co-production.

In this study, we critically examine how the village maps produced in previous participatory mapping workshops have been used to strengthen Musrenbang practice. To do so, we employed the Sustainable Development Goal (SDG)-based evaluation framework developed in a previous study (Akbar, Flacke, Martinez, \& van Maarseveen, 2020a). The framework, which was developed using SDGs 11.3 and 16.7 as the basis, acts as the analytical framework in this study. Out of 15 criteria, we tested 8 (shown in the third ring in Figure 5-1) that are relevant to the assessment of map usage in Musrenbang practice. 


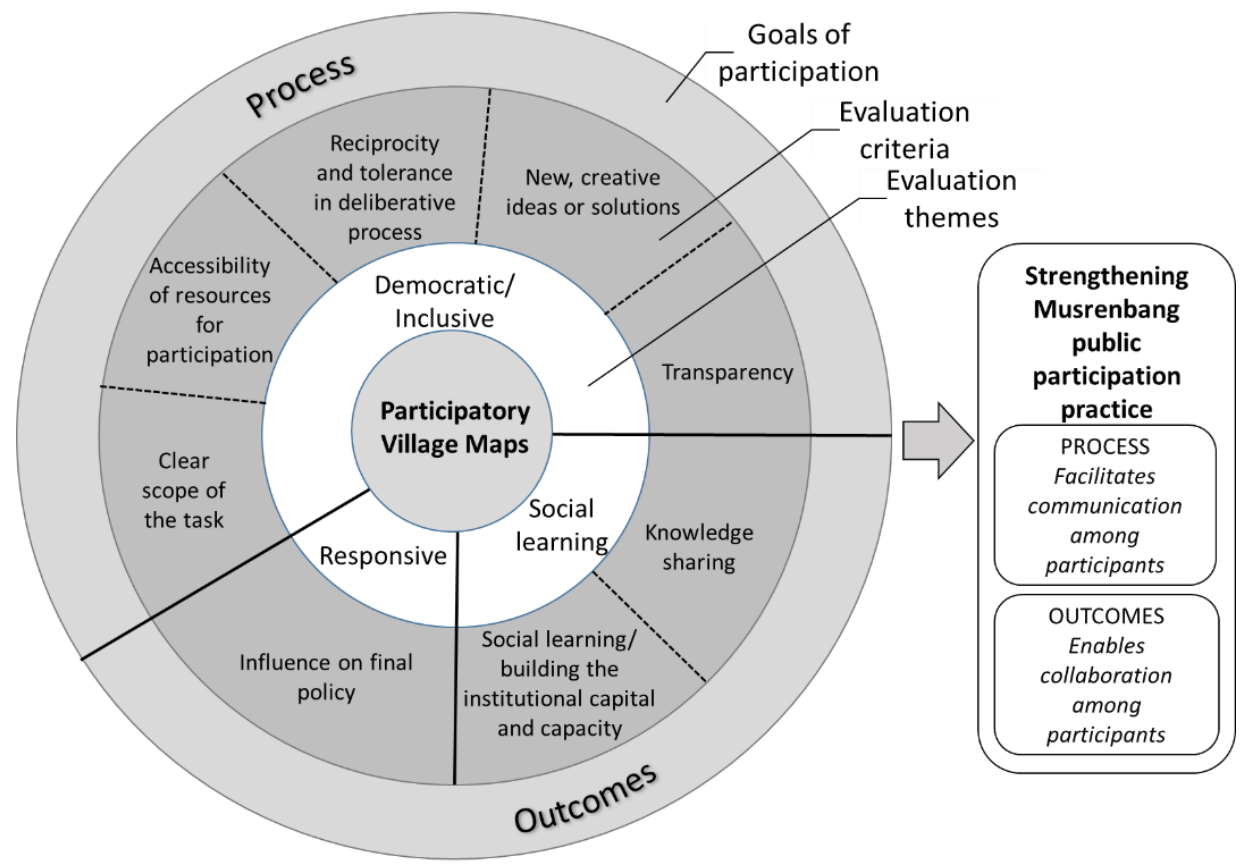

Figure 5-1. A conceptual framework to assess how village maps produced during participatory mapping activities can strengthen Musrenbang practice

Facilitation of communication between participants is an essential factor for strengthening the public participation process. Public participation should be a democratic and inclusive process for the participants so that it is accessible to the wider community and is not restricted to an elite or privileged group (Haklay, 2013). Engagement in creating participatory village maps has the potential to achieve this purpose by facilitating communication between participants (Akbar, Flacke, Martinez, Aguilar, \& van Maarseveen, 2020). The maps provide a clear indication of the scope of the task (Innes \& Booher, 1999; Rowe et al., 2004) that enables participants to identify the spatial extent of the village administrative area that needs to be addressed in the Musrenbang. The participatory process is more transparent (Rowe \& Frewer, 2000), since the village maps, as the data needed to support the deliberative process, are available and accessible (Rowe et al., 2004; Rowe \& Frewer, 2000). The use of maps may stimulate a reciprocal and tolerant deliberative process that enables open and fair communication between participants (Agger \& Löfgren, 2008; Laurian \& Shaw, 2008). Furthermore, participants can use the maps to formulate creative ideas or solutions for better results or decisions (Beierle, 2002; Innes \& Booher, 1999). 
Public participation should also be responsive to development issues (Swapan, 2016), while promoting the social learning of participants (Flacke et al., 2020). Thus, enabling participant collaboration is also crucial to strengthen the outcomes of public participation practice. The participatory village maps used in public participation practice should be able to stimulate collaboration and knowledge sharing (Akbar, Flacke, Martinez, Aguilar, \& van Maarseveen, 2020; Innes \& Booher, 1999). The maps should support social learning and increase the villagers' capacity to learn and work collaboratively to solve the community's problems (Flacke et al., 2020; Perdana \& Ostermann, 2019). Such public participation practice may raise the participants satisfaction as their opinions can influence the final policy outcomes (Agger \& Löfgren, 2008; Webler et al., 2001).

Despite the various potential benefits of using participatory maps in public participation practice, it is important to keep in mind that the maps may also have some negative impacts on local communitieswhat Fox et al. (Fox et al., 2006) called 'the ironic effects' of participatory mapping. Some information regarded by local communities as sensitive, such as religious or sacred places, can be exposed to external actors (McCall, 2006). The map-making process can become 'a small-group elitist activity' involving a few stakeholders who have greater knowledge and access to the maps (Kahila-Tani et al., 2019). The technology gaps between different groups in the community can maintain the existing power disparities between local stakeholders (Chapin et al., 2005). The information presented on maps may provoke conflicts among stakeholders because of boundary disputes or competition for land (Reyes-García et al., 2012; Sirait et al., 1994), have repercussions on gender inequalities (Catacutan et al., 2014; Gilbert \& Masucci, 2006), and trigger land grabbing (Shahab, 2016). Therefore, this study attempts to objectively examine the positive and negative impacts of participatory village maps using the criteria listed in Figure 5-1. 


\subsection{Methodology}

\subsubsection{The case study}

We studied the Musrenbang in five villages in Deli Serdang District, Indonesia. The Musrenbang functions as a legal mechanism for citizens to participate actively in the local development planning and budgeting processes while aligning top-down and bottom-up planning programmes (Butler, Bohensky, Suadnya, et al., 2016; Sutiyo, 2015). It is implemented annually in public meeting format at several hierarchical levels, from the village, sub-district, and provincial to the national. Various stakeholders are involved in the meeting, including government officials, the private sector, and citizen representatives, such as women's groups, religious or community leaders, and youth groups (Akbar, Flacke, Martinez, \& van Maarseveen, 2020a). The Musrenbang plays an essential role in discussing, clarifying, harmonising, and building a consensus on development priorities at each level of the process (Indika \& Vonika, 2019; Sutiyo, 2013). At the village level, the Musrenbang is crucial as the first phase of the hierarchical participatory planning process and is a medium for rural citizens to share their views or aspirations and propose specific programmes to solve various development problems in the village (Grillos, 2017).

Five villages were chosen for the case study based on four major criteria: (1) the villages were located in different sub-districts, (2) the ethnicity of the population was primarily Javanese, (3) the main livelihood of the population was farming/agriculture, and (4) the villagers were willing to participate in the study. The selected villages were Denai Lama, Kramat Gajah, Kolam, Sidoharjo I Pasar Miring, and Tandem Hulu II. We divided the villages into an intervention group, which included Denai Lama, Kramat Gajah, and Kolam, and a control group, which included Sidoharjo I Pasar Miring and Tandem Hulu. The division of villages into two groups is useful for comparing contrasting cases or situations under different treatments to seek explanations and gain an understanding of the social phenomena in different contexts (Bryman, 2012). This method allows the researcher to compare the impact of an intervention with what would have happened if there had been no intervention or to compare the impacts of different kinds of intervention (Banerjee \& Duflo, 2009; Bryman, 2012). Similar to a 
previous study by Reyes-García et al. (2012), we randomly allocated the selected villages into the two groups. We did not inform any of the villages about the division and the names of the other villages involved in this study, as well as the different treatment of each village. The randomisation of experimental participants is crucial 'as it means that the members of the different groups in the experiment are to all intents and purposes alike' (Bryman, 2012, p. 55). Two modes of intervention were used: (1) a mapping intervention to produce participatory village maps and (2) the use of participatory village maps during the Musrenbang at the village level.

We visited and evaluated the Musrenbang in all villages twice, in 2018 (before the interventions) and in 2020 (after the interventions). We have reported the results of the Musrenbang (2018) and the mapping workshops (2019) in previous publications (Aguilar et al., 2021; Akbar, Flacke, Martinez, \& van Maarseveen, 2020a, 2020b; Akbar, Flacke, Martinez, Aguilar, \& van Maarseveen, 2020). This study is a report of our second visit to the Musrenbang (2020) to examine the use of maps during the process in the case study areas.

\subsubsection{The participatory mapping workshops}

We conducted one participatory mapping workshop for each of the intervention villages in October-November 2019. We used two methods: digital participatory mapping (DM) in Denai Lama and Kramat Gajah and non-digital participatory mapping (NDM) in Kolam (Figure 5-2). A high-resolution satellite image was used as a background layer to help participants to identify and draw elements in their village. (Each satellite image had a high resolution $(50 \mathrm{~cm})$ and was a natural colour composition (pan-sharpened) image covering the whole village administrative area. The satellite images were captured on 16 January 2019 (Kolam), 19 April 2019 (Denai Lama), and 19 May 2019 (Kramat Gajah) by the WorldView2 and WorldView3 platforms (https:// worldview.earthdata.nasa.gov/).) Prior to the workshops, none of the villages had a georeferenced village map. We employed the Open Geospatial Tool (OGITO) application in the digital mapping workshops (Aguilar et al., 2021; Akbar, Flacke, Martinez, Aguilar, \& van Maarseveen, 2020). The OGITO tool allowed participants to draw on the satellite image displayed on a touchscreen monitor. For the nondigital mapping workshop, we manually drew on each village's printed 
satellite image using colour markers and stickers. The lead author then transferred the sketches drawn by the participants into a GIS to produce village maps in digital and hardcopy formats. Three mapssatellite image map, infrastructure/public facilities map, and land-use map-mandated by the Head of Geospatial Information Agency (BIG) Regulation 3 of 2016 were created and handed over to the village stakeholders. We also provided two additional maps: a boundary map and a proposed development map. The latter was based on the results of participants' discussions during the participatory mapping workshops. In the last session, we asked them to identify problems and possible solutions for their village. Then, the participants drew the discussion result on the satellite image that we used in the participatory mapping workshops to produce a proposed development map. This map was then used to support the Musrenbang deliberative process. 

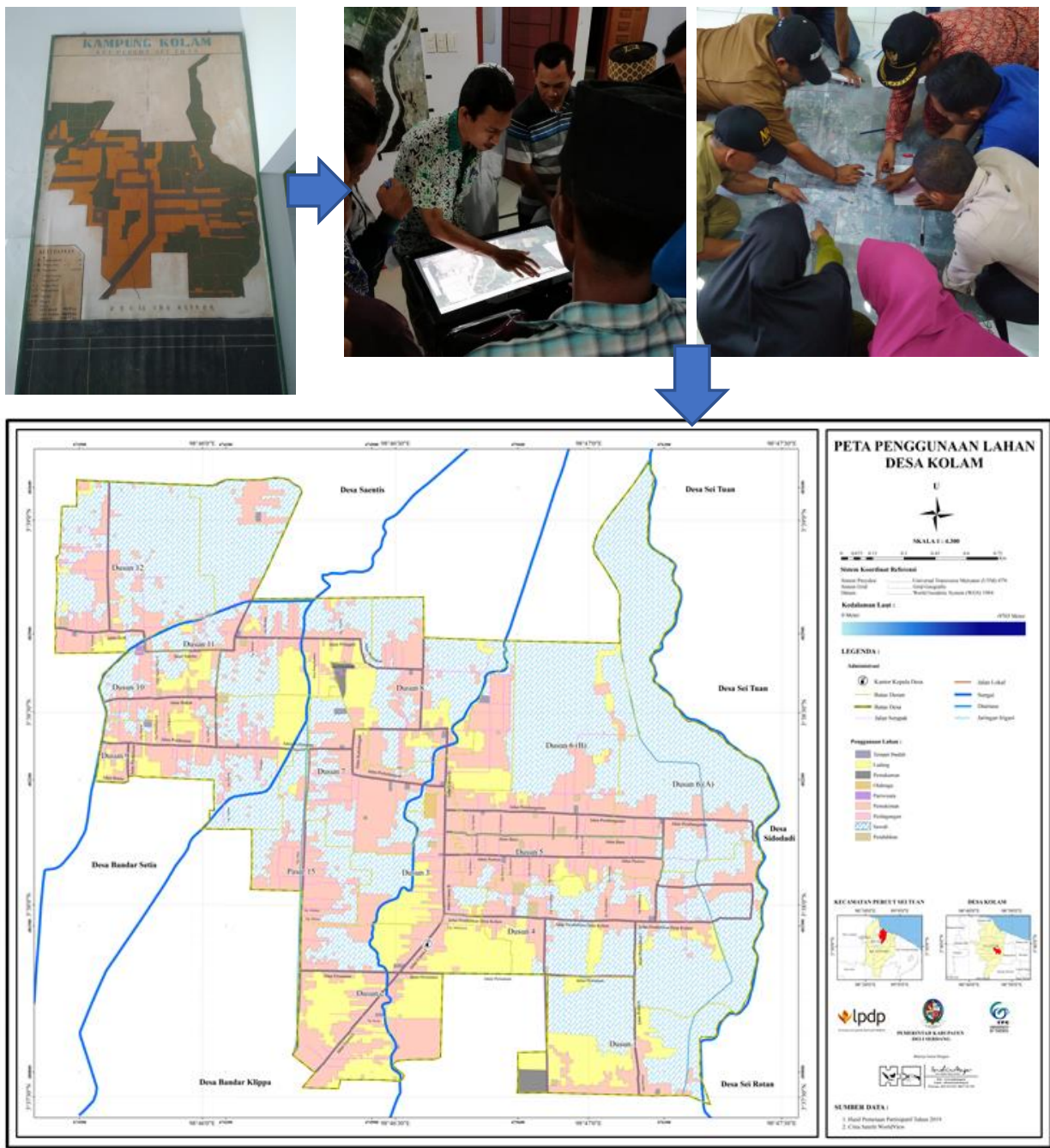

Figure 5-2. The participatory village map-making process, from a sketch map, created during digital or non-digital participatory mapping workshops, to a (georeferenced) village map

We did not conduct any participatory mapping workshops in the control villages (Sidoharjo I Pasar Miring and Tandem Hulu II). However, Sidoharjo I Pasar Miring had produced its own village maps by hiring a private consultant in 2019. These maps were created with the involvement of only the village head and staff but not the other village stakeholders. The other control village, Tandem Hulu II, did not have or produce any maps at the time of data collection. 


\subsubsection{Data collection and analysis}

The lead author attended the Musrenbang in each village in January 2020. A passive observation was conducted to observe how the Musrenbang was implemented and how the villages that had village maps used them during the deliberative process of the Musrenbang (the observation guidelines are provided in Appendix M). At the end of the Musrenbang session, the participants were asked to fill a selfadministered questionnaire (based on the conceptual framework in Figure 5-1) to collect their opinions about the Musrenbang implementation and the use of the village map during the process (Appendix N). A semi-structured interview (Appendix O) was also conducted in January-February 2020 with 69 Musrenbang participants. The details are shown in Table 5-1.

Table 5-1. Information about participatory mapping workshop participants, Musrenbang participants, and interviewees

\begin{tabular}{|c|c|c|c|c|c|c|c|}
\hline \multirow{2}{*}{$\begin{array}{c}\text { Village } \\
\text { Musrenbang } \\
2020 \\
\text { attendance } \\
\text { (male/ } \\
\text { female) }\end{array}$} & \multirow[b]{2}{*}{$\begin{array}{c}\text { Population } \\
\text { and } \\
\text { density } / \mathbf{k m}^{2} \\
(2019)^{*}\end{array}$} & \multirow[b]{2}{*}{$\underset{\left(\mathbf{k m}^{2}\right)^{*}}{\operatorname{Area}}$} & \multirow[b]{2}{*}{$\begin{array}{l}\text { Type of } \\
\text { interventi } \\
\text { on }\end{array}$} & \multicolumn{2}{|c|}{$\begin{array}{c}\text { Participants of } \\
\text { village mapping } \\
\text { workshops } \\
(2019)\end{array}$} & \multicolumn{2}{|c|}{$\begin{array}{l}\text { Musrenbang participants } \\
\text { interviewed (2020) }\end{array}$} \\
\hline & & & & $\begin{array}{l}\text { Number } \\
\text { of males }\end{array}$ & $\begin{array}{c}\text { Number } \\
\text { of } \\
\text { females }\end{array}$ & $\begin{array}{l}\text { Number of } \\
\text { Musrenbang } \\
\text { participants } \\
\text { interviewed }\end{array}$ & $\begin{array}{c}\text { Number of } \\
\text { interviewees } \\
\text { who } \\
\text { participated } \\
\text { in the } \\
\text { mapping } \\
\text { workshops }\end{array}$ \\
\hline $\begin{array}{c}\text { Denai Lama } \\
(29 / 17)\end{array}$ & $\begin{array}{c}2927 \\
(1096)\end{array}$ & 2.67 & $\begin{array}{c}\text { Digital } \\
\text { mapping }\end{array}$ & 16 & - & 15 & 9 \\
\hline $\begin{array}{l}\text { Kramat Gajah } \\
(17 / 19) \\
\end{array}$ & $\begin{array}{c}2237 \\
(1491) \\
\end{array}$ & 1.50 & $\begin{array}{l}\text { Digital } \\
\text { mapping }\end{array}$ & 10 & - & 18 & 8 \\
\hline $\begin{array}{l}\text { Kolam } \\
(28 / 3)\end{array}$ & $\begin{array}{l}17,418 \\
(2913) \\
\end{array}$ & 5.98 & $\begin{array}{c}\text { Non-digital } \\
\text { mapping }\end{array}$ & 15 & 15 & 16 & 15 \\
\hline $\begin{array}{c}\text { Sidoharjo I } \\
\text { Pasar Miring } \\
(23 / 9) \\
\end{array}$ & $\begin{array}{c}5614 \\
(1315)\end{array}$ & 4.19 & $\begin{array}{c}\text { No } \\
\text { intervention }\end{array}$ & - & - & 11 & - \\
\hline $\begin{array}{c}\text { Tandem Hulu } \\
\text { II } \\
(15 / 6)\end{array}$ & $\begin{array}{c}9298 \\
(2183)\end{array}$ & 4.26 & $\begin{array}{l}\text { No } \\
\text { intervention }\end{array}$ & - & - & 9 & - \\
\hline
\end{tabular}

* Source: Statistics of Indonesia (2020)

Audio and video recordings were made of all meetings and interviews. All participants verbally gave their informed consent to all data collection from the fieldwork. The questionnaire responses were compiled and analysed using frequency analysis, while the meeting notes and interviews were transcribed and analysed systematically using the content analysis method. All interviewees' names were substituted with codes to anonymise them (Appendix P). 


\subsection{Results}

\subsubsection{To what extent do the participatory village maps support the Musrenbang by facilitating communication between participants?}

Based on the evaluation criteria, we obtained some notable results for five criteria related to the process of public participation.

5.3.1.1 Clear scope of the task: Defining the spatial extent of the village area that needs to be addressed in the Musrenbang

The participatory village maps provided clear information about the extent of the village area and its boundaries. Valid information about the exact boundaries of neighbourhoods or villages was necessary for most of the participants whom we interviewed from all villages. The population size, village area, and population density (Table 5-1) did not have a bearing on the importance of boundaries for the village communities. The boundaries defined the scope of the task to help participants to focus on the topics related or relevant to their villages. Most of the interviewees in the intervention village group (Denai Lama, Kramat Gajah, and Kolam) responded that the maps used in the Musrenbang were helpful to better understand their village areas. The maps also enabled them to identify the boundaries with other villages and the boundaries of each neighbourhood in the villages. Interviewee C18 said, 'It [the exact boundaries] is important, so a map is needed. If we want to plan a project development in our village, we must know the exact position' (C18, personal communication, 11 February 2020). In this study, we did not observe an increase in conflict due to participatory mapping, but rather a reduction. The exact boundaries reduced tensions among heads of neighbourhoods when dealing with land registration or taxation issues (B8, personal communication, 28 January 2020).

The questionnaire results supported the finding for the intervention group that the village maps used during the Musrenbang had helped them to better understand their villages (Figure 5-3). Only a small percentage of respondents in Denai Lama (3\%) and Kramat Gajah (2\%) responded 'strongly disagree' and 'neutral', respectively, to the statement that the map was helpful for them to understand their village better. The responses of participants from the control villages were not 
included, since question 18 in the questionnaire was not relevant to them (see Appendix N).

In my opinion, the village maps used in this Musrenbang were helpful for me to know more about my village (\%)

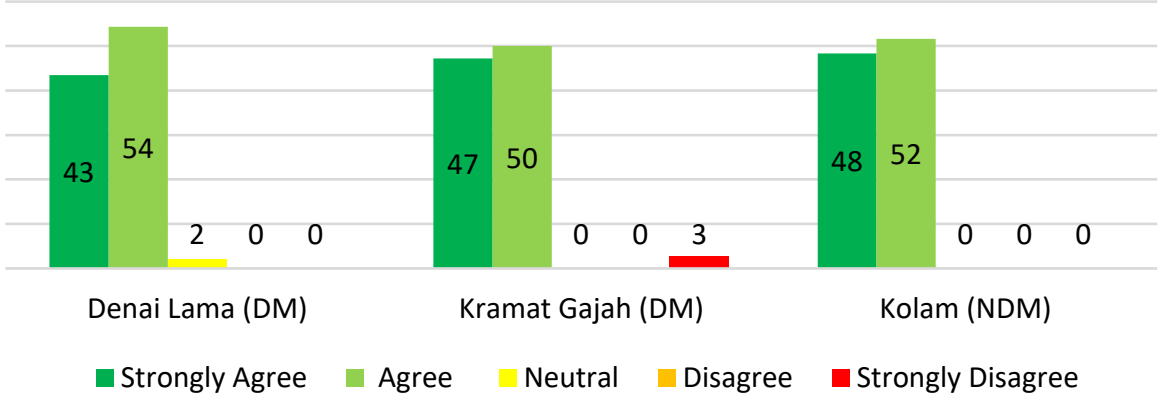

Figure 5-3. The helpfulness of village maps to the respondents for knowing more about their villages

In the control villages (Sidoharjo I Pasar Miring and Tandem Hulu II), the participants had difficulty identifying the area being discussed due to the lack of visualised supporting data, such as maps. They also revealed that village maps and information about boundaries were essential. For example, when asked about the possibility of using village maps in the Musrenbang, the three heads of neighbourhoods in Sidoharjo I Pasar Miring (D9, D10, and D11) gave the same response to whether village maps were important for showing boundary information. D10 said, '[The Musrenbang] will be much better. We can identify the boundaries, [for example the boundaries of] neighbourhood Pasar 7 [and] neighbourhood Pringgan, right?' (D10, personal communication, 6 February 2020). Another interviewee from Tandem Hulu II also expressed his opinion about why the village map was necessary: 'Because not all village officials, including the BPD (village council), understand each neighbourhood's area. We know where neighbourhood 1, 2, 4 or 9 [is] located, but the details, such as [information about] pathways in each neighbourhood, we do not know' (E5, personal communication, 17 February 2020). 
5.3.1.2 Transparency: Village maps made the decision-making process in the Musrenbang more transparent

The participatory village maps helped the Musrenbang process to be more transparent. The maps displayed at the Musrenbang helped to provide participants with sufficient information about the process and the results of the planning discussion. The intervention villages used the participatory village maps in different ways, as shown in Figure 54. Denai Lama and Kramat Gajah displayed the printed village maps at the front of the meeting room so that the audiences could see them. Kolam used a slide projector to display the village map on the front wall of the venue.

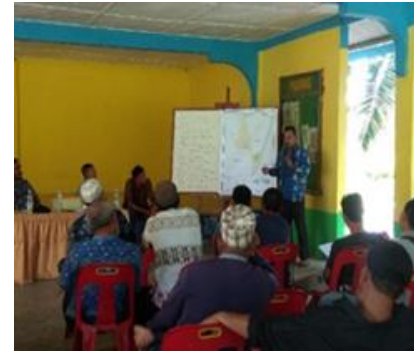

(a)

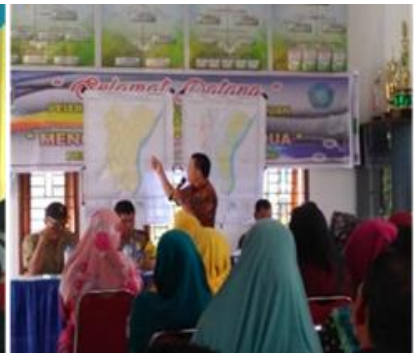

(b)

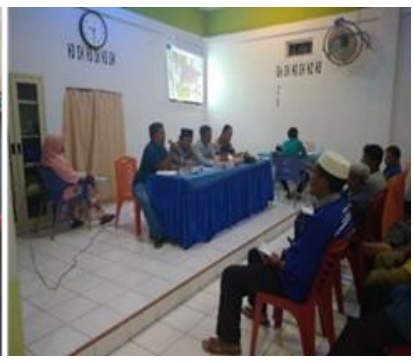

(c)

Figure 5-4. The village map was used at the Musrenbang: (a) Denai Lama, (b) Kramat Gajah, and (c) Kolam

Source: author photo

The village heads of Denai Lama and Kolam used only the proposed development map during the Musrenbang, while the village head of Kramat Gajah used two maps, the proposed development map and the land-use map. The village heads used the maps to explain projects that needed to be implemented and showed the prioritised sites on the maps to convince the audience that the projects were crucial and should be prioritised (Figure 5-4). As a result, most of the interviewees from the intervention villages responded that the use of village maps had made the Musrenbang process more transparent. An interviewee from Denai Lama said, 'The last Musrenbang was not the same as the Musrenbang in previous years. The last one was a bit flexible and more transparent' (A8, personal communication, 18 February 2020). An interviewee from Kramat Gajah stated, 'The [last] Musrenbang was transparent. Very transparent. We all could see the plans [on the maps 
presented]. All of them were transparent ${ }^{\prime}$ (C18, personal communication, 11 February 2020).

The use of the maps also made the discussion about budget allocation more transparent. An interviewee from Denai Lama said, 'At least we knew, with all the presented data [all became clear]. The communities were constantly asking for information about the budget allocation and the sources. Those [kinds of information] were necessary. The village government should be open and transparent to the communities' (A6, personal communication, 5 February 2020). C2 also stated that the maps made the Musrenbang process more transparent, '[The process was] transparent and more open. All participants could know that the budget allocation will be used for financing this [project] or that [project]' (C2, personal communication, 7 February 2020).

The villages in the control group, Sidoharjo I Pasar Miring and Tandem Hulu II, did not use maps during the Musrenbang, although the former already had village maps. Interviewees D1 and D8 from Sidoharjo I Pasar Miring said that only the village head and secretary could access the maps. They also noted that the maps still contained some disputed village and neighbourhood boundaries. The village head decided not to make the maps public, because the boundaries were a sensitive issue that could provoke conflicts between citizens or with neighbouring villages (D8, personal communication, 11 February 2020).

Many interviewees from the control villages expressed their concerns about the lack of transparency during Musrenbang deliberations. Decisions about development priorities or budget allocation plans were made without any data or tools to support the discussion. Such a situation led to the participants wondering about the exact locations of the topics being discussed or why a budget needed to be allocated to a particular project. An interviewee from Tandem Hulu II said, 'Well, you were there and saw it yourself. In the last Musrenbang, we only talked, without presenting any data [during the discussion]' (E9, personal communication, 26 February 2020). 
5.3.1.3 Accessibility of resources for participation: Data are essential for public participation practice

The participants' responses to the questionnaire show that the use of village maps had a positive influence on Musrenbang implementation. Previously, hardly any geographical data were used in the Musrenbang. The data used were often only a list of proposed programmes prepared by heads of neighbourhoods. They were handwritten on a sheet of paper and presented orally by each head of neighbourhood without supporting tools, such as a whiteboard or a slide projector. The heads of neighbourhoods rarely updated the lists, so they remained the same for years (D4, personal communication, 6 February 2020). However, in the 2020 Musrenbang, there was a substantial difference as villagers from Denai Lama, Kramat Gajah, and Kolam used village maps for the first time during the Musrenbang. As shown in Figure 5-5, most participants in the intervention group agreed that appropriate data were available to support the Musrenbang process.

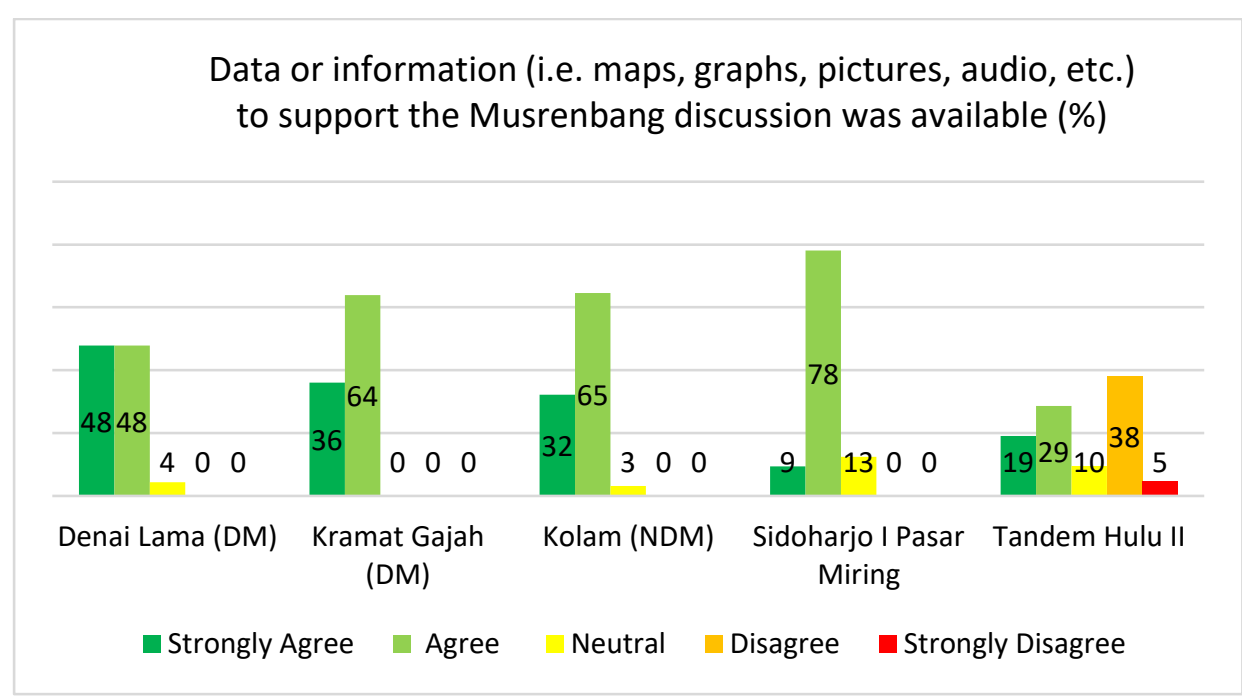

Figure 5-5. The availability of data to support the Musrenbang process

This finding indicates that the participants in the intervention villages were aware that the village maps shown during the meeting made the latest Musrenbang different from previous ones. Respondent A9 considered the 2020 Musrenbang to be better than those in previous years. He said that the maps enhanced the deliberative process of the Musrenbang; the discussion was more constructive and faster because participants could directly identify, see, and point to the locations being 
discussed on the maps. Previously, they only discussed development priorities or plans without supporting data that clearly showed the exact locations (A9, personal communication, 18 February 2020).

In contrast, the responses of participants in the control group, particularly those from Tandem Hulu II, indicated that they felt the Musrenbang deliberation was not supported with sufficient data. Interestingly, Sidoharjo I Pasar Miring had responses almost similar to those from villages in the intervention group. In this village, the Musrenbang organiser combined the process with the regular biannual farmers' meeting. The organiser split a two-hour meeting to discuss two different agendas, the Musrenbang itself and the meeting to decide the schedule of paddy-planting plans. Consequently, the participants were less representative because most of them were farmers who attended the meeting because their main purpose was to discuss the paddy-planting plans, not the village development priorities/plans. This may explain why their responses to the questionnaire were different from those of the participants from Tandem Hulu II. However, the interviews revealed that most participants representing citizens' groups from both villages admitted the absence of supporting data during the Musrenbang implementation. They said that they had no understanding of the topics discussed, because no supporting data were displayed. This finding indicates that relying only on the list of proposed development programmes prepared by the heads of neighbourhoods may not be sufficient to support the Musrenbang deliberative process.

The majority of participants from each village also agreed that having data to support the discussion in the Musrenbang was important. However, the participants from the three villages that used village maps during the Musrenbang showed considerably greater agreement than villages that did not use geospatial data during the process (Figure 5-6). This finding suggests that if we had used village maps during the Musrenbang in these two villages, we would have obtained the same responses as those from the villages that used maps during the process. 
In my opinion, data or information was needed to support the Musrenbang discussion (\%)

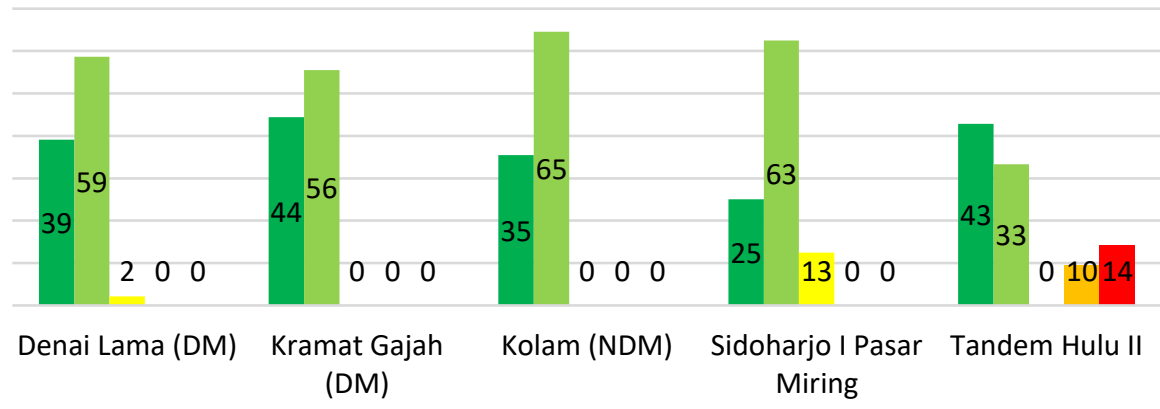

$\square$ Strongly Agree $\square$ Agree $\square$ Neutral $\square$ Disagree $\square$ Strongly Disagree

Figure 5-6. The importance of having data to support the Musrenbang

5.3.1.4 New, creative ideas or solutions: Maps were helpful to determine the areas discussed

The Musrenbang participants effectively used the participatory village maps to formulate new, creative ideas or solutions. Participants could comprehensively define the village problems, integrate them, and use scientific or technical analysis during the deliberative process. In the questionnaire, we found different responses from the intervention (Denai Lama, Kramat Gajah, and Kolam) and control villages (Sidoharjo I Pasar Miring and Tandem Hulu II) to the question of whether the data available were effectively used during the Musrenbang (Figure 5-7). The majority of respondents from the intervention villages strongly agreed/agreed that the data were used effectively. A small percentage of respondents from Denai Lama and Kolam were neutral or disagreed. In contrast, the responses from the control group participants were generally mixed, with about a third disagreeing. 
Data or information available was effectively used during the Musrenbang (\%)

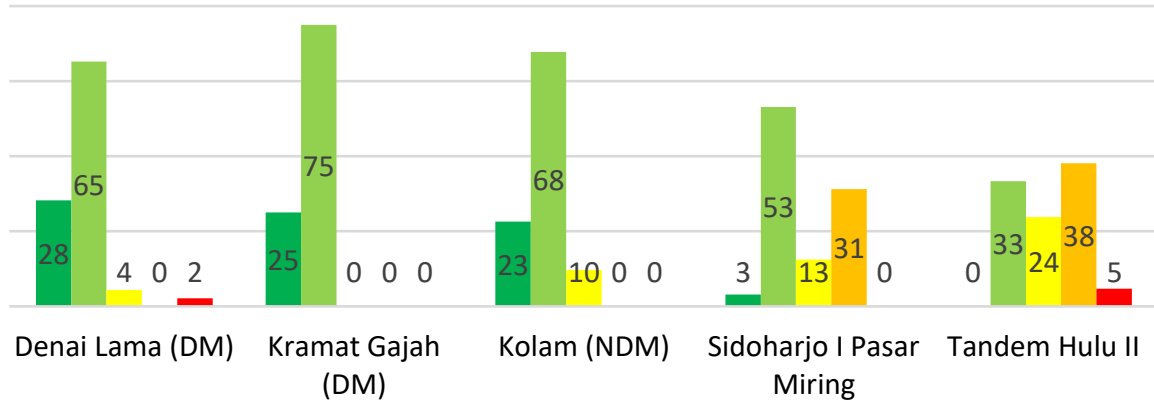

- Strongly Agree $\square$ Agree Neutral Disagree $\square$ Strongly Disagree

Figure 5-7. The effective use of available data during the Musrenbang.

In the intervention villages, when a discussion about the administrative area arose, some participants referred to the maps to confirm the boundaries or make decisions. The maps also allowed them to think creatively in solving problems. For example, in Kolam, the maps were used to discuss the ideal number of farmer groups that the village should have based on the existing agricultural area. Interviewee B1 said:

"From the maps, we found that some agricultural areas have changed to residential areas. So the current [agricultural] area does not match the requirement [the number of farmer groups]. So we need to merge some farmer groups. The maps were very helpful for that purpose" (B1, personal communication, 28 January 2020).

The maps were also helpful for updating data on neighbourhood areas. In Kolam, all heads of neighbourhoods received a printed neighbourhood map that could be used to update the current conditions of their areas. Relevant updated information, such as population size, socio-economic indicators, and land registration, could help them to think creatively and formulate feasible solutions for their neighbourhoods and the village.

In contrast, the control villages did not use any data during the Musrenbang; consequently, there were no innovative approaches to identify or solve problems discussed in the Musrenbang (E9, personal communication, 26 February 2020). 
5.3.1.5 Deliberative processes characterised by reciprocity and tolerance: They continue to be dominated by certain elites

The participatory village maps were also helpful for supporting the deliberative process in the Musrenbang. Open and fair communication between participants was established during the Musrenbang in the intervention villages. More than $90 \%$ of the respondents in the three villages agreed that maps could help the Musrenbang deliberation (Figure 5-8). Only a small percentage was neutral about the helpfulness of maps in this regard. The responses from control villages were not included, since question 19 in the questionnaire was not relevant to these villages (see Appendix $\mathrm{N}$ ).

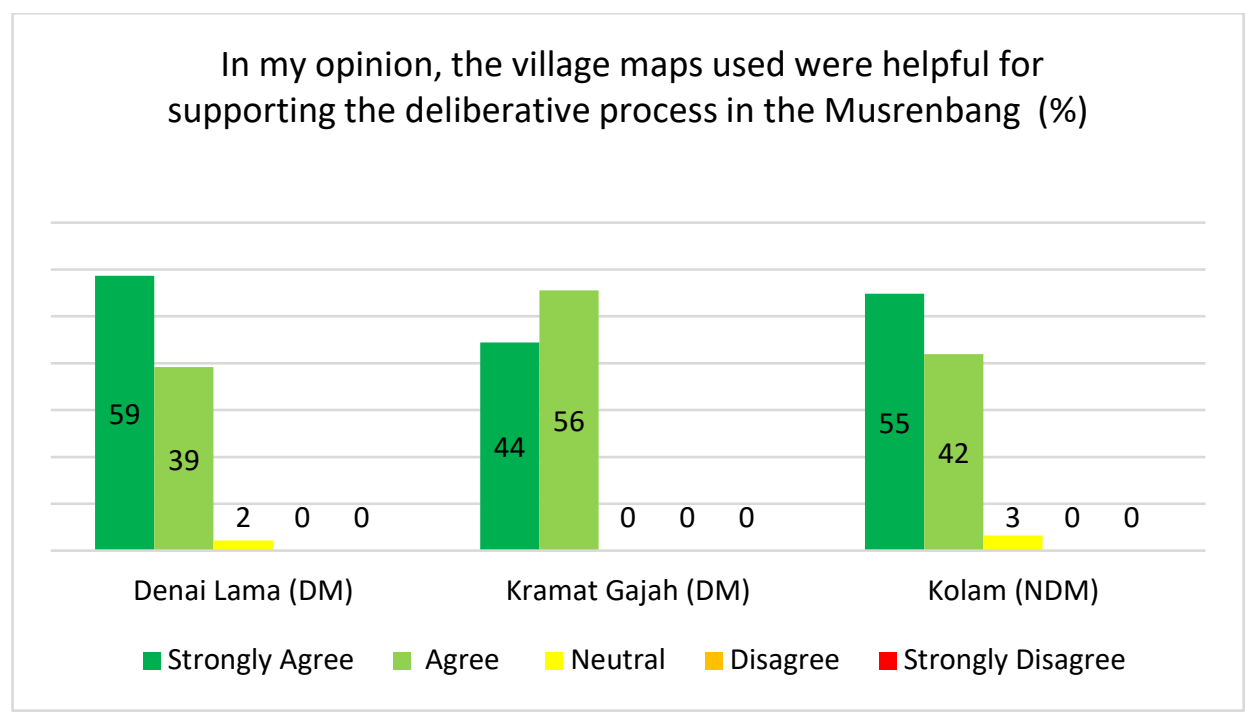

Figure 5-8. The use of village maps to support the deliberative process in the Musrenbang.

The interviews also revealed that the use of maps increased the citizens' trust in the village government. Interviewee $A 10$ said that the maps were crucial to understand which particular topic was being discussed or needed to be prioritised. This kind of information is important to inform decision making in the Musrenbang process. Moreover, the visualisation of the village area on the maps facilitated the participants' engagement with the topics of discussion (A10, personal communication, 5 February 2020). In the control villages that did not use maps, we found the ambiance of the Musrenbang deliberation in 2020 almost similar to that of the Musrenbang in 2018. The discussion was tedious and boring, and most participants kept 
silent during the meeting. The atmosphere of the Musrenbang was more like that of a ceremony than of a decision-making forum.

Although the participatory village maps had a positive influence on the Musrenbang deliberation, the majority of respondents from most of the villages were of the view that some participants dominated the discussions. More than half or two-thirds of the participants from Denai Lama, Kramat Gajah, Kolam, and Tandem Hulu II agreed that some participants were too dominant during the deliberations (Figure 5-9). The Sidoharjo I Pasar Miring participants gave mixed responses.

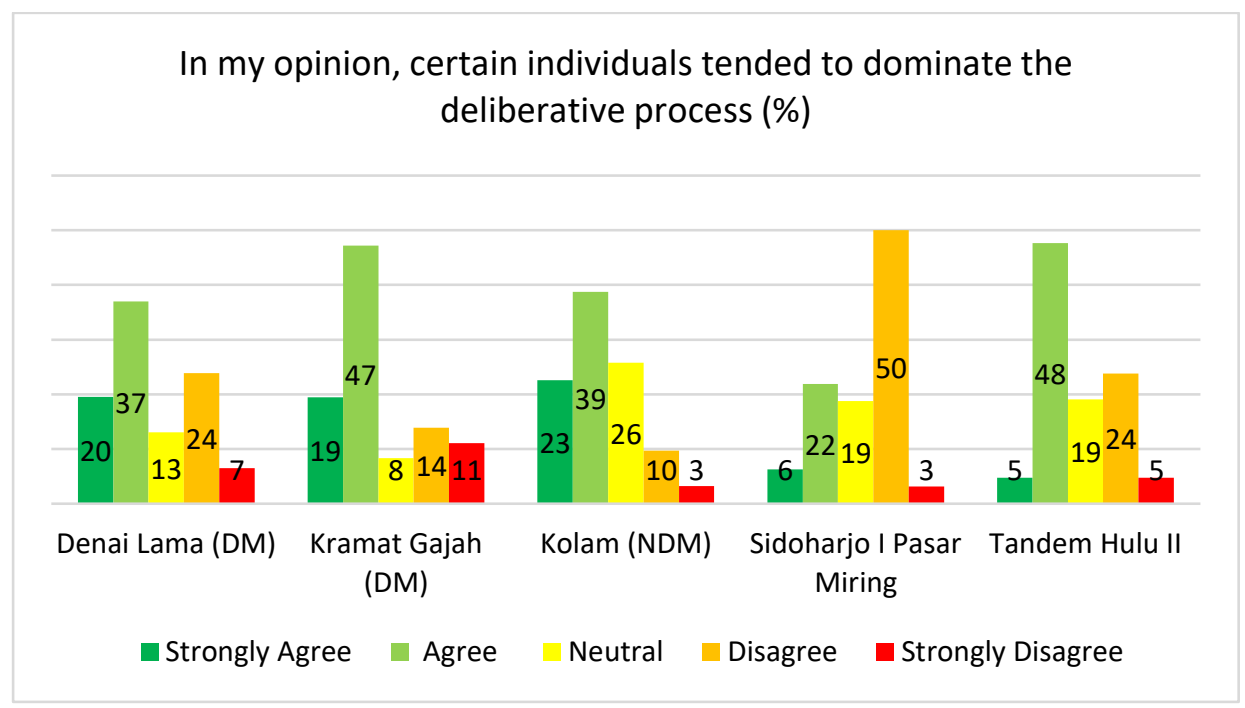

Figure 5-9. Domination of the Musrenbang deliberations by certain participants.

In Sidoharjo I Pasar Miring, only one-third of the participants agreed that certain individuals dominated the deliberative process (Figure 59). The participants' background as farmers and the purpose of the meeting, as discussed in Section 4.1.3, could be the two main reasons why their responses were somewhat different from those of the participants from other villages.

Our observations also confirm that in all intervention and control villages, the discussion tended to be dominated by some participants, particularly village officials or community leaders who had more control and influence within the village communities. We noted three main causes for this issue. First, the village elites (village head, village staff, village council (BPD), village development board (LKMD), and heads of neighbourhoods) often used their roles as Musrenbang organisers to 
pre-select the attendees. The elites preferred to invite participants, from their circles or kinship groups, who would not oppose their ideas or development proposals. Interviewee A4 said that ideally, the participants from the intervention villages could use the participatory village maps to critically discuss the development proposal. However, since many of the Musrenbang attendees were related to individuals in the elite circles, only a few participants used the maps to oppose or criticise the proposals (A4, personal communication, 5 February 2020).

Second, some participants did not feel comfortable enough to have their say at the meeting, because the meeting arrangements were too formal and ceremonial. The schedule was also tight. The organisers only provided two to three hours for a Musrenbang meeting. The tight schedule was exacerbated by bad time management habits. All the meetings we attended always started late, by half to one hour from the time stated in the invitation, which significantly reduced the opportunity for detailed discussion among participants. Agenda items were too many and included opening remarks from the village council, officials of the sub-district government, and honoured guests from different institutions. Such arrangements led to participants having less time for fruitful discussion with other attendees. Moreover, this situation caused public speaking anxiety in some participants about articulating their opinions during the deliberative process. Interviewee B10 said, 'If we are not used to speaking in front of many people, it would feel awkward. We could not express our opinion' (B10, personal communication, 28 January 2020).

The meeting arrangement also led to fewer females participating in the Musrenbang, particularly in Kolam, Tandem Hulu II, and Sidoharjo I Pasar Miring (see Table 5-1). However, high female participation in the Musrenbang, as was seen in Denai Lama and Kramat Gajah, also did not guarantee that the female participants could contribute more during the deliberative process. The meeting arrangements also drove female participants to feel shy and less confident in conveying their views. A woman participant, A5, from Denai Lama said, 'They have [different] opinions, but do not have bravery [to convey their opinions]. That is the main problem. Not all people can speak in front of lots of people. Nervous. Sometimes it makes us remain silent, and just listening' (A5, personal communication, 5 February 2020). We also observed that female participants simply agreed with the males' opinions during the deliberative processes. Interviewee $A 6$ said that 
female participants remained silent during the meeting because they typically had the same opinions or ideas. Therefore, normally, one person talked on their behalf (A6, personal communication, 5 February 2020).

Third, the meeting venue brought another problem to Musrenbang implementation. Typically, it was the village meeting hall, which was often too small to accommodate a large group of people. The venue could be too noisy and crowded, and the meeting leaders could not efficiently control the crowds. Interviewee B4 said that while someone was speaking in the forum, others did not listen as they talked with the persons who sat next to them (B4, personal communication, 28 January 2020).

These findings indicate that the use of participatory village maps could not fully overcome the domination of the discussion by some individuals, primarily because the elites were not willing to create a democratic and inclusive participatory process for all citizens. Moreover, the maps were less effective when the meeting leaders or the organisers could not satisfactorily manage the deliberative process.

\subsubsection{To what extent do the participatory village maps support the Musrenbang outcomes by enabling collaboration between participants?}

The evaluation resulted in significant findings for three criteria related to the outcomes of public participation, as described below.

\subsubsection{Knowledge sharing: Maps were helpful for sharing development issues in the villages}

The participatory village maps enabled participants to share their knowledge with other participants. We observed that the discussion among participants from the intervention villages (Denai Lama, Kramat Gajah, Kolam) became quite intense when someone referred to the maps. Interviewee B2 said, 'When a citizen shared his/her opinion, we gained new information about the current condition that previously we did not know' (B2, personal communication, 28 January 2020). A woman interviewee from Kolam said, 'Knowledge sharing occurred, among the heads of neighbourhoods, among community leaders, the youth club. In the past, their opinions were less considered. Now, they 
can share with each other' (B5, personal communication, 28 January 2020).

The participatory village maps were also helpful for clarifying or informing the development plans displayed on the map. For example, when a participant from Denai Lama asked why the street lamps had not been installed yet in his neighbourhood, the village head answered by pointing out the plan for street lamp instalment listed on the proposed development plan map. Interviewee A15 was of the same view: 'In the last [Musrenbang] meeting, several participants were discussing some issues in a small group. The issues discussed in the small group were then shared with other participants [using the available maps]' (A15, personal communication, 5 February 2020).

We also observed that people who attended the participatory mapping workshops were more active in the discussion. They had a better understanding of the maps because they were involved in creating them. Therefore, they could share their knowledge while relating the issues with the aid of the displayed maps. They were better able than the other participants to refer to the maps and relate the maps to the discussed topics. They also felt more confident in the Musrenbang after participating in the mapping workshops. Respondent A7 from Denai Lama said, 'For me, receiving the knowledge [of how to produce village maps in a participatory manner] has made me more confident in the Musrenbang' (A7, personal communication, 18 February 2020). A respondent from Kolam, B4, said that he became a source of information for other Musrenbang participants, who did not take part in the mapping workshops, when they had difficulties identifying the area discussed on the displayed maps (B4, personal communication, 28 January 2020).

In the control villages, the situation was different. Knowledge sharing occurred, but participants had difficulty identifying the objects or locations mentioned in the Musrenbang. They relied heavily on their mental maps of the village area. Therefore, sharing knowledge was challenging since no visual data, such as maps, were available. 


\subsubsection{Social learning/building institutional capital and capacity}

The results also imply that the participatory village maps allowed participants in the intervention villages to experience social learning. The maps enhanced the capacity of the participants to handle issues or conflicts and allowed them to collaborate in solving their common problems. We observed that at least three stages of social learning occurred in the Musrenbang. The participants from the intervention villages experienced all three stages, while participants from control villages only experienced the first stage of social learning. First, the questionnaire showed the rise in awareness of participants from all villages that participatory village maps or other supporting data should be available for the Musrenbang process. The interviews also discovered that data availability continued to be challenging, particularly for interviewees from the control villages. The maps could also stimulate participants to learn and work collaboratively to solve their problems. Interviewee C9 from Kramat Gajah said, 'I finally understand that the Musrenbang could be the [right] place to discuss and solve the village problems. The citizens can share their concerns in the Musrenbang meeting, so I learned that we need to discuss [to solve our common problems]. The process was transparent' (C9, personal communication, 11 February 2020).

Second, participants from the intervention villages showed behavioural changes when addressing village issues. The participants began to understand the benefits of maps in Musrenbang practice. For example, they finally understood that they could visualise almost everything on a map, as demonstrated by the proposed development map they used during the Musrenbang. The maps also changed their way of perceiving and handling problems. Interviewee C4 said, 'By using the map, we can clearly see the village boundaries. We can also measure the length, distance [between two places], and the area directly on the maps' (C4, personal communication, 7 February 2020).

Several interviewees from the intervention villages also revealed that the participatory village maps had been used several times before the Musrenbang. The village head of Kolam took the initiative to print copies of the village maps at a neighbourhood scale and then distributed them to each neighbourhood. Consequently, the heads of neighbourhoods could use the maps for updating socio-economic and population data for their neighbourhoods. Similarly, in Denai Lama, 
given the importance of the agricultural sector as the main livelihood, a thematic map displaying the working areas of farmers' groups was produced to measure each group's exact area, estimate the production in each area, and decide on the allocation of subsidised fertilisers for each group. In the past, they had never used a map to calculate or make such decisions. They learned how geospatial data, such as maps, can be a useful tool to visualise problems spatially and formulate solutions in a short period.

Third, the participants began to challenge underlying assumptions or values. For example, we found that discussion about sustainable development and land-use changes was quite intense in Kolam and Denai Lama. During the discussion, the participatory village maps became a valuable source for identifying the area. They discussed some profound challenges of the rapid land-use changes in their village, while also proposing alternatives or solutions. A respondent from Kolam said that the maps enabled him to recognise the village's land-use changes. He stated, 'I noticed the land-use changes in our village area [on the map]. For example, I found a site that used to be a paddy field area which has now changed into residential areas' (B3, personal communication, 12 February 2020). He questioned their previous assumption that residential areas can bring more economic benefits than agricultural areas. This old assumption had triggered rapid land-use changes in the village. This kind of awareness would be helpful for the better management of spatial planning in villages, for example, for identifying which parts of the villages could be planned for built-up areas and for thinking critically about land-use changes that might endanger the sustainability of the agricultural sector, the main livelihood of village communities.

5.3.2.3 Influence on final policy: Participants' opinions were heard and taken into account

Participants feel satisfied when their views are heard and taken into account. Their involvement in the participatory process is more meaningful if their opinions can influence the final policy or decisions. Our interviews showed that most participants in the intervention and control villages felt that they had influence over the final policy or decisions. Interviewee A13 from Denai Lama said, 'Although the village head has the authority to take the final decision, he may not know what [developments] are needed in each neighbourhood. That is why 
we need to discuss' (C13, personal communication, 5 February 2020). Interviewee C9 from Kramat Gajah said, 'Any decisions made [in Musrenbang] came from our discussion and consensus' (C9, personal communication, 11 February 2020). However, we also observed that the participatory village maps used in the intervention villages helped participants to formulate their ideas when proposing alternatives or solutions. The maps enabled them to express their opinions in a structured way so that their views were heard and considered important. This kind of 'help' was not evident in the control villages.

The questionnaire also showed the same result. Most Musrenbang participants from all villages chose 7 to 10 in the questionnaire scale to rate their satisfaction with the Musrenbang process (Figure 5-10). However, the responses of participants from the intervention and control villages were different. Respondents from the intervention villages generally gave higher ratings for satisfaction with the Musrenbang in their villages than those from the control villages. This result indicates that the intervention villages were more satisfied with the Musrenbang process than the control villages.

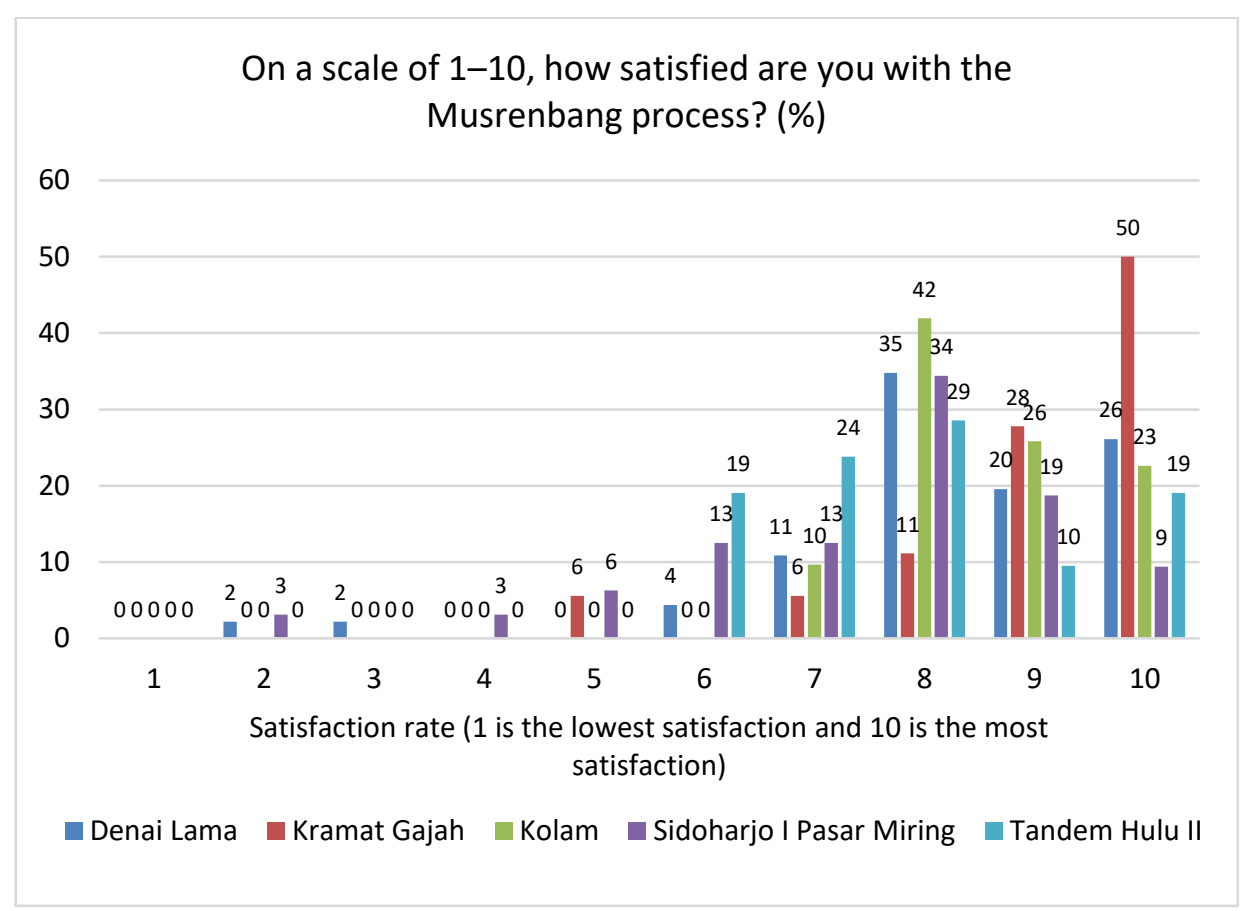

Figure 5-10. Participants' satisfaction with the Musrenbang process. 


\subsection{Discussion and Conclusions}

The empirical results of our case study indicate several vital issues related to the use of participatory village maps in Musrenbang public participation practice at the village level. First, the findings reveal that the use of participatory village maps in the Musrenbang strengthened its implementation. Most of the participants in the intervention villages agreed that the last Musrenbang, which used the participatory village maps, was much better than the previous Musrenbang. The maps enhanced communication between participants in the Musrenbang by providing a clear definition of the village area, geospatial data as resources for participation, transparency, new and creative solutions, and a dynamic deliberative process. The findings also show that the participatory village maps received positive responses from most of the Musrenbang participants. Their knowledge of the village area improved, enabling them to relate the discussion topics to the village maps used in the Musrenbang. They found that supporting data, such as maps, made the process more transparent and enhanced the Musrenbang deliberative process.

The participatory village maps also enabled collaboration between participants to achieve common goals in the Musrenbang. The visualisation of geospatial data helped the users to easily interpret the information displayed on the maps and acquire knowledge (Kraak, 2003). Knowledge sharing was evident as participants could effectively convey their concerns using the maps. Various levels of social learning were also apparent as some participants started to question previous land-use policy that might endanger the sustainability of the villagers' main livelihood. The maps helped participants to convey their ideas or concerns, which were heard or adopted in the village development plans and eventually raised their satisfaction in the Musrenbang implementation.

The situation in the control villages was different. There was almost no difference between the Musrenbang in 2020 and that in previous years. The discussion was boring and ceremonial. The process lacked transparency. Data were not available to support the discussion. Participants also had difficulty identifying the objects or locations of the topics being discussed. The division of villages into intervention and control groups led to different results and experiences for the Musrenbang process as well as for the Musrenbang participants. 
However, despite the maps enhancing the Musrenbang deliberations in the intervention villages, the potential of the participatory village maps appears not to have been fully realised. Participatory village maps could not completely overcome the power disparities between participants in the Musrenbang. Certain actors, particularly the village head and village officials, still dominated the deliberative process, indicating that it is still highly influenced by local political elites and government officials (Aswad et al., 2012; Purba, 2011, 2010; Sutiyo, 2015). Their participation in map making enabled them to acquire greater knowledge and access to the maps than the other Musrenbang participants, thereby turning the process into a 'small-group elitist activity', as mentioned by Kahila-Tani et al. (2019). The village head and community leaders usually play an important role in the community, especially by controlling the local decision forums in the village (Sullivan, 2019). They can use their influence wisely to drive the community to engage actively in achieving common interests. Conversely, they can also manipulate the community to support their ideas or interests; for example, they could use the maps to persuade and convince Musrenbang participants to support their development proposals, which may not reflect the real demands and needs of the community.

The situation is exacerbated when the village head and officials often intentionally pre-select and invite participants who would not oppose their ideas or development proposals. Consequently, although the Musrenbang public meeting is supposed to be open to and inclusive of all citizens, in reality, only specific individuals can attend the meeting. Thus, the agenda and final decisions are often in the hands of the elites. The pre-selection of participants may prevent individuals or marginal groups from accessing or attending the Musrenbang, which eventually perpetuates the power disparities between participants. These power disparities may weaken the Musrenbang implementation as well as prevent the optimal use of participatory village maps. Therefore, a comprehensive understanding of the local context and actors is crucial to minimise and mitigate unexpected factors, such as power disparities. More importantly, however, the village elites' political will to make the public participation process more inclusive and accessible to all citizens is also a prerequisite to its success (Bednarska-Olejniczak et al., 2020) as well as to an increase in the effective use of maps in public participation practice (Reyes-García et al., 2012). 
This study also revealed that female participants show a great interest in exploring or using participatory village maps. However, they do not feel confident enough to engage in the Musrenbang deliberations. The local cultural context and strong patriarchal values within society may be crucial factors that hinder women from contributing to the Musrenbang process (Rhoads, 2012; Taylor et al., 2006). Some studies have shown that women have extensive knowledge of their locality. For example, Corbett and Keller found that women have valuable cultural and historical information that might not otherwise have been gathered or included if they were not involved in participatory mapping workshops (Corbett \& Keller, 2006). In the Brazilian Amazon, the women of Moikarakô are able to recognise important places and objects displayed on satellite images, especially gardens and domestic spaces (The inhabitants of Moikarakô et al., 2006). Such knowledge deriving from their mental maps (Pánek, 2016) and 'a view from below' experience from their daily activities (Gilbert \& Masucci, 2006) indicates that women could optimally use village maps if they had more space or opportunities to explore them during the Musrenbang.

The optimal use of participatory village maps was also highly influenced by the meeting arrangements for public participation. Poor arrangements can lead to elite domination (Kahila-Tani et al., 2019) as well as prevent participants from conveying their opinions due to public-speaking anxiety (Falco, 2016). Organisers should provide convenient settings more conducive to the discussion. The leader of the meeting should also manage the meeting professionally to create a democratic and pleasant atmosphere for all participants. Effective arrangements for public participation would prevent elite domination, while stimulating participants to engage actively during deliberations.

Public acceptance of participatory maps is also crucial to ensure that they are optimally used in public participation practice. We can learn from the control village that used a private consultant to produce village maps without involving all village stakeholders. The outcome of this exercise was less accurate results, with much important information, especially the boundaries, being unclear; consequently, the village head preferred not to use the maps for any purpose, including for the Musrenbang process. The village head had predicted that the community would question the information displayed on the maps, or worse, completely reject them. 
By reflecting on the participatory village maps used in the intervention villages, we may conclude that the process of the participatory mapping workshops in these villages attained the third-level 'interactive involvement' in participatory mapping suggested by McCall and Minang (2005). At this level, the participants are actively involved in the map-making process, decide on what kind of maps they want to produce, and use the maps to help them in the participatory planning process (McCall \& Minang, 2005). Many scholars have suggested that it is important to ensure that the village communities are involved in the map-making process (Brown \& Fagerholm, 2015; Corbett \& Keller, 2004; McCall, 2021; Pánek, 2015b). Local stakeholders with their local spatial knowledge are reliable sources of data to produce local maps. They should be invited to be involved from the initial phase of the mapmaking process since they know the village area well (Kahila-Tani et al., 2019; McCall \& Dunn, 2012). The involvement would not only acknowledge their local spatial knowledge but also increase the community's acceptance of the participatory maps (McCall, 2003, 2021; Verplanke et al., 2016). Active involvement could also determine users' acceptance of the maps produced in the participatory mapping exercise since they would feel more included, engaged, and valued (McCall, 2021). The involvement could also build their trust in the researcher (McCall \& Dunn, 2012) and boost the community's sense of ownership of the mapping results (Pánek, 2015b). This may explain why the maps produced by stakeholders in the intervention villages had greater acceptance within the communities compared to the maps produced by a consultant for one of the control villages.

The use of participatory village maps in the Musrenbang also shows that discussion about boundaries is important for village stakeholders. The question of the certainty and precision of maps produced in participatory mapping exercises was raised by McCall (2006). He implied that the information displayed on maps, for instance, information about valuable resources or sacred places and boundaries, could be sensitive for the local communities and could even provoke conflicts. Unclear boundaries could provoke land grabbing by other parties (Shahab, 2016) or conflicts with other villages (Ambarwulan et al., 2018; Reyes-García et al., 2012). Therefore, the determination and affirmation of village boundaries are crucial for clarifying the village administrative area's precision and legal certainty (Ambarwulan et al., 2018). Our case study also suggests that boundary information is 
helpful for easing conflicts between heads of neighbourhoods when dealing with land registration and taxation issues.

However, it is important to note that in the Indonesian context, the legal basis of the village maps produced by participatory mapping initiatives of non-governmental institutions is still uncertain. Although the Village Law 6/2014 and the Head of Geospatial Information Agency (BIG) Regulation 3 of 2016 regulate village mapping and village spatial planning, there is no guarantee that the products of participatory mapping activities would be acknowledged by upper levels of the government or integrated with formal (national and district) spatial planning (de Vos, 2018). As a result, the village boundaries drawn on village maps are still considered tentative. The government often considers mapping as a complex process that requires legitimate and skilful mappers and proper methodologies and techniques, with standard cartographic rules. Therefore, it is important to inform or consult with the upper levels of the government before participatory mapping takes place. The consultation could initiate constructive discussion or negotiation between governmental and nongovernmental actors; this may eventually raise the bargaining position of the maps produced by communities to obtain formal governmental recognition.

This study also showed that all intervention villages used the proposed development map during the Musrenbang. This map displayed all the identified development issues and proposed projects based on the discussion in the mapping workshops. This map differed mainly from the other four maps (the satellite image, infrastructure/public facilities, land-use, and boundary maps) produced in the mapping workshops in that it did not fully follow the strict layout prescribed in existing regulation, such as the Head of Geospatial Information Agency (BIG) Regulation 3 of 2016. The proposed development map allowed mapping workshop participants to create or use their own symbols when drawing the identified village problems and suggested solutions. As a result, the proposed development map was useful for supporting the Musrenbang deliberation in the intervention villages for two reasons. First, the map presented the real needs and development priorities of the village communities; therefore, the displayed information was a neat fit with the main purpose of the meeting. Second, the map was easy to use and understandable to the village 
community since the symbols were originally made by the community itself.

This study had some limitations. First, not all Musrenbang participants were involved in our digital and non-digital participatory mapping workshops; this may mean that some participants did not understand the maps used in the Musrenbang. Improving the mapping methods is necessary. For example, an online application that can accommodate the engagement of more people could be a solution; it may attract diverse stakeholders and outreach groups to participate in the mapmaking process (Brown \& Kyttä, 2014; Jankowski et al., 2019; Kraak, 2004). Second, although the Musrenbang has a critical role in identifying and listing projects with the highest priority for villages, this study did not investigate the final budget allocation as well as project implementation. The Musrenbang is merely one part of the whole planning process, and the finalisation of the plan can take several months after the Musrenbang. An in-depth analysis of the final budget allocation and project implementation is beyond the scope of this study but could be an interesting future research topic.

Despite these limitations, this study clearly indicates the importance of participatory village maps in strengthening public participation practice at the village level. The analysis contributes to the discussion on solutions acceptable to different countries in the field of participatory planning in rural areas. Our results also contribute empirically to the research on participatory mapping methods and use of maps in public participation practice. 
Chapter 6: Synthesis 
The Sustainable Development Goals (SDGs), adopted by all United Nations Member States in 2015, provide a shared pathway for countries to reach peace and prosperity for their people through sustainable development. To be successful, the global goals and targets specified in the SDGs must be localised appropriately so that they are applicable at different governance levels, from the national and regional to the local urban and rural scale (Pfeffer \& Georgiadou, 2019; Ulbrich et al., 2018).

Public participation plays an essential role in the implementation and localisation of the SDGs, particularly for reaching targets 11.3 and 16.7. Both targets explicitly state that public participation should support sustainable human settlement planning and management by enabling relevant stakeholders to be directly involved in the decisionmaking process. The localisation of the two SDG targets through public participation requires suitable methods and tools to accommodate diverse stakeholders (Fisher \& Fukuda-Parr, 2019) and evaluate their achievements (Janoušková et al., 2018; Yonehara et al., 2017). Since social, economic, and environmental development is almost entirely geographically based (Scott \& Rajabifard, 2017), geospatial data, such as satellite images, aerial photographs, and maps, can play an important role in the planning, execution, measurement and evaluation of SDG implementation (Avtar et al., 2020; Kraak et al., 2018).

Various scholars have focused on the localisation of SDGs and strengthening of public participation practice (Fisher \& Fukuda-Parr, 2019; Flacke et al., 2020; Klopp \& Petretta, 2017; Koch \& Krellenberg, 2018; Liu et al., 2019). However, most studies have concentrated on urban areas. The issues of sustainable development and public participation practice in rural areas are still understudied (BednarskaOlejniczak et al., 2020; Murdoch, 1993). This thesis fills this gap by seeking to understand how public participation at the rural level can contribute to the localisation of SDGs while attaining sustainable development in villages. Furthermore, this study also attempts to investigate to what extent geospatial data could help localise the SDGs while strengthening public participation practice in rural areas. 
This broader objective is divided into four sub-objectives:

1. To evaluate the implementation of the Musrenbang at the village level in Indonesia by using an SDG-based evaluation framework.

2. To examine the extent of spatial knowledge and the scale of its use in formal public participation practice and its potential to enhance practice.

3. To develop a collaborative spatial learning framework that enables the integration of stakeholders' spatial knowledge, facilitates their communication and collaboration, and leads stakeholders in knowledge co-production and social learning processes.

4. To assess the extent to which village maps produced at participatory mapping workshops help strengthen public participation practice at the village level.

Section 6.1 presents a summary of the main findings for each subobjective. Section 6.2 provides the overall goals and the general conclusion. Section 6.3 presents a reflection on the contributions of the study. Section 6.4 presents the limitations of this study. Section 6.5 provides recommendations for future research.

\subsection{Summary of main findings}

\subsubsection{Objective 1: To evaluate the implementation of the Musrenbang at the village level in Indonesia by using an SDG- based evaluation framework}

This sub-objective provides an understanding of the implementation of the Musrenbang within the study areas. This sub-objective also contextualises the SDG concept by developing a public participation evaluation framework with the SDG indicators 11.3.2 and 16.7.2. In addition, this chapter discusses the evaluation of Musrenbang practice and highlights some factors that may impede its implementation (see Chapter 2 for details).

The Musrenbang is regulated firmly in Law Number 25 of 2004 on the System of National Development Planning and its derivative regulations. The legal framework provides guidance for the local governments to conduct the Musrenbang regularly each year at all 
governance levels, from the village to the country. According to the law, as a bottom-up approach, the Musrenbang should be implemented in compliance with the existing regulations and involve citizens and relevant stakeholders in the decision-making process. The Musrenbang should be responsive to the resolution of development problems while facilitating democratic and inclusive public participation of communities.

In the study areas, the Musrenbang was generally implemented at the village level through public meetings. Various stakeholders were invited to participate in the meetings to identify the major problems faced by the villages and discuss possible projects or programmes to solve them. The village head or the village council acted as the meeting leader whose main responsibility was to facilitate the discussion to reach a consensus on village development plans, including budget estimation.

An SDG evaluation framework with the SDG indicators 11.3.2 and 16.7.2 was developed to assess the implementation of the Musrenbang in villages in the study areas. Various public participation criteria suggested by scholars were carefully selected to correspond with the indicators. Based on the evaluation results, three main problems in implementing the village Musrenbang were identified. First, the process did not comply with the existing regulations. Different laws have caused confusion among villagers, resulting in delays in the planning and execution of development programmes. Second, meeting participants lacked knowledge integration and learning processes. Limited or no data to support the discussion and formal setting of the Musrenbang inhibited the participants from expressing their opinions or knowledge. Consequently, less local knowledge was captured during the deliberative processes of the Musrenbang. Third, the power relations among the stakeholders also undermined the implementation of the Musrenbang. Four stakeholder groups could be identified in the village Musrenbang: the upper government (officials from higher administrative divisions of government), village elite, supporters of the village elite, and community-based organisations/ordinary citizens. The village elite and their supporters often dominated the whole process, while community-based organisations/ordinary citizens had less power to influence the discussion and the final decision. The upper government, with more power to influence, had little interest in strengthening the decision-making process in the Musrenbang or 
minimising the domination of certain stakeholder groups (see Chapter 2 for details).

This study concludes that the contextualisation of SDG indicators 11.3.2 and 16.7.2 can be a good starting point for public participation practice. The framework was beneficial to finding the misalignments in the implementation of the village Musrenbang and highlighted several crucial factors that need further improvement. The developed evaluation framework can be applied elsewhere; however, it requires proper conceptualisation and contextualisation to fit the local context where public participation takes place. This study also concludes that a comprehensive understanding of the stakeholders' knowledge, including how to integrate and exchange the knowledge, could be a useful medium to improve the current Musrenbang practice while minimising the power gaps between participants in the process.

\subsubsection{Objective 2: To examine the extent of spatial knowledge and the scale of its use in formal public participation practice and its potential to enhance practice}

This sub-objective explores the spatial knowledge and geospatial data present during the implementation of the Musrenbang. Specifically, this chapter aims to identify the spatial knowledge of villagers, how this knowledge was used in the Musrenbang, and the potential of spatial knowledge and geospatial data to enhance the public participation practice of the Musrenbang (see Chapter 3 for details).

To achieve this sub-objective, a three-dimensional cube framework was developed to understand the utilisation of spatial knowledge in public participation practice. The framework consisted of three mutually dependent aspects: the types, levels, and socio-spatial relationships of spatial knowledge. The framework was used to classify and identify the dynamics, actors, and activities involved in utilising spatial knowledge in implementing the Musrenbang.

The findings show that all four types of spatial knowledge - tacit, context-embedded community, context-embedded sectoral, and expert - were present and that the respondents possessed at least one type of knowledge. They acquired spatial knowledge through their formal or informal daily activities, social interactions or professional practice. The respondents in the study areas also possessed all three levels of spatial knowledge - landmark, route, and survey. The three 
levels show the developmental phases of how individuals acquire spatial knowledge; thus, transition from one level to another is attained through learning or experience. All respondents passed the landmark level as they could identify the particular location of an object in the village, such as the village office, mosques, or primary schools. However, individuals who remained at this level could not draw the relative positions of objects located in different places or travel between places. The majority of the respondents attained the route level. They could identify landmarks in the village and link or travel between these landmarks using the shortest route; for example, they could show the shortest route from the mosque to the village office. Only a few respondents, most of whom worked as government officials, attained the survey level. Individuals at this level could interpret information displayed in a two-dimensional map. They could measure the distance between landmarks directly on the map, and they were, therefore, able to link and navigate between places without being limited by travel paths.

The socio-spatial relationships - understanding, bounded solidarity, and power or dominance to control land management - between the villagers in the study areas also showed interesting results. Although most respondents had a sufficient understanding of their village areas, this study found that village officials, heads of neighbourhoods, and women had greater knowledge of their village than other respondents. The village officials and heads of neighbourhoods had greater knowledge because they had to understand the administrative areas of the village as part of their duties as public officials. The women had more knowledge of the village because they spent most of their time there. Therefore, their daily activities and social interactions with neighbours enabled them to better understand the village area. For example, some women respondents said that they could identify the exact location of each house in their neighbourhoods, the owner, and each individual who lived in the house. This study also found that the neighbourhood or village borders became a crucial topic for the villagers. Borders not only define the scope of an area, but also create bounded solidarity between the people who live in that area. During the FGDs and interviews, the respondents often used the village border to orientate themselves or to position particular landmarks in the village. The border is also crucial for claiming the existence of activities of certain stakeholder groups; for example farmer groups in all our 
case study villages knew the boundaries of the agricultural areas, and even made a sketch map that illustrated the agricultural areas and the infrastructure that supported agricultural activities. Furthermore, the border is a sensitive issue that can lead to conflicts between villages or neighbourhoods. Thus, defining the exact boundaries between villages and neighbourhoods is important to guarantee the exact administrative areas of each village as well as to minimise border conflicts between neighbours. This study also found power disparities among the Musrenbang participants. The village elite had more power to control the meeting, including to take the final decisions. With such power gaps, they could manipulate the utilisation of spatial knowledge to favour their interests and influence.

The Musrenbang participants utilised their spatial knowledge intuitively during the meeting. They admitted that their spatial knowledge was valuable for identifying places within their villages, but they were unaware of its potential to strengthen the implementation of the Musrenbang. This study also found that the villages had geospatial data, such as the village map that was manually drawn, unscaled and without any geographical coordinates, using pens or markers on paper or whiteboard. The map was only used for village office decoration. The villagers never used the map for any development purposes, including for supporting the Musrenbang implementation.

The study concludes that comprehending the types, levels, and sociospatial relationships of the spatial knowledge of stakeholders could be helpful for understanding and identifying suitable methods for using or integrating the knowledge. The use and integration of spatial knowledge should fully consider the local context and characteristics of the stakeholders and ensure that different groups of stakeholders with distinct interests and influence can express their spatial knowledge and collaborate to achieve common goals in public participation practice. 


\subsubsection{Objective 3: To develop a collaborative spatial learning framework that enables the integration of stakeholders' spatial knowledge, facilitates their communication and collaboration, and leads stakeholders in knowledge co-production and social learning processes}

This sub-objective aims to develop and test a suitable method that uses geospatial data to support the decision-making processes at the village level and helps achieve the SDGs. A collaborative spatial learning framework was developed to integrate the spatial knowledge of the stakeholders by building on their communication and collaboration and to facilitate knowledge co-production and social learning of the stakeholders.

The framework was applied in three participatory mapping workshops held in the case study areas. The workshops included two digital participatory mapping exercises: one used the OGITO (Open Geospatial Interactive Tool) application; and the other was a nondigital conventional exercise using transparent plastic layers, markers, and stickers. A photo-mapping method using a high-resolution satellite image was employed to help the selected village stakeholders to identify and sketch the map objects. The participants were pre-selected by the village elite, particularly the village head, head of the village council (BPD), and head of the village empowerment board (LKMD). The composition of the participants represented the stakeholder groups that participated in the village Musrenbang, namely the village head, village secretary, BPD, LKMD, community leaders, youth group (Karang Taruna) and women's group (PKK). The participants sketched four village maps (a boundary map, facilities map, land use map, and proposed development map) during the participatory mapping workshops.

This study concludes that the participatory mapping workshops helped the stakeholders to produce georeferenced village maps. The workshops also helped to increase the participants' awareness of sustainable development at the rural scale and to sustainably implement the village development plans (see Chapter 4 for details). 


\subsubsection{Objective 4: To assess the extent to which village maps produced at participatory mapping workshops help strengthen public participation practice at the village level}

This sub-objective attempts to investigate the role of the village maps produced at the participatory mapping workshops in enhancing the Musrenbang processes. Using various criteria from the SDG evaluation framework as discussed in Chapter 2, the implementation of the Musrenbang in five villages in the study areas was evaluated. The evaluation aims to understand how the participatory village maps can facilitate communication and collaboration among Musrenbang participants in the case study areas. Three of the five villages were classified as the intervention group because they took part in the participatory village mapping workshops. The other two villages were in the control group since they did not undertake any mapping exercises (see Chapter 5 for details).

The comparison of the two groups shows that the implementation of the Musrenbang in the intervention group, which used participatory village maps, was better than that in the control group, which did not use any maps during the application of the Musrenbang. The use of participatory village maps in the Musrenbang process strengthened its implementation. Most of the participants in the intervention group responded positively that after using the maps, the last Musrenbang was much better than the previous one. The maps facilitated communication among Musrenbang participants; the Musrenbang was more transparent and the deliberative process more vibrant. The maps visualised the exact boundaries of the village areas to the Musrenbang participants, making the scope of the task clearer. They also stimulated new or creative inputs from the participants to enrich the discussion in the Musrenbang. In addition, the maps enabled collaboration between participants during the Musrenbang. They experienced knowledge sharing and social learning, which built their capacity to solve common problems. They were also more satisfied with the Musrenbang processes because the maps allowed their views or opinions to be heard or taken into account.

Despite much evidence of the positive outcomes of using participatory village maps in Musrenbang implementation, the findings also show that the potential of the maps was not fully realised. The participatory village maps could not entirely eliminate the power disparities among 
the stakeholder groups in Musrenbang implementation. Certain actors still dominated the deliberative process. As the most dominant group, the village elite often intentionally pre-selected participants who would not oppose them as invitees to the Musrenbang. Pre-selection of participants may prevent individuals or marginal groups from accessing or attending the Musrenbang, although the process is supposed to be open to and inclusive of all citizens.

\subsection{Overall goals and general conclusions}

This study can be located in the ongoing discourses on better methods to localise the SDGs, particularly in public participation practice. As a regular public participation exercise held at each governance level in Indonesia, the Musrenbang has the potential to localise the SDGs while improving the quality of the decision-making process. Thus, this study attempts to localise the SDG targets 11.3 and 16.7, while evaluating and strengthening the implementation of the Musrenbang in collaboration with village stakeholders. This study tested the fundamental assumption that localisation could strengthen the participatory process in the Musrenbang by means of spatial knowledge and geospatial data interventions.

The insights from this study highlight new perspectives and show whether or not the assumption holds. The comparison of Musrenbang implementation between the intervention and control villages showed that participatory village maps had a positive influence by strengthening the implementation of the Musrenbang in the intervention villages. The villages in the intervention group implemented the Musrenbang better than the villages in the control group. The maps produced at the participatory mapping workshops and the mapping experience helped to stimulate Musrenbang participants to better use their spatial knowledge. Visualisation of the village from the sky was useful for relating the participants' spatial knowledge with the village area discussed at the Musrenbang meeting.

It is also important to note that the participatory research method (Cornwall \& Jewkes, 1995) employed in this study was successful in facilitating the stakeholders involved in the Musrenbang to become active respondents that shaped the design and direction of the study. This method requires careful preparation, as well as close 
communication and interaction with the respondents. The Musrenbang stakeholders were involved in this study from the first to the last phase through various data collection activities, i.e. focus group discussion, questionnaire, interviews, and direct observation. Their involvement provided a sharing and learning environment for all parties. Building the trust of communities and having fair mutual connections are prerequisites for applying participatory research methods. The research design should acknowledge and adopt the local knowledge and local context of the case study areas. Therefore, the design of the research intervention approaches, such as the participatory mapping method and the options for the maps produced, were also derived from the inputs of the villagers as the main respondents in this study.

Although the participatory village maps were beneficial, this study found that their potential was not fully realised due to the power disparities among participants. Musrenbang participants were mostly pre-selected by the village elite, particularly by the village head and village officials. As organisers, they had the privilege of setting the meeting, including choosing the attendees. The village elite preferred to only invite participants who would not have opposed them during Musrenbang deliberations; consequently, the agenda was set and the final decisions were made often by the village elite. This practice clearly does not comply with the SDG targets 11.3 and 16.7 which promote public participation practice inclusive of all individuals in the community.

This situation of power gaps could be an impediment to SDG implementation at the local scale. SDGs were formulated to be actionoriented and universally applicable (Hák et al., 2016), which make SDG targets and indicators often too 'technical, managerial and measurable' for framing development (Fisher \& Fukuda-Parr, 2019). As a result, power and structural inequalities are often neglected in SDGs, although these problems exist within local communities (Ulbrich et al., 2018). Localisation of the SDGs compels a comprehensive understanding of the local context so that unexpected factors such as power disparities can be minimised or mitigated. The participatory mapping workshops and the village maps produced in this study certainly enhanced the Musrenbang process; however, making the process more inclusive and accessible to all citizens was beyond the reach of the participatory mapping workshops and the village maps. The decision eventually resided with the village stakeholders, particularly the elite. Their 
political will to involve citizens in the whole process is a prerequisite to the success of public participation practice (Bednarska-Olejniczak et al., 2020).

Overall, the findings of this study clearly show that geospatial data and spatial knowledge could serve as important media to localise the SDGs to be more tangible and operational. Furthermore, this study makes an empirical contribution to the research on participatory mapping methods and the use of maps in public participation practice. This contribution should renew the debate as well as amplify the calls for other studies to examine the localisation of SDGs in public participation practice in rural areas which would be quite relevant for other contexts.

\subsection{Reflections and Main Contributions}

This section presents the main contributions of this study to scientific research and its input to the strengthening of the Musrenbang public participatory planning process as well as to the case study areas.

\subsubsection{Contributions to scientific research}

This study serves as a starting point for a new discourse on the need to reformulate the localisation of SDGs, particularly in public participation practice at the local-rural level which is highly influential yet relatively understudied by scholars. Public participation practice should have policy impacts on citizens so that it 'can actually upscale to meet at scale existing challenges and contribute at scale to SDGs' (Cabannes, 2019, p. 9). Therefore, the localisation of SDGs should promote a bottom-up rather than a top-up approach that considers the local context and local stakeholders (UCLG, 2018). A profound understanding of how public participation at the rural governance level is implemented is valuable for better localising the SDGs at the operational level.

As a useful start to developing better and usable frameworks in different contexts, this study provides three conceptual frameworks: the SDG public participation evaluation framework (Chapter 2); the cube framework (Chapter 3); and the collaborative spatial learning framework (Chapter 4). These three frameworks could broaden the scope of solution-finding as the factors that play roles in public 
participation practice are diverse in nature and overlapping in extent. The SDG public participation evaluation framework could serve as a starting point for assessing public participation practice in other contexts. The cube framework could help to identify and examine the spatial knowledge used in an activity that involves diverse actors. The collaborative spatial learning framework, which was applied in participatory mapping workshops, could be used to help a group of communities or stakeholders to utilise their spatial knowledge to communicate, collaborate, co-produce knowledge, and experience social learning. When employing these frameworks, it is important to consider the local context of the case study. For example, in defining the criteria for evaluating public participation practice, it is important to have a basic understanding of the procedures, mechanisms, and the cultural context of the society. The chosen criteria should meet these aspects appropriately for optimal evaluation.

The localisation of SDG targets through public participation practice requires suitable methods and tools to accommodate diverse stakeholders (Fisher \& Fukuda-Parr, 2019) and evaluate their achievement (Janoušková et al., 2018; Yonehara et al., 2017). Thus, this study provides an innovative approach to assessing public participation practice by using the SDG indicators 11.3.2 and 16.7.2 as the basis of evaluation. The framework was developed using the global indicators of SDGs and the criteria suggested by various scholars in the public participation knowledge domain (see Chapter 2 for details). Therefore, this SDG evaluation framework would not only be helpful for assessing Musrenbang implementation in villages in the case study areas but also be useful for appraising public participation practice in different countries or contexts.

Citizens' spatial knowledge and sufficiently developed spatial skills are necessary for modern society because our daily activities cannot be separated from spatial and geographical components (Goodchild, 2006). The second framework - the cube framework (see Chapter 3 for details) - could facilitate a better understanding of how the stakeholders involved in public participation practice acquire and utilise their spatial knowledge. In this study, the cube framework was used to identify and classify the spatial knowledge possessed by the Musrenbang stakeholders. The classification of spatial knowledge into types, levels, and socio-spatial relationships of people who own and 
use the knowledge could provide a theoretical foundation to enrich scholarly discourses on spatial knowledge.

Many studies have shown the benefits of using geospatial data to strengthen public participation practice. Geospatial data allow evidence-based decision-making (Eilola et al., 2019), facilitate the exchange of spatial knowledge among stakeholders (McCall \& Dunn, 2012), and support knowledge co-production and social learning (Shrestha et al., 2018b). This study also contributes a third framework. The collaborative spatial learning framework enables communication, collaboration, social learning and knowledge co-production of stakeholders creating and using geospatial data (see Chapter 4 for details). The framework adds valuable insights to the discourses on geospatial data use in public participation practice. The framework was implemented by conducting participatory mapping workshops in three villages as the case study areas; the workshops acted as an empirical study comparing digital and non-digital participatory mapping approaches to facilitating spatial knowledge integration. In addition, the study also explored the role of participatory mapping workshops in raising village stakeholders' awareness of sustainable development issues in their villages, thus contributing to the achievement of SDGs at the local-rural level and context.

Participatory mapping can facilitate knowledge production while linking national initiatives and data with local people's knowledge (Burdon et al., 2019). Therefore, the participatory village maps produced during this study can contribute to the One Map Policy (OMP) regulated by legislation.

This study involves empirical research that employs a participatory research method that 'focuses on a process of sequential reflection and action, earned out with and by local people rather than on them' (Cornwall \& Jewkes, 1995, p. 1667). The research design and implementation of this study attempt to acknowledge the local knowledge and perspectives of the villagers in the case study areas. Their roles and knowledge are acknowledged and form the basis of study and planning of all the research stages. Participatory mapping method is used to ensure the local people can fully engage during the study period. Participatory mapping can facilitate knowledge production while linking national initiatives and data with local people's knowledge (Burdon et al., 2019). Therefore, in Indonesian context, this 
study is not only useful for engage local people in the research process, but also produce participatory village maps that can contribute to the One Map Policy (OMP) regulated by legislation.

This study divided the case study villages into an intervention group (three villages) and a control group (two villages). The division allowed the researcher to critically examine the assumptions, test the framework, and compare the impact of the interventions on the implementation of the Musrenbang in the villages (see Chapter 5 for details). Therefore, this study may provide valuable inputs for future studies that use this experimental design in their research applications.

\subsubsection{Contributions to the Musrenbang public participation practice}

The Musrenbang has an important role in development planning as a phase in which various actors can participate in deliberations on development and budgeting priorities. Therefore, the practice should be evaluated regularly to improve its processes and results. The SDG evaluation framework can be a useful tool to assess the implementation of Musrenbang in other villages in Indonesia and at higher administrative divisions (sub-district, district, city, province, and national).

The findings of this study indicate that the participatory village maps created in the workshops helped to strengthen the Musrenbang public participation practice in villages in the study areas. The Musrenbang became a more effective process to address the diverse problems of the villages. The discussion became more fruitful and transparent. The maps also allowed participants to communicate, collaborate, and exchange new information and knowledge. The respondents of this study also suggested some potential uses of the maps for other development purposes arising out of the Musrenbang. For example, villagers were able to provide spatial information about an urgent task by adding it to the map, with accurate geographical coordinates for the location, i.e. broken irrigation tunnels or roads that needed repair. This kind of information could make the higher administrative divisions act quickly and effectively to identify and solve problems.

The improvement of the Musrenbang process achieved in this study can be duplicated in other villages in Indonesia, for example in the 83,436 villages that conduct the Musrenbang annually. The use of 
geospatial data in Musrenbang implementation would greatly enhance the quality of the process.

\subsubsection{Contributions to the case study areas}

The Indonesian government launched the Village SDGs through the Ministerial Decree 13/2020 and the Ministry of Village Development of Disadvantaged Regions and Transmigration to implement the Goals at the village level. Clearly, the implementation of the Village SDGs requires comprehensive efforts, multiple actors, and sufficient data. Participatory village maps could be one form of data useful for the implementation. In addition, this study raised villagers' awareness of sustainable development issues relevant to them. This would benefit the villagers because they are more prepared for the Village SDGs implementation prescribed by decree.

The participatory village maps created during this study were useful for preserving and documenting the local spatial knowledge of the villagers. The participatory mapping workshops enabled the current generation of villagers to codify their tacit knowledge into village maps. These maps would be a valuable source of knowledge for future generations of villagers.

The villages now have georeferenced village maps created by stakeholders through the participatory mapping workshops that facilitated the integration of their spatial knowledge. The participatory mapping activity has built their sense of ownership of the maps, which strengthens their bounded solidarity as the inhabitants of the villages. The villagers have actively contributed to the creation of the maps; therefore, in principle, they are the main owners of the maps as well as the main beneficiaries. To maintain the sustainability of this project for the future, all the raw data and the village maps, in printed and digital formats, have been delivered to the villages (in the intervention group), so that they can use the data for other purposes. Regular communication with the villagers is maintained to discuss or share experiences of how to optimally use the village maps.

Maps created in the participatory mapping workshops can be used for other village development projects. The maps have moved beyond their previous function as village office decoration to become a source of knowledge for many citizens who visit the village office. In Kramat Gajah, the maps displayed in the office have attracted many visitors to 
ask about and discuss some issues within the village area. The maps facilitated discussion and knowledge exchange among village officials and citizens. Furthermore, the data were also shared with the subdistrict and district governments, to ensure that they were notified that the villages already have village maps which can be used to support any development projects.

The activities during this research have taught the researcher and the villagers that they should build their communication and collaboration to tackle any problems they may have. They can learn as a group and co-produce knowledge. With these experiences, they have begun to appreciate other views and gain new knowledge from other individuals.

\subsection{Limitations of the study}

The results of this study show that it has some limitations which should be addressed to improve future studies. First, the cultural context of this study was a limitation. As Indonesian people, the respondents in this study were always friendly and tended to avoid saying no or giving negative responses; however, this might also have affected the reliability of the results of the study. Therefore, complementary methods for data collection were used in the study to triangulate different sources of data, which makes findings or conclusions more credible (Yin, 2003). Before data collection, a comprehensive review of the literature on the Musrenbang was conducted. Direct observation of a Musrenbang meeting was also made to examine the practice directly and to record essential findings in the meeting notes. The participants were asked to complete a self-administered questionnaire to examine their opinions about the Musrenbang process before they left the meeting venue. A frequency analysis of the questionnaire data was performed, and then the data were cross-checked using the observation notes and interviews to validate the findings. In-depth semi-structured interviews were used to ensure that the interviews could validate the findings, as well as to explore new data or information not covered in the observations and the questionnaire. For content analysis, a basic coding process was implemented to categorise large amounts of text in the data collected. The coding was performed iteratively to ensure important findings were not missed. Then the relationships between categories were identified through iterative 
analysis. The performance of these activities consistently for the data was expected to justify and validate the findings and results of this study.

Second, this study may attract the criticism that it has a conflict of interest since the researcher is an Indonesian national who resides in Indonesia. To mitigate this issue, the research was planned and performed carefully in an ethical manner. The 'participant-as-observer' role was used when carrying out direct observations so that the results were objective while preventing the researcher going 'native' (Bryman, 2012; Yin, 2003). As trust is a critical issue in participatory approaches (Corbett, 2009; Cornwall \& Jewkes, 1995), communication and direct interactions with the villagers began in 2016 which were successful in gradually building their trust in the researcher. The researcher spoke in the local language and visited the villages regularly to build relationships with the communities. For the mapping tools used in the participatory mapping workshops, free resources, which can be easily accessed and used (i.e. open-source software), were used. The free software used in the digital mapping workshops and low-cost tools used in the non-digital mapping workshops present opportunities for the villagers to replicate the mapping activity in the future. After data processing, both the maps generated and the raw data were delivered to the villagers. Regular communication with the villagers is ongoing to keep them updated about the results and progress of this study. Such approaches may be useful for conducting participatory research and even for modifying or inventing innovative methods for participatory research in future studies.

Third, although the participatory mapping workshops were useful for capturing and codifying local knowledge into maps, the low number of participants might have influenced the quality of the results. Not all valuable local perspectives and knowledge were captured due to the limited number of participants engaged in the workshops. Thus, the maps produced may not reflect the richness of knowledge of the whole village community. In addition, in this study, the participatory mapping workshops were conducted during one full day. Although useful for reducing the days spent in the field and the cost of implementation, a one-day workshop may not be sufficient to expect a significant change in behaviour of the village stakeholders. A longer time span may be useful to examine the further impacts of the workshops on village stakeholders' behaviour. 


\subsection{Recommendations for future research}

This study regarded the localisation of SDGs as an important attempt to achieve the global goals by 2030 and in particular as an effort to apply inclusive and democratic public participation practice as stated in targets 11.3 and 16.7. As the many targets and indicators of SDGs are universal and created through a global perspective, further research could explore the localisation of other targets or indicators so that the Goals can be more operational and applicable in diverse local contexts.

This study used the Musrenbang public participation practice in Indonesia as a case study. Therefore, the study may not precisely reflect the situations in other countries in the global South. Further studies should explore multiple cases from different countries to enable a broader understanding of the impact of public participation practice on localisation of SDGs, especially in rural areas. A variety of case studies in different contexts would contribute diverse ideas and perspectives that can enrich the discourse on public participation practice.

This study also provides initial insights into the benefits of a collaborative spatial learning framework for improving public participation practice in Indonesia. However, it is important to note that the framework requires intensive engagement of stakeholders to build communication and collaboration as well as for social learning and knowledge co-production. Such engagement often extends over a longer timescale and is highly influenced by institutional and political contexts. Therefore, the framework developed in this study still needs to be explored in practice in other contexts. Further research could provide answers to the question whether such a framework could foster or constrain communication, collaboration, social learning and knowledge co-production during collaborative endeavours of stakeholders under various institutional, social, and political conditions.

Although it is important to engage more people in the collaborative process to gain more outcomes that are positive, some extraordinary situations, such as the COVID-19 pandemic, also force scholars and practitioners to think of other innovative ways to design participatory research, such as participatory mapping workshops in compliance with health protocols. A pandemic could be an entry point to critically 
redesign conventional research data collection methods that require direct communication or interaction between the researcher and the respondents. Future research could also focus on this issue, for example by exploring the possibilities of a participatory mapping workshop design that facilitates group collaboration in different places but at the same or a different time to keep everyone safe during the mapmaking process.

This study involved the village stakeholders from the initial phase of the collaborative spatial learning framework to the application of the framework through participatory mapping workshops. The regular interactions and involvement eventually raised the villagers' awareness of the usefulness of the maps they produced. During data collection, the villagers themselves generated some ideas for the potential use of the participatory village maps for purposes other than public participation practice. For example, the maps may be used to model water distribution for crop production or to simulate the impact of the village budget allocation on changes in land use. These ideas have the potential to be exciting research topics, and the participatory village maps created during this study could provide baseline data for such studies.

In 2020, the government of Indonesia launched the Village SDGs programme to localise SDG values in the rural Indonesian context. Furthermore, in 2021, the central government required every village to adopt the Village SDGs programme in its development planning documents. Consequently, the Musrenbang plays an important role in the synchronisation of village development targets and priorities with the SDGs. This situation is a challenge to scholars and policymakers to conduct a comprehensive investigation on whether the Village SDGs programme would help or hinder villagers in their efforts to solve their local problems and meet their real needs.

Although the Musrenbang has a critical role in the identification and listing of the development priorities of villages, this study did not investigate how the participatory village maps could influence the final budget allocation, including project implementation. An in-depth analysis of the influence of village maps on the final budget allocation and implementation may be an interesting future research development. 


\section{Bibliography}

Abelson, J., Forest, P., Eyles, J., Smith, P., Martin, E., \& Gauvin, F. (2003). Deliberations about deliberative methods: Issues in the design and evaluation of public participation processes. Social Science and Medicine, 57(2), 239-251. https://doi.org/10.1016/S0277-9536(02)00343-X

Abidin, H. Z. (2019). Status and Future Plans One Map Policy Indonesia (Issue August). Geospatial Information Agency of Indonesia (BIG). https://doi.org/10.13140/RG.2.2.13395.73762

Aditya, T. (2010). Usability issues in applying participatory mapping for neighborhood infrastructure planning. Transactions in GIS, 14(SUPPL. 1), 119-147. https://doi.org/10.1111/j.14679671.2010.01206.x

Agger, A., \& Löfgren, K. (2008). Democratic Assessment of Collaborative Planning Processes. Planning Theory, 7(2), 145164. https://doi.org/10.1177/1473095208090432

Aguilar, R., Calisto, L., Flacke, J., Akbar, A., \& Pfeffer, K. (2021). OGITO, an Open Geospatial Interactive Tool to support collaborative spatial planning with a maptable. Computers, Environment and Urban Systems, 86, 101591. https://doi.org/10.1016/j.compenvurbsys.2020.101591

Aguilar, R., Flacke, J., \& Pfeffer, K. (2020). Towards supporting collaborative spatial planning: Conceptualization of a maptable tool through user stories. ISPRS International Journal of GeoInformation, 9(1). https://doi.org/10.3390/ijgi9010029

Ahamed, T., Khan, M. I. N., Takigawa, T., Koike, M., Tasnim, F., \& Zaman, J. M. Q. (2009). Resource management for sustainable development: A community- and GIS-based approach. Environment, Development and Sustainability, 11(5), 933-954. https://doi.org/10.1007/s10668-008-9159-y

Akbar, A., Flacke, J., Martinez, J., Aguilar, R., \& van Maarseveen, M. (2020). Knowing My Village from the Sky: A Collaborative Spatial Learning Framework to Integrate Spatial Knowledge of Stakeholders in Achieving Sustainable Development Goals. ISPRS International Journal of Geo-Information, 9(9), 515. https://doi.org/10.3390/ijgi9090515

Akbar, A., Flacke, J., Martinez, J., \& van Maarseveen, M. (2020a). Participatory planning practice in rural Indonesia: A sustainable development goals-based evaluation. Community Development, 
51(3), 243-260.

https://doi.org/10.1080/15575330.2020.1765822

Akbar, A., Flacke, J., Martinez, J., \& van Maarseveen, M. (2020b). Spatial Knowledge: A Potential to Enhance Public Participation? Sustainability, 12(12), 5025. https://doi.org/10.3390/su12125025

Akbar, A., Flacke, J., Martinez, J., \& van Maarseveen, M. (2021). The Role of Participatory Village Maps in Strengthening Public Participation Practice. ISPRS International Journal of GeoInformation, 10(8), 512. https://doi.org/10.3390/ijgi10080512

Albrechts, L. (2002). The planning community reflects on enhancing public involvement. Views from academics and reflective practitioners. Planning Theory \& Practice, 3(3), 331-347. https://doi.org/10.1080/1464935022000019563

Ambarwulan, W., Wulan, T. R., Lestari, S., Patmasari, T., \& Suparwati, T. (2018). Application of Remotely Sensed Satellite Imagery for Village Boundary Mapping in Indonesia : Case study in Hulu Sungai Tengah Regency, South Kalimantan, Indonesia. FIG Congress 2018.

Anokye, N. A. (2013). Stakeholder Participation in Water Resources Management: The Case of Densu Basin in Ghana. In PhD Thesis. VU University.

Antlöv, H. (2003). Village government and rural development in Indonesia: The new democratic framework. Bulletin of Indonesian Economic Studies, 39(2), 193-214. https://doi.org/10.1080/00074910302013

Antlöv, H., Wetterberg, A., \& Dharmawan, L. (2016). Village Governance, Community Life, and the 2014 Village Law in Indonesia. Bulletin of Indonesian Economic Studies, 52(2), 161183. https://doi.org/10.1080/00074918.2015.1129047

Arnstein, S. (1969). A Ladder Of Citizen Participation. Journal of the American Institute of Planners, 35(4), 216-224. https://doi.org/10.1080/01944366908977225

Asthana, S., Richardson, S., \& Halliday, J. (2002). Partnership Working in Public Policy Provision: A Framework for Evaluation. Social Policy and Administration, 36(7), 780-795. https://doi.org/10.1111/1467-9515.00317

Aswad, S., Heywood, P., \& Susilawati, C. (2012). The roles of procedural justice and social learning in improving self organizing capabilities of local communities for sustainable development in decentralized Indonesia. OIDA International 
Journal of Sustainable Development, 3(10), 73-90.

https://papers.ssrn.com/sol3/papers.cfm?abstract_id=2047740

Avtar, R., Aggarwal, R., Kharrazi, A., Kumar, P., \& Kurniawan, T. A. (2020). Utilizing geospatial information to implement SDGs and monitor their Progress. Environmental Monitoring and Assessment, 192(35).

https://doi.org/https://doi.org/10.1007/s10661-019-7996-9

Banerjee, A. V, \& Duflo, E. (2009). The experimental approach to development economics. Annual Review of Economics, 1, 151178.

https://doi.org/10.1146/annurev.economics.050708.143235

Baud, I., Pfeffer, K., Scott, D., Denis, E., \& Sydenstricker, J. (2014). Participatory "spatial" knowledge management configurations in metropolitan governance networks for $S D$. http://dare.uva.nl/record/1/461814

Baud, I., Pfeffer, K., Sydenstricker, J., \& Scott, D. (2011). Developing participatory "spatial" knowledge models in metropolitan governance networks for sustainable development: literature review. http://dare.uva.nl/record/1/349502

Baud, I., Scott, D., Pfeffer, K., Sydenstricker-Neto, J., \& Denis, E. (2015). Reprint of: Digital and spatial knowledge management in urban governance: Emerging issues in India, Brazil, South Africa, and Peru. Habitat International, 46, 225-233.

https://doi.org/10.1016/j.habitatint.2015.01.018

Bednarska-Olejniczak, D., Olejniczak, J., \& Svobodová, L. (2020). How a Participatory Budget Can Support Sustainable Rural Development-Lessons From Poland. Sustainability, 12(7), 2620. https://doi.org/10.3390/su12072620

Bednarz, S. W., Acheson, G., \& Bednarz, R. S. (2006). Maps and map learning in social studies. Social Education, 70(7), 398-404, 432. http://www.literacyinlearningexchange.org/sites/default/files/be dnarz_socialeducation.pdf

Beierle, T. C. (2002). The quality of stakeholder-based decisions. Risk Analysis, 22(4), 739-749. https://doi.org/10.1111/02724332.00065

Beierle, T. C., \& Konisky, D. M. (2000). Values, Conflict, and Trust in Participatory Environmental Planning. Journal of Policy Analysis and Management, 19(4), 587-602.

https://doi.org/10.1002/1520-6688(200023)19:4<587::AIDPAM4 $>3.0 . \mathrm{CO} ; 2-\mathrm{Q}$

Beverly, J. L., Uto, K., Wilkes, J., \& Bothwell, P. (2008). Assessing 
spatial attributes of forest landscape values: an internet-based participatory mapping approach. Canadian Journal of Forest Research, 38(2), 289-303. https://doi.org/10.1139/X07-149

Blair, H. (2013). Participatory budgeting and local governance (No. 10; Vol. 10). http://www.icld.se/eng/pdf/icld-workingpaper_10tryck-low.pdf

Bovaird, T., \& Loeffler, E. (2012). From Engagement to Coproduction: The Contribution of Users and Communities to Outcomes and Public Value. Voluntas: International Journal of Voluntary and Nonprofit Organizations, 23(4), 1119-1138. https://doi.org/10.1007/s11266-012-9309-6

BPS. (2018). Deli Serdang Regency in Figures 2016. BPS-Statistics of Deli Serdang Agency.

Bradley, Q. (2018). Neighbourhood planning and the production of spatial knowledge. Town Planning Review, 89(1), 23-42. https://doi.org/10.3828/tpr.2018.2

Brown, G., \& Fagerholm, N. (2015). Empirical PPGIS/PGIS mapping of ecosystem services: a review and evaluation. Ecosystem Services, 13, 119-133. https://doi.org/10.1016/j.ecoser.2014.10.007

Brown, G., \& Kyttä, M. (2014). Key issues and research priorities for public participation GIS (PPGIS): A synthesis based on empirical research. Applied Geography, 46, 122-136. https://doi.org/10.1016/j.apgeog.2013.11.004

Bryman, A. (2012). Social research methods (4th ed.). Oxford University Press.

Burdon, D., Potts, T., McKinley, E., Lew, S., Shilland, R., Gormley, K., Thomson, S., \& Forster, R. (2019). Expanding the role of participatory mapping to assess ecosystem service provision in local coastal environments. Ecosystem Services, 39, 101009. https://doi.org/10.1016/j.ecoser.2019.101009

Burford, G., Hoover, E., Velasco, I., Janoušková, S., Jimenez, A., Piggot, G., Podger, D., \& Harder, M. K. (2013). Bringing the "Missing Pillar" into sustainable development goals: Towards intersubjective values-based indicators. Sustainability, 5(7), 3035-3059. https://doi.org/10.3390/su5073035

Butler, J. R. A., Bohensky, E. L., Darbas, T., Kirono, D. G. C., Wise, R. M., \& Sutaryono, Y. (2016). Building capacity for adaptation pathways in eastern Indonesian islands: Synthesis and lessons learned. Climate Risk Management, 12, A1-A10. https://doi.org/10.1016/j.crm.2016.05.002 
Butler, J. R. A., Bohensky, E. L., Suadnya, W., Yanuartati, Y., Handayani, T., Habibi, P., Puspadi, K., Skewes, T. D., Wise, R. M., Suharto, I., Park, S. E., \& Sutaryono, Y. (2016). Scenario planning to leap-frog the Sustainable Development Goals: An adaptation pathways approach. Climate Risk Management, 12, 83-99. https://doi.org/10.1016/j.crm.2015.11.003

Cabannes, Y. (2019). Participatory Budgeting: a powerful and expanding contribution to the achievement of SDGs and primarily SDG 16.7 (Vol. 30, Issue 9). https://participate.oidp.net/uploads/decidim/attachment/file/212 /CABANNES_FINAL_FOR_UCLG_MARCH_2019.pdf

Callahan, K. (2007). Citizen participation: Models and methods. International Journal of Public Administration, 30(11), 11791196. https://doi.org/10.1080/01900690701225366

Carton, L. J. (2007). Map making and map use in a multi-actor context: Spatial visualizations and frame conflicts in regional policymaking in the Netherlands [TU Delft]. In PhD Thesis. http://repository.tudelft.nl/view/ir/uuid:f5821d4b-5299-4af9baad-176dbf1daabb/

Carton, L. J., \& Thissen, W. A. H. (2009). Emerging conflict in collaborative mapping: Towards a deeper understanding? Journal of Environmental Management, 90(6), 1991-2001. https://doi.org/10.1016/j.jenvman.2007.08.033

Catacutan, D., McGaw, E., \& Llanza (eds.), M. (2014). In Equal Measure: A User Guide to Gender Analysis in Agroforestry. In D. Catacutan, E. McGaw, \& M. Llanza (Eds.), In Equal Measure: A User Guide to Gender Analysis in Agroforestry. World Agroforestry Centre (ICRAF) Southeast Asia Regional Program.

Chambers, R. (1981). Rapid rural appraisal: rationale and repertoire. Public Administration and Development, 1(2), 95-106. https://doi.org/10.1002/pad.4230010202

Chambers, R. (1994a). Participatory rural appraisal (PRA): Analysis of experience. World Development, 22(9), 1253-1268. https://doi.org/10.1016/0305-750X(94)90003-5

Chambers, R. (1994b). Participatory rural appraisal (PRA): Challenges, potentials and paradigm. World Development, 22(10), 1437-1454. https://doi.org/10.1016/0305$750 \times(94) 90030-2$

Chambers, R. (1994c). The origins and practice of participatory rural appraisal. World Development, 22(7), 953-969. https://doi.org/10.1016/0305-750X(94)90141-4 
Chambers, R. (2006). Participatory Mapping and Geographic Information Systems: Whose Map? Who is Empowered and Who Disempowered? Who Gains and Who Loses? The Electronic Journal of Information Systems in Developing Countries, 25(2), 1-11. https://doi.org/10.1002/j.1681-4835.2006.tb00163.x

Chapin, M., Lamb, Z., \& Threlkeld, B. (2005). Mapping indigenous lands. Annual Review of Anthropology, 34, 619-638. https://doi.org/10.1146/annurev.anthro.34.081804.120429

Chess, C. (2000). Evaluating environmental public participation: Methodological questions. Journal of Environmental Planning and Management, 43(6), 769-784. https://doi.org/10.1080/09640560020001674

Cinderby, S., \& Forrester, J. M. (2016). Co-designing Possible Flooding Solutions: Participatory Mapping Methods to Identify Flood Management Options from a UK Borders Case Study. Journal for Geographic Information Science, 1, 149-156. https://doi.org/10.1553/giscience2016_01_s149 Steve

Coenen, F. H. J. M., Hofman, P. S., \& Huitema, D. (1998). Green participation? Public participation and its effects on the quality of environmental decision making. International Congress of Administrative Sciences, 1-27. http://doc.utwente.nl/5203/1/Green_participation_Coenen.pdf

Collins, L. (2018). The Impact of Paper Versus Digital Map Technology on Students' Spatial Thinking Skill Acquisition. Journal of Geography, 117(4), 137-152. https://doi.org/10.1080/00221341.2017.1374990

Coonrod, J. (2015). Participatory Local Democracy: Key to community-led rural development. Development, 58(2-3), 333340. https://doi.org/10.1057/s41301-016-0008-2

Corbett, J. M. (2003). Empowering technologies? Introducing participatory geographic information and multimedia systems in two Indonesian communities [University of Victoria]. In ProQuest Dissertations and Theses.

https://search.proquest.com/dissertations-theses/empoweringtechnologies-introducing-participatory/docview/305299013/se2 ? accountid $=41849$

Corbett, J. M. (2009). Good practices in participatory mapping: a review prepared for the International Fund for Agricultural Development (IFAD). International Fund for Agricultural Development (IFAD). http://www.popline.org/node/213092

Corbett, J. M., Cochrane, L., \& Gill, M. (2016). Powering Up: 
Bibliography

Revisiting Participatory GIS and Empowerment. The Cartographic Journal, 53(4), 335-340.

https://doi.org/10.1080/00087041.2016.1209624

Corbett, J. M., \& Keller, C. P. (2004). Empowerment and Participatory Geographic Information and Multimedia Systems : Observations from Two Communities in Indonesia. Information Technologies \& International Development, 2(2), 25-44.

Corbett, J. M., \& Keller, C. P. (2005). An Analytical Framework to Examine Empowerment Associated with Participatory Geographic Information Systems (PGIS). Cartographica: The International Journal for Geographic Information and Geovisualization, 40(4), 91-102. https://doi.org/10.3138/J590-6354-P38V-4269

Corbett, J. M., \& Keller, C. P. (2006). Using Community Information Systems to express traditional knowledge embedded in the landscape. Participatory Learning and Action, 54(1), 21-27.

Corbett, J. M., Rambaldi, G., Kyem, P., \& Weiner, D. (2006). Overview: mapping for change-the emergence of a new practice. Participatory Learning and Action, 54(1), 13-19.

Cornwall, A. (2008). Unpacking "Participation" Models, meanings and practices. Community Development Journal, 43(3), 269-283. https://doi.org/10.1093/cdj/bsn010

Cornwall, A., \& Jewkes, R. (1995). What is participatory research? Social Science \& Medicine, 41(12), 1667-1676. https://doi.org/10.1016/0277-9536(95)00127-S

Cunningham, M. A. (2005). Why Geography Still Needs Pen and Ink Cartography. Journal of Geography, 104(3), 119-126. https://doi.org/10.1080/00221340508978625

Curşeu, P. L., \& Schruijer, S. G. L. (2020). Participation and goal achievement of multiparty collaborative systems dealing with complex problems: A natural experiment. Sustainability, 12(3), 987. https://doi.org/10.3390/su12030987

Damastuti, E., \& de Groot, R. (2019). Participatory ecosystem service mapping to enhance community-based mangrove rehabilitation and management in Demak, Indonesia. Regional Environmental Change, 19(1), 65-78. https://doi.org/10.1007/s10113-0181378-7

Dana, G. V, \& Nelson, K. C. (2012). Social Learning Through Environmental Risk Analysis of Biodiversity and GM Maize in South Africa. Environmental Policy and Governance, 22(4), 238252. https://doi.org/10.1002/eet. 1587 
Daskalaki, M. (2018). Alternative organizing in times of crisis: Resistance assemblages and socio-spatial solidarity. European Urban and Regional Studies, 25(2), 155-170. https://doi.org/10.1177/0969776416683001

de Vos, R. (2018). Counter-Mapping against oil palm plantations: reclaiming village territory in Indonesia with the 2014 Village Law. Critical Asian Studies, 50(4), 615-633. https://doi.org/10.1080/14672715.2018.1522595

Dewi, R. (2016). Recognition Through Participatory Mapping? The Role of Adat Land in the Implementation of the Merauke Integrated Food and Energy Estate in Papua, Indonesia. Austrian Journal of South-East Asian Studies, 9(1), 87-106. https://doi.org/10.14764/10.ASEAS-2016.1-6

Edelenbos, J., \& Klijn, E. (2006). Managing stakeholder involvement in decision making: A comparative analysis of six interactive processes in the Netherlands. Journal of Public Administration Research and Theory, 16(3), 417-446. https://doi.org/10.1093/jopart/mui049

Eilola, S., Fagerholm, N., Mäki, S., \& Khamis, M. (2015). Realization of participation and spatiality in participatory forest management-a policy-practice analysis from Zanzibar, Tanzania. Journal of Environmental Planning and Management, 58(7), 1242-1269.

https://doi.org/10.1080/09640568.2014.921142

Eilola, S., Käyhkö, N., Ferdinands, A., \& Fagerholm, N. (2019). Landscape and Urban Planning A bird's eye view of my village Developing participatory geospatial methodology for local level land use planning in the Southern Highlands of Tanzania. Landscape and Urban Planning, 190, 103596. https://doi.org/10.1016/j.landurbplan.2019.103596

Elder, M., Bengtsson, M., \& Akenji, L. (2016). An optimistic analysis of the means of implementation for sustainable development goals: Thinking about goals as means. Sustainability, 8(9), 962. https://doi.org/10.3390/su8090962

Elwood, S. (2006a). Beyond cooptation or resistance: Urban spatial politics, community organizations, and GIS-based spatial narratives. Annals of the Association of American Geographers, 96(2), 323-341. https://doi.org/10.1111/j.14678306.2006.00480.x

Elwood, S. (2006b). Negotiating Knowledge Production: The Everyday Inclusions, Exclusions, and Contradictions of Participatory GIS 
Research. The Professional Geographer, 58(2), 197-208. https://doi.org/https://doi.org/10.1111/j.14679272.2006.00526.x

Elwood, S., \& Leitner, H. (2003). GIS and spatial knowledge production for neighborhood revitalization: Negotiating state priorities and neighborhood visions. Journal of Urban Affairs, 25(2), 139-157. https://doi.org/10.1111/1467-9906.t01-100003

Engen, S., Runge, C., Brown, G., Fauchald, P., Nilsen, L., \& Hausner, V. (2018). Assessing local acceptance of protected area management using public participation GIS (PPGIS). Journal for Nature Conservation, 43, 27-34. https://doi.org/10.1016/j.jnc.2017.12.002

Falco, E. (2016). Digital Community Planning: The Open Source Way to the Top of Arnstein's Ladder. International Journal of $E$ Planning Research, 5(2), 1-22. https://doi.org/10.4018/IJEPR.2016040101

Falco, E., Zambrano-Verratti, J., \& Kleinhans, R. (2019). Web-based participatory mapping in informal settlements: The slums of Caracas, Venezuela. Habitat International, 94, 102038. https://doi.org/10.1016/j.habitatint.2019.102038

Feng, L., Wu, Q., Wu, W., \& Liao, W. (2020). Decision-MakerOriented VS . Collaboration: China 's Public Participation in Environmental Decision-Making. Sustainability, 12, 1334. https://doi.org/10.3390/su12041334

Feruglio, F., \& Rifai, A. (2017). Participatory budgeting in Indonesia: past, present and future. Institute of Development Studies. https://opendocs.ids.ac.uk/opendocs/handle/123456789/12733

Fisher, A., \& Fukuda-Parr, S. (2019). Introduction-Data, Knowledge, Politics and Localizing the SDGs. Journal of Human Development and Capabilities, 20(4), 375-385. https://doi.org/10.1080/19452829.2019.1669144

Flacke, J., \& de Boer, C. (2017). An interactive planning support tool for addressing social acceptance of renewable energy projects in the Netherlands. ISPRS International Journal of Geo-Information, 6(10), 313. https://doi.org/10.3390/ijgi6100313

Flacke, J., Shrestha, R., \& Aguilar, R. (2020). Strengthening participation using interactive planning support systems: A systematic review. ISPRS International Journal of GeoInformation, 9(1), 1-34. https://doi.org/10.3390/ijgi9010049

Fox, J. (2002). Siam mapped and mapping in Cambodia: Boundaries, 
sovereignty, and indigenous conceptions of space. Society and Natural Resources, 15(1), 65-78.

https://doi.org/10.1080/089419202317174020

Fox, J., Suryanata, K., Hershock, P., \& Pramono, A. H. (2006). Mapping power: ironic effects of spatial information technology. Participatory Learning and Action, 54(1), 98-105. http://www.iapad.org/wp-content/uploads/2015/07/pla54-fullen. pdf $\#$ page $=99$

Fung, A. (2006). Varieties of participation in complex governance. Public Administration Review, 66(s1), 66-75. https://doi.org/10.1111/j.1540-6210.2006.00667.x

Fung, A. (2015). Putting the Public Back into Governance: The Challenges of Citizen Participation and Its Future. Public Administration Review, 75(4), 513-522. https://doi.org/10.1111/puar.12361

Ghose, R. (2003). Community participation, spatial knowledge production, and GIS use in inner-city revitalization. Journal of Urban Technology, 10(1), 39-60. https://doi.org/10.1080/1063073032000086326

Gilbert, M. R., \& Masucci, M. (2006). The implications of including women's daily lives in a feminist GIScience. Transactions in GIS, 10(5), 751-761. https://doi.org/10.1111/j.14679671.2006.01026.x

Giuliani, G., Mazzetti, P., Santoro, M., Nativi, S., van Bemmelen, J., Colangeli, G., \& Lehmann, A. (2020). Knowledge generation using satellite earth observations to support sustainable development goals (SDG): A use case on Land degradation. International Journal of Applied Earth Observation and Geoinformation, 88, 102068.

https://doi.org/10.1016/j.jag.2020.102068

Gold, R. (1958). Roles in Sociological Field Observations. Social Forces, 36(3), 217-223. https://doi.org/10.2307/2573808

Goodchild, M. F. (2006). The Fourth R? Rethinking GIS Education. ESRI ArcNews.

http://www.esri.com/news/arcnews/fall06articles/the-fourthr.html

Grillos, T. (2017). Participatory Budgeting and the Poor: Tracing Bias in a Multi-Staged Process in Solo, Indonesia. World Development, 96, 343-358. https://doi.org/10.1016/j.worlddev.2017.03.019

Hajer, M. A., \& Wagenaar, H. (2003). Deliberative Policy Analysis: 
Understanding Governance in the Network Society. In M. Hajer \& $\mathrm{H}$. Wagenaar (Eds.), Cambridge University Press (1st ed.). Cambridge University Press.

https://pdfs.semanticscholar.org/33bc/8666d1fbef9e07ddef1dee 1cce41c8534deb.pdf

Hák, T., Janoušková, S., \& Moldan, B. (2016). Sustainable Development Goals: A need for relevant indicators. Ecological Indicators, 60, 565-573. https://doi.org/10.1016/j.ecolind.2015.08.003

Haklay, M. (2010). How good is volunteered geographical information? A comparative study of OpenStreetMap and ordnance survey datasets. Environment and Planning B, 37(4), 682-703. https://doi.org/10.1068/b35097

Haklay, M. (2013). Neogeography and the delusion of democratisation. Environment and Planning A, 45(1), 55-69. https://doi.org/10.1068/a45184

Haselsberger, B. (2014). Decoding borders. Appreciating border impacts on space and people. Planning Theory and Practice, 15(4), 505-526.

https://doi.org/10.1080/14649357.2014.963652

Healey, P. (1997). Collaborative planning: Shaping places in fragmented societies (Y. Rydin \& A. Thornley (eds.)). Macmillan Press Ltd. https://doi.org/10.1007/978-1-349-25538-2

Healey, P. (1998a). Building institutional capacity through collaborative approaches to urban planning. Environment and Planning A, 30(9), 1531-1546. https://doi.org/10.1068/a301531

Healey, P. (1998b). Collaborative Planning in a Stakeholder Society. Town Planning Review, 69(1), 1-21. https://doi.org/10.3828/tpr.69.1.h651u2327m86326p

Hernández, D. (1994). Qualitative Representation of Spatial Knowledge (J. Carbonell \& J. Siekmann (eds.)). Springer-Verlag.

Holden, M. (2008). Social learning in planning: Seattle's sustainable development codebooks. Progress in Planning, 69(1), 1-40. https://doi.org/10.1016/j.progress.2007.12.001

Hordijk, M. (2005). Participatory governance in Peru: exercising citizenship. Environment and Urbanization, 17(1), 219-236. https://doi.org/10.1177/095624780501700111

Hordijk, M., Miranda Sara, L., Sutherland, C., \& Scott, D. (2015). Participatory instruments and practices in urban governance. In J. Gupta, K. Pfeffer, H. Verrest, \& M. Ros-Tonen (Eds.), 
Geographies of Urban Governance (pp. 127-146). Springer. https://doi.org/10.1007/978-3-319-21272-2_7

Howard, J., \& Wheeler, J. (2015). What community development and citizen participation should contribute to the new global framework for sustainable development. Community Development Journal, 50(4), 552-570. https://doi.org/10.1093/cdj/bsv033

Hussein, A. (2009). The use of triangulation in social sciences research: Can qualitative and quantitative methods be combined? Journal of Comparative Social Work, 4(1), 106-117. https://doi.org/10.31265/jcsw.v4i1.48

Indika, D. R., \& Vonika, N. (2019). Increasing Transparency and Community Participation through the Open Government Partnership in Bojonegoro Regency. Achieving and Sustaining SDGs 2018 Conference: Harnessing the Power of Frontier Technology to Achieve the Sustainable Development Goals (ASSDG 2018), 216, 41-51. https://doi.org/10.2991/assdg18.2019.

Innes, J. E., \& Booher, D. E. (1999). Consensus building and complex adaptive systems: A framework for evaluating collaborative planning. Journal of the American Planning Association, 65(4), 412-423. https://doi.org/10.1080/01944369908976031

Innes, J. E., \& Booher, D. E. (2004). Reframing public participation: strategies for the 21st century. Planning Theory \& Practice, 5(4), 419-436. https://doi.org/10.1080/1464935042000293170

Innes, J. E., \& Booher, D. E. (2010). Planning with complexity: an introduction to collaborative rationality for public policy. Routledge.

Irvin, R., \& Stansbury, J. (2004). Citizen participation in decision making: is it worth the effort? Public Administration Review, 64(1), 55-65. https://doi.org/10.1111/j.15406210.2004.00346.x

Ishikawa, T., \& Montello, D. R. (2006). Spatial knowledge acquisition from direct experience in the environment: Individual differences in the development of metric knowledge and the integration of separately learned places. Cognitive Psychology, 52(2), 93-129. https://doi.org/https://doi.org/10.1016/j.cogpsych.2005.08.003

Jankowski, P., Czepkiewicz, M., Młodkowski, M., Zwoliński, Z., \& Wójcicki, M. (2019). Evaluating the scalability of public participation in urban land use planning: A comparison of Geoweb methods with face-to-face meetings. Environment and 
Planning $B, 46(3), 511-533$.

https://doi.org/10.1177/2399808317719709

Janoušková, S., Hák, T., \& Moldan, B. (2018). Global SDGs assessments: Helping or confusing indicators? Sustainability, 10(5), 1-14. https://doi.org/10.3390/su10051540

Jessop, B., Brenner, N., \& Jones, M. (2008). Theorizing sociospatial relations. Environment and Planning D, 26(3), 389-401. https://doi.org/10.1068/d9107

Johnson, K. A., Dana, G. V, Jordan, N. R., Draeger, K. J., Kapuscinski, A., Olabisi, L. K. S., \& Reich, P. B. (2012). Using Participatory Scenarios to Stimulate Social Learning for Collaborative Sustainable Development. Ecology and Society, 17(2), art9. https://doi.org/10.5751/ES-04780-170209

Kahila-Tani, M., Broberg, A., \& Kyttä, M. (2016). Let the Citizens Map-Public Participation GIS as a Planning Support System in the Helsinki Master Plan Process. Planning Practice \& Research, 31(2), 195-214. https://doi.org/10.1080/02697459.2015.1104203

Kahila-Tani, M., Kytta, M., \& Geertman, S. (2019). Does mapping improve public participation? Exploring the pros and cons of using public participation GIS in urban planning practices. Landscape and Urban Planning, 186, 45-55. https://doi.org/10.1016/j.landurbplan.2019.02.019

Kent, A. J., Vujakovic, P., Eades, G., \& Davis, M. (2020). Putting the UN SDGs on the Map: The Role of Cartography in Sustainability Education. Cartographic Journal, 57(2), 93-96. https://doi.org/10.1080/00087041.2020.1770424

Kienberger, S. (2014). Participatory mapping of flood hazard risk in Munamicua, District of Búzi, Mozambique. Journal of Maps, 10(2), 269-275.

https://doi.org/https://doi.org/10.1080/17445647.2014.891265

King, K., \& McGrath, S. (2004). Knowledge for Development?: Comparing British, Japanese, Swedish and World Bank Aid. Zed Books.

Kirschner, P. A., Sweller, J., Kirschner, F., \& Zambrano, J. R. (2018). From Cognitive Load Theory to Collaborative Cognitive Load Theory. International Journal of Computer-Supported Collaborative Learning, 13(2), 213-233. https://doi.org/10.1007/s11412-018-9277-y

Klopp, J. M., \& Petretta, D. L. (2017). The urban sustainable development goal: Indicators, complexity and the politics of 
measuring cities. Cities, 63, 92-97.

https://doi.org/10.1016/j.cities.2016.12.019

Koç, H., \& Demir, S. B. (2014). Developing Valid and Reliable Map Literacy Scale. Review of International Geographical Education Online, 4(2), 120-137.

http://www.academia.edu/download/36045199/RIGEO-V4-N23.pdf

Koch, F., \& Krellenberg, K. (2018). How to contextualize SDG 11? Looking at indicators for sustainable urban development in Germany. ISPRS International Journal of Geo-Information, 7(12), 464. https://doi.org/10.3390/ijgi7120464

Kraak, M. J. (2003). Geovisualization illustrated. ISPRS Journal of Photogrammetry and Remote Sensing, 57(5-6), 390-399. https://doi.org/10.1016/S0924-2716(02)00167-3

Kraak, M. J. (2004). The role of the map in a Web-GIS environment. Journal of Geographical Systems, 6(2), 83-93. https://doi.org/10.1007/s10109-004-0127-2

Kraak, M. J., Ricker, B., \& Engelhardt, Y. (2018). Challenges of mapping sustainable development goals indicators data. ISPRS International Journal of Geo-Information, 7(12), 482. https://doi.org/10.3390/ijgi7120482

Kushandajani, K. (2016). Village Authority based on Indigenous Right and Local Scale Authority: Implications of Law No.6/2014 toward Village Authority. In M. Griffith, T. Warsito, Z. Bin Ahmad, K. Hubacek, D. Trinidad, J. Weiss, A. Nurmandi, J. Choi, S. Kim, E. P. Purnomo, D. Holmes, A. Tamronglak, S. Roengtam, T.

Rahman, T. Purwaningsih, Nurazizah, A. N. Rasyid, R. Ramdani, D. S. Kencono, \& A. Handoyo (Eds.), International Conference on Social Politics (pp. 111-119). Jusuf Kalla School of Government (JKSG).

Laurian, L., \& Shaw, M. M. (2008). Evaluation of public participation: The practices of certified planners. Journal of Planning Education and Research, 28(3), 293-309.

https://doi.org/10.1177/0739456X08326532

Leino, H. (2012). Boundary Interaction in Emerging Scenes: Two Participatory Planning Cases from Finland. Planning Theory and Practice, 13(3), 383-396. https://doi.org/10.1080/14649357.2012.706629

Liu, S., Bai, J., \& Chen, J. (2019). Measuring SDG 15 at the County Scale: Localization and Practice of SDGs Indicators Based on Geospatial Information. ISPRS International Journal of Geo- 
Bibliography

Information, 8(11), 515. https://doi.org/10.3390/ijgi8110515

Lokka, I. E., \& Çöltekin, A. (2020). Perspective switch and spatial knowledge acquisition: effects of age, mental rotation ability and visuospatial memory capacity on route learning in virtual environments with different levels of realism. Cartography and Geographic Information Science, 47(1), 14-27. https://doi.org/10.1080/15230406.2019.1595151

Lubis, M. I., \& Langston, J. D. (2015). Understanding landscape change using participatory mapping and geographic information systems: case study in North Sulawesi, Indonesia. The 1st International Symposium on LAPAN-IPB Satellite for Food Security and Environmental Monitoring, 206 - 214. http://www.sciencedirect.com/science/article/pii/S18780296150 0095X

Ludwig, T. (2017). The Key to Engaging with the SDGs: Utilizing Rio Principle 10 to Succeessfully Implement the U.N. Sustainable Development Goals. Sustainable Development Law \& Policy, 16(2), 26-48.

http://digitalcommons.wcl.american.edu/sdlp/vol16/iss2/7

Maceachren, A. M., \& Brewer, I. (2004). Developing a conceptual framework for visually-enabled geocollaboration. International Journal of Geographical Information Science, 18(1), 1-34. https://doi.org/10.1080/13658810310001596094

MacFeely, S. (2018). The 2030 Agenda: An Unprecedented Statistical Challenge. Berlin: Friedrich Ebert Stiftung. http://library.fes.de/pdf-files/iez/14796.pdf

Mahi, B. R. (2010). Intergovernmental relations and decentralization in Indonesia: new arrangements and their impacts on local welfare. Economics and Finance Indonesia, 58(2), 49-72. http://www3.grips.ac.jp/coslog/public_html/activity/02/symposi um_h21/file/symposium-21.pdf \#page $=59$

Manrique-Sancho, M. T., Avelar, S., Iturrioz-Aguirre, T., \& MansoCallejo, M. A. (2018). Using the Spatial Knowledge of Map Users to Personalize City Maps: A Case Study with Tourists in Madrid, Spain. ISPRS International Journal of Geo-Information, 7(8), 332. https://doi.org/10.3390/ijgi7080332

Martinez, J. (2009). The use of GIS and indicators to monitor intraurban inequalities. A case study in Rosario, Argentina. Habitat International, 33(4), 387-396.

https://doi.org/10.1016/j.habitatint.2008.12.003

Martinez, J., Pfeffer, K., \& Baud, I. (2016). Factors shaping 
cartographic representations of inequalities. Maps as products and processes. Habitat International, 51, 90-102.

https://doi.org/https://doi.org/10.1016/j. habitatint.2015.10.010

Martinez, J., Pfeffer, K., \& van Dijk, T. (2011). E-government Tools, Claimed Potentials/Unnamed Limitations The Case of KalyanDombivli. Environment and Urbanization Asia, 2(2), 223-234. https://doi.org/10.1177/097542531100200206

McCall, M. K. (2003). Seeking good governance in participatory-GIS: a review of processes and governance dimensions in applying GIS to participatory spatial planning. Habitat International, 27, 549-573. https://doi.org/https://doi.org/10.1016/S01973975(03)00005-5

McCall, M. K. (2006). Precision for whom? Mapping ambiguity and certainty in (Participatory) GIS. Participatory Learning and Action, 54(1), 114-119.

McCall, M. K. (2008). Participatory Mapping and Participatory GIS (PGIS) for CRA, Community DRR and Hazard Assessment. ProVention Consortium, CRA Toolkit, Participation. http://drm.cenn.ge/Trainings/Multi Hazard Risk Assessment/Lectures_ENG/Session 04 Elements at risk/Background/PGIS for Disaster Risk Assessment.pdf

McCall, M. K. (2021). Participatory Mapping and PGIS: Secerning Facts and Values, Representation and Representativity. International Journal of E-Planning Research, 10(3), 105-123. https://doi.org/10.4018/IJEPR.20210701.0a7

McCall, M. K., \& Dunn, C. E. (2012). Geo-information tools for participatory spatial planning: Fulfilling the criteria for 'good'governance? Geoforum, 43(1), 81-94. https://doi.org/10.1016/j.geoforum.2011.07.007

McCall, M. K., Martinez, J., \& Verplanke, J. (2015). Shifting boundaries of volunteered geographic information systems and modalities: learning from PGIS. ACME: An International EJournal for Critical Geographies, 14(3), 791-826. http://ojs.unbc.ca/index.php/acme/article/view/1234

McCall, M. K., \& Minang, P. A. (2005). Assesing Participatory GIS for Community-Based Natural Resource Management: Claiming Community Forests in Cameroon. The Geographic Journal, 171(4), 340-356. https://doi.org/10.1111/j.14754959.2005.00173.x

Ministry of Village Development in Disadvantaged Regions \& Transmigration. (2020). SDGs Desa Berkontribusi 74 Persen atas 
Pencapaian Nasional.

https://kemendesa.go.id/berita/view/detil/3486/sdgs-desaberkontribusi-74-persen-atas-pencapaian-nasional

Miranda Sara, L., Jameson, S., Pfeffer, K., \& Baud, I. (2016). Risk perception: The social construction of spatial knowledge around climate change-related scenarios in Lima. Habitat International, 54, 136-149. https://doi.org/10.1016/j.habitatint.2015.12.025

Montello, D. R. (1998). A new framework for understanding the acquisition of spatial knowledge in large-scale environments. In M. Egenhofer \& R. Golledge (Eds.), Spatial and temporal reasoning in geographic information systems (pp. 143-154). Oxford University Press.

Moore, K. R., \& Elliott, T. J. (2016). From participatory design to a listening infrastructure: A case of urban planning and participation. Journal of Business and Technical Communication, 30(1), 59-84. https://doi.org/10.1177/1050651915602294

Morita, K., Okitasari, M., \& Masuda, H. (2020). Analysis of national and local governance systems to achieve the sustainable development goals: case studies of Japan and Indonesia. Sustainability Science, 15(1), 179-202. https://doi.org/10.1007/s11625-019-00739-z

Mosedale, S. (2005). Assessing women's empowerment: Towards a conceptual framework. Journal of International Development, 17(2), 243-257. https://doi.org/10.1002/jid.1212

Mostert, E. (2003). The challenge of public participation. Water Policy, 5(2), 179-197. https://doi.org/10.1017/CBO9781107415324.004

Mostert, E., Pahl-Wostl, C., Rees, Y., Searle, B., Tàbara, D., \& Tippett, J. (2007). Social Learning in European River-Basin Management: Barriers and Fostering Mechanisms from 10 River Basins. Ecology and Society, 12(1), 19. http://www.ecologyandsociety.org/vol12/iss1/art19/

Murdoch, J. (1993). Sustainable rural development: towards a research agenda. Geoforum, 24(3), 225-241. https://doi.org/10.1016/0016-7185(93)90018-D

Muro, M., \& Jeffrey, P. (2012). Time to Talk? How the Structure of Dialog Processes Shapes Stakeholder Learning in Participatory Water Resources Management. Ecology and Society, 17(1), 3. https://doi.org/10.5751/ES-04476-170103

Murphy, J. T. (2007). The Challenge of Upgrading in African Industries: Socio-Spatial Factors and the Urban Environment in 
Mwanza, Tanzania. World Development, 35(10), 1754-1778. https://doi.org/10.1016/j.worlddev.2007.06.003

Natarajan, L. (2017). Socio-spatial learning: A case study of community knowledge in participatory spatial planning. Progress in Planning, 111, 1-23. https://doi.org/https://doi.org/10.1016/j.progress.2015.06.002

Nonaka, I., \& Konno, N. (1998). The Concept of "Ba": Building a Foundation for Knowledge Creation. California Management Review, 40(3), 40-54. http://cmr.ucpress.edu/content/ucpcmr/40/3/40.full.pdf

Nonaka, I., \& Takeuchi, H. (1995). The knowledge-creating company: how Japanese companies create the dynamics of innovation. Oxford University Press.

Osti, G. (2015). Socio-spatial relations: an attempt to move space near society. In Polyarchies: DiSPeS Studies and Researchers (Vol. 4, Issue April). https://arts.units.it/retrieve/handle/11368/2846171/49524/Soci o-spatialrelationsanattempttomovespacenearsociety.pdf

Pahl-Wostl, C., Craps, M., Dewulf, A., Mostert, E., Tabara, D., \& Taillieu, T. (2007). Social Learning and Water Resources Management. Ecology and Society, 12(2), 5. http://www.ecologyandsociety.org/ vol12/iss2/art5/\%0AResearch,

Pánek, J. (2015a). Aramani - Decision-support tool for selecting optimal participatory mapping method. Cartographic Journal, 52(2), 107-113. https://doi.org/10.1080/00087041.2015.1119473

Pánek, J. (2015b). How participatory mapping can drive community empowerment - A case study of Koffiekraal, South Africa. South African Geographical Journal, 97(1), 18-30. https://doi.org/10.1080/03736245.2014.924866

Pánek, J. (2016). From Mental Maps to GeoParticipation. Cartographic Journal, 53(4), 300-307. https://doi.org/10.1080/00087041.2016.1243862

Parker, B. (2006). Constructing community through maps? Power and praxis in community mapping. Professional Geographer, 58(4), 470-484. https://doi.org/10.1111/j.1467-9272.2006.00583.x

Patel, Z., Greyling, S., Simon, D., Arfvidsson, H., Moodley, N., Primo, N., \& Wright, C. (2017). Local responses to global sustainability agendas: learning from experimenting with the urban sustainable development goal in Cape Town. Sustainability 
Science, 12(5), 785-797. https://doi.org/10.1007/s11625-0170500-y

Patmasari, T. (2019). The Role of Geospatial Information for Accelerating the Delineation of Village Boundaries in Indonesia using Cartometric Method. International Journal of Advanced Engineering Research and Science, 6(7), 46-58. https://doi.org/10.22161/ijaers.677

Perdana, A. P., \& Ostermann, F. O. (2018). A Citizen Science Approach for Toponyms Collecting Toponyms. ISPRS International Journal of Geo-Information, 7(222). https://doi.org/10.3390/ijgi7060222

Perdana, A. P., \& Ostermann, F. O. (2019). Eliciting Knowledge on Technical and Legal Aspects of Participatory Toponym Handling. ISPRS International Journal of Geo-Information, 8(11), 500. https://doi.org/10.3390/ijgi8110500

Perkins, C. (2013). Cultures of map use. The Cartographic Journal, 45(2), 150-158. https://doi.org/10.1179/174327708X305076

Pfeffer, K., Baud, I., Denis, E., Scott, D., \& Sydenstricker-Neto, J. (2013). Participatory spatial knowledge management tools: empowerment and upscaling or exclusion? Information, Communication \& Society, 16(2), 258-285. https://doi.org/10.1080/1369118X.2012.687393

Pfeffer, K., \& Georgiadou, Y. (2019). Global Ambitions, Local Contexts: Alternative Ways of Knowing the World. ISPRS International Journal of Geo-Information, 8(11), 516. https://doi.org/10.3390/ijgi8110516

Pfeffer, K., Martinez, J., O'Sullivan, D., \& Scott, D. (2015). Geotechnologies for spatial knowledge: challenges for inclusive and sustainable urban development. In J. Gupta, K. Pfeffer, H. Verrest, \& M. Ros-Tonen (Eds.), Geographies of Urban Governance (pp. 147-173). Springer. http://link.springer.com/chapter/10.1007/978-3-319-21272-2_8

Pogge, T., \& Sengupta, M. (2015). The Sustainable Development Goals as drafted: Nice idea, poor execution. Washington International Law Journal Association, 24(3), 1-17. https://doi.org/10.3366/ajicl.2011.0005

Polanyi, M. (1967). The tacit dimension. Anchor. http://library.wur.nl/WebQuery/clc/363268

Purba, R. (2011). Public Participation in Development Planning: A Case Study of Indonesian Musrenbang. International Journal of Interdisciplinary Social Sciences, 5(12), 265-277. 
Purba, R. (2010). Decentralization and public participation: Learning from Indonesia. 18th Biennial Conference of the Asian Studies Association of Australia: Crises and Opportunities: Past, Present and Future, 1-11.

Quick, K. S., \& Feldman, M. S. (2011). Distinguishing participation and inclusion. Journal of Planning Education and Research, 31(3), 272-290. https://doi.org/10.1177/0739456X11410979

Rambaldi, G. (2005). Who owns the map legend? URISA Journal, $17(1), 5-13$.

http://citeseerx.ist.psu.edu/viewdoc/download?doi=10.1.1.113.8 89\&rep $=$ rep $1 \&$ type $=$ pdf $\#$ page $=5$

Rambaldi, G., Chambers, R., McCall, M. K., \& Fox, J. (2006). Practical ethics for PGIS practitioners, facilitators, technology intermediaries and researchers. Participatory Learning and Action, 54(1), 106-113.

Ramirez-Gomez, S. O. I., Brown, G., Verweij, P. A., \& Boot, R. (2016). Participatory mapping to identify indigenous community use zones: Implications for conservation planning in southern Suriname. Journal for Nature Conservation, 29, 69-78. https://doi.org/10.1016/j.jnc.2015.11.004

Ramirez-Gomez, S. O. I., Torres-Vitolas, C. A., Schreckenberg, K., Honzák, M., Cruz-Garcia, G. S., Willcock, S., Palacios, E., PérezMiñana, E., Verweij, P. A., \& Poppy, G. M. (2015). Analysis of ecosystem services provision in the Colombian Amazon using participatory research and mapping techniques. Ecosystem Services, 13(1), 93-107. https://doi.org/10.1016/j.ecoser.2014.12.009

Raum, S. (2018). A framework for integrating systematic stakeholder analysis in ecosystem services research: Stakeholder mapping for forest ecosystem services in the UK. Ecosystem Services, 29, 170-184. https://doi.org/10.1016/j.ecoser.2018.01.001

Reed, M. S., Graves, A., Dandy, N., Posthumus, H., Hubacek, K., Morris, J., Prell, C., Quinn, C. H., \& Stringer, L. C. (2009). Who's in and why? A typology of stakeholder analysis methods for natural resource management. Journal of Environmental Management, 90(5), 1933-1949. https://doi.org/10.1016/j.jenvman.2009.01.001

Reyes-García, V., Orta-Martínez, M., Gueze, M., Luz, A. C., PanequeGálvez, J., Macía, M. J., Pino, J., \& TAPS Bolivian Study Team. (2012). Does participatory mapping increase conflicts? A randomized evaluation in the Bolivian Amazon. Applied 
Geography, 34, 650-658.

https://doi.org/10.1016/j.apgeog.2012.04.007

Rhoads, E. (2012). Women's Political Participation in Indonesia: Decentralisation, Money Politics and Collective Memory in Bali. Journal of Current Southeast Asian Affairs, 31(2), 35-56. https://doi.org/10.1177/186810341203100202

Richardson, A. E., Montello, D. R., \& Hegarty, M. (1999). Spatial knowledge acquisition from maps and from navigation in real and virtual environments. Memory \& Cognition, 27(4), 741-750. http://link.springer.com/article/10.3758/BF03211566

Rowe, G., \& Frewer, L. J. (2000). Public Participation Methods: A Framework for Evaluation. Science, Technology \& Human Values, 25(1), 3-29. https://doi.org/10.1177/016224390002500101

Rowe, G., \& Frewer, L. J. (2005). A typology of public engagement mechanisms. Science Technology and Human Values, 30(2), 251-290. https://doi.org/10.1177/0162243904271724

Rowe, G., Marsh, R., \& Frewer, L. J. (2004). Evaluation of a Deliberative Conference. Science, Technology, \& Human Values, 29(1), 88-121. https://doi.org/10.1177/0162243903259194

Saner, R., Yiu, L., \& Nguyen, M. (2019). Monitoring the SDGs: Digital and Social Technologies to Ensure Citizen Participation, Inclusiveness and Transparency. Development Policy Review, 38(4), 483-500. https://doi.org/10.1111/dpr.12433

Santos, L., Coutinho-Rodrigues, J., \& Antunes, C. H. (2011). A web spatial decision support system for vehicle routing using Google Maps. Decision Support Systems, 51(1), 1-9. https://doi.org/10.1016/j.dss.2010.11.008

Schatzki, T. R. (1991). Spatial Ontology and Explanation. Annals of the Association of American Geographers, 81(4), 650-670. https://doi.org/10.1111/j.1467-8306.1991.tb01713.x

Schlossberg, M., \& Shuford, E. (2005). Delineating "Public" and "Participation" in PPGIS. URISA Journal, 16(2), 15-26. https://scholarsbank.uoregon.edu/xmlui/handle/1794/1343

Schusler, T. M., Decker, D. J., \& Pfeffer, M. J. (2003). Social Learning for Collaborative Natural Resource Management. Society \& Natural Resources, 16(4), 309-326. https://doi.org/10.1080/08941920390178874

Schweizer, K., Herrmann, T., Janzen, G., \& Katz, S. (1998). The route direction effect and its constraints. In C. Freksa, C. Habel, \& K. Wender (Eds.), Spatial Cognition: An Interdisciplinary 
Approach to Representing and Processing Spatial Knowledge (pp. 19-38). Springer.

Scott, G., \& Rajabifard, A. (2017). Sustainable development and geospatial information: a strategic framework for integrating a global policy agenda into national geospatial capabilities. GeoSpatial Information Science, 20(2), 59-76. https://doi.org/10.1080/10095020.2017.1325594

Shahab, N. (2016). Indonesia: One Map Policy. Open Government Partnership. https://www.opengovpartnership.org/wpcontent/uploads/2001/01/case-study_Indonesia_One-MapPolicy.pdf

Shao, G., Li, F., \& Tang, L. (2011). Multidisciplinary perspectives on sustainable development. International Journal of Sustainable Development and World Ecology, 18(3), 187-189. https://doi.org/10.1080/13504509.2011.572304

Shrestha, R., Flacke, J., Martinez, J., \& van Maarseveen, M. (2014). SUSS Revisited: An Interactive Spatial Understanding Support System (ISUSS) for Collaborative Spatial Problem Structuring. AESOP Conference From Control to Co-evolution.

http://www.jufo-

salus.de/cms/Medienpool/Veroeffentlichung_Ressourcen_Bilder/ Shrestha-et-al-2014-ISUSS.pdf

Shrestha, R., Flacke, J., Martinez, J., \& van Maarseveen, M. (2018a). Interactive cumulative burden assessment: Engaging stakeholders in an adaptive, participatory and transdisciplinary approach. International Journal of Environmental Research and Public Health, 15(2), 260.

https://doi.org/10.3390/ijerph15020260

Shrestha, R., Flacke, J., Martinez, J., \& van Maarseveen, M. (2018b). Knowledge Co-Production and Social Learning on Environmental Health Issues: A Role for Interactive GIS-Based Approaches. In M. van Maarseveen, J. Flacke, \& J. Martinez (Eds.), GIS in Sustainable Urban Planning and Management: A Global Perspective (pp. 83-102). Taylor \& Francis. https://research.utwente.nl/en/publications/knowledge-coproduction-and-social-learning-on-environmental-heal

Shrestha, R., Köckler, H., Flacke, J., Martinez, J., \& van Maarseveen, M. (2017). Interactive Knowledge Co-Production and Integration for Healthy Urban Development. Sustainability, 9(11), 1945. https://doi.org/10.3390/su9111945

Sieber, R. E. (2000). Conforming (to) the opposition: the social 
construction of geographical information systems in social movements. International Journal of Geographical Information, 14(8), 775-793. https://doi.org/10.1080/136588100750022787

Sieber, R. E., Robinson, P. J., Johnson, P. A., \& Corbett, J. M. (2016). Doing public participation on the geospatial web. Annals of the American Association of Geographers, 106(5), 1030-1046. https://doi.org/10.1080/24694452.2016.1191325

Siegel, A. W., \& White, S. H. (1975). The Development of Spatial Representations of Large-Scale Environments. Advances in Child Development and Behavior, 10, 9-55. https://doi.org/https://doi.org/10.1016/S0065-2407(08)600075

Simão, A., Densham, P. J., \& Haklay, M. M. (2009). Web-based GIS for collaborative planning and public participation: An application to the strategic planning of wind farm sites. Journal of Environmental Management, 90(6), 2027-2040. https://doi.org/10.1016/j.jenvman.2007.08.032

Sirait, M., Prasodjo, S., Podger, N., Flavelle, A., \& Fox, J. (1994). Mapping customary land in East Kalimantan, Indonesia: A tool for forest management. Ambio, 23(7), 411-417. https://doi.org/10.2307/4314246

Smith, D. A. (2003). Participatory mapping of community lands and hunting yields among the Buglé of western Panama. Human Organization, 62(4), 332-343. https://doi.org/10.17730/humo.62.4.cye51kbmmjkc168k

Solís, P., McCusker, B., Menkiti, N., Cowan, N., \& Blevins, C. (2018). Engaging global youth in participatory spatial data creation for the UN sustainable development goals: The case of open mapping for malaria prevention. Applied Geography, 98, 143155. https://doi.org/10.1016/j.apgeog.2018.07.013

Sopanah, A. (2011). Refusal of a local goverment budgeting: an interpretive case study. Asia Pacific Journal of Accounting and Finance, 1(2), 165-177.

http://accounting.feb.ui.ac.id/apjaf/pub/pub2/6

Sopanah, A. (2012). Ceremonial Budgeting: Public Participation in Development Planning at an Indonesian Local Government Authority. Journal of Applied Management Accounting Research, $10(2), 73-84$.

http://ezproxy2.utwente.nl/login?url=http://search.ebscohost.co $\mathrm{m} /$ login . aspx ?direct $=$ true $\& \mathrm{db}=\mathrm{bsh} \& A \mathrm{~N}=84370043 \&$ site $=$ ehost live 
Stern, E., \& Leiser, D. (1988). Levels of Spatial Knowledge and Urban Travel Modeling. Geographical Analysis, 20(2), 140-155. https://doi.org/10.1111/j.1538-4632.1988.tb00172.x

Sullivan, L. (2019). Conservation in Context: Toward a Systems Framing of Decentralized Governance and Public Participation in Wildlife Management. Review of Policy Research, 36(2), 242261. https://doi.org/10.1111/ropr.12326

Sumarto, H. S. (2008). Promoting Citizen Participation in Local Governance in Indonesia: Practices, Policies, and Agenda. http://unpan1.un.org/intradoc/groups/public/documents/apcity/ unpan049827.pdf

Sutanta, H., Rajabifard, A., \& Bishop, I. D. (2013). Disaster risk reduction using acceptable risk measures for spatial planning. Journal of Environmental Planning and Management, 56(6), 761785. https://doi.org/10.1080/09640568.2012.702314

Sutiyo, S. (2013). A Study on Implementation of Decentralized Rural Development in Indonesia: Case of Three Villages in Purbalingga District, Central Java Province (Issue September) [Hiroshima University]. https://doi.org/10.1007/978-4-431-54774-7_10

Sutiyo, S. (2015). Roles of Neighborhood Group to Promote Participatory Development in Indonesia: Case of Three Villages in Purbalingga District, Central Java Province. Journal of Government and Politics, 6(1), 125-135. https://doi.org/10.18196/jgp.2015.0010

Swapan, M. S. H. (2016). Who participates and who doesn't? Adapting community participation model for developing countries. Cities, 53, 70-77. https://doi.org/10.1016/j.cities.2016.01.013

Szyszka, M., \& Polko, P. (2020). Interactive maps of social problems and security threats illustrated with an example of solutions currently used in Upper Silesia. Sustainability, 12(3), 1229. https://doi.org/10.3390/su12031229

Tan, D. T., Siri, J. G., Gong, Y., Ong, B., Lim, S. C., MacGillivray, B. H., \& Marsden, T. (2019). Systems approaches for localising the SDGs: Co-production of place-based case studies. Globalization and Health, 15(1), 1-10. https://doi.org/10.1186/s12992-0190527-1

Tandon, R. (2008). Participation, citizenship and democracy: Reflections on 25 years' of PRIA. Community Development Journal, 43(3), 284-296. https://doi.org/10.1093/cdj/bsn019

Taylor, J., Murphy, C., Mayes, S., Mwilima, E., Nuulimba, N., \& 
Slater-Jones, S. (2006). Land and natural resource mapping by San communities and NGOs: experiences from Namibia. Participatory Learning and Action, 54(1), 79-84.

Tebbutt, E., Brodmann, R., Borg, J., MacLachlan, M., Khasnabis, C., \& Horvath, R. (2016). Assistive products and the Sustainable Development Goals (SDGs). Globalization and Health, 12(79), 16. https://doi.org/10.1186/s12992-016-0220-6

Teghil, A., Boccia, M., Bonavita, A., \& Guariglia, C. (2019). Temporal features of spatial knowledge: Representing order and duration of topographical information. Behavioural Brain Research, 376, 112218. https://doi.org/10.1016/j.bbr.2019.112218

The inhabitants of Moikarakô, de Robert, P., Faure, J., \& Laques, A. (2006). The power of maps: cartography with indigenous people in the Brazilian Amazon. Participatory Learning and Action, 54(1), 74-78.

The United Nations. (2016). The Sustainable Development Agenda. https://www.un.org/sustainabledevelopment/developmentagenda/

The United Nations. (2017). Resolution adopted by the General Assembly on 6 July 2017. https://undocs.org/A/RES/71/313

UCLG. (2018). Sustainable Development Through Local Action: Sustainable Development Goals and Local Government Associations (Issue December). https://www.local2030.org/library/705/SustainableDevelopment-through-Local-Action.pdf

Ulbrich, P., de Albuquerque, J. P., \& Coaffee, J. (2018). The impact of urban inequalities on monitoring progress towards the sustainable development goals: Methodological considerations. ISPRS International Journal of Geo-Information, 8(1), 6. https://doi.org/10.3390/ijgi8010006

UN-Desa. (2018). Accelerating SDG 11 achievement: Policy brief in support of the first SDG 11 review at the UN high-level political forum 2018.

https://sustainabledevelopment.un.org/content/documents/1944 52018_HLPF_Thematic_Review_of_SDG_11_UNHabitat_12_June _2018_original.pdf

UN-GGIM. (2018). Integrated Geospatial Information Framework: A Strategic Guide to Develop and Strengthen National Geospatial Information Management. https://ggim.un.org/meetings/GGIMcommittee/8th-Session/documents/Part 1-IGIF-OverarchingStrategic-Framework-24July2018.pdf 
UN-Habitat and UNDP. (2016). Roadmap for localizing the SDGs: Implementation and monitoring at subnational level. https://unhabitat.org/sites/default/files/download-managerfiles/Roadmap Localising SDG FINAL.pdf

UN Statistics Division. (2018). IAEG-SDGs Tier Classification for Global SDG Indicators. https://unstats.un.org/sdgs/iaegsdgs/tier-classification/

van Ewijk, E., \& Baud, I. (2009). Partnerships between Dutch municipalities and municipalities in countries of migration to the Netherlands; knowledge exchange and mutuality. Habitat International, 33, 218-226. https://doi.org/10.1016/j.habitatint.2008.10.014

Vaughn, L., \& Jacquez, F. (2020). Participatory Research Methods Choice Points in the Research Process. Journal of Participatory Research Methods, 1(1), 13244. https://doi.org/10.35844/001c.13244

Vergara-Asenjo, G., Sharma, D., \& Potvin, C. (2015). Engaging Stakeholders: Assessing Accuracy of Participatory Mapping of Land Cover in Panama. Conservation Letters, 8(6), 432-439. https://doi.org/10.1111/conl.12161

Verkoren, W. (2008). The owl and the dove: knowledge strategies to improve the peacebuilding practice of local non-governmental organisations. University of Amsterdam.

Verplanke, J., McCall, M. K., Uberhuaga, C., Rambaldi, B., \& Haklay, M. (2016). A Shared Perspective for PGIS and VGI. The Cartographic Journal, 53(4), 308-317. https://doi.org/10.1080/00087041.2016.1227552

Videira, N., Antunes, P., Santos, R., \& Lobo, G. (2006). Public and Stakeholder Participation in European Water Policy: a Critical Review of Project Evaluation Processes. European Environment, 16, 19-31. https://doi.org/10.1002/eet.401

Warburton, E. (2016). Jokowi and the New Developmentalism. Bulletin of Indonesian Economic Studies, 52(3), 297-320. https://doi.org/10.1080/00074918.2016.1249262

Wario, H., Roba, H., \& Kaufmann, B. (2015). Shaping the Herders' "Mental Maps": Participatory Mapping with Pastoralists' to Understand Their Grazing Area Differentiation and Characterization. Environmental Management, 56(3), 721-737. https://doi.org/10.1007/s00267-015-0532-y

Wartmann, F. M., \& Purves, R. S. (2017). What's (not) on the map: Landscape features from participatory sketch mapping differ 
from local categories used in language. Land, 6(4), 79. https://doi.org/10.3390/land6040079

Wästberg, B. S., Billger, M., \& Adelfio, M. (2020). A user-based look at visualization tools for environmental data and suggestions for improvement - An inventory among city planners in Gothenburg. Sustainability, 12(7), 2282. https://doi.org/10.3390/su12072882

Webler, T., Kastenholz, H., \& Renn, O. (1995). Public participation in impact assessment: a social learning perspective. Environmental Impact Assessment Review, 15(5), 443-463. https://doi.org/https://doi.org/10.1016/0195-9255(95)00043-E

Webler, T., Tuler, S., \& Krueger, R. (2001). What is a good public participation process? Five perspectives from the public. Environmental Management, 27(3), 435-450. https://doi.org/10.1007/s002670010160

Whatmore, S. J. (2009). Mapping knowledge controversies: science, democracy and the redistribution of expertise. Progress in Human Geography, 33(5), 587-598. http://journals.sagepub.com/doi/abs/10.1177/03091325093398 41

Widianingsih, I., \& Morrell, E. (2007). Participatory planning in Indonesia: seeking a new path to democracy. Policy Studies, 28(1), 1-15. https://doi.org/10.1080/01442870601121320

Wood, J. (2005). "How green is my valley?" Desktop geographic information systems as a community-based participatory mapping tool. Area, 37(2), 159-170. https://doi.org/10.1111/j.1475-4762.2005.00618.x

Yanow, D. (2003). Accessing Local Knowledge. In M. Hajer \& H. Wagenaar (Eds.), Deliberative Policy Analysis: Understanding Governance in the Network Society (pp. 228-246). Cambridge University Press.

Yeap, W. K., \& Jefferies, M. E. (2000). On early cognitive mapping. Spatial Cognition and Computation, 2(2), 85-116. https://doi.org/10.1023/A:1011447309938

Yin, R. K. (2003). Case Study Research: Design and Methods (3rd ed.). SAGE Publications.

Yonehara, A., Saito, O., Hayashi, K., Nagao, M., Yanagisawa, R., \& Matsuyama, K. (2017). The role of evaluation in achieving the SDGs. Sustainability Science, 12(6), 969-973. https://doi.org/10.1007/s11625-017-0479-4 
Appendices 


\section{Appendix A}

\section{Criteria in evaluating public participation}

\begin{tabular}{|c|c|c|c|}
\hline No & Evaluation Criteria & Scholars & Explanation \\
\hline \multicolumn{4}{|c|}{ Process } \\
\hline 1 & Clear task scope & $\begin{array}{l}\text { (Innes \& Booher, 1999; Rowe \& } \\
\text { Frewer, 2000; Rowe, Marsh, } \\
\text { Frewer, 2004; Conley \& Moote, } \\
\text { 2003; Beierle \& Konisky, 2000; } \\
\text { Baker, Hincks, Sherriff, 2010; } \\
\text { Baiocchi \& Ganuza, 2013; Kasdin, } \\
\text { 2017) }\end{array}$ & $\begin{array}{l}\text { Clear context, scope, aim, } \\
\text { outputs, and rational of the } \\
\text { process }\end{array}$ \\
\hline 2 & Representativeness & $\begin{array}{l}\text { (Innes \& Booher, 1999; Moote } \\
\text { et.al, 1997; Conley \& Moote, } \\
\text { 2003; Rowe \& Frewer, 2000; } \\
\text { Rowe, Marsh, Frewer, 2004; } \\
\text { Webler, 1995, Agger \& Lofgren, } \\
\text { 2008; Abelson et.al, 2003; } \\
\text { Baiocchi \& Ganuza, 2013; Kim \& } \\
\text { Schachter, 2013) }\end{array}$ & $\begin{array}{l}\text { All relevant stakeholders } \\
\text { who have interests or } \\
\text { affected by the processes } \\
\text { were clearly identified, } \\
\text { invited, and had a role in the } \\
\text { process }\end{array}$ \\
\hline 3 & Transparency & $\begin{array}{l}\text { (Conley \& Moote, 2003; Reed, } \\
\text { 2008; Rowe \& Frewer, 2000; } \\
\text { Rowe, Marsh, Frewer, 2004, Agger } \\
\text { \& Lofgren, 2008; Baker, Hincks, } \\
\text { Sherriff, 2010; Baiocchi \& Ganuza, } \\
\text { 2013; Kim \& Schachter, 2013; } \\
\text { Kasdin, 2017) }\end{array}$ & $\begin{array}{l}\text { The process was } \\
\text { transparent; information } \\
\text { about process and result } \\
\text { were accessible and } \\
\text { available in proper details }\end{array}$ \\
\hline 4 & $\begin{array}{l}\text { Accessibility of resources } \\
\text { for participation }\end{array}$ & $\begin{array}{l}\text { (Rowe \& Frewer, 2000; Rowe, } \\
\text { Marsh, Frewer, 2004; Webler, } \\
\text { 1995; Abelson et.al 2003; } \\
\text { Widianingsih \& Morrell, 2007; } \\
\text { Kasdin, 2017) }\end{array}$ & $\begin{array}{l}\text { Participants involved had } \\
\text { sufficient skills and } \\
\text { understanding about the } \\
\text { process; data/information } \\
\text { to support the process was } \\
\text { available; sufficient time } \\
\text { and facilities for } \\
\text { implementation }\end{array}$ \\
\hline 5 & $\begin{array}{l}\text { New, creative ideas or } \\
\text { solutions }\end{array}$ & $\begin{array}{l}\text { (Innes \& Booher, 1999; Beierle, } \\
\text { 2002; Webler, 1995) }\end{array}$ & $\begin{array}{l}\text { Defining problems in a } \\
\text { comprehensive and } \\
\text { integrated way; using } \\
\text { scientific or technical } \\
\text { analyses to improve } \\
\text { decision-making processes }\end{array}$ \\
\hline 6 & $\begin{array}{l}\text { Integration of different } \\
\text { types of knowledge }\end{array}$ & $\begin{array}{l}\text { (Innes \& Booher, 1999; Moote } \\
\text { et.al, 1997; Agger \& Lofgren, } \\
\text { 2008; Reed, 2008; Tippett et.al, } \\
\text { 2007; Webler, Tuler, Krueger, } \\
\text { 2001) }\end{array}$ & $\begin{array}{l}\text { Different types of } \\
\text { knowledge used in the } \\
\text { processes; tacit knowledge } \\
\text { became explicit during the } \\
\text { process }\end{array}$ \\
\hline
\end{tabular}




\begin{tabular}{|c|c|c|c|}
\hline No & Evaluation Criteria & Scholars & Explanation \\
\hline 7 & $\begin{array}{lr}\text { Deliberative } & \text { processes } \\
\text { characterised } & \text { by } \\
\text { reciprocity and } & \text { tolerance }\end{array}$ & $\begin{array}{l}\text { (Innes \& Booher, 1999; Webler \& } \\
\text { Tuler, 2000; Webler, Tuler, } \\
\text { Krueger, 2001; Beierle \& Konisky, } \\
\text { 2000; Agger \& Lofgren, 2008; } \\
\text { Abelson et.al, 2003; Baiocchi \& } \\
\text { Ganuza, 2013) }\end{array}$ & $\begin{array}{l}\text { The discussion was fair; } \\
\text { communications among } \\
\text { participants were built; } \\
\text { certain groups or individuals } \\
\text { did not dominate the } \\
\text { deliberative process }\end{array}$ \\
\hline 8 & $\begin{array}{l}\text { Rules are agreed in } \\
\text { advance }\end{array}$ & $\begin{array}{l}\text { (Webler, 1995; Webler, Tuler, } \\
\text { Krueger, 2001; Sabatier et.al, } \\
\text { 2005; Remm et.al, 1995; Baiocchi } \\
\text { \& Ganuza, 2013) }\end{array}$ & $\begin{array}{l}\text { Clear regulations about the } \\
\text { process; participants can } \\
\text { contribute to propose rules } \\
\text { during the process }\end{array}$ \\
\hline 9 & Access to the process & $\begin{array}{l}\text { (Innes \& Booher, 1999; Moote } \\
\text { et.al, 1997; Conley \& Moote, } \\
\text { 2003; Webler \& Tuler, 2000; } \\
\text { Webler, Tuler, Krueger, 2001; } \\
\text { Agger \& Lofgren, 2008; Baiocchi \& } \\
\text { Ganuza, 2013) }\end{array}$ & $\begin{array}{l}\text { Having access to the } \\
\text { decision-making processes; } \\
\text { everyone has equal } \\
\text { opportunities to have a say } \\
\text { at the meeting }\end{array}$ \\
\hline 10 & Decision making authority & $\begin{array}{l}\text { (Moote et.al, 1997; Conley \& } \\
\text { Moote, 2003; Mostert, 2003; } \\
\text { Baiocchi \& Ganuza, 2013) }\end{array}$ & $\begin{array}{l}\text { Decision-making authority } \\
\text { is explicitly shared among } \\
\text { all participants. }\end{array}$ \\
\hline 11 & $\begin{array}{l}\text { Consistent with existing } \\
\text { laws and policies }\end{array}$ & (Conley \& Moote, 2003) & $\begin{array}{l}\text { The processes and results of } \\
\text { the public participation are } \\
\text { in accordance with the laws. }\end{array}$ \\
\hline \multicolumn{4}{|c|}{ Outcome } \\
\hline 12 & $\begin{array}{l}\text { Policy-response options } \\
\text { suggested/Influence on } \\
\text { final policy }\end{array}$ & $\begin{array}{l}\text { (Webler, 1995; Webler \& Tuler, } \\
\text { 2000; Webler, Tuler, Krueger, } \\
\text { 2001; Rowe \& Frewer, 2000; } \\
\text { Abelson et.al, 2003; Baiocchi \& } \\
\text { Ganuza, 2013) }\end{array}$ & $\begin{array}{l}\text { Proposed alternatives or } \\
\text { solutions were taken into } \\
\text { account; the draft plans } \\
\text { were improved after the } \\
\text { process }\end{array}$ \\
\hline 13 & Knowledge sharing & $\begin{array}{l}\text { (Innes \& Booher, 1999; Moote } \\
\text { et.al, 1997;Agger \& Lofgren, } \\
\text { 2008; Webler, Tuler, Krueger, } \\
\text { 2001) }\end{array}$ & $\begin{array}{l}\text { The participants shared } \\
\text { their knowledge and } \\
\text { understanding to others. }\end{array}$ \\
\hline 14 & $\begin{array}{l}\text { Social learning/building } \\
\text { the institutional capital } \\
\text { and capacity }\end{array}$ & $\begin{array}{l}\text { (Innes \& Booher, 1999; Mostert, } \\
\text { 2003; Moote et.al, 1997; Conley \& } \\
\text { Moote, 2003; Agger \& Lofgren, } \\
\text { 2008, Webler \& Tuler, 2000; } \\
\text { Webler, Tuler, Krueger, 2001; } \\
\text { Asthana et.al 2002) }\end{array}$ & $\begin{array}{l}\text { Common understanding was } \\
\text { built; increased trust; } \\
\text { improved capacity to handle } \\
\text { conflicts; willing to } \\
\text { cooperate in solving } \\
\text { common problems }\end{array}$ \\
\hline 15 & $\begin{array}{l}\text { Budget allocation for } \\
\text { public capital }\end{array}$ & $\begin{array}{l}\text { (Zamboni, 2007; Grillos, 2017; } \\
\text { Kim \& Schachter, 2013; Kasdin, } \\
\text { 2017) }\end{array}$ & $\begin{array}{l}\text { Available funding was } \\
\text { allocated for public capital } \\
\text { use which has direct impact } \\
\text { to the society. }\end{array}$ \\
\hline
\end{tabular}




\section{Appendix B}

Profiles of the Musrenbang's participants in five villages

\begin{tabular}{|c|c|c|c|c|c|c|c|c|c|c|}
\hline \multirow{3}{*}{ Attributes } & \multicolumn{10}{|c|}{ Villages } \\
\hline & \multicolumn{2}{|c|}{$\begin{array}{c}\text { Denai Lama } \\
(n=39)\end{array}$} & \multicolumn{2}{|c|}{$\begin{array}{l}\text { Kolam } \\
(n=55)\end{array}$} & \multicolumn{2}{|c|}{$\begin{array}{c}\text { Kramat } \\
\text { Gajah } \\
(n=31)\end{array}$} & \multicolumn{2}{|c|}{$\begin{array}{l}\text { Sidoarjo I } \\
\text { Pasar Miring } \\
\quad(n=44)\end{array}$} & \multicolumn{2}{|c|}{$\begin{array}{l}\text { Tandem } \\
\text { Hulu II } \\
(n=25)\end{array}$} \\
\hline & Freq & $\%$ & Freq & $\%$ & Freq & $\%$ & Freq & $\%$ & Freq & $\%$ \\
\hline \multicolumn{11}{|l|}{ Age (year) } \\
\hline$<21$ & - & - & - & - & - & - & - & - & - & - \\
\hline $31-40$ & 13 & 33,3 & 9 & 16,4 & 8 & 25,8 & 10 & 22,7 & 7 & 28,0 \\
\hline $41-50$ & 16 & 41,0 & 33 & 60,0 & 14 & 45,2 & 18 & 40,9 & 13 & 52,0 \\
\hline $51-60$ & 3 & 7,7 & 5 & 9,1 & 4 & 12,9 & 12 & 27,3 & 4 & 16,0 \\
\hline$>60$ & - & - & 5 & 9,1 & 2 & 6,5 & 3 & 6,8 & - & - \\
\hline \multicolumn{11}{|l|}{ Sex } \\
\hline Male & 33 & 84,6 & 44 & 80,0 & 14 & 45,2 & 24 & 54,5 & 18 & 72,0 \\
\hline Female & 6 & 15,4 & 11 & 20,0 & 17 & 54,8 & 20 & 45,5 & 7 & 28,0 \\
\hline
\end{tabular}

Education

SD

$\begin{array}{lllllllll}\text { (Elementary } & 4 & 10,3 & 3 & 5,5 & - & - & 2 & 4,5\end{array}$ school)

$\begin{array}{llllllllll}\text { SMP } & \text { (Junior } \\ \text { High School) } & 9 & 23,1 & 13 & 23,6 & 12 & 38,7 & 10 & 22,7 & 1\end{array}$

\begin{tabular}{|c|c|c|c|c|c|c|c|c|c|c|}
\hline $\begin{array}{l}\text { SMA (Senior } \\
\text { High School) }\end{array}$ & 19 & 48,7 & 22 & 40,0 & 13 & 41,9 & 22 & 50,0 & 14 & 56,0 \\
\hline Diploma & 1 & 2,6 & 4 & 7,3 & 2 & 6,5 & 3 & 6,8 & 2 & 8,0 \\
\hline S1 (Bachelor) & 6 & 15,4 & 13 & 23,6 & 4 & 12,9 & 7 & 15,9 & 6 & 24,0 \\
\hline S2 (Master) & - & - & - & - & - & - & - & - & 2 & 8,0 \\
\hline
\end{tabular}

Race

\begin{tabular}{lllllllllll}
\hline Javanese & 33 & 84,6 & 49 & 89,1 & 22 & 71,0 & 38 & 86,4 & 17 & 68,0 \\
\hline
\end{tabular}


Appendices

\begin{tabular}{|c|c|c|c|c|c|c|c|c|c|c|}
\hline Malay & 6 & 15,4 & 1 & 1,8 & - & - & 2 & 4,5 & 1 & 4,0 \\
\hline Bataknese & - & - & 3 & 5,5 & 3 & 9,7 & 1 & 2,3 & - & - \\
\hline Karonese & - & - & - & - & 1 & 3,2 & 1 & 2,3 & 4 & 16,0 \\
\hline Sundanese & - & - & 1 & 1,8 & 4 & 12,9 & - & - & 1 & 4,0 \\
\hline Mandailing & - & - & 1 & 1,8 & 1 & 3,2 & - & - & - & - \\
\hline Tionghoa & - & - & - & - & - & - & - & - & 2 & 8,0 \\
\hline Others & - & - & - & - & - & - & 2 & 4,5 & - & - \\
\hline $\begin{array}{l}\text { Total } \\
\text { population } \\
(2016)\end{array}$ & \multicolumn{2}{|c|}{2.764} & \multicolumn{2}{|c|}{16.753} & \multicolumn{2}{|c|}{2.104} & \multicolumn{2}{|c|}{5.292} & \multicolumn{2}{|c|}{8.773} \\
\hline
\end{tabular}

$n=$ number of respondents (attendees who filled the questionnaire)

\section{Notes:}

Not all attendees filled the questionnaire since they were not willing to fill out the questionnaire or they had left the meeting venue before the meeting ended. Number of attendees in each village based on the attendance list, as follows: Denai Lama: 49; Kolam: 56; Kramat Gajah: 34; Sidoarjo I Pasar Miring: 60; Tandem Hulu II: 28 


\section{Appendix C}

\section{Self-completion questionnaire}

\section{Musrenbang in} Village

Date:

\section{A. Respondent's Identity}

Please fill in the blank or choose one answer that best represents your views by circling it.

1. How old are you? old

2. Sex
a. Male
b. Female

3. Education level:
a. SD
b. SMP
c. SMA/SMK
d. Diploma
e. S-1 f.S-2
g. S-3

4. Races

5. Please explain briefly what is your role in the Musrenbang? Representing which stakeholders?

\section{B. Respondent's Point of View Towards the Musrenbang Implementation}

Please put a tick $(\checkmark)$ in the box next to one answer that best represents your views (i.e. SA $\square$ ). If you have further comments, please fill the dots provided in each statement.

( $S A=$ Strongly Agree; $A=$ Agree; $U=$ Undecided; $D=$ Disagree; $S D=$ Strongly Disagree)

1. The goal of the Musrenbang is clear for me.
SA $\square$
A $\square$
$U$ ㅁ
$\mathrm{D} \square$
SD

Comments:

2. The Musrenbang process was made transparent for me.
SA $\square$
A $\square$
$\cup \square$
$\mathrm{D} \square$
SD $\square$

Comments:

3. Rules of the Musrenbang were agreed in advance by the participants.
SA
A $\square$
$U \square$
$\mathrm{D} \square$
SD

Comments: 
4. I could identify the real problems faced by our villages in an integrated and comprehensive way.
SA $\square$
$A \square$
$\mathrm{U} \square$
$\mathrm{D} \square$
SD $\square$

Please explain

5. The participants invited to Musrenbang have represented all important stakeholders in the village.
SA $\square$
A $\square$
$\mathrm{U} \square$
$\mathrm{D} \square$
SD $\square$

If not. Who else should be involved?

6. Each participant has the same opportunities to have a say at the meeting.
SA $\square$
A $\square$
$\mathrm{U} \square$
$\mathrm{D} \square$
SD

If not. Why?

7. Certain individuals tend to dominate the deliberative processes.
SA L
A
$\cup \square$
$D \square$
SD $\square$

Who were more dominant?

Who were less dominant?

8. There were little opportunities to share knowledge among participants.
SA $\square$
$A \square$
$U \square$
$\mathrm{D} \square$
SD $\square$

Comments:

9. Different opinions were not integrated well in the discussion.
SA $\square$
A $\square$
$\mathrm{U} \square$
$\mathrm{D} \square$
SD $\square$

Why. Please explain

10. Decisions were not made through consensus of participants.
SA $\square$
A $\square$
$U \square$
$\mathrm{D} \square$
SD $\square$
Why? Please explain 
11. Data/information (i.e. maps, graphs, pictures, audio etc) to support the deliberative and decision making processes was not available.
SA $\square$
$\mathrm{A} \square$
$U \square$
$\mathrm{D} \square$
SD $\square$

If available. What kind of data/information provided?

If NOT available. What kind of data/information that should be available to support the process?

12. Data/information is needed to support the deliberative processes and decision making.
SA $\square$
$\mathrm{A} \square$
$\mathrm{U} \square$
$\mathrm{D} \square$
SD $\square$

Please explain

13. I learn nothing from other Musrenbang participants.
SA
$A \square$
$U \square$
$\mathrm{D} \square$
SD $\square$

Please explain

14. Common understanding was built among participants.
SA $\square$
$A$
U
$\mathrm{D} \square$
SD

Please explain

15. Budget allocation for public capital is still limited.
SA $\square$
$A \square$
$\cup \square$
$\mathrm{D} \square$
SD

Why? Please explain 


\section{Appendix D}

\section{Interview List for Participants (non-government)}

\section{Interviews with Stakeholders:}

Name

Village

Sub-district

Date of Data Collection

\begin{tabular}{|l|l|l|l|}
\hline Date & Month & $\begin{array}{c}\text { Time } \\
\text { (start) }\end{array}$ & Time (finish) \\
\hline & & & \\
\hline
\end{tabular}

\section{Result of the interview :}

[ 1 ] Complete the interview

[ 2 ] Rejecting to be interviewed

[ 3 ] Rejecting during the interview.

\section{[ 4 ] Others} ..)

\section{Introduction}

Hello, my name is Aulia Akbar. I am here on behalf of the Universiteit of Twente as a researcher about the Musrenbang practice. We recently attended the Musrenbang in your village, and we had announced that we would be approach you for an interview. Do you have some time to participate and answer some questions for us? The interview should take about an hour.

Before we start I want to shortly tell you what we would like to talk to you about today. We would like ask you some questions about your opinions and experiences about the village Musrenbang implementation. We try to investigate more about how the governance processes in the Musrenbang and how the participants' knowledge were used at the discussion. You attended the Musrenbang, followed the processes from the beginning until the end, and filled the questionnaire. So I would like to get further information about the Musrenbang process.

We also want to know more about the knowledge used in the Musrenbang. I believe that as a citizen of this village, you know very well about your neighbourhood. That means that you have the local knowledge that the outsiders might not know. Of course, for everyone this is different. Each people 
has their own knowledge and they may use, integrate, exchange, with other participants at the Musrenbang meeting. Thus, we are interested to get more information about these issues.

In answering our questions there are no right or wrong answers; we are interested in your own experience. Of course your name will remain secret and everything we talk about will be anonymous. If you have any questions during the interview or our questions are not clear, please let me know. Do you have any questions before we begin?

\section{Background of the Interviewee}

1. Do you live in ....... Village?

2. From which neighbourhood?

3. How long have you lived in ............. Village?

4. What are you doing for a living? What is your position? How long have you been working in that position?

\section{Representativeness in Musrenbang (not applicable for Musrenbang organiser)}

5. Could you tell me how did you get the invitation for attending the Musrenbang? When did you receive the invitation?

6. What is your role when you are invited to the last Musrenbang? To represent which groups?

7. How many times have you ever attended a Musrenbang practice with that role?

8. Did you ever have other roles? If yes, please explain.

9. Which stakeholders are invited to the meeting? Who is responsible to decide which stakeholders to be invited to the meeting?

10. Do you think the participants have represented all important stakeholders in the village? If NOT, who else should be invited?

\section{Awareness of the scope and process of Musrenbang}

11. What do you think about the aims of the Musrenbang?

12. Do you think that the scope of the Musrenbang is clear and appropriate for participants?

13. Can you explain what do your constituents expect from your participation in the Musrenbang?

\section{Data/information availability}

14. Did you receive any data/information (i.e. maps, diagrams, pictures, etc) from the Musrenbang organiser at the meeting?

15. If yes, what kind of data/information did you get at the meeting?

16. If no, what kind of data/information that you think needs to be provided at the meeting?

17. If the organiser give you data/information, do you prefer to receive before or during the meeting? Why? 
18. Why do you think it is important to have available data/information at the meeting?

\section{Facilities of the Musrenbang}

19. What was good and not so good about the facilities provided at the meeting? What needs to be improved?

20. What do you think about the time allocation of the meeting?

21. What do you think about the hall used for the meeting?

\section{Rules are agreed in advance}

22. Were the rules of the meeting well-informed to the participants at the beginning of the meeting?

23. If yes, what were the rules agreed before the discussion?

24. If no, do you think it is important to agree the rules prior the discussion? What are the rules that need to be agreed?

\section{Deliberative processes}

25. How well do you know other stakeholders?

26. Have you ever worked with other stakeholders invited to the meeting? Tell me your experience?

27. What do you think about the opportunities for participants to have a say at the meeting?

28. Did you think there were certain stakeholders dominating the discussion?

29. Who did have more domination in the process? Who did have less domination?

30. What are the factors that make certain people more dominant or less dominant?

31. What do you think the solution to minimise the domination and make the process more equal for all?

\section{Decision making processes}

32. How can you reach consensus about the plans and budget priorities?

33. Were your ideas, opinions, suggestions taken into consideration by other participants?

34. Did you learn something from others ideas, opinions, suggestions'?

35. If there is dispute among stakeholders, what are the actions to resolve the dispute?

36. In general, do you think such participatory planning and budgeting practice can be helpful in making better plans for your neighbourhood?

37. To what extent does the village government and village councils give their effort to inform people about ongoing projects and events in your village?

38. To what extent new, creative ideas or solutions from participants can influence the first draft proposed by the village government? 


\section{Public capital spending plan}

39. Was the amount of money to spend on public capital discussed in the meeting? How much is the percentage of the money will be spent in public capital?

40. What do you think about the amount of the money allocated on public capital projects/programs?

\section{Knowledge used and Social learning experiences}

41. To what extent did you share your knowledge to other participants? Did other stakeholders also share their knowledge?

42. Did you find common understanding among stakeholders?

43. Did the deliberative processes allow you to understand other participants' point of view?

\section{Spatial knowledge}

44. Have you ever worked with a map? For what purpose do you ever work with a map?

45. What kind of maps have you ever worked with?

46. Can you interpret the information provided in the map?

47. Let me show you a map, the digital and the analog map. This map shows the area of your village. Do you know your neighbourhood well? Can you show me where are the locations of some points of interests in your village?

48. With the knowledge about the space and location that you have, to what extent did you use the knowledge in the Musrenbang discussion?

\section{Village map}

49. Are you aware that according to the laws, each village must have a village map?

50. If you are asked to draw a sketch map of your neighbourhood, what do you think?

51. What do you think if the maps are used to support the Musrenbang deliberative processes?

52. What do you think if each stakeholder involved in the Musrenbang contribute to produce a village map?

53. Which stakeholders do you think need to be involved in producing the village maps? Why?

\section{Transparency}

54. How can you access the result of the Musrenbang?

55. How can you make sure that your contributions at the Musrenbang were taken into account? 


\section{Respondent Identity}

1. How old are you? .......... years old

2. Education level :

$\begin{array}{ll}\text { SD } & {[1]} \\ \text { SMP } & {[2]} \\ \text { SMU } & {[3]} \\ \text { Diploma } & {[4]} \\ \text { S1 } & {[5]} \\ \text { S2 } & {[6]}\end{array}$

3. Sex:

Male [1]

Female [2]

4. Races:

$1]$

[3]

$[4]$

5]

]

Malay [1]

Java [2]

Karo [3]

Mandailing [4]

Simalungun [5]

Toba [6]

Sunda [7]

Banten [8]

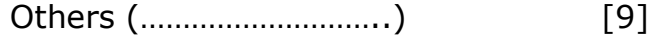

Thank you for your answers and cooperation.

Interviewer,

Aulia Akbar 


\section{Appendix E}

\section{Interview List for Organisers/Governments}

\section{Interviews with Stakeholders:}

Name

Village

Sub-district

Date of Data Collection

\begin{tabular}{|l|l|l|l|}
\hline Date & Month & $\begin{array}{c}\text { Time } \\
\text { (start) }\end{array}$ & Time (finish) \\
\hline & & & \\
\hline
\end{tabular}

\section{Result of the interview :}

[ 1 ] Complete the interview

[ 2 ] Rejecting to be interviewed

[ 3 ] Rejecting during the interview.

\section{[ 4 ] Others} )

\section{Introduction}

Hello, my name is Aulia Akbar. I am here on behalf of the Universiteit of Twente as a researcher about the Musrenbang practice. We recently attended the Musrenbang in your village, and we had informed you few times ago that we would have an interview with you. Do you have some time to participate and answer some questions for us? The interview should take about an hour.

Before we start I want to shortly tell you what we would like to discuss with you today. We would like ask you some questions about your opinions and experiences about the village Musrenbang implementation. We try to investigate more about how the governance processes in the Musrenbang and how the participants' knowledge were used at the discussion. Basically, I would like to get further information about the Musrenbang process from the government's perspective, especially the organiser.

We also want to know more about the knowledge used in the Musrenbang. It is common that local people have their own local knowledge that the outsiders might not know. Of course, for everyone this is different. Each people has their own knowledge and they may use, integrate, exchange, with other participants 
at the Musrenbang meeting. Thus, we are interested to get more information about these issues.

In answering our questions there are no right or wrong answers; we are interested in your own experience. Of course your name will remain secret and everything we talk about will be anonymous. If you have any questions during the interview or our questions are not clear, please let me know. Do you have any questions before we begin?

\section{Background of the Interviewee}

1. Could you tell me a bit about your background? Origins, education, previous positions?

2. How long have you been working for this position?

3. How long have you been working to organise the Musrenbang?

\section{Representativeness in Musrenbang}

4. Could you tell me are there any criteria to be a participant of Musrenbang?

5. Which stakeholders are invited to the meeting? Who is responsible to decide which stakeholders to be invited to the meeting?

6. What do you think about the composition of the participants of Musrenbang? Do you think it is already appropriate with the purpose of Musrenbang? If yes. Why? If no. Who else should be invited?

\section{Awareness of the scope and process of Musrenbang}

7. Could you give me information about the aims of the Musrenbang?

8. Do you think that the scope of the Musrenbang is clear and appropriate for participants?

9. Can you explain what do your constituents expect from Musrenbang?

10. Were there any actions from the local government to disseminate the importance of Musrenbang?

\section{Data/information availability}

11. Did you provide any data/information for the Musrenbang participants?

12. If yes, what kind of data/information did you give at the meeting? Why

13. If no, what kind of data/information that you think needs to be provided at the meeting? Why?

14. What do you think the importance of having sufficient data/information at the meeting?

\section{Facilities of the Musrenbang}

15. What was good and not so good about the facilities provided at the meeting? What needs to be improved?

16. What do you think about the time allocation of the meeting?

17. What do you think about the hall used for the meeting? 


\section{Rules are agreed in advance}

18. Were the rules of the meeting well-informed to the participants at the beginning of the meeting?

19. If yes, what were the rules agreed before the discussion?

20. If no, do you think it is important to agree the rules prior the discussion? What are the rules that need to be agreed?

\section{Deliberative processes}

21. How well do you know other stakeholders?

22. Have you ever worked with other stakeholders invited to the meeting? Tell me your experience?

23. What do you think about the opportunities for participants to have a say at the meeting?

24. Did you think there were certain stakeholders dominating the discussion?

25. Who did have more domination in the process? Who did have less domination?

26. What are the factors that make certain people more dominant or less dominant?

27. What do you think the solution to minimise the domination and make the process more equal for all?

\section{Decision making processes}

28. Could you describe how the consensus about the plans and budget priorities can be reached?

29. Were new ideas, opinions, suggestions taken into consideration in the meeting?

30. Did you learn something from others ideas, opinions, suggestions'?

31. If there are disputes among stakeholders. What are the actions to achieve consensus?

32. In general, do you think such participatory planning and budgeting practice can be helpful in making better plans for your neighbourhood? Is it effective to make better plans?

33. To what extent does the village government and village councils give their effort to inform people about ongoing projects and events in the village?

34. To what extent new, creative ideas or solutions from participants can influence the first draft proposed by the village government?

\section{Public capital spending plan}

35. Could you tell me the proportion of money that must be spent into public capital projects?

36. Was the amount of money to spend on public capital discussed in the meeting? How much is the percentage of the money will be spent in public capital? 


\section{Knowledge used and Social learning experiences}

37. To what extent did you share your knowledge to other participants? Did other stakeholders also share their knowledge?

38. Did you find common understanding among stakeholders?

39. Did the deliberative processes allow all participants to understand other participants' point of view?

\section{Respondent Identity}

1. How old are you? years old

2. Education level : SD

SMP

SMU

Diploma

S2

3. Sex:

Male

Female

4. Races:

Malay

Java

Karo

Mandailing

Simalungun

Toba

Sunda

Banten

Others

Thank you for your answers and cooperation.

Interviewer,

Aulia Akbar 


\section{Appendix F}

Number of interviewees at different level of government structures

\begin{tabular}{|c|c|c|}
\hline Level of government structure & & $\begin{array}{c}\text { Number of } \\
\text { interviewees }\end{array}$ \\
\hline \multirow[t]{5}{*}{ Village level } & Kolam & 8 \\
\hline & Sidoharjo I Pasar Miring & 8 \\
\hline & Kramat Gajah & 8 \\
\hline & Denai Lama & 9 \\
\hline & Tandem Hulu II & 7 \\
\hline \multirow[t]{5}{*}{ Sub-district level } & Percut Sei Tuan & 3 \\
\hline & Pagar Merbau & 2 \\
\hline & Galang & 3 \\
\hline & Pantai Labu & 3 \\
\hline & Hamparan Perak & 2 \\
\hline \multirow[t]{4}{*}{ District level } & Bappeda & 1 \\
\hline & DPMD & 1 \\
\hline & Parliament Member & 1 \\
\hline & & 56 \\
\hline
\end{tabular}




\section{Appendix G}

\section{Stakeholder Analysis Matrix}

\begin{tabular}{|c|c|c|c|c|c|c|}
\hline $\begin{array}{c}\text { Stakeholder } \\
\text { Name }\end{array}$ & Impact & $\begin{array}{l}\text { Inte- } \\
\text { rest }\end{array}$ & $\begin{array}{l}\text { Influ- } \\
\text { ence }\end{array}$ & $\begin{array}{l}\text { What is } \\
\text { important } \\
\text { to the } \\
\text { stakehol- } \\
\text { der? }\end{array}$ & $\begin{array}{c}\text { How could } \\
\text { the } \\
\text { stakehol- } \\
\text { der } \\
\text { contribute } \\
\text { to the } \\
\text { practice? }\end{array}$ & $\begin{array}{c}\text { How } \\
\text { could the } \\
\text { stakehol- } \\
\text { der block } \\
\text { the } \\
\text { practice? }\end{array}$ \\
\hline $\begin{array}{l}\text { BAPPEDA } \\
\text { (District's } \\
\text { Regional } \\
\text { Development } \\
\text { Planning } \\
\text { Agency) }\end{array}$ & Low & Low & High & $\begin{array}{l}\text { The } \\
\text { document } \\
\text { plans } \\
\text { produced in } \\
\text { Musrenbang } \\
\text { are crucial } \\
\text { for achieving } \\
\text { regional } \\
\text { planning } \\
\text { targets }\end{array}$ & $\begin{array}{l}\text { Developing } \\
\text { and } \\
\text { dissemina- } \\
\text { ting } \\
\text { standard } \\
\text { operational } \\
\text { procedure } \\
\text { (SOP) for } \\
\text { annual } \\
\text { planning } \\
\text { practice }\end{array}$ & $\begin{array}{l}\text { Delaying } \\
\text { the SOP } \\
\text { process } \\
\text { through } \\
\text { planning } \\
\text { time plans }\end{array}$ \\
\hline $\begin{array}{l}\text { Dinas } \\
\text { Pemberdayaan } \\
\text { Masyarakat } \\
\text { Desa (District's } \\
\text { Village } \\
\text { Community } \\
\text { Empowerment } \\
\text { Department) }\end{array}$ & High & High & High & $\begin{array}{l}\text { The } \\
\text { document } \\
\text { plans } \\
\text { produced in } \\
\text { Musrenbang } \\
\text { are essential } \\
\text { for achieving } \\
\text { the } \\
\text { department } \\
\text { work } \\
\text { performance } \\
\text { /targets }\end{array}$ & $\begin{array}{l}\text { Developing } \\
\text { and } \\
\text { dissemina- } \\
\text { ting } \\
\text { standard } \\
\text { operational } \\
\text { procedure } \\
\text { (SOP) from } \\
\text { village } \\
\text { budget } \\
\text { policy }\end{array}$ & $\begin{array}{l}\text { Delay in } \\
\text { issuing the } \\
\text { Regent's } \\
\text { Regulation } \\
\text { about } \\
\text { Village } \\
\text { Budget } \\
\text { Policy }\end{array}$ \\
\hline $\begin{array}{l}\text { DPRD (District } \\
\text { Council) }\end{array}$ & Low & Medium & High & $\begin{array}{l}\text { 1) ensure } \\
\text { that their } \\
\text { interests } \\
\text { and or their } \\
\text { constituents' } \\
\text { interests are } \\
\text { accommo- } \\
\text { dated in the } \\
\text { document } \\
\text { plans; 2) } \\
\text { gaining } \\
\text { popularity } \\
\text { for re- } \\
\text { election } \\
\text { purpose }\end{array}$ & $\begin{array}{l}\text { 1) } \\
\text { participating } \\
\text { actively in } \\
\text { the process; } \\
\text { 2) following- } \\
\text { up the } \\
\text { results to } \\
\text { the next } \\
\text { planning } \\
\text { stages }\end{array}$ & $\begin{array}{l}\text { 1) } \\
\text { favoring } \\
\text { their } \\
\text { interests } \\
\text { over } \\
\text { programs } \\
\text { stated in } \\
\text { the } \\
\text { document } \\
\text { plans; 2) } \\
\text { domina- } \\
\text { ting the } \\
\text { discussion } \\
\text { session }\end{array}$ \\
\hline
\end{tabular}




\begin{tabular}{|c|c|c|c|c|c|c|}
\hline $\begin{array}{c}\text { Stakeholder } \\
\text { Name }\end{array}$ & Impact & $\begin{array}{l}\text { Inte- } \\
\text { rest }\end{array}$ & $\begin{array}{l}\text { Influ- } \\
\text { ence }\end{array}$ & $\begin{array}{l}\text { What is } \\
\text { important } \\
\text { to the } \\
\text { stakehol- } \\
\text { der? }\end{array}$ & $\begin{array}{c}\text { How could } \\
\text { the } \\
\text { stakehol- } \\
\text { der } \\
\text { contribute } \\
\text { to the } \\
\text { practice? }\end{array}$ & $\begin{array}{l}\text { How } \\
\text { could the } \\
\text { stakehol- } \\
\text { der block } \\
\text { the } \\
\text { practice? }\end{array}$ \\
\hline $\begin{array}{l}\text { Camat (Head } \\
\text { of Sub-district) }\end{array}$ & Medium & Medium & High & $\begin{array}{l}\text { 1) } \\
\text { performance } \\
\text { indicator; 2) } \\
\text { reputation } \\
\text { among } \\
\text { villages; 3) } \\
\text { responsibili- } \\
\text { ty as the } \\
\text { representati- } \\
\text { ve of the } \\
\text { district } \\
\text { government }\end{array}$ & $\begin{array}{l}\text { 1) deciding } \\
\text { the } \\
\text { Musrenbang } \\
\text { schedule; } 2 \text { ) } \\
\text { supervising } \\
\text { the process }\end{array}$ & $\begin{array}{l}\text { Atten- } \\
\text { dance at } \\
\text { village } \\
\text { Musren- } \\
\text { bang could } \\
\text { influence } \\
\text { partici- } \\
\text { pants' } \\
\text { attitudes }\end{array}$ \\
\hline $\begin{array}{l}\text { Kasi PMD } \\
\text { (Sub-district } \\
\text { Head Section } \\
\text { of Village } \\
\text { Community } \\
\text { Empowerment } \\
\text { ) }\end{array}$ & Medium & High & High & $\begin{array}{l}\text { 1) } \\
\text { performance } \\
\text { indicator; 2) } \\
\text { reputation } \\
\text { among } \\
\text { villages; 3) } \\
\text { responsibili- } \\
\text { ty as the } \\
\text { representa- } \\
\text { tive of the } \\
\text { Head of sub- } \\
\text { district }\end{array}$ & $\begin{array}{l}\text { 1) deciding } \\
\text { the } \\
\text { Musrenbang } \\
\text { schedule; } 2 \text { ) } \\
\text { source of } \\
\text { information; } \\
\text { 3) } \\
\text { supervising } \\
\text { the process }\end{array}$ & $\begin{array}{l}\text { Atten- } \\
\text { dance at } \\
\text { village } \\
\text { Musren- } \\
\text { bang could } \\
\text { influence } \\
\text { partici- } \\
\text { pants' } \\
\text { attitudes }\end{array}$ \\
\hline $\begin{array}{l}\text { Kepala Desa } \\
\text { (Village Head) }\end{array}$ & High & High & High & $\begin{array}{l}\text { 1) } \\
\text { performance } \\
\text { indicator; } 2 \text { ) } \\
\text { trust and } \\
\text { reputation } \\
\text { among } \\
\text { citizens; } 3 \text { ) } \\
\text { required } \\
\text { procedures } \\
\text { to achieve } \\
\text { Village } \\
\text { Head's } \\
\text { vision }\end{array}$ & $\begin{array}{l}\text { 1) } \\
\text { encourage } \\
\text { meaningful } \\
\text { public } \\
\text { participation } \\
\text {; 2) } \\
\text { involving all } \\
\text { impacted } \\
\text { groups; } 3 \text { ) } \\
\text { decision } \\
\text { made } \\
\text { through } \\
\text { consensus }\end{array}$ & $\begin{array}{l}\text { 1) mani- } \\
\text { pulating } \\
\text { decisions; } \\
\text { 2) only } \\
\text { inviting or } \\
\text { favoring } \\
\text { specific } \\
\text { groups }\end{array}$ \\
\hline
\end{tabular}




\begin{tabular}{|c|c|c|c|c|c|c|}
\hline $\begin{array}{c}\text { Stakeholder } \\
\text { Name }\end{array}$ & Impact & $\begin{array}{l}\text { Inte- } \\
\text { rest }\end{array}$ & $\begin{array}{l}\text { Influ- } \\
\text { ence }\end{array}$ & $\begin{array}{l}\text { What is } \\
\text { important } \\
\text { to the } \\
\text { stakehol- } \\
\text { der? }\end{array}$ & $\begin{array}{c}\text { How could } \\
\text { the } \\
\text { stakehol- } \\
\text { der } \\
\text { contribute } \\
\text { to the } \\
\text { practice? }\end{array}$ & $\begin{array}{c}\text { How } \\
\text { could the } \\
\text { stakehol- } \\
\text { der block } \\
\text { the } \\
\text { practice? }\end{array}$ \\
\hline $\begin{array}{l}\text { Pendamping } \\
\text { Desa (Village } \\
\text { Supervisor) }\end{array}$ & High & High & High & $\begin{array}{l}\text { 1) perfor- } \\
\text { mance } \\
\text { indicator; } 2 \text { ) } \\
\text { trust from } \\
\text { village } \\
\text { officials and } \\
\text { citizens; 3) } \\
\text { Ministry of } \\
\text { Village, } \\
\text { Under- } \\
\text { developed } \\
\text { Area, and } \\
\text { Transmigra- } \\
\text { tion } \\
\text { (Kemendes } \\
\text { PDTT); 4) } \\
\text { good plans } \\
\text { lead to good } \\
\text { implementa- } \\
\text { tion }\end{array}$ & $\begin{array}{l}\text { 1) direct } \\
\text { supervision; } \\
\text { 2) source of } \\
\text { information; } \\
\text { 3) drafting } \\
\text { village } \\
\text { document } \\
\text { plans }\end{array}$ & $\begin{array}{l}\text { 1) lack of } \\
\text { skills/ } \\
\text { capacity } \\
\text { for } \\
\text { supervi- } \\
\text { sion; 2) } \\
\text { not } \\
\text { cooperate } \\
\text { well with } \\
\text { various } \\
\text { stakehol- } \\
\text { ders }\end{array}$ \\
\hline $\begin{array}{l}\text { BPD (Village } \\
\text { Council) }\end{array}$ & Medium & High & High & $\begin{array}{l}\text { 1) BPD is } \\
\text { the person } \\
\text { in charge of } \\
\text { Musrenbang } \\
\text { implementa- } \\
\text { tion; } 2 \text { ) } \\
\text { stand up for } \\
\text { people's } \\
\text { interests; } 3 \text { ) } \\
\text { trust from } \\
\text { citizens }\end{array}$ & $\begin{array}{l}\text { 1) } \\
\text { coordinating } \\
\text { with village } \\
\text { head and } \\
\text { his/her } \\
\text { staff; } 2 \text { ) } \\
\text { preparing } \\
\text { and carrying } \\
\text { out the } \\
\text { village } \\
\text { Musrenbang } \\
\text { well }\end{array}$ & $\begin{array}{l}\text { 1) conflict } \\
\text { or compe- } \\
\text { tition with } \\
\text { village } \\
\text { head; } 2 \text { ) } \\
\text { refusal to } \\
\text { implement } \\
\text { Musren- } \\
\text { bang }\end{array}$ \\
\hline $\begin{array}{l}\text { LKMD (Village } \\
\text { Community } \\
\text { Resilience } \\
\text { Board) }\end{array}$ & High & High & Medium & $\begin{array}{l}\text { 1) faster } \\
\text { Musrenbang } \\
\text { could lead to } \\
\text { faster } \\
\text { document } \\
\text { plans which } \\
\text { then lead to } \\
\text { faster } \\
\text { implementa- } \\
\text { tion; } 2 \text { ) } \\
\text { plans lead to } \\
\text { development } \\
\text { projects, } \\
\text { projects lead } \\
\text { to salary }\end{array}$ & $\begin{array}{l}\text { 1) good } \\
\text { coordination } \\
\text { with village } \\
\text { officials and } \\
\text { BPD; } 2 \text { ) } \\
\text { helping out } \\
\text { the head of } \\
\text { the } \\
\text { neighbour- } \\
\text { hood to } \\
\text { identify real } \\
\text { problems/ } \\
\text { needs; } 3 \text { ) } \\
\text { actively } \\
\text { engage in } \\
\text { the } \\
\text { discussion }\end{array}$ & $\begin{array}{l}\text { conflicts } \\
\text { with other } \\
\text { stakehol- } \\
\text { ders }\end{array}$ \\
\hline
\end{tabular}




\begin{tabular}{|c|c|c|c|c|c|c|}
\hline $\begin{array}{c}\text { Stakeholder } \\
\text { Name }\end{array}$ & Impact & $\begin{array}{l}\text { Inte- } \\
\text { rest }\end{array}$ & $\begin{array}{l}\text { Influ- } \\
\text { ence }\end{array}$ & $\begin{array}{l}\text { What is } \\
\text { important } \\
\text { to the } \\
\text { stakehol- } \\
\text { der? }\end{array}$ & $\begin{array}{c}\text { How could } \\
\text { the } \\
\text { stakehol- } \\
\text { der } \\
\text { contribute } \\
\text { to the } \\
\text { practice? }\end{array}$ & $\begin{array}{c}\text { How } \\
\text { could the } \\
\text { stakehol- } \\
\text { der block } \\
\text { the } \\
\text { practice? }\end{array}$ \\
\hline $\begin{array}{l}\text { Kepala Dusun } \\
\text { (Head of } \\
\text { Neighbour- } \\
\text { hood) }\end{array}$ & High & High & Medium & $\begin{array}{l}\text { 1) fight for } \\
\text { neighbour- } \\
\text { hood's } \\
\text { interests; 2) } \\
\text { concerns } \\
\text { from the } \\
\text { neighbour- } \\
\text { hood are } \\
\text { heard and } \\
\text { followed-up; } \\
\text { 3) get trust } \\
\text { from citizens }\end{array}$ & $\begin{array}{l}\text { 1) } \\
\text { implement } \\
\text { the } \\
\text { neighbour- } \\
\text { hood } \\
\text { meeting; 2) } \\
\text { articulate } \\
\text { the } \\
\text { neighbour- } \\
\text { hood's } \\
\text { interests } \\
\text { well. }\end{array}$ & $\begin{array}{l}\text { 1) conflicts } \\
\text { with other } \\
\text { stakehol- } \\
\text { ders; } 2 \text { ) } \\
\text { failure to } \\
\text { identify } \\
\text { real } \\
\text { problems/ } \\
\text { needs }\end{array}$ \\
\hline $\begin{array}{l}\text { Perangkat } \\
\text { Desa (Village } \\
\text { Staffs) }\end{array}$ & Medium & Medium & Low & $\begin{array}{l}\text { Performance } \\
\text { indicator }\end{array}$ & $\begin{array}{l}\text { 1) ensure all } \\
\text { administrati- } \\
\text { ve and } \\
\text { technical } \\
\text { utilities are } \\
\text { well } \\
\text { prepared; 2) } \\
\text { documenting } \\
\text { the process } \\
\text { and results }\end{array}$ & $\begin{array}{l}\text { 1) incapa- } \\
\text { ble of } \\
\text { doing their } \\
\text { jobs } \\
\text { correctly; } \\
\text { 2) conflicts } \\
\text { with other } \\
\text { stakehol- } \\
\text { ders }\end{array}$ \\
\hline $\begin{array}{l}\text { Kelompok } \\
\text { Tani/Nelayan } \\
\text { (Farming/Fish } \\
\text { eries groups) }\end{array}$ & High & High & Low & $\begin{array}{l}\text { 1) concerns } \\
\text { heard and } \\
\text { followed-up; } \\
\text { 2) way to } \\
\text { develop } \\
\text { their villages }\end{array}$ & $\begin{array}{l}\text { 1) identify } \\
\text { real } \\
\text { problems/ } \\
\text { needs; } 2 \text { ) } \\
\text { proposing } \\
\text { ideas and } \\
\text { solutions }\end{array}$ & $\begin{array}{l}\text { lack of } \\
\text { knowledge } \\
\text { about the } \\
\text { proce- } \\
\text { dures }\end{array}$ \\
\hline $\begin{array}{l}\text { Kelompok } \\
\text { Perempuan/ } \\
\text { PKK (Women } \\
\text { groups) }\end{array}$ & High & Medium & Low & $\begin{array}{l}\text { 1) concerns } \\
\text { heard and } \\
\text { followed-up; } \\
\text { 2) way to } \\
\text { develop } \\
\text { their villages }\end{array}$ & $\begin{array}{l}\text { 1) identify } \\
\text { real } \\
\text { problems/ } \\
\text { needs; } 2 \text { ) } \\
\text { proposing } \\
\text { ideas and } \\
\text { solutions }\end{array}$ & $\begin{array}{l}\text { lack of } \\
\text { knowledge } \\
\text { about the } \\
\text { proce- } \\
\text { dures }\end{array}$ \\
\hline $\begin{array}{l}\text { Kelompok } \\
\text { Pemuda/ } \\
\text { Karang Taruna } \\
\text { (Youth groups) }\end{array}$ & Medium & Medium & Low & $\begin{array}{l}\text { 1) concerns } \\
\text { heard and } \\
\text { followed-up; } \\
\text { 2) way to } \\
\text { develop } \\
\text { their villages }\end{array}$ & $\begin{array}{l}\text { 1) identify } \\
\text { real } \\
\text { problems/ } \\
\text { needs; } 2 \text { ) } \\
\text { proposing } \\
\text { ideas and } \\
\text { solutions }\end{array}$ & $\begin{array}{l}\text { lack of } \\
\text { knowledge } \\
\text { about the } \\
\text { proce- } \\
\text { dures }\end{array}$ \\
\hline
\end{tabular}




\begin{tabular}{|c|c|c|c|c|c|c|}
\hline $\begin{array}{c}\text { Stakeholder } \\
\text { Name }\end{array}$ & Impact & $\begin{array}{l}\text { Inte- } \\
\text { rest }\end{array}$ & $\begin{array}{l}\text { Influ- } \\
\text { ence }\end{array}$ & $\begin{array}{l}\text { What is } \\
\text { important } \\
\text { to the } \\
\text { stakehol- } \\
\text { der? }\end{array}$ & $\begin{array}{c}\text { How could } \\
\text { the } \\
\text { stakehol- } \\
\text { der } \\
\text { contribute } \\
\text { to the } \\
\text { practice? }\end{array}$ & $\begin{array}{c}\text { How } \\
\text { could the } \\
\text { stakehol- } \\
\text { der block } \\
\text { the } \\
\text { practice? }\end{array}$ \\
\hline $\begin{array}{l}\text { Pengusaha } \\
\text { (Business } \\
\text { players) }\end{array}$ & Medium & High & Medium & $\begin{array}{l}\text { 1) concerns } \\
\text { heard and } \\
\text { followed-up; } \\
\text { 2) get } \\
\text { involved in } \\
\text { the village } \\
\text { projects }\end{array}$ & $\begin{array}{l}\text { 1) identify } \\
\text { real } \\
\text { problems/ } \\
\text { needs; 2) } \\
\text { proposing } \\
\text { ideas and } \\
\text { solutions }\end{array}$ & $\begin{array}{l}\text { lack of } \\
\text { knowledge } \\
\text { about the } \\
\text { proce- } \\
\text { dures }\end{array}$ \\
\hline $\begin{array}{l}\text { LSM di Desa } \\
\text { (Local } \\
\text { NGOs/CBOs) }\end{array}$ & Low & Medium & Medium & $\begin{array}{l}\text { 1) obtain the } \\
\text { latest } \\
\text { information } \\
\text { about the } \\
\text { village } \\
\text { development } \\
; 2 \text { ) get } \\
\text { involved in } \\
\text { the village } \\
\text { projects }\end{array}$ & $\begin{array}{l}\text { 1) identify } \\
\text { real } \\
\text { problems/ } \\
\text { needs; 2) } \\
\text { proposing } \\
\text { ideas and } \\
\text { solutions }\end{array}$ & $\begin{array}{l}\text { lack of } \\
\text { knowledge } \\
\text { about the } \\
\text { proce- } \\
\text { dures }\end{array}$ \\
\hline $\begin{array}{l}\text { Tokoh Agama } \\
\text { (religious } \\
\text { leader) }\end{array}$ & Medium & High & High & $\begin{array}{l}\text { 1) concerns } \\
\text { heard and } \\
\text { followed-up; } \\
\text { 2) way to } \\
\text { develop } \\
\text { their villages }\end{array}$ & $\begin{array}{l}\text { 1) identify } \\
\text { real } \\
\text { problems/ } \\
\text { needs; 2) } \\
\text { proposing } \\
\text { ideas and } \\
\text { solutions }\end{array}$ & $\begin{array}{l}\text { lack of } \\
\text { knowledge } \\
\text { about the } \\
\text { proce- } \\
\text { dures }\end{array}$ \\
\hline $\begin{array}{l}\text { Tokoh } \\
\text { Masyarakat } \\
\text { (community } \\
\text { leader) }\end{array}$ & High & High & High & $\begin{array}{l}\text { 1) concerns } \\
\text { heard and } \\
\text { followed-up; } \\
\text { 2) way to } \\
\text { develop } \\
\text { their villages }\end{array}$ & $\begin{array}{l}\text { 1) identify } \\
\text { real } \\
\text { problems/ } \\
\text { needs; 2) } \\
\text { proposing } \\
\text { ideas and } \\
\text { solutions }\end{array}$ & $\begin{array}{l}\text { lack of } \\
\text { knowledge } \\
\text { about the } \\
\text { proce- } \\
\text { dures }\end{array}$ \\
\hline $\begin{array}{l}\text { Masyarakat } \\
\text { Umum } \\
\text { (ordinary } \\
\text { citizens) }\end{array}$ & High & Low & Low & $\begin{array}{l}\text { 1) concerns } \\
\text { heard and } \\
\text { followed-up; } \\
\text { 2) way to } \\
\text { develop } \\
\text { their villages }\end{array}$ & $\begin{array}{l}\text { 1) identify } \\
\text { real } \\
\text { problems/ } \\
\text { needs; } 2 \text { ) } \\
\text { proposing } \\
\text { ideas and } \\
\text { solutions }\end{array}$ & $\begin{array}{l}\text { lack of } \\
\text { knowledge } \\
\text { about the } \\
\text { proce- } \\
\text { dures }\end{array}$ \\
\hline
\end{tabular}




\section{Appendix H}

\section{Semi-structured in-depth interviews questions list.}

Tools: Voice recorder, and Google Map application on a Tablet.

\section{Data/Information Availability}

1. How was the discussion in Musrenbang?

2. Did the topic of discussion also mention particular places/locations within the village? Why?

3. When discussing specific places/locations, did you use any maps during the discussion? Did the Musrenbang organisers provide maps?

4. Did you receive any data/information from the Musrenbang organiser? Was it useful?

5. If yes, what kind of data/information did you get during the Musrenbang meeting?

6. If not, what kind of data/information do you think needs to be available for the Musrenbang meeting?

7. If the Musrenbang organiser gives you data/information, do you prefer to receive the data/information before or during the event? Why?

8. Do you think it is important to have data/information available for the Musrenbang meeting? Why?

\section{Knowledge utilisation and social learning experience}

9. To what extent did you share your knowledge to other participants? Did other participants also share their knowledge?

10. Do you think the participants effectively shared their knowledge to others? Why?

11. Was a common understanding among stakeholders reached during the Musrenbang meeting?

12. Was the discussion in the Musrenbang helpful for you to understand other participants' point of view?

\section{Spatial knowledge}

13. Have you ever worked with maps? For what purpose did you work with maps?

14. What kind of maps have you ever used?

15. Can you understand the information shown on maps? 
16. Let me show you a map showing your village area (in digital format and analogue). Can you identify your neighbourhoods or living place? Can you point at some primary objects/places (such as village head office, mosque, etc.) in your village?

17. Using this map (in digital format and analogue), do you know what the distance is between primary objects/places A and B? How can you measure the distance between $A$ and $B$ ?

18. In the field, do you know what the distance is between primary objects/places $A$ and $B$ ? How can you measure the distance between $A$ and $B$ ? Can we produce maps using the data between $A$ and $B$ ? How can we draw the positions and the distances into maps?

19. Do you know your village well? If I ask you a specific place in your village, can you imagine the place in your mind?

20. Based on previous questions, it seems that you have spatial knowledge. This is a knowledge about space and place. Did you recognise it?

21. Were discussions about name of places or geographical locations included in the deliberative processes of Musrenbang? How?

22. Were the participants using their spatial knowledge that they have during the Musrenbang deliberative processes?

23. To what extent did you use your spatial knowledge during the Musrenbang discussion?

\section{Village Maps}

24. Does the village have maps? What kind of maps? How and when were the maps produced?

25. Did you use the maps during the Musrenbang? How?

26. Why did you use the maps during the Musrenbang?

27. Did you use the maps for other development purposes out of Musrenbang?

28. Did you know that based on the laws, each village must have village maps?

29. Please draw the sketch map showing your village in this blank sheet. Can you do that?

30. What is your opinion if we use maps during the Musrenbang meeting?

31. What is your opinion if we involve each stakeholder who attended the Musrenbang to create the maps in a participatory manner?

32. If you think it is possible, who are the stakeholders that need to be involved for the participatory mapping workshop? Why? 


\section{Appendix I}

\section{Focus Group Discussion}

\section{Purpose}

To gain information about the development of collaborative spatial learning methodology that can integrate different types of spatial knowledge and facilitate social learning (Objective 2 ).

\section{Participants}

The focus group discussion invited diverse stakeholders who were involved in the Musrenbang meeting.

- Head of the village (Kepala Desa)

- Head of the village parliament board (Ketua BPD)

- Head of the village empowerment board (Ketua LPMD)

- $\quad$ Staff of the village office (Staf Kantor Desa) who is responsible to conduct the Musrenbang

- Head of the neighbourhood (Kepala Dusun)-2 people per village

- Head of the youth club (Ketua Karang Taruna)

- Head of the women club (Ketua PKK)

- Village companion (Pendamping Desa)

- Religious leaders

- Village prominent person

\section{Tools}

Voice recorder, video recorder, sticky notes, pens, projector, and laptop.

Q.1. Let us reflect to the Musrenbang implementation few weeks ago. What do you think some positive aspect of the Musrenbang implementation? Please write down your thoughts on the sticky notes provided.

After all participants wrote on the sticky notes. The moderator asks the participants to put the sticky notes on the wall. Moderator leads the discussion while rearranging the order of the sticky notes based on the topics of discussion. During the discussion, moderator can trigger some additional questions to raise the discussion among participants.

1. Are you familiar with the Village Law?

2. Can you tell us about the impact of the issuance of Village Law to the local governance processes?

3. What are the impacts of the new law to the Musrenbang processes? 
4. Did you find that the current Musrenbang practices effective to discuss the plans? Why?

5. What do you think that needs to be added to increase the effectiveness?

6. What do you think about data availability? Is it important? Why?

Q.2. Now, please write down some negative aspects that need to be improved in the Musrenbang implementation?

The procedure is the same as the previous question. Moderator puts the sticky notes and categorises the answers based on the discussion. Moderator then asks some additional questions to stimulate the discussion among participants.

1. Do you think that sufficient data/information available could help the processes?

2. Have you ever worked with a map? What kind of maps? For what purpose?

3. Did you find it is useful to work with a map?

4. What do you think if we also use maps in the Musrenbang processes?

5. Are you aware that the new law obliges each village to have village maps?

6. If I show you a satellite image, can you identify your point of interest in the village? (by showing a satellite image map with several points of interests).

Q.3. Based on our discussion today, it seemed that each of us has their own spatial knowledge, which is the knowledge about how you perceive the geographical location and place around you. What do you think about producing village maps by integrating all the spatial knowledge that you have into maps?

Additional questions to stimulate the discussion.

1. Do you think that the opinions and knowledge from the local people are necessary in the mapping processes? Why and how?

2. Considering that each village must have village maps., do you prefer to produce the maps in a participatory way or just 'given' from the upper government? Why?

Q.4. Please allow me to give you a slight presentation about some methods used to produce maps in a participatory manner (give a Power Point presentation (around $5 \mathrm{~min}$ ) about digital and non-digital participatory mapping method; alternatively, watch short videos about the participatory mapping in other places). After presentation, discuss!

Additional questions to stimulate the discussion.

1. If we would like to develop a participatory mapping methodology, which one do you prefer, drawing the maps in a digital or non-digital procedure? 
2. What things do you think need to be consider when developing the participatory mapping methodology?

3. Do you think the workshop should be facilitated with a mapping expert? Why?

4. Do we need to do site-visit when mapping? Why?

5. Do you think that we can make use of the maps we have produced to improve the current Musrenbang practices? Why and how?

Q.5. In terms of stakeholders that need to be involved in the participatory mapping processes. Who are the stakeholders that should be involved in the participatory mapping workshop? Why do we need to involve them?

Additional questions to stimulate the discussion.

1. Do you think that with the composition of the stakeholders involved would increase the effectiveness of the participatory mapping workshop?

2. Do you think that the map making could enhance the communication and collaboration among stakeholders?

3. Who are the stakeholders that you think have more power and influence in the processes? What ways do you think could minimise the power and influence imbalance? How?

Thank you for your cooperation to participate participating in this focus group discussion. 


\section{Appendix J}

\section{Profile of the participatory mapping workshop participants}

\begin{tabular}{|c|c|c|c|c|c|c|}
\hline \multirow{3}{*}{ Attributes } & \multicolumn{6}{|c|}{ Villages } \\
\hline & \multicolumn{2}{|c|}{$\begin{array}{c}\text { Denai } \\
\text { Lama } \\
(n=16)\end{array}$} & \multicolumn{2}{|c|}{$\begin{array}{c}\text { Kramat } \\
\text { Gajah } \\
(n=10)\end{array}$} & \multicolumn{2}{|c|}{$\begin{array}{c}\text { Kolam } \\
(n=29)\end{array}$} \\
\hline & Freq & $\%$ & Freq & $\%$ & Freq & $\%$ \\
\hline \multicolumn{7}{|l|}{ Respondents' background } \\
\hline \multicolumn{7}{|l|}{ Age (year) } \\
\hline $18-30$ & 1 & 6 & 0 & 0 & 0 & 0 \\
\hline $31-50$ & 12 & 75 & 6 & 60 & 25 & 86 \\
\hline $51-65$ & 3 & 19 & 4 & 40 & 3 & 10 \\
\hline More than 65 & 0 & 0 & 0 & 0 & 1 & 3 \\
\hline \multicolumn{7}{|l|}{ Sex } \\
\hline Male & 16 & 100 & 10 & 100 & 14 & 48 \\
\hline Female & 0 & 0 & 0 & 0 & 15 & 52 \\
\hline \multicolumn{7}{|l|}{ Education } \\
\hline Primary school & 1 & 6 & 1 & 10 & 1 & 3 \\
\hline Junior high school & 4 & 25 & 3 & 30 & 7 & 24 \\
\hline Senior high school & 9 & 56 & 5 & 50 & 18 & 62 \\
\hline Diploma & 1 & 6 & 0 & 0 & 2 & 7 \\
\hline Bachelor & 1 & 6 & 0 & 0 & 1 & 3 \\
\hline Not say & 0 & 0 & 1 & 10 & 0 & 0 \\
\hline \multicolumn{7}{|l|}{ Role in the village } \\
\hline Village officials & 5 & 31 & 4 & 40 & 2 & 7 \\
\hline BPD (Village council) & 4 & 25 & 1 & 10 & 3 & 10 \\
\hline LKMD (Village development board) & 3 & 19 & 1 & 10 & 0 & 0 \\
\hline Head of neighbourhood & 4 & 25 & 3 & 30 & 9 & 31 \\
\hline PKK (Women group) & 0 & 0 & 0 & 0 & 11 & 38 \\
\hline Karang Taruna (Youth group) & 0 & 0 & 0 & 0 & 0 & 0 \\
\hline $\begin{array}{c}\text { Tokoh masyarakat (community } \\
\text { leaders) }\end{array}$ & 0 & 0 & 1 & 10 & 4 & 14 \\
\hline Others & 0 & 0 & 0 & 0 & 0 & 0 \\
\hline \multicolumn{7}{|l|}{$\begin{array}{l}\text { Respondents' Literacy } \\
\text { Frequency of Use }\end{array}$} \\
\hline Computer & & & & & & \\
\hline Daily & 6 & 38 & 3 & 30 & 2 & 7 \\
\hline Every week & 1 & 6 & 0 & 0 & 0 & 0 \\
\hline Once per month & 0 & 0 & 0 & 0 & 1 & 3 \\
\hline Few times per year & 1 & 6 & 2 & 20 & 10 & 34 \\
\hline Never & 8 & 50 & 5 & 50 & 16 & 55 \\
\hline \multicolumn{7}{|l|}{ Digital maps } \\
\hline Daily & 2 & 13 & 0 & 0 & 0 & 0 \\
\hline Every week & 2 & 13 & 0 & 0 & 6 & 21 \\
\hline Once per month & 1 & 6 & 0 & 0 & 0 & 0 \\
\hline Few times per year & 2 & 13 & 6 & 60 & 8 & 28 \\
\hline Never & 9 & 56 & 4 & 40 & 15 & 52 \\
\hline
\end{tabular}




$\begin{array}{ccccccc}\text { Paper maps } & 2 & 13 & 0 & 0 & 0 & 0 \\ \text { Daily } & 2 & 13 & 1 & 10 & 1 & 3 \\ \text { Every week } & 0 & 0 & 3 & 30 & 1 & 3 \\ \text { Once per month } & 11 & 69 & 6 & 60 & 11 & 38 \\ \text { Few times per year } & 1 & 6 & 0 & 0 & 16 & 55 \\ \text { Never } & & & \end{array}$

Participation in a group mapping

activity

Never

1-2 times

3-5 times

More than 5 times

\begin{tabular}{cccccc}
3 & 19 & 3 & 30 & 11 & 38 \\
11 & 69 & 6 & 60 & 16 & 55 \\
1 & 6 & 1 & 10 & 2 & 7 \\
1 & 6 & 0 & 0 & 0 & 0 \\
\hline
\end{tabular}

$n=$ number of respondents (attendees who filled the questionnaire).

In Kolam village, from thirty participants, there was one participant who left the workshop early and did not fill the questionnaire. 


\section{Appendix K}

\section{Questionnaire}

This survey is part of the mapping activity in the village: . Your participation will be a great help to us. Please agree or disagree with the following statements. The responses will be kept anonymous. They will be used to better understand your perception of the participatory mapping workshop. In addition, summarised data will be used in scientific articles to be published. Please complete this survey before you leave.

Thank you for your participation!

Part 1. Your perception of the participatory mapping workshop

\begin{tabular}{|c|c|c|c|c|c|}
\hline $\begin{array}{c}\text { By Participating in } \\
\text { This Participatory } \\
\text { Workshop... }\end{array}$ & $\begin{array}{l}\text { Strongly } \\
\text { Disagree }\end{array}$ & Disagree & Neutral & Agree & $\begin{array}{l}\text { Strongly } \\
\text { Agree }\end{array}$ \\
\hline $\begin{array}{c}\text { I learned a lot about our } \\
\text { village }\end{array}$ & 1 & 2 & 3 & 4 & 5 \\
\hline $\begin{array}{l}\text { My knowledge about my } \\
\text { village increased }\end{array}$ & 1 & 2 & 3 & 4 & 5 \\
\hline $\begin{array}{c}\text { We identified the } \\
\text { villages' underlying } \\
\text { problems }\end{array}$ & 1 & 2 & 3 & 4 & 5 \\
\hline $\begin{array}{c}\text { We collaborated as a } \\
\text { team in the mapmaking } \\
\text { process }\end{array}$ & 1 & 2 & 3 & 4 & 5 \\
\hline $\begin{array}{c}\text { The participants } \\
\text { discussed the issues in } \\
\text { an open way }\end{array}$ & 1 & 2 & 3 & 4 & 5 \\
\hline $\begin{array}{l}\text { I could articulate my } \\
\text { opinions during the } \\
\text { mapping workshop }\end{array}$ & 1 & 2 & 3 & 4 & 5 \\
\hline $\begin{array}{l}\text { Each participant had the } \\
\text { same opportunities to } \\
\text { share their knowledge }\end{array}$ & 1 & 2 & 3 & 4 & 5 \\
\hline $\begin{array}{c}\text { Other participants at the } \\
\text { workshop listened to } \\
\text { what I said }\end{array}$ & 1 & 2 & 3 & 4 & 5 \\
\hline $\begin{array}{l}\text { We learned from each } \\
\text { other during the } \\
\text { mapping workshop }\end{array}$ & 1 & 2 & 3 & 4 & 5 \\
\hline $\begin{array}{l}\text { After this workshop, my } \\
\text { trust in other } \\
\text { participants increased }\end{array}$ & 1 & 2 & 3 & 4 & 5 \\
\hline $\begin{array}{l}\text { I believe the map } \\
\text { produced would be } \\
\text { useful for village } \\
\text { development }\end{array}$ & 1 & 2 & 3 & 4 & 5 \\
\hline $\begin{array}{l}\text { I would recommend } \\
\text { using maps during the } \\
\text { Musrenbang practice }\end{array}$ & 1 & 2 & 3 & 4 & 5 \\
\hline
\end{tabular}




\section{Part 2. About yourself}

This part aims to know about your personal background and experience with maps and participatory mapping activities. Please fill the questions below by selecting one of the given options.

1. Fill in your gender:

$\square$ Female $\square$ Male $\square$ Prefer not to say

2. Age group:

$\square<18$ years $\square 18-30$ years $\square 31-50$ years $\square 51-65$ years $\square>65$ years

3. Select your highest completed educational level

$\square$ Primary School $\square$ High School $\square$ Bachelor $\square$ MSc $\square$ PhD

4. What role do you hold in the community organisation?

$\square$ Village official, as:

$\square$ Village council (BPD), as:

$\square$ Village development board (LKMD), as:

$\square$ Women group (PKK), as:

$\square$ Youth group (Karang Taruna), as:

$\square$ Community leader.

$\square$ Other. Please specify:

5. How often do you use a computer/laptop?

$\square$ Never $\square$ Few times per year $\square$ Once per month $\square$ Every week $\square$ Daily

6. How often do you use a map in the paper?

$\square$ Never $\square$ Few times per year $\square$ Once per month $\square$ Every week $\square$ Daily

7. How often do you use a digital map (e.g., in a phone)?

$\square$ Never $\square$ Few times per year $\square$ Once per month $\square$ Every week $\square$ Daily

8. Have you participated in a group mapping activity?

$\square$ Never $\square$ 1-2 times $\square$ 3-5 times $\square$ More than five times 


\section{Appendix L}

\section{In-Depth Interviews of the Participatory Mapping Workshop Participants}

This interview is part of the mapping activity in the village: to gain additional information about your perception of the participatory mapping workshop. Your participation will be a great help to us. The interview will be recorded, and your responses will be kept anonymous. The data will be analysed and used in scientific articles to be published.

\section{Background information}

1. What is your name?

2. What is your occupation?

3. How long have you worked there? Where did you work before?

4. What is your role in the village?

5. What is your education?

6. Can I have your phone number? Can I call your number if I have other questions?

The participants' experiences with visualised geospatial data and mapping workshop

1. Have you ever used a paper map before the mapping workshop? Please explain.

2. Have you ever used a digital map on a computer before the mapping workshop? On your mobile phone? Please explain.

3. Have you ever used a satellite image before the workshop? Please explain.

4. Have you ever participated in a participatory mapping workshop before the workshop? Please explain.

The implementation of the participatory mapping workshop

1. What do you think about the methods used during the participatory mapping workshop?

2. What do you think about the mapping tools? Please explain.

3. What were the strengths of the mapping workshop? What were the benefits? Please explain.

4. What were the challenges that you had during the workshops? Please explain.

5. What were the limitations of the mapping workshop that could be improved? Please explain.

6. What do you think about the tasks given during the workshop? Please explain.

7. What do you think about the time allocation? Please explain.

8. What do you think about the moderation of the workshop? Please explain. 
9. Did you find the satellite image that we used was useful? Why? Please explain.

The communication and collaboration

1. What do you think about the communication among the participants during the workshop? Please explain.

2. What do you think about the knowledge used during the workshop? Please explain.

3. In your opinion, to what extent the participants use and share their knowledge? How? Please explain.

4. To what extent did the workshop allow each participant to share their opinions of knowledge? How? Please explain.

5. What do you think about the collaboration among the participants during the workshops? Please explain.

6. Did participants in the workshop appreciate others' point of view? How? Please explain.

7. Did your knowledge about the village increase after participating in the workshop? How? Please explain.

The knowledge co-production and social learning

1. What do you think about the integration of spatial knowledge during the workshop? Please explain.

2. To what extent did your trust to other participants increase after participating in the workshop? Please explain.

3. What kind of collective actions or decisions were made during the workshop? Please explain.

4. What do you think about the maps produced during the workshop? Would you recommend to use the maps in the Musrenbang or other projects? Why?

5. Did the workshop help participants to codify their spatial knowledge? Why? How? Please explain.

6. To what extent did the workshop help participants to think systematically? How? Please explain.

7. To what extent did the workshop help participants to think holistically? Please explain.

8. To what extent did the workshop help to build the relationships among participants so that participants were willing to collaborate? How? Please explain.

9. Did the workshop help participants to reach a common understanding? How? Please explain. 


\section{Appendix M}

\section{Village Musrenbang Observation Sheet}

Village:

Date:

Observer:

\section{Evaluation of the Musrenbang process}

1. Did participants understand the purpose of holding Musrenbang?

2. Was the implementation of the Musrenbang sufficiently transparent?

3. Did the participants agree with the rules in advance of Musrenbang?

4. Can the participants identify the main problems faced by the village? How?

5. Did all participants have the same opportunity to express their opinions?

6. Did anyone dominate / dominate the discussion process? Who were they? How did they dominate the course of the discussion?

7. Were there any passive participants in the discussion? What could be the cause?

8. In general, how was the discussion process at the Musrenbang? Was it live / dynamic, or not? Please elaborate.

9. Did participants share knowledge / information with each other? How?

10. Was a common understanding among participants with different opinions? Examples?

11. Was there a learning process in Musrenbang? How did the learning process occur?

12. Was there mutual understanding among the participants?

Evaluation of the data used to support the Musrenbang

1. Was data available to support the discussion process at Musrenbang (e.g maps, list of planned activities, photos of locations, statistical data, etc.)? If so, what kind of data was available?

2. How did Musrenbang participants use the existing data?

3. Was the available data been used optimally? Did it support the discussion?

4. Were the village maps used in the discussion process? How did they use it?

5. Did participants learn about their village from the maps? How?

6. Was the village maps helpful for the Musrenbang discussion process or not? or even hinder the discussion process? Please elaborate.

7. Did any of the participants share their opinions regarding the use of maps in the Musrenbang process? What did they say?

8. Did their experience participating in participatory mapping activities some time ago support them to be more active in the discussion process at the Musrenbang? Elaborate. 


\section{Appendix N}

\section{Questionnaire for village Musrenbang participants}

Village :

Date :

This questionnaire form is part of the research conducted by Mr. Aulia Akbar, PhD student from ITC-University of Twente. This is an anonymous questionnaire, so you don't need to fill your name on the form. Data that is collected will be used to understand the process of village Musrenbang and will be published for academic/research purpose. Please fill this form before you leave the Musrenbang venue. If you have any enquiries, please ask, or you can contact Aulia Akbar at HP/WA: +628196030291.

Thank you for your kind attention and help.

\section{a. Evaluation towards the Musrenbang process}

Based on your experience in the Musrenbang process, please put a cross sign $(X)$ next to the answers that you choose.

\begin{tabular}{|c|c|c|c|c|c|}
\hline About the Musrenbang Process & 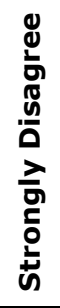 & 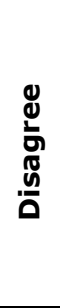 & $\begin{array}{l}\overline{0} \\
\frac{5}{3} \\
\overline{0} \\
z\end{array}$ & 选 & 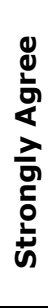 \\
\hline 1. The goal of the Musrenbang was clear for me. & 1 & 2 & 3 & 4 & 5 \\
\hline $\begin{array}{l}\text { 2. The Musrenbang process was made transparent for } \\
\text { me. }\end{array}$ & 1 & 2 & 3 & 4 & 5 \\
\hline $\begin{array}{l}\text { 3. Rules of the Musrenbang were agreed in advance } \\
\text { by the participants. }\end{array}$ & 1 & 2 & 3 & 4 & 5 \\
\hline $\begin{array}{l}\text { 4. I could identify the real problems faced by our } \\
\text { villages. }\end{array}$ & 1 & 2 & 3 & 4 & 5 \\
\hline $\begin{array}{l}\text { 5. The participants invited to the Musrenbang } \\
\text { represented all relevant stakeholders in the villages. }\end{array}$ & 1 & 2 & 3 & 4 & 5 \\
\hline $\begin{array}{l}\text { 6. Each participant had the same opportunity to have } \\
\text { a say at the meeting. }\end{array}$ & 1 & 2 & 3 & 4 & 5 \\
\hline
\end{tabular}


7. Certain individuals tended to dominate the deliberative processes.

8. There were many opportunities to share knowledge among participants.

$\begin{array}{lllll}1 & 2 & 3 & 4 & 5\end{array}$

9. Different opinions were integrated well in the discussion.

$\begin{array}{lllll}1 & 2 & 3 & 4 & 5\end{array}$

10. Decisions were made through the consensus of participants.

$\begin{array}{lllll}1 & 2 & 3 & 4 & 5\end{array}$

11. I learnt new things from other Musrenbang participants.

$\begin{array}{lllll}1 & 2 & 3 & 4 & 5\end{array}$

12. A common understanding was built among participants.

$\begin{array}{lllll}1 & 2 & 3 & 4 & 5\end{array}$

13. Budget allocation for public capital is still limited. $\quad \begin{array}{lllllll}1 & 2 & 3 & 4 & 5\end{array}$

\section{b. Evaluation about the data/information used to support the Musrenbang}

\begin{tabular}{|c|c|c|c|c|c|}
\hline $\begin{array}{c}\text { About the Data/Information Available to Support } \\
\text { the Discussion in the Musrenbang }\end{array}$ & 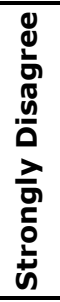 & 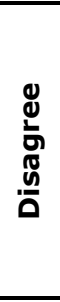 & $\begin{array}{l}\bar{\pi} \\
\frac{2}{2} \\
\frac{0}{2}\end{array}$ & むँ & 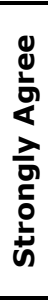 \\
\hline $\begin{array}{l}\text { 1. Data or information (i.e., maps, graphs, pictures, } \\
\text { audio) to support the discussion of Musrenbang was } \\
\text { available (please tick any data available). }\end{array}$ & 1 & 2 & 3 & 4 & 5 \\
\hline $\begin{array}{l}\square \text { Maps } \square \text { Pictures } \square \text { List of projects } \square \text { Graphs } \square \\
\text { Others }\end{array}$ & & & & & \\
\hline $\begin{array}{l}\text { 2. Data or information available was effectively used } \\
\text { during the Musrenbang. }\end{array}$ & 1 & 2 & 3 & 4 & 5 \\
\hline $\begin{array}{l}\text { 3. In my opinion, data/information was needed to } \\
\text { support the discussion in the Musrenbang. }\end{array}$ & 1 & 2 & 3 & 4 & 5 \\
\hline $\begin{array}{l}\text { 4. I did not need any data/information to support the } \\
\text { discussion in the Musrenbang. }\end{array}$ & 1 & 2 & 3 & 4 & 5 \\
\hline $\begin{array}{l}\text { 5. In my opinion, the village maps used in this } \\
\text { Musrenbang were helpful for me to know more about my } \\
\text { village. } \\
\text { (Please ignore this question if irrelevant). }\end{array}$ & 1 & 2 & 3 & 4 & 5 \\
\hline $\begin{array}{l}\text { 6. In my opinion, the village maps used were helpful to } \\
\text { support the deliberative process in the Musrenbang. } \\
\text { (Please ignore this question if irrelevant). }\end{array}$ & 1 & 2 & 3 & 4 & 5 \\
\hline
\end{tabular}




\section{c. About yourself}

Please choose or fill the answer that is most appropriate for you.

1. Sex:

$\square$ Woman $\square$ Man

2. Age:

$\square$ Less than 18 y.o. $\square$ 18-30 y.o. $\square$ 31-50 y.o. $\square$ 51-65 y.o. $\square>65$ y.o.

3. Last education

$\square$ SD/MI $\square$ SMP/MTs $\square$ SMA/SMK/MA $\square$ Diploma $\square$ S1 $\square$ S2 $\square$ S3

4. Your position/role in the village?

$\square$ Village government, as:

$\square$ Head of neighbourhood, as:

$\square$ BPD; as:

$\square$ LKMD; as:

PKK; as:

Karang Taruna; as:

$\square$ Tokoh masyarakat, as:

$\square$ Others. Please explain:

5. Did you attend the participatory mapping workshop held in the village hall to create village maps some time ago?

$\square$ Yes $\square$ No

6. Did you find the participatory mapping workshop that you attended useful for you to participate effectively in the Musrenbang?

$\square$ Yes $\square$ No $\square$ Not relevant

7. How often do you use printed maps?

$\square$ Never $\square$ Few times in a year $\square$ Once a month $\square$ Every week $\square$ Every day

8. How often do you use digital maps (e.g., Google Maps on the smartphone)?

$\square$ Never $\square$ Few times in a year $\square$ Once a month $\square$ Every week $\square$ Every day

9. How many times have you ever participated in the Musrenbang?
$\square$ Never
$\square$ 1-2 times
口 3-5 times
$\square$ More than 5 times

10. On a scale of $1-10$, how satisfied are you with the Musrenbang process? (Please circle a number that is appropriate for you; 1 is the lowest satisfaction, and 10 is the most satisfaction.)
1
2
34
5
67
89
10

Thank you for your time for filling the questionnaire. 


\section{Appendix 0}

Semi-Structured Interview for Musrenbang Participants

\section{Interviews with Stakeholders:}

Name

Village

Sub-district

Date of Data Collection

\begin{tabular}{|l|l|l|l|}
\hline Date & Month & $\begin{array}{c}\text { Time } \\
\text { (start) }\end{array}$ & Time (finish) \\
\hline & & & \\
\hline
\end{tabular}

\section{Introduction}

Dear Sir/Madam, my name is Aulia Akbar. I am here on behalf of the Universiteit of Twente as a researcher about the Musrenbang practice. We would like ask you some questions about your opinions and experiences about the previous village Musrenbang implementation.

In answering our questions there are no right or wrong answers; we are interested in your own experience. Your name will remain secret and everything we talk about will be anonymous. If you have any questions during the interview or our questions are not clear, please let us know.

\section{Background of the Interviewee}

1. Could you tell me your full name?

2. From which neighbourhood?

3. How long have you lived in Village?

4. What are you doing for a living? What is your position? How long have you been working in that position?

\section{Representativeness in Musrenbang}

1. What was your role when you attended the last Musrenbang? To represent which groups?

2. How many times have you ever attended a Musrenbang practice with that role?

3. Did you ever have other roles? If yes, please explain.

4. Do you think the participants have represented all important stakeholders in the village? If NOT, who else should be invited? 


\section{Awareness of the scope and process of Musrenbang}

1. How many times have you ever participated in the Musrenbang?

2. What do you think about the aims of the Musrenbang?

3. Do you think that the scope of the Musrenbang is clear and appropriate for participants?

\section{The deliberation process}

1. What do you think about the transparency in Musrenbang process?

2. In general, what do you think about the discussion process in Musrenbang?

3. What do you about the opportunities for participants to have a say at the meeting?

4. Did you think there were certain stakeholders dominating the discussion?

5. Who did have more domination in the process? Who did have less domination?

6. What are the factors that make certain people more dominant or less dominant?

7. About the discussion process, was it dynamic, lively, or maybe too formal? Why?

\section{Decision making processes}

1. What do you think about the decision-making process in Musrenbang?

2. How can you reach consensus about the plans and budget priorities?

\section{Knowledge used and Social learning experiences}

1. To what extent did you share your knowledge to other participants? Did other stakeholders also share their knowledge?

2. How did the deliberative processes allow you to understand other participants' point of view?

\section{Data/information availability}

1. Did the Musrenbang organiser provide any data/information (i.e. maps, diagrams, pictures, etc)?

2. If yes, what kind of data/information did you get at the meeting?

3. If no, what kind of data/information that you think needs to be provided at the meeting?

4. Do you think it is important to have available data/information at the meeting? Why? 


\section{Village map utilisation in Musrenbang}

1. Was there any village map used during the Musrenbang? (If the answer is NO, then go to questions 29 and 30, then finish the interview)

2. If yes, could you explain how the maps were used during the Musrenbang?

3. Did the Musrenbang in previous years ever use a village map?

4. What do you think about the utilisation of maps during the Musrenbang?

5. Did you think the maps helpful to know more about your village? How?

6. Did you find the maps useful to support the deliberation of Musrenbang? How?

\section{Participation in participatory mapping workshops}

1. Did you participate in the participatory mapping workshop some time ago? (If the answer is NO, then finish the interview).

2. If yes, did you find the workshop useful for you? How?

3. Could you elaborate the effect of participating in the workshops towards your involvement in Musrenbang?

4. Thank you for your answers and support for this research.

Interviewer,

Aulia Akbar 


\section{Appendix P}

All of the interviewees' name were kept anonymous by using codes as below:

$A 1, A 2, A 3, \ldots=$ codes for interviewees from Denai Lama village

$\mathrm{B} 1, \mathrm{~B} 2, \mathrm{~B} 3, \ldots=$ codes for interviewees from Kolam village

$\mathrm{C} 1, \mathrm{C} 2, \mathrm{C} 3, \ldots=$ codes for interviewees from Kramat Gajah village

D1, D2, D3,... = codes for interviewees from Sidoharjo I Pasar Miring village

$E 1, E 2, E 3, \ldots=$ codes for interviewees from Tandem Hulu II village 


\section{Summary}

Localising the Sustainable Development Goals (SDGs) is crucial for their achievement by 2030. Being a global framework, the SDGs targets and indicators need to be conceptualised and contextualised to be applicable in the local context. This research explores the localisation of SDGs targets 11.3 and 16.7 for improved public participation by studying the public participation practice in Indonesia, called Musrenbang. As an annual participatory planning meeting in Indonesia, Musrenbang provides a forum for various stakeholders to make decisions about development planning and budgeting priorities. Despite its essential role, the Musrenbang meeting is often conducted poorly, like a 'ceremonial' activity favouring certain groups while limiting citizens involvement in the planning processes. As a result, the diverse types of knowledge of the stakeholders are not utilised optimally, affecting the communication and collaboration among them. The participatory processes often fail to stimulate the stakeholders to express their knowledge explicitly and limit its integration among stakeholders. Although discussions about particular locations or places are common in public participation practices, spatial knowledge, i.e. the knowledge of how the individuals, social groups, and institutions perceive particular places into their characteristics and meanings, is often underutilised in the Musrenbang practices.

This limited integration of knowledge is further exacerbated by the fact that only limited data and information are available to support the deliberative processes of Musrenbang, particularly geospatial data such as village maps. Although current laws, e.g. Village Law No.6/2014, implies that each village must have village maps to support the development and local decision-making, the utilisation of maps is rarely found in the Musrenbang at village level. The central government cannot afford to make the village maps available due to limited funding, diverse geographical terrains, and lacking coordination among institutions. Likewise, the village government cannot produce the maps due to a lack of mapping knowledge and technologies and the strict regulations imposed by the upper government in terms of maps production.

While a large body of research has studied the localisation of SDGs and the strengthening of public participation practices, most studies focus 
on urban areas. There is less research on how the localisation of SDGs and public participation can take place in rural areas. This study fills this gap by understanding how public participation in rural areas may contribute to the localisation of SDGs by examining the role of geospatial data in localising the SDGs and strengthening public participation in rural areas. The study was conducted in five villages in Deli Serdang district, Indonesia, divided into three villages with interventions and two villages as the control group. In the intervention group, the villages participated in a digital or non-digital participatory mapping workshop to produce their village maps. In the control group, no mapping workshops were conducted to create village maps.

The study has four objectives. For the first objective, an SDGs evaluation framework was developed based on indicators 11.3.2 and 16.7.2, and then the framework was used to evaluate the Musrenbang implementation in all case study areas. The focus of the evaluation was to identify the underlying problems from the villagers' perspective and explore options to formulate feasible solutions in order to enhance and strengthen the participatory process in the Musrenbang implementation (see Chapter 2 for details).

Based on the evaluation result, three main problems that impeded the Musrenbang at village level were identified. First, the Musrenbang process did not comply with existing regulations. Different laws published by various ministries have caused confusion among the village stakeholders about which laws should be followed. Second, a lack of available data hampers the Musrenbang implementation, resulting in a lack of knowledge integration and learning processes among the participants during the deliberation process. Third, power gaps among stakeholder groups in Musrenbang impede the implementation. There were four stakeholder groups in the village Musrenbang, the upper government, village elites, village elites' supporters, and community-based organisations/ordinary citizens. Among these groups, the village elites and the village elites' supporters had more power and influence than the community-based organisations/ordinary citizens during the decision-making process in Musrenbang. The upper government, which has more ability to influence, showed little interest in mitigating the domination of certain stakeholder groups or improving the deliberation process in Musrenbang. This study concluded that a comprehensive understanding of the Musrenbang stakeholders' knowledge and a 
suitable method to integrate and exchange the stakeholders' knowledge is urgently needed to strengthen the Musrenbang practices while minimising the power gaps among the Musrenbang participants.

For the second objective, this study aimed at understanding the spatial knowledge of the stakeholders involved. The analysis was used to foresee the potential of spatial knowledge in strengthening the participatory process of the Musrenbang as well as to fill the geospatial data gaps in the case study areas. A three-dimensional cube framework was developed to understand better the utilisation of spatial knowledge in public participation practices. The framework consists of three mutually dependent aspects: the types, levels, and socio-spatial relationships of spatial knowledge. The framework was used to classify and identify the dynamics, actors, and activities involved in the spatial knowledge utilisation during the Musrenbang process (see Chapter 3 for details).

The findings of this study revealed that spatial knowledge has the potential to enhance the Musrenbang public participation practice. The participants confirmed that they could better engage in the deliberation process of Musrenbang if they can contribute their spatial knowledge. Therefore, the utilisation of spatial knowledge should be accompanied by sufficient and reliable geospatial data such as maps. Musrenbang participants can bring in their spatial knowledge and maps for various purposes, such as deciding the most accessible location for public health facilities, examining the impacts of a project to the surrounding area, or analysing the distribution of projects or budgets in all neighbourhoods. Better use of spatial knowledge could also stimulate intense communication and collaboration between participants, not only during the Musrenbang implementation but also in other village development projects. Therefore, this study recommends developing a suitable participatory mapping method that enables stakeholders to express their spatial knowledge. Such a participatory method would help village stakeholders to use their spatial knowledge to produce geospatial data of their areas, which can then be used to support public participation practices like Musrenbang.

For the third objective, a collaborative spatial learning framework was developed to strengthen the Musrenbang implementation and tested the framework in three villages included in the intervention group of the case study areas. The framework was implemented through digital 
and non-digital participatory mapping workshops. The digital participatory mapping workshop used the OGITO (Open Geospatial Interactive Tool) application through a maptable. The non-digital participatory mapping workshop used conventional mapping exercises with transparent plastic layers showing markers and stickers. A highresolution satellite image of the villages was used to help the participants identify, sketch, and draw the village maps. The composition of the participants represented the stakeholder groups who participated in the village Musrenbang. The sketch maps were later finalised and transformed into the GIS format by the researcher (see Chapter 4 for details).

This study concludes that the digital and non-digital participatory mapping workshops were practical to help the village stakeholders to produce georeferenced village maps. The mapping workshops were helpful to accelerate the village map production at the village level and stimulated village stakeholders to learn collaboratively to utilise their spatial knowledge. The mapping workshops were also valuable for stimulating communication and collaboration among stakeholders, integrating the stakeholders' spatial knowledge through knowledge coproduction, and facilitating social learning for stakeholders to better engage in the Musrenbang practices. Furthermore, the mapping workshops were also helpful to localise the SDGs by raising awareness of village stakeholders to better understand and contextualise the SDGs concepts at the local village level.

For the fourth objective, the focus was to investigate how the participatory village maps produced from the mapping workshops in Chapter 4, could strengthen the Musrenbang implementation, particularly in enabling communication and collaboration among the participants. Using criteria from the SDGs evaluation framework discussed in Chapter 2, the Musrenbang implementation in five villages in the study areas was evaluated (see Chapter 5 for details).

The comparison result of the Musrenbang in the intervention and the control groups showed a better Musrenbang implementation in the intervention group, which used participatory village maps, than in the control group, which did not use any maps during the Musrenbang. Most of the participants in the intervention villages reacted positively to the utilisation of the maps during the Musrenbang. The maps facilitated the communication among participants in Musrenbang, 
made the deliberation process more transparent and tolerant. The exact village boundaries on the maps gave clear task scope to the participants. The maps enabled participants to provide new or creative inputs to enrich the discussion.

Additionally, the maps were also helpful for enabling participants to collaborate, share their knowledge, and experience social learning. Participants were satisfied with the Musrenbang processes because the maps allow their views or opinions to be heard or taken into account. In contrast, the Musrenbang in the control villages remained the same as in the previous observation. The process was too formal and ceremonial. Lack of discussion occurred as no supporting data available during the deliberation process.

Although the improvement of Musrenbang implementation was evident in all intervention villages, the findings also reveal that the potential of the participatory village maps was not fully utilised. Power gaps among stakeholder groups could not be entirely eliminated during the Musrenbang implementation. Certain actors, particularly the village elites, still dominated the deliberation process. They often intentionally pre-selected the participants who would not oppose the elites as the invitees of the Musrenbang. Consequently, the Musrenbang was not accessible for all individuals or marginal groups in the villages, although Musrenbang should be accessible for all citizens. This situation may impede the achievement of SDGs targets 11.3. and 16.7 that emphasises the openness and inclusiveness of public participation practices for all community members.

Overall, this study concludes that geospatial data and spatial knowledge could serve as an essential medium to localise the SDGs to be more tangible and operational in the local context. Formulating suitable methods that can optimally make use of the spatial knowledge of the stakeholders while ensuring geospatial data availability is necessary. The method should engage stakeholders to communicate, collaborate, and experience social learning and knowledge coproduction. Geospatial data produced from such activities could strengthen the public participation practices and raise the awareness of local communities to better understand and apply the SDGs at the local level. This study contributes to the discourse on the drivers of public participation practices in the global south. This study also informs scholars and policymakers to invent and take innovative 
approaches such as collaborative spatial learning to strengthen public participation practices and achieve the SDGs in the local, rural contexts. 


\section{Samenvatting}

Voor het halen van de Sustainable Development Goals (SDG) in 2030 is het cruciaal om deze doelstellingen te vertalen naar de lokale schaal. Omdat de SDG doelen en indicatoren in een wereldwijd kader zijn geformuleerd moeten ze eerst worden geconceptualiseerd en in de juiste context geplaatst voor ze toepasbaar zijn op lokale schaal. Dit onderzoek verkent het naar de lokale situatie vertalen van SDG doelen 11.3 en 16.7 ten behoeve van een verbeterde publieke participatie door deze te bestuderen in de publieke participatie praktijk van Indonesië, Musrenbang genaamd. De Musrenbang, een jaarlijkse publieke participatie bijeenkomst in Indonesië, biedt een forum voor diverse belanghebbenden voor het nemen van besluiten over ontwikkelingsplanning en prioritering van budgetten. Ondanks het wezenlijke belang wordt de Musrenbang bijeenkomst vaak pover uitgevoerd en wel als een 'ceremoniële' activiteit ten gunste van bepaalde groepen met inperking van de inspraak van burgers in de planning processen. Dientengevolge wordt allerlei kennis van belanghebbenden niet optimaal gebruikt met nadelige gevolgen voor de onderlinge communicatie en samenwerking. De participatie processen mislukken vaak doordat belanghebbenden niet worden gestimuleerd om hun kennis expliciet te maken en beperken als zodanig de integratie van de kennis van stakeholders. Hoewel discussies over bepaalde locaties en plaatsen niet ongebruikelijk zijn in de publieke participatie praktijk, wordt met name de ruimtelijke kennis, d.w.z. de kennis over hoe individuen, maatschappelijke groeperingen en instituties bepaalde plaatsen in betekenis en karakteristieken ervaren, onderbenut in de Musrenbang praktijk.

Deze beperkte integratie van kennis wordt verder versterkt door het feit dat slechts beperkte gegevens en informatie, in het bijzonder georuimtelijke gegevens zoals dorpskaarten, beschikbaar zijn om het proces van beraadslaging binnen de Musrenbang te ondersteunen. Hoewel de huidige wetgeving, bijvoorbeeld Village Law No.6/2014, voorschrijven dat elk dorp dorpskaarten moet hebben om de planning en de lokale besluitvorming te ondersteunen, worden kaarten zelden gebruikt in de Musrenbang op dorpsniveau. De centrale overheid kan het zich niet veroorloven dorpskaarten beschikbaar te maken vanwege beperkte financiële middelen, diversiteiten in geografisch terrein, en 
een gebrek aan coördinatie tussen instituties. Dorpsoverheden kunnen eveneens geen kaarten produceren vanwege ontbrekende cartografische kennis en technologieën, en de strikte regels opgelegd door hogere autoriteiten ten aanzien van de productie van kaarten.

Hoewel veel onderzoek is gedaan naar de vertaling van de SDG naar de lokale schaal en naar de versterking van de praktijk van publieke participatie, hebben de meeste studies betrekking op stedelijke gebieden. Minder onderzoeken zijn gedaan naar hoe beide onderwerpen aan te pakken in rurale gebieden. Deze studie voorziet in deze lacune door te begrijpen hoe publieke participatie in rurale gebieden kan bijdragen aan het naar lokale schaal vertalen van de SDG door de rol te onderzoeken die georuimtelijke data hierbij kunnen spelen. Het onderzoek is uitgevoerd in vijf dorpen in het Deli Serdang district, Indonesië, waarbij drie dorpen fungeerden als interventie groep en twee dorpen als controle groep. In de interventiegroep namen de dorpen deel aan een digitale of niet-digitale participatieve kartering workshop waarbij hun dorpskaart werd geproduceerd. Voor de dorpen in de controle groep gebeurde dit niet.

De studie had vier onderzoeksdoeleinden. Het eerste doel was de ontwikkeling van een SDG evaluatie kader gebaseerd op de indicatoren 11.3.2 en 16.7.2, waarbij dit kader is gebruikt om de Musrenbang implementatie te evalueren in alle case studie gebieden. De focus van de evaluatie lag bij het identificeren van onderliggende problemen vanuit het perspectief van de dorpsbewoners en bij het verkennen van opties voor het formuleren van haalbare oplossingen om het participatieve karakter van de Musrenbang implementatie te verbeteren en versterken (zie hoofdstuk 2 voor de details).

Uit de evaluatie komen drie belangrijke problemen naar voren die de Musrenbang op dorpsniveau negatief beïnvloeden. Ten eerste: het proces van de Musrenbang voldeed niet aan bestaande regelgeving. Verschillende wetten uitgevaardigd door meerdere ministeries hebben verwarring gezaaid onder de belanghebbenden uit de dorpen over welke wetten te volgen. Ten tweede wordt de Musrenbang implementatie gehinderd door een tekort aan beschikbare data, waardoor kennisintegratie en leerprocessen tussen de deelnemers gedurende het proces van beraadslaging moeilijk van de grond komen. Ten derde vormen machtsverschillen tussen stakeholder groeperingen een belemmering voor de Musrenbang implementatie. Er zijn vier 
categorieën stakeholders in de Musrenbang op dorpsniveau: de hogere overheid, de dorpselite, de volgers van de dorpselite, en gemeenschapsorganisaties/gewone burgers. Van deze groeperingen hadden de dorpselite en de volgers van de dorpselite meer macht en invloed gedurende het proces van besluitvorming in de Musrenbang dan de gemeenschapsorganisaties/gewone burgers. De hogere overheid, die meer mogelijkheden heeft om invloed uit te oefenen, toonde weinig belangstelling voor het terugdringen van de dominantie van bepaalde groeperingen en voor het verbetering van het proces van beraadslaging. De studie concludeerde dat een meer uitgebreid begrip voor de kennis van de stakeholders in de Musrenbang en een passende methode om de kennis van de stakeholders te integreren en uit te wisselen dringend gewenst zijn om de praktijk van de Musrenbang te versterken en tegelijkertijd de machtsverschillen tussen de deelnemers te verkleinen.

Het tweede onderzoeksdoel was gericht op het begrijpen van de ruimtelijke kennis van de betrokken stakeholders. De analyse is uitgevoerd om het potentieel van de ruimtelijke kennis in het versterken van het participatieve proces van de Musrenbang te verkennen, alsmede om de georuimtelijke data lacunes in de case studie gebieden te reduceren. Een driedimensionaal kubus kader is ontwikkeld om te begrijpen hoe beter gebruik kan worden gemaakt van de ruimtelijke kennis in de publieke participatie praktijk. Het kader bestaat uit drie wederzijds afhankelijke aspecten: de typen, de niveaus en de sociaal-ruimtelijke relaties van ruimtelijke kennis. Het kader is gebruikt voor het classificeren en identificeren van de dynamiek, de actoren en de activiteiten bij het benutten van de ruimtelijke kennis tijdens het proces van de Musrenbang (zie hoofdstuk 3 voor de details).

De studie heeft aangetoond dat de ruimtelijke kennis in potentie de publieke participatie in de Musrenbang praktijk kan verbeteren. De deelnemers bevestigden dat zij beter in het overleg binnen de Musrenbang tot hun recht zouden komen als ze hun ruimtelijke kennis konden inbrengen. Daarom moet het gebruik van deze ruimtelijke kennis vergezeld gaan van voldoende en betrouwbare georuimtelijke data zoals kaarten. De deelnemers aan de Musrenbang kunnen hun ruimtelijke kennis en kaarten inzetten voor verschillende doelen, zoals de besluitvorming over de meest toegankelijke locatie voor volksgezondheidsvoorzieningen, het onderzoeken van de gevolgen van een project op de omgeving, of het analyseren van de verdeling van 
projecten en budgetten over alle buurten/wijken. Beter gebruik van ruimtelijke informatie zou ook de communicatie en samenwerking tussen deelnemers kunnen intensiveren, niet alleen gedurende de Musrenbang maar ook bij andere ontwikkelingsprojecten in de dorpen. Daarom adviseert deze studie een passende participatieve karteringsmethode te ontwikkelen die belanghebbenden in staat stelt hun ruimtelijke kennis te uiten. Zo'n participatieve methode zou stakeholders in de dorpen helpen om hun ruimtelijke kennis om te zetten in georuimtelijke data van hun gebieden ten behoeve van publieke participatieve Musrenbang praktijk.

Het derde onderzoeksdoel betrof de ontwikkeling van een gezamenlijk ruimtelijk leerkader ter versterking van de Musrenbang implementatie en het testen van dit kader in de drie case studie dorpen van de interventiegroep. Het leerkader is toegepast in digitale en niet-digitale participatieve kartering workshops. De digitale participatieve kartering workshop gebruikte de OGITO (Open Geospatial Interactive Tool) applicatie met behulp van een Map Table. De niet-digitale participatieve kartering workshop maakte gebruik van conventionele kartering exercities met behulp van transparante plastic vellen met markeringen en stickers. Een hoge resolutie satelliet beeld van de dorpen stelde de deelnemers in staat om dorpskaarten te identificeren, schetsen en tekenen. De samenstelling van de deelnemers was representatief voor de stakeholder groeperingen die betrokken waren bij de Musrenbang van het betreffende dorp. In een later stadium zijn de schetsen gecompleteerd en getransformeerd naar GIS formaat door de onderzoeker (zie hoofdstuk 4 voor de details).

De studie concludeert dat de digitale en niet-digitale participatieve kartering workshops van praktisch nut bij het produceren door de belanghebbende dorpsbewoners van dorpskaarten met gereferenties. De workshops zorgde voor een versnelling van de productie van dorpskaarten en stimuleerden de belanghebbende dorpsbewoners om gezamenlijk te leren hun ruimtelijke kennis te benutten. De kartering workshops waren ook waardevol ten aanzien van de communicatie en samenwerking tussen de stakeholders, de integratie van de ruimtelijke kennis via kennis co-productie en het faciliteren van sociale leerprocessen bij stakeholders tijdens het overleg in de Musrenbang praktijk. Bovendien hielpen de workshops bij de vertaalslag van de SDG naar lokaal niveau door de bewustwording van de 
belanghebbende dorpsbewoners te versterken bij het begrijpen en contextualiseren van de SDG concepten op lokaal niveau.

Bij het vierde onderzoeksdoel lag de focus van het onderzoek op het onderzoeken of en hoe de participatieve dorpskaarten geproduceerd gedurende de kartering workshops als beschreven in hoofdstuk 4 de implementatie van de Musrenbang zouden kunnen verbeteren in het bijzonder ten aanzien van de communicatie en samenwerking tussen de deelnemers. Met gebruikmaking van de criteria afkomstig van het SDG evaluatie kader uit hoofdstuk 2 is de Musrenbang implementatie in de vijf geselecteerde dorpen geëvalueerd (zie hoofdstuk 5 voor de details).

Het resultaat van het vergelijkend onderzoek van de Musrenbang tussen de interventie groep en de controle groep liet zien dat tijdens de implementatie van de Musrenbang gebruik werd gemaakt van de participatieve dorpskaarten bij de interventiegroep met positieve gevolgen voor het proces, maar dat geen enkele kaart werd gebruikt bij de controle groep. De meeste deelnemers van de dorpen uit de interventiegroep reageerden positief op het gebruik van de kaarten gedurende de Musrenbang. De kaarten faciliteerden de communicatie tussen de deelnemers tijdens de Musrenbang, en maakten het overleg transparanter en beter te accepteren. De exacte dorpsgrenzen op de kaarten gaven beter inzicht in de scope van de taak voor de deelnemers. De kaarten stelden de deelnemers in staat nieuwe inzichten te verwerven en creatieve input te leveren hetgeen de discussie verrijkt heeft.

Daarnaast stelde de kaarten de deelnemers in staat om samen te werken, de kennis te delen en sociale leerprocessen te ervaren. Deelnemers toonden tevredenheid over het verloop van het Musrenbang proces omdat de kaarten het mogelijk maakten hun ideeën en meningen kenbaar te maken en een rol te laten spelen. Daarentegen verliep het Musrenbang proces in de dorpen in de controle groep als voorheen was waargenomen. Het proces was zeer formeel en ceremonieel. Discussies waren zeer beperkt tot afwezig mede omdat geen ondersteunende data beschikbaar waren tijdens het overleg.

Hoewel de versterking van het Musrenbang proces in alle dorpen van de interventiegroep evident was, tonen de bevindingen ook aan dat het potentieel van de participatieve dorpskaarten nog niet volledig benut 
is. Machtsverschillen tussen stakeholder groeperingen konden niet volledig worden geëlimineerd in de Musrenbang. Bepaalde actoren, in het bijzonder de dorpselite, domineerden nog altijd het overleg. $\mathrm{Zij}$ selecteerden vooraf doelbewust deelnemers als genodigden bij de Musrenbang waarvan ze wisten dat ze niet zouden opponeren tegen de dorpselite. Als gevolg hiervan was de Musrenbang niet toegankelijk voor alle individuen en marginale groepen uit de dorpen, hoewel de Musrenbang toegang zou moeten geven tot alle burgers. Deze omstandigheid vormt een belemmering voor het halen van de SDG doelen 11.3 en 16.7 die de nadruk leggen op openheid en inclusiviteit van de praktijk van publieke participatie voor alle leden van de gemeenschap.

De algehele conclusie van dit onderzoek is dat georuimtelijke data en ruimtelijke kennis kunnen dienen als een essentieel hulpmiddel om de vertaalslag van de SDG naar lokaal niveau meer tastbaar en operationeel te maken. Het formuleren van passende methoden om optimaal gebruik te maken van de ruimtelijke kennis van stakeholders en daarmee het zeker stellen van de beschikbaarheid van georuimtelijke data is noodzakelijk. De methode moet stakeholders overhalen om te communiceren, samen te werken, sociale leerprocessen en kennis co-productie te ervaren. Georuimtelijke data die geproduceerd worden tijdens zulke activiteiten kunnen de publieke participatie praktijk versterken en de bewustwording bij lokale gemeenschappen vergroten om de SDG beter te begrijpen en toe te passen op lokaal niveau. Dit onderzoek draagt bij aan het discours over de drijfveren van de publieke participatieve praktijken in de Global South. Deze studie levert ook belangrijke informatie voor wetenschappers en beleidsmakers bij het bedenken en toepassen van innovatieve benaderingen zoals ruimtelijke sociale leerprocessen met het oog op het versterken van de publieke participatie praktijk en het bereiken van de SDG in lokale rurale contexten. 


\section{About the author}

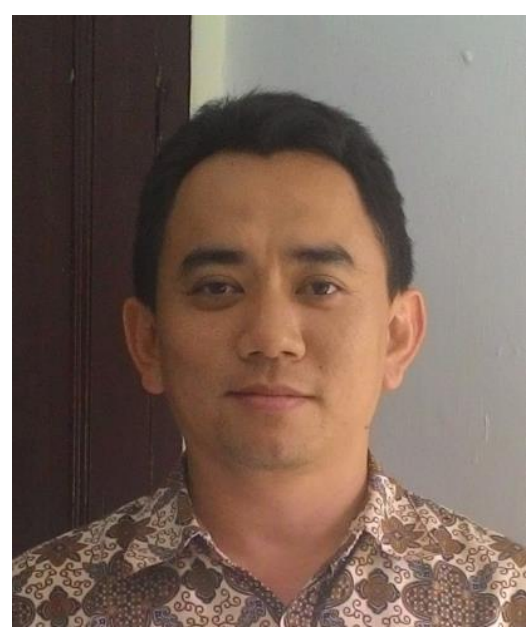

Aulia Akbar was born on the $4^{\text {th }}$ of June, 1981 in Binjai, Indonesia. He graduated from Universitas Gadjah Mada (UGM), Yogyakarta, Indonesia, in 2004 where he obtained a bachelor degree in Geodetic Engineering. He then worked in a private consulting firm as a geodetic surveyor before joining the Regional Development Planning Agency (BAPPEDA) of Deli Serdang district, Indonesia in 2005. In 2010 he was awarded the Australian Development Scholarship (ADS) to study in Australia. He studied Master of Development Practice (Advanced) in the University of Queensland, Australia and obtained his master degree in 2011. After completing his study, he returned to the BAPPEDA and assigned as the Head of Public Works Section in 2014 and then became the Head of Infrastructure Division in 2015.

In March-May 2014, he went to ITC-University of Twente to join a short-course funded by NUFFIC scholarship. Inspired by contents and learning experiences of the short-course, he returned to the University of Twente in 2016 for pursuing a PhD degree funded by the Government of Indonesia through the LPDP (Lembaga Pengelola Dana Pendidikan) scholarships program.

His research interests cut across public participation, participatory mapping, spatial knowledge, geospatial data, urban and regional planning, community development and sustainable development. The result of his research led to publications and this thesis.

\section{Scientific Publications}

(included in this thesis)

Akbar, A., Flacke, J., Martinez, J., van Maarseveen, M. F. A. M. (2020). Participatory planning practice in rural Indonesia: A sustainable development goals-based evaluation. Community Development, 51(3), 243-260. https://doi.org/10.1080/15575330.2020.1765822 
Akbar, A., Flacke, J., Martinez, J., van Maarseveen, M. F. A. M. (2020). Spatial knowledge: A potential to enhance public participation? Sustainability, 12(12),

https://doi.org/10.3390/su12125025

5025 .

Akbar, A., Flacke, J., Martinez, J., Aguilar, R., van Maarseveen, M. F. A. M. (2020). Knowing my village from the sky: A collaborative spatial learning framework to integrate spatial knowledge of stakeholders in achieving sustainable development goals. ISPRS International Journal of Geo-Information, 9(9), 515. https://doi.org/10.3390/ijgi9090515

Akbar, A., Flacke, J., Martinez, J., van Maarseveen, M. F. A. M. (2021). The Role of Participatory Village Maps in Strengthening Public Participation Practice. ISPRS International Journal of GeoInformation, 10(8), 512. https://doi.org/10.3390/ijgi10080512

(other scientific publications)

Aguilar, R., Calisto, L., Flacke, J., Akbar, A., Pfeffer, K. (2021). OGITO, an Open Geospatial Interactive Tool to support collaborative spatial planning with a maptable. Computers, Environment and Urban Systems, 86, 101591.

https://doi.org/10.1016/j.compenvurbsys.2020.101591

\section{Conference papers and presentations}

Akbar, A., Flacke, J., Martinez, J., van Maarseveen, M. F. A. M. (2019). Participatory Village Mapping to Improve Public Participation Practice in Indonesia. In International Society of Participatory Mapping (ISPM) Conference, 17-19 June 2019, Espoo, Finland. https://doi.org/10.13140/RG.2.2.26336.51208

Akbar, A., Flacke, J., Martinez, J., van Maarseveen, M. F. A. M. (2020). A Collaborative Framework to Improve Public Participation Practice. In Proceedings of the 16th Participatory Design Conference 2020Participation (s) Otherwise-Volume 2 (pp. 133-137). 15-19 June 2020, Manizales, Colombia. https://doi.org/10.1145/3384772.3385126 